\title{
Crystallographic studies on diheme cytochrome $c$ enzymes
}

\author{
Dissertation \\ zur Erlangung des Doktorgrades \\ der Mathematisch-Naturwissenschaftlichen Fakultäten \\ der Georg-August-Universität zu Göttingen
}

\author{
vorgelegt von \\ Maren Hoffmann \\ aus Göttingen
}

Göttingen 2007 
D7

Referent:

Prof. Dr. Oliver Einsle

Korreferent:

Prof. Dr. Ralf Ficner

Tag der mündlichen Prüfung:

04.05.2007 


\section{Table of contents}

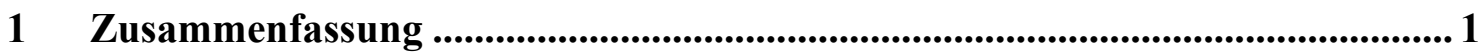

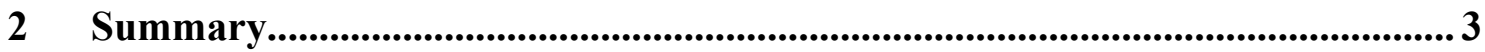

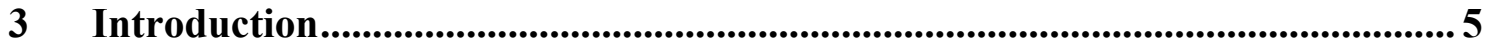

3.1 Dissimilatory Metal-Reducing Bacteria …............................................... 5

3.2 Iron as Electron Acceptor in Geobacter sulfurreducens .............................. 7

3.3 Alternative Electron Acceptors................................................................. 8

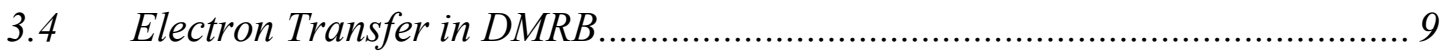

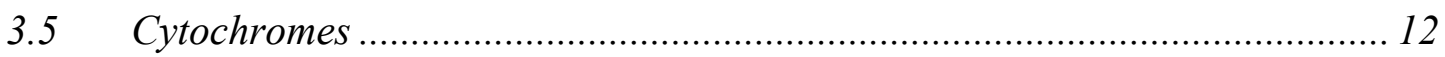

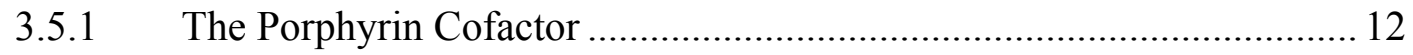

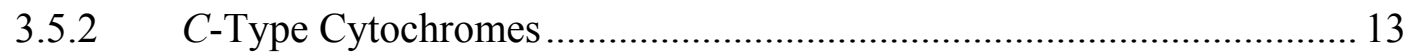

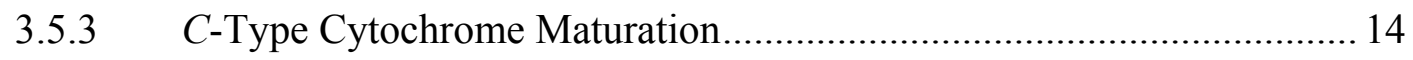

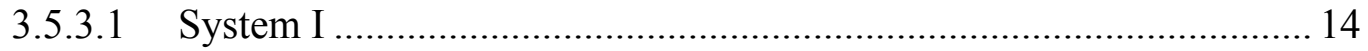

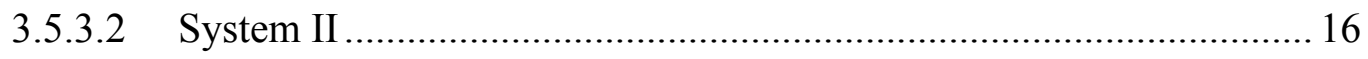

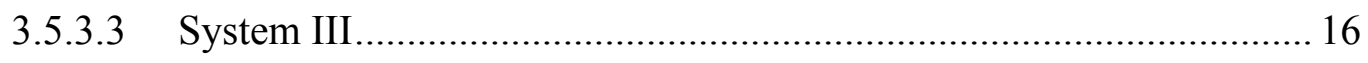

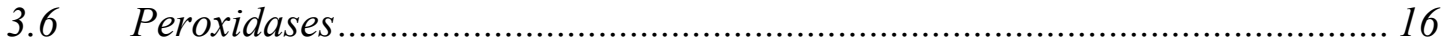

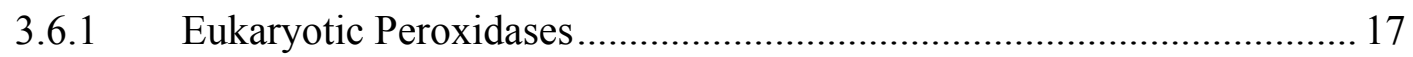

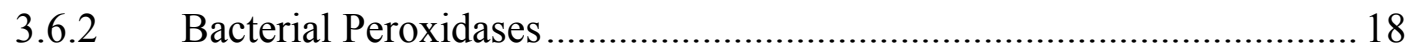

3.6.2.1 Structure of Cytochrome $c$ Peroxidases............................................. 19

3.6.2.2 Reaction Mechanism........................................................................ 20

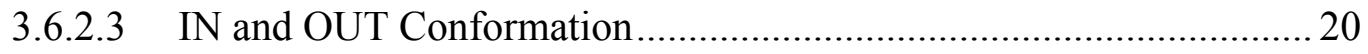

3.6.2.4 Electron Transfer within the Cytochrome $c$ Peroxidases.................... 21

3.6.3 Other Diheme Cytochrome $c$ Enzymes …......................................... 22

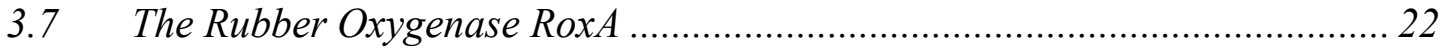

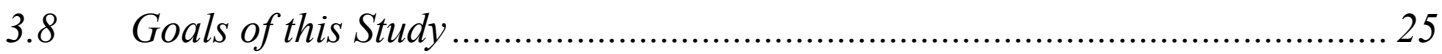

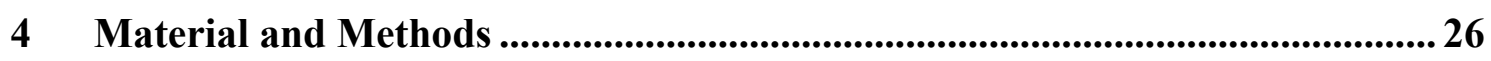

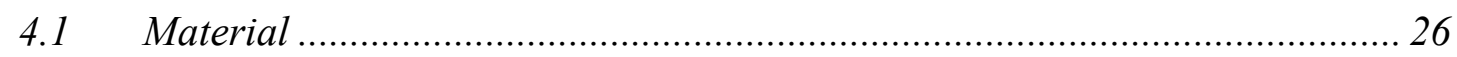

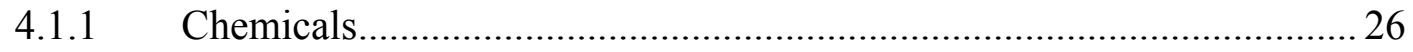

4.1.2 DNA and Protein Molecular Weight Marker ...................................... 26

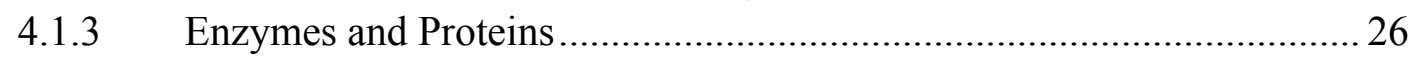

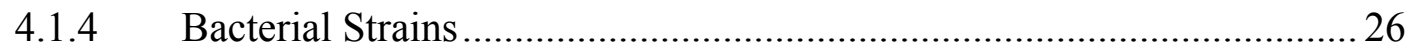

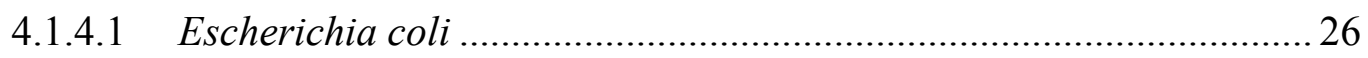

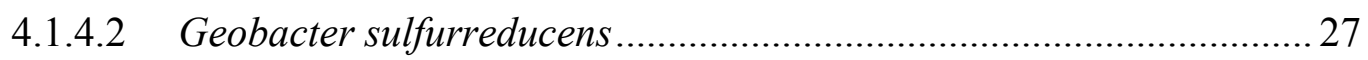

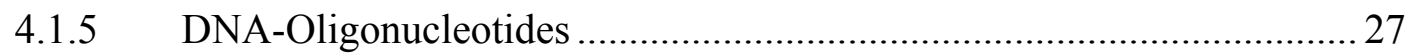




\begin{tabular}{|c|c|c|}
\hline breviations & & \\
\hline 4.1.6 & Plasmids . & \\
\hline 4.1.6.1 & $\mathrm{pEC} 86$ & \\
\hline 4.1.6.2 & pETSN-22.. & \\
\hline Met & hods.. & \\
\hline 4.2 .1 & Microbiological Methods.... & \\
\hline 4.2.1.1 & 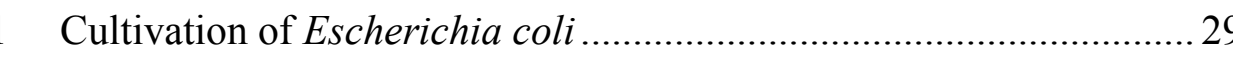 & \\
\hline 4.2.1.2 & 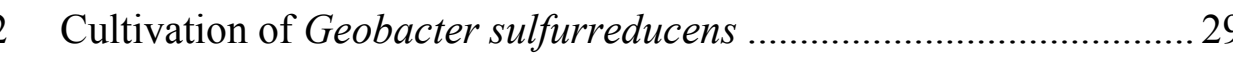 & \\
\hline 4.2.1.3 & Production and Transformation of Competent E. coli Cells............... 30 & \\
\hline 4.2.1.4 & Cultivation of Geobacter sulfurreducens in Soft Agar Tubes............ 31 & \\
\hline 4.2.1.5 & Production of Geobacter sulfurreducens DMSO Stocks.................... 31 & \\
\hline 4.2 .2 & 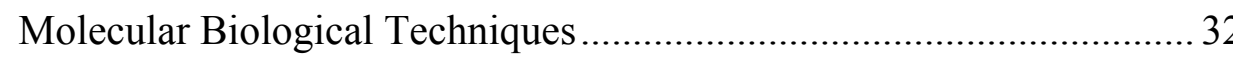 & \\
\hline 4.2.2.1 & 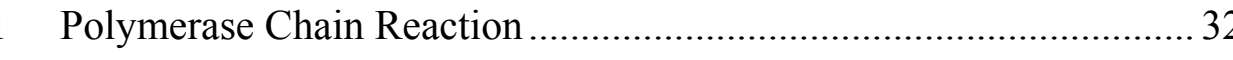 & \\
\hline 4.2.2.2 & DNA Isolation from Agarose Gels \& Purification of PCR Products . 32 & \\
\hline 4.2.2.3 & Isolation of Plasmid DNA from Bacteria …........................................ 32 & \\
\hline 4.2.2.4 & Isolation of Genomic DNA from Geobacter sulfurreducens .............. 33 & \\
\hline 4.2.2.5 & 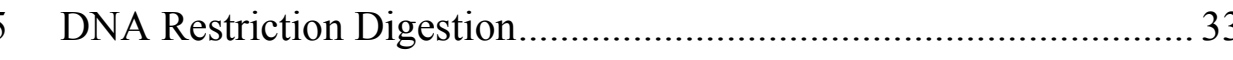 & \\
\hline 4.2.2.6 & 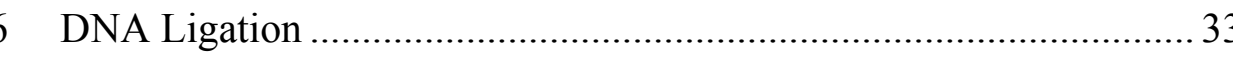 & \\
\hline 4.2.2.7 & DNA Sequencing ................................ & \\
\hline 4.2.2.8 & Agarose Gel Electrophoresis ........ & \\
\hline 4.2 .3 & Protein Biochemical Methods............ & \\
\hline 4.2.3.1 & Cell Disruption.......................................... & \\
\hline 4.2.3.2 & Affinity Chromatography ...................... & \\
\hline 4.2.3.3 & Size Exclusion Chromatography ........ & \\
\hline 4.2.3.4 & 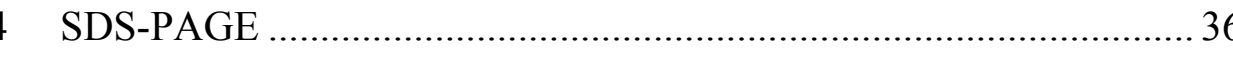 & \\
\hline 4.2.3.5 & Heme Staining........................................... & \\
\hline 4.2 .4 & Protein Concentration Determination .... & \\
\hline 4.2 .5 & 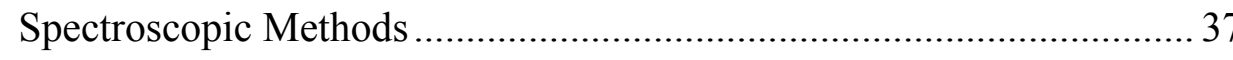 & \\
\hline 4.2.5.1 & Electron Excitation Spectroscopy .................... & \\
\hline 4.2.5.2 & Activity Assay...................................... & \\
\hline 4.2 .6 & Crystallographic Methods ...................... & \\
\hline 4.2.6.1 & 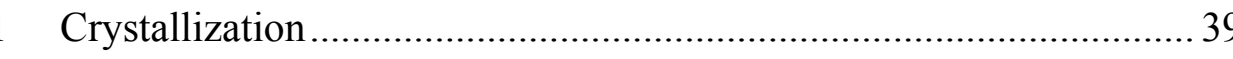 & \\
\hline 4.2.6.2 & Cryo-Cooling ...................................... & \\
\hline 4.2.6.3 & 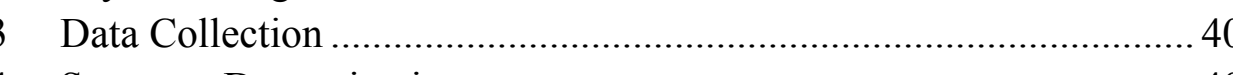 & \\
\hline 4.2.6.4 & 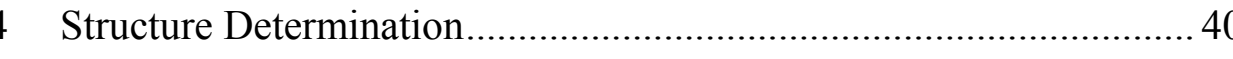 & \\
\hline 4.2.6.5 & 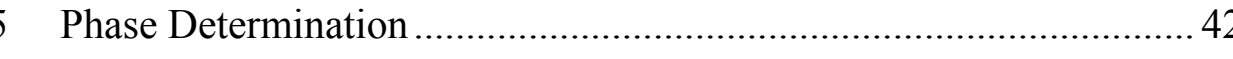 & \\
\hline 4.2.6 & 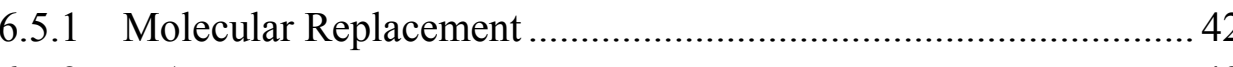 & \\
\hline 4.2.6 & 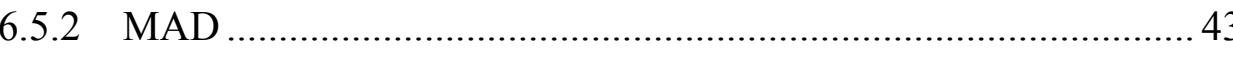 & \\
\hline 4.2 .6 & 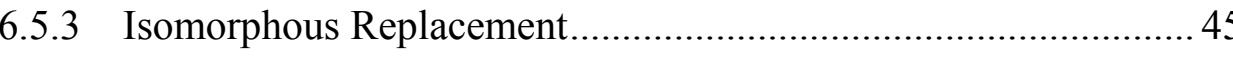 & \\
\hline 4.2.6.6 & 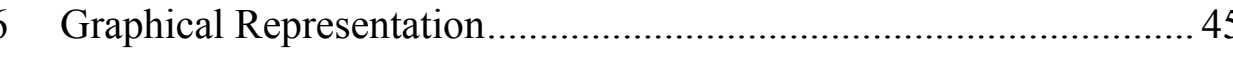 & \\
\hline
\end{tabular}

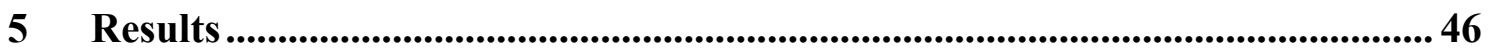

5.1 Purification of the Recombinant Peroxidases from G. sulfurreducens ......... 46

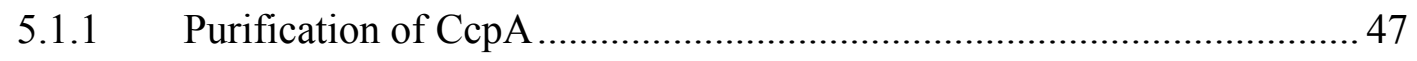


5.1.2 Purification of MacA ............................................................................. 48

5.1.3 Representative Purification of CcpA and MacA ................................. 49

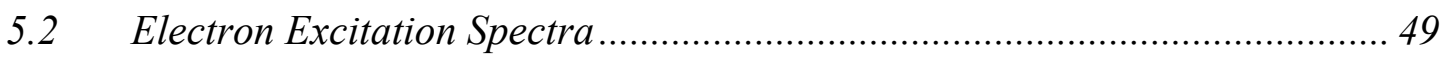

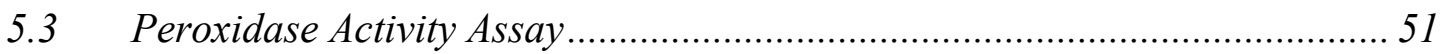

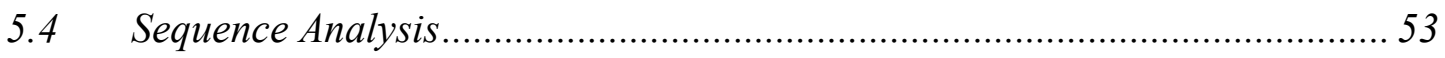

5.5 Crystallization and Structure Determination ................................................ 54

5.5.1 Crystallization of CcpA and Data Collection ...................................... 54

5.5.2 Structure Determination of CcpA and Refinement................................ 56

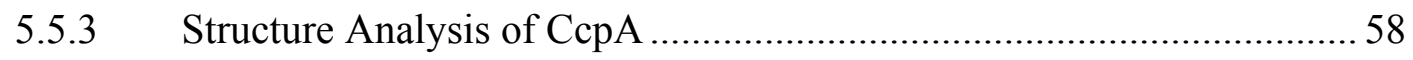

5.5.4 Crystallization and Data Collection of MacA........................................ 58

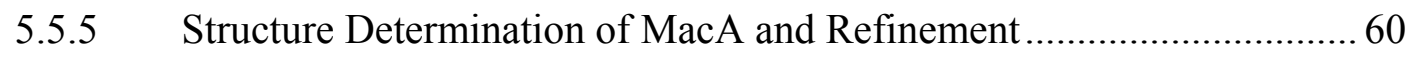

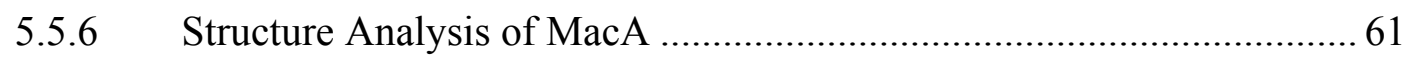

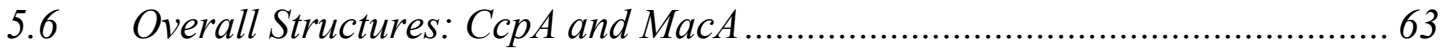

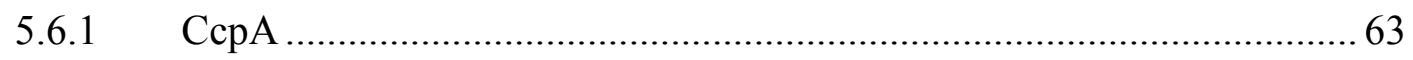

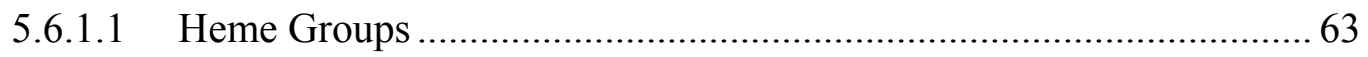

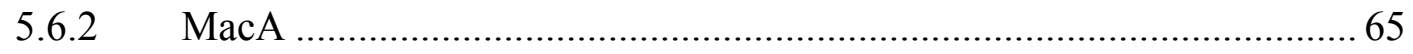

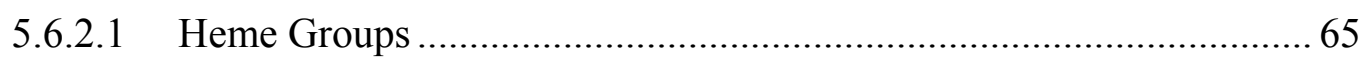

5.6.3 Comparison of the Overall Structure to Other Peroxidases..................... 67

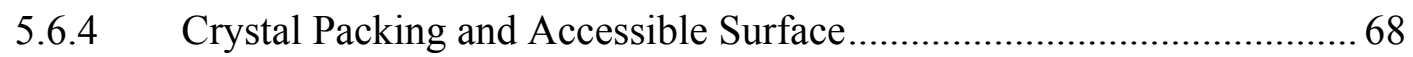

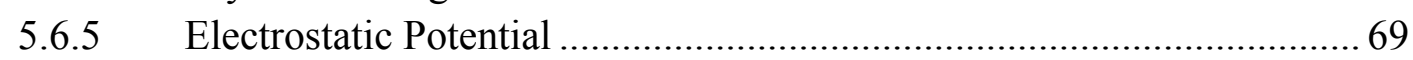

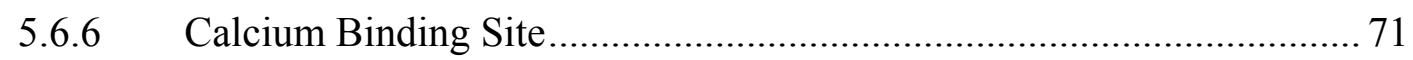

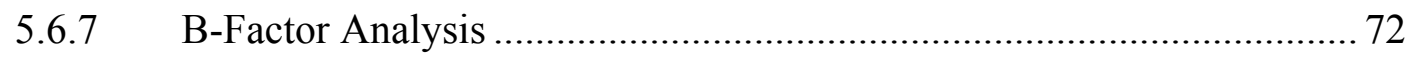

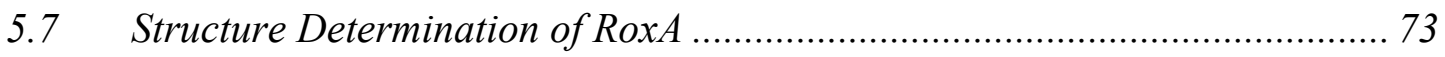

5.7.1 Crystallization, Data Collection and Structure Determination of RoxA 73

5.7.2 Structure Determination of RoxA and Refinement ............................. 74

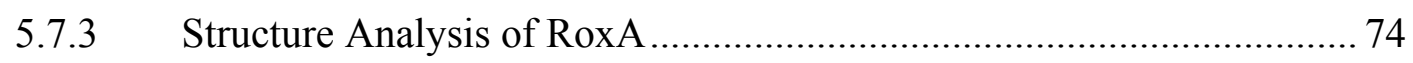

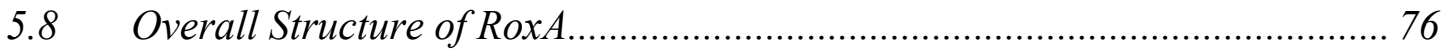

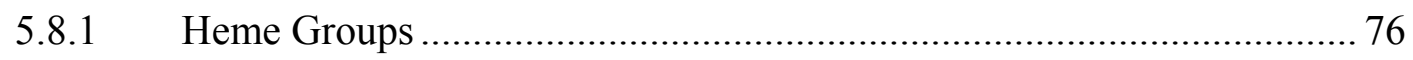

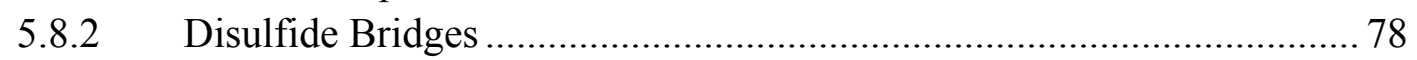

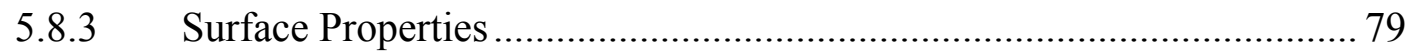

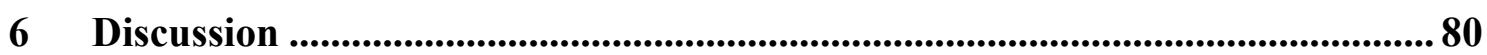

6.1 The Physiological Role of CcpA and MacA in Geobacter sulfurreducens..... 80

6.1.1 Gene Expression of $c c p A$ and $m a c A$ in the rel $_{\text {Gsu }}$ Mutant..................... 81

6.1.2 Gene Expression of $c c p A$ and $m a c A$ in the $r p o S$ Deletion Mutant ......... 81

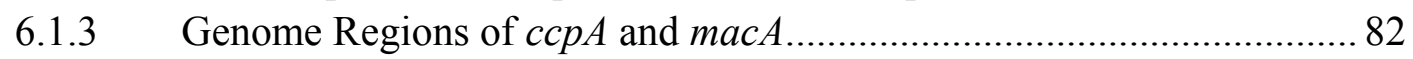

6.1.4 Description of the macA Deletion Mutant ............................................. 83

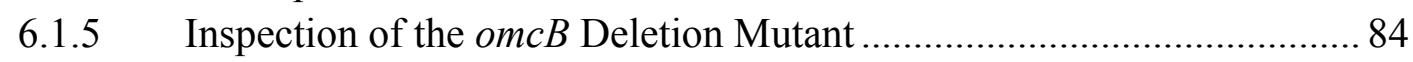

6.1.6 Implications for the Function of CcpA and MacA ….......................... 85

6.2 Bacterial Cytochrome c Peroxidases.............................................................. 85 


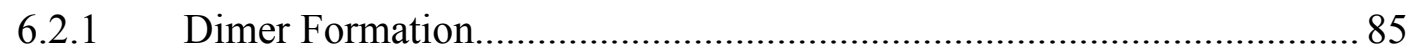

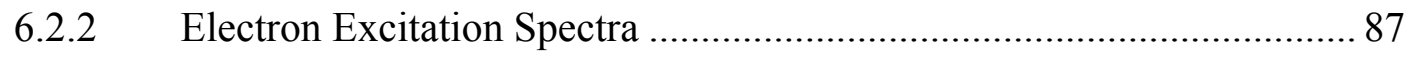

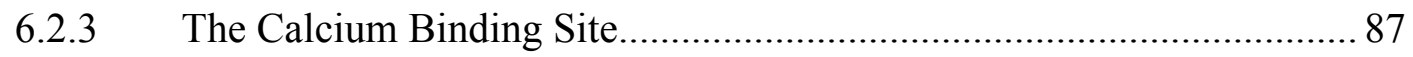

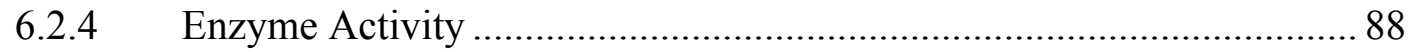

6.2.5 Catalytic Reaction Mechanism of Cytochrome $c$ Peroxidases ............... 90

6.2.6 Electron Transfer in Cytochrome $c$ Peroxidases.................................... 93

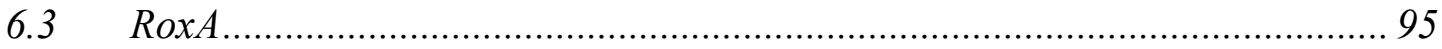

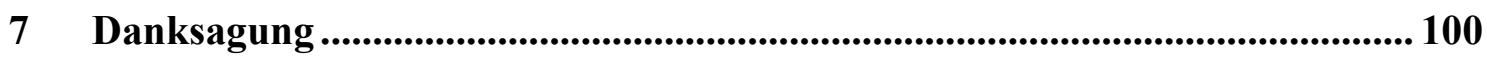

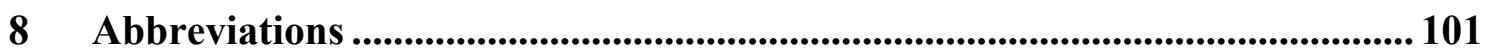

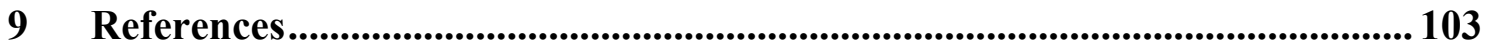

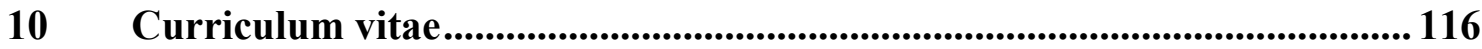




\section{Zusammenfassung}

Abhängig von ihrer Umwelt und ihrem physiologischen Zustand bilden Bakterien unterschiedliche Elektronentransportketten aus. Elektronentransportsysteme in der inneren Membran übertragen Elektronen von verschiedenen Elektronendonoren wie NADH, organischen Molekülen oder Wasserstoff an lösliche Elektronenakzeptoren wie z.B. Sauerstoff, Nitrat oder Sulfat. Da Geobacter-Arten zu den vorherrschenden Mikroorganismen in vielen Bodenhabitaten gehören, wo die dissimilatorische Metallreduktion den dominierenden Stoffwechelprozess darstellt, ist der Elektronentransport innerhalb der Bakterien $\mathrm{zu}$ den unlöslichen Eisen(III) oxiden besonders interessant. Ziel der vorliegenden Arbeit war, die Funktion der periplasmatischen $c$-Typ Cytochrome CcpA und MacA des $\delta$-Proteobakteriums Geobacter sulfurreducens aufzuklären und beide Proteine biochemisch wie auch strukturell zu charakterisieren.

Bakterielle Cytochrom $c$ Peroxidasen sind eine weit verbreitete Familie von periplasmatischen Enzymen, die Elektronen aus dem zentralen Stoffwechsel erhalten und die Reduktion von Wasserstoffperoxid mit Hilfe des Häm-Kofaktors katalysieren. Die beiden Proteine aus Geobacter sulfurreducens wurden im Hinblick auf PeroxidaseAktivität untersucht, welche auch tatsächlich nachgewiesen werden konnte. Bei CcpA wie auch bei MacA handelt es sich also um Cytochrom $c$ Peroxidasen, deren physiologischer Elektronendonor allerdings noch unbekannt ist. Eine direkte Beteiligung von CcpA und MacA am Elektronentransport zu unlöslichem Eisen wird angenommen (Butler et al., 2004), konnte aber bislang nicht eindeutig nachgewiesen werden und erscheint auf der Basis der Ergebnisse der vorliegenden Arbeit eher unwahrscheinlich.

Da die Struktur der homologen Cytochrom $c$ Peroxidase aus dem Organismus Pseudomonas aerugiosa gelöst ist (Fülöp et al., 1995), war es möglich, die Kristallstrukturen von CcpA und MacA durch Molekularen Ersatz zu bestimmen. CcpA und MacA bilden Dimere und besitzen jeweils zwei Hämgruppen pro Monomer, wobei sich die Hämgruppen in zwei verschiedenen Domänen befinden. Im hydrophoben Interface zwischen den beiden Domänen befindet sich ein Calciumion, das 
wahrscheinlich der Stabilisierung der Reste, die am Elektronentransfer zwischen den beiden Hämgruppen beteiligt sind, dient. Die Strukturen von CcpA und MacA sind den Strukturen der schon bekannten Cytochrom $c$ Peroxidasen sehr ähnlich. Der Vergleich zeigt weiterhin, dass der Hauptunterschied zu den schon bekannten Cytochrom $c$ Peroxidasen aus anderen Organismen hauptsächlich vom Austausch geladener Reste an der Oberfläche herrührt, wodurch die Proteine aus Geobacter sulfurreducens deutlich basischer sind.

Das als „rubber oxygenase“ bezeichnete Protein RoxA aus Xanthomonas sp. Stamm $35 \mathrm{Y}$ ist ein $74.1 \mathrm{kDa}$ großes, Dihäm-Cytochrom $c$, das in vitro zur Spaltung von Kautschuk in der Lage ist. Die Struktur von RoxA wurde durch Multiwavelength Anomalous Dispersion-Phasierung (MAD) gelöst und bis zu einer Auflösung von $1.8 \AA$ verfeinert. In den Datenbanken wurden keine Strukturen gefunden, die eine signifikante Ähnlichkeit zu der Gesamtstruktur von RoxA zeigen. Allerdings weist der Bereich, in dem sich die beiden Hämgruppen befinden, strukturelle Homologien zu bakteriellen Dihäm-Cytochrom $c$ Peroxidasen auf. Die beiden Hämgruppen sind annähernd senkrecht zueinander angeordnet, wobei die beiden Eisenatome $21.5 \AA$ voneinander entfernt sind. Aminosäurereste, denen eine essentielle Rolle im Elektronentransfer zwischen den Hämgruppen nachgesagt wird, sind in der Struktur von RoxA vorhanden. 


\section{Summary}

Bacteria express various electron transport chains depending on their environment and their physiological state. Membrane electron transport systems carry electrons from a number of different electron donors such as NADH, organic molecules or hydrogen to a variety of soluble electron acceptors, e.g. oxygen, nitrate or sulfate. As members of the Geobacteraceae are the predominant microorganisms in a variety of subsurface environments in which dissimilatory metal reduction is an important process, the electron transfer chain to insoluble Fe(III) oxides is of special interest. The purpose of the present work was to elucidate the function of the periplasmic diheme cytochromes $c$ $\mathrm{CcpA}$ and MacA from the $\delta$-proteobacterium Geobacter sulfurreducens and to biochemically and structurally characterize both proteins.

Bacterial diheme cytochrome $c$ peroxidases are a widespread family of periplasmic enzymes that receive electrons from the central metabolism and catalyze the reduction of hydrogen peroxide by means of the heme cofactor. Both proteins from Geobacter sulfurreducens were analyzed with regard to peroxidase activity which could be detected. However, the physiological electron donor is still unknown. A direct participation of MacA and CcpA in electron transport to insoluble iron in Geobacter sulfurreducens is proposed (Butler et al., 2004), but it could not be proven unambiguously and seems, in the light of the results of the present work, rather unlikely. As the structure of the homologous cytochrome $c$ peroxidase of Pseudomonas aeruginosa has been solved (Fülöp et al., 1995), it was possible to determine the crystal structures of CcpA and MacA by molecular replacement. CcpA and MacA are dimeric enzymes with one heme group located in each domain of the monomer. In the hydrophobic interface in between the two domains, one calcium ion could be identified that serves probably the stabilization of the residues participating in electron transfer between the two heme groups. Both structures are very similar to known cytochrome $c$ peroxidases. Comparison of CcpA and MacA to known cytochrome $c$ peroxidases reveals that the divergence is due to substitutions of charged residues on the surface, resulting in a significantly more basic protein. 
The rubber oxygenase RoxA from Xanthomonas sp. strain $35 \mathrm{Y}$ is a $74.1 \mathrm{kDa}$ diheme cytochrome $c$ enzyme that has the ability to degrade rubber latex in vitro. The structure of RoxA had been determined by multiwavelength anomalous dispersion at the K-edge of iron and was refined to a resolution of $1.8 \AA$. No significant similarity to the overall structure of any known protein was found. However, the structural region comprising both heme groups shows structural homologies to bacterial diheme cytochrome $c$ peroxidases. The two heme groups of RoxA are roughly perpendicular to each other and they are separated by an iron-iron distance of $21.5 \AA$. Residues proposed to be essential for electron transfer in between the heme groups in cytochrome $c$ peroxidases are also present in RoxA. 


\section{Introduction}

\subsection{Dissimilatory Metal-Reducing Bacteria}

Iron is one of the most abundant metals on earth. In soils and sediments, high amounts of ferric iron $\left(\mathrm{Fe}^{3+}\right)$ oxides can be found in the forms of hematite $\left(\alpha-\mathrm{Fe}_{2} \mathrm{O}_{3}\right)$, magnetite $\left(\mathrm{Fe}_{3} \mathrm{O}_{4}\right)$, goethite $(\alpha-\mathrm{FeOOH})$ and ferrihydrite $\left(\mathrm{Fe}_{5} \mathrm{HO}_{8} \cdot 4 \mathrm{H}_{2} \mathrm{O}\right)$ (Kappler and Straub, 2005). Pyrite $\left(\mathrm{FeS}_{2}\right)$, siderite $\left(\mathrm{FeCO}_{3}\right)$ and vivanite $\left(\mathrm{Fe}_{3}\left(\mathrm{PO}_{4}\right)_{2}\right)$ belong to important ferrous iron $\left(\mathrm{Fe}^{2+}\right)$ minerals. Thus, in anoxic soils and freshwater sediments, iron represents an important electron acceptor and donor in both of its oxidation states. Several groups of prokaryotes can use iron as substrate to generate energy. Microorganisms such as Rhodobacter ferrooxidans (Kappler and Straub, 2005) catalyze the oxidation of ferrous iron under anoxic conditions. Dissimilatory metal-reducing bacteria (DMRB) residing in groundwater, sediments and soils use ferric iron as electron acceptor. By coupling the oxidation of organic compounds or molecular hydrogen (Coppi et al., 2004) to the reduction of different extracellular electron acceptors such as Fe(III), Mn(IV) and U(IV) (Lovley, 1993), they generate energy for their growth. The prominent physiological feature of the Geobacter species is their ability to oxidize organic electron donors completely to carbon dioxide. Geobacter metallireducens and other Geobacteraceae are even able to oxidize aromatic hydrocarbons to $\mathrm{CO}_{2}$ and transfer the electrons to $\mathrm{Fe}(\mathrm{III})$ (Kane et al., 2002).

From a variety of bacterial and archaeal families it is known, that they reduce Fe(III) dissimilatorily (Lovley et al., 2004). Species like Shewanella oneidensis (DiChristina et al., 1988), Desulfuromonas acetoxidans (Roden and Lovley, 1993), Geobacter metallireducens (Lovley et al., 1993) and Geobacter sulfurreducens (Caccavo et al., 1994) are examples of dissimilatory metal-reducing bacteria. The widespread appearance of iron-reducing bacteria also correlates with the availability of $\mathrm{Fe}$ (III). Many sediments and soils contain ferric iron minerals in the range of 50-200 mmol per $\mathrm{kg}$ wet weight. Ferric iron is therefore an important electron donor even if it is insoluble at neutral pH (Lovley et al., 2004; Kappler and Straub, 2005). On the other hand, the dissimilatory metal-reducing bacteria in general occupy a central position in the global 
biogeochemical cycles of metals and serve as catalysts in a variety of important environmental processes, such as the production of minerals (biomineralization), the oxidation of metals (biocorrosion) and the degradation, detoxification and immobilization of contaminations and pollutants (bioremediation).

The process of iron reduction was investigated especially for the species Geobacter and Shewanella, which belong to the $\delta$ - and $\gamma$-proteobacteria, respectively. The metabolism of Geobacter species is of particular interest, as they are widely distributed in diverse anoxic soils and sediments and they are often the most abundant microorganisms (Coates et al., 1996; Lovley et al., 2004), where the microbial reduction of $\mathrm{Fe}(\mathrm{III})$ is an important process. Due to the high abundance of $\mathrm{Fe}(\mathrm{III})$ and $\mathrm{Mn}(\mathrm{IV})$ in these environments, the reduction of iron and manganese is responsible for the anaerobic oxidation of considerable amounts of organic carbon in the form of e.g. acetate.
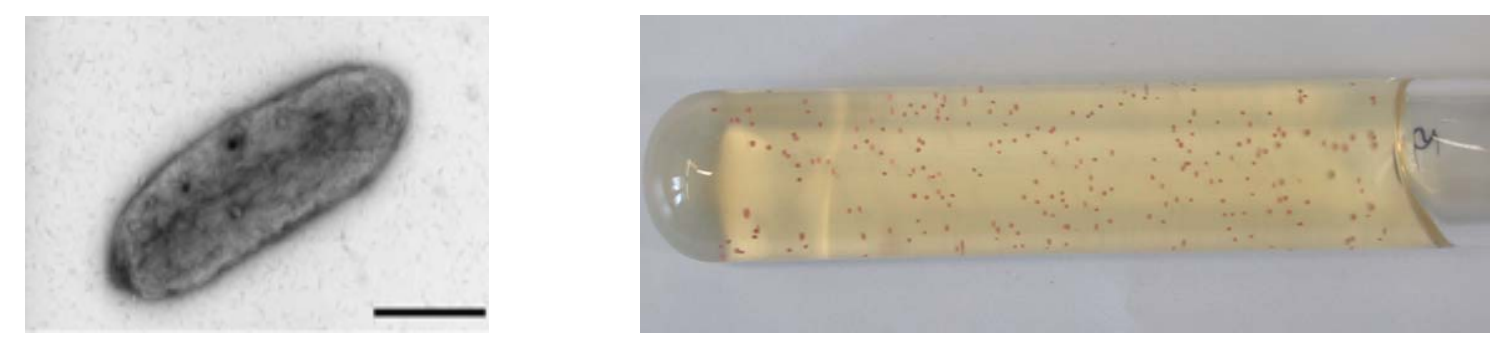

Figure 1: left: Transmission electron micrograph of Geobacter sulfurreducens cells grown with soluble $\mathrm{Fe}(\mathrm{III})$ citrate, scale bar $0.5 \mu \mathrm{m}$. (Reguera et al., 2005). Right: Colonies of Geobacter sulfurreducens from a dilution series.

The $\delta$-proteobacterium Geobacter sulfurreducens was one of the first dissimilatory metal-reducing bacteria with a completely sequenced genome (Methé et al., 2003). The G. sulfurreducens genome comprises $3.81 \mathrm{Mb}$ with 3,466 predicted protein encoding genes (Methé et al., 2003). The importance of electron transport is highlighted by the unusually large number of genes for $c$-type cytochromes (see 3.5), 111 altogether and 73 of which contain two or more heme groups. Comparison to the other metal ionreducing bacteria Shewanella oneidensis (a $\gamma$-proteobacterium) and Desulfovibrio vulgaris (a $\delta$-proteobacterium) revealed that some $c$-type cytochromes are common in these three species, but that 43 are unique to G. sulfurreducens (Methé et al., 2003). Genes predicted to code for proteins that are involved in response to oxidative stress such as catalase, superoxide dismutase and cytochrome $c$ peroxidases are present in the genome of Geobacter sulfurreducens as well as genes for flagella and pili production. 
Even genes appearing to encode a terminal cytochrome $c$ oxidase were found indicating that G. sulfurreducens has the ability to use oxygen as terminal electron acceptor (Lin et al., 2004). The availability of the genome sequence provided new insights into the function of the DMRB and especially into the physiology of Geobacter sulfurreducens that was previously thought to be nonmotile and strict anaerob.

\subsection{Iron as Electron Acceptor in Geobacter sulfurreducens}

Every cell faces the problem of energy generation in order to survive. In this context, electron transfer reactions are of fundamental importance. However, in contrast to the microorganisms that reduce final electron acceptors in form of free diffusing gas or soluble substrates, DMRB are faced with an exceptional challenge: They respire anaerobically with terminal electron acceptors that are as Fe(III) oxide highly insoluble at $\mathrm{pH}$ values above 4 . Consequently, the oxides cannot diffuse into the cell or be uptaken, while $\mathrm{Fe}(\mathrm{III})$ present one of the most important electron acceptor in anaerobic environments. In theory, the order in which electron acceptors are utilized is determined by the redox potential. At low $\mathrm{pH}, \mathrm{Fe}^{3+} / \mathrm{Fe}^{2+}$ has a redox potential $\left(\mathrm{E}_{0}{ }^{\prime}=+0.76 \mathrm{~V}\right)$ comparable to oxygen making the reduction of $\mathrm{Fe}(\mathrm{III})$ an energetically favorable reaction. However, the energy associated with the reduction of Fe(III) at circumneutral $\mathrm{pH}$ is less energetically favorable as the redox potential is less positive $\left(\mathrm{E}_{0}{ }^{\prime}=+0.2 \mathrm{~V}\right)$ (Madigan et al., 2002).
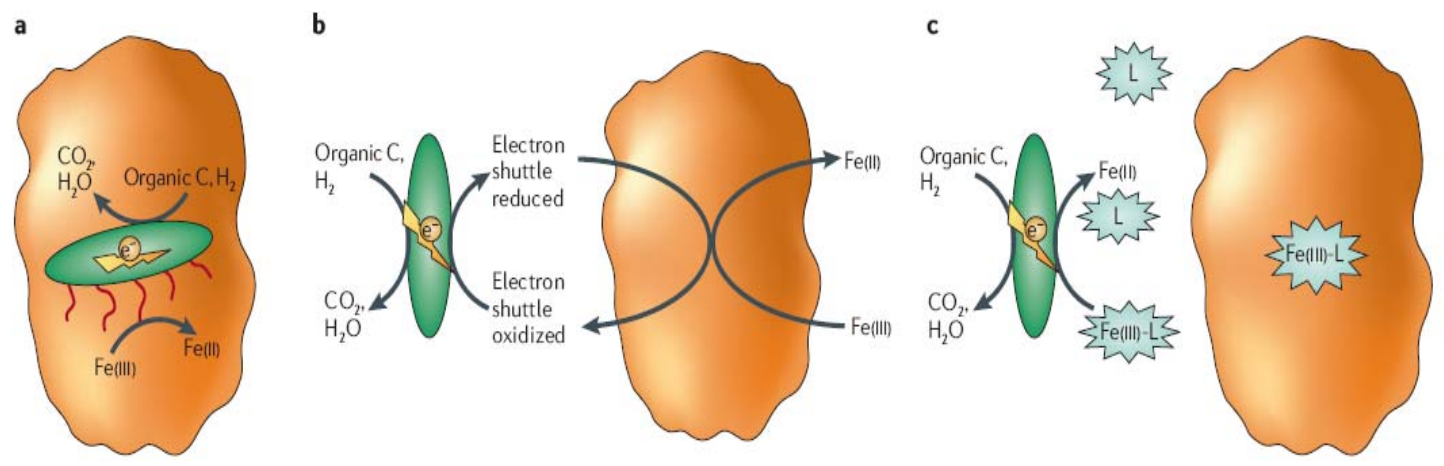

Figure 2: Different strategies of electron transport to insoluble Fe(III) oxides (Weber et al., 2006). (a) In Geobacter species, direct contact to the insoluble Fe(III) oxides is required. The extracellular pili are proposed to act as electrical conductors. (b) Low molecular electron shuttles carry electrons to the insoluble iron. (c) The secretion of $\mathrm{Fe}^{3+}$ chelators by microorganisms such as Geothrix sp. aids in the dissolution of $\mathrm{Fe}(\mathrm{III})$ oxides and provides more readily available $\mathrm{Fe}(\mathrm{III})$. 
DMRB can also reduce $\mathrm{U}(\mathrm{VI})$ or $\mathrm{Tc}(\mathrm{VII})$, that exist as soluble substrates but are reduced to insoluble end products.

To circumvent the physiological problem associated with the insolubility of the substrate or end products of the metabolism, diverse strategies were developed by different metal-reducing species (see figure 2) (DiChristina, 2005).

In contrast to Geobacter species, Shewanella species have resolved the problem by excreting low molecular electron shuttles, carrying electrons from the cell to insoluble iron that is subsequently reduced abiotically (Newman and Kolter, 2000). An alternative solution to reduce insoluble Fe(III) without making direct contact to the insoluble $\mathrm{Fe}(\mathrm{III})$ oxides is the production and secretion of siderophores, a common tool of various bacteria and fungi to enhance iron solubility under iron-limiting conditions (Butler, 1998; Kraemer et al., 2005). Siderophores are low molecular weight $\mathrm{Fe}^{3+}$ chelating compounds with high specificity and affinity for iron. The dissolved ferric siderophore complexes are then recognized and can be transported across the cell membrane.

Another possibility to respire insoluble iron is a terminal reductase located in the outer membrane that takes electrons from the central metabolism in the cytoplasm and transfers them by direct contact to the insoluble iron minerals. $C$-type cytochromes are a part of the electron transport chain to the extracellular iron reductase in G. sulfurreducens (DiChristina, 2005). Additionally, the production of so-called nanowires has been reported to facilitate electron transfer to the $\mathrm{Fe}$ (III) oxide surface. These extracellular pili act as electrical conductor, but they are not necessarily required for the attachment to the iron mineral surface (Reguera et al., 2005). In case of Geobacter metallireducens, it was shown that pili help in accessing insoluble Fe(III) by chemotaxis (Childers et al., 2002).

\subsection{Alternative Electron Acceptors}

Geobacter sulfurreducens uses also elemental sulfur, Co(III)-EDTA or malate as electron acceptors (Caccavo et al., 1994). Like most Fe(III)-reducing bacteria, G. sulfurreducens reduces as well $\mathrm{Mn}(\mathrm{VI})$ and other metals. Toxic metals or metalloids often occur in their soluble form in the groundwater and thus are mobile. However, under anoxic conditions microorganisms such as Geobacteraceae are able to reduce them to insoluble end products that precipitate and can be removed from the 
groundwater (Lovley, 2001; Lovley, 2002). Especially the ability to reduce uranium makes Geobacter sulfurreducens an interesting tool for bioremediation.

Growth on fumarate results in a threefold higher cell yield compared to Fe(III) citrate as electron acceptor (Esteve-Núñez et al., 2004), meaning that the reduction of fumarate provides more energy than reduction of $\mathrm{Fe}(\mathrm{III})$ citrate. However, it was shown that, as long as $\mathrm{Fe}(\mathrm{III})$ was present in the culture, the levels of mRNA for fumarate reductase were significantly lower under acetate-limiting conditions such that the fumarate reduction was inhibited and the utilization of fumarate as an electron donor was favored (Esteve-Núñez et al., 2004).

Geobacteraceae can also use graphite electrodes as sole electron acceptors for anaerobic respiration. There, electron donors like acetate are completely oxidized to $\mathrm{CO}_{2}$. The rates of electron transport can be compared to those of electron transport to $\mathrm{Fe}(\mathrm{III})$ citrate $(0.21$ to $1.2 \mu \mathrm{mol}$ electrons $/ \mathrm{mg}$ of protein/ $\mathrm{min}$ in comparison to 1-3 $\mu \mathrm{mol}$ electrons/ mg of protein/ min during transfer to soluble Fe(III) citrate) (Bond and Lovley, 2003). This was the first report of microbial electricity production. The experiments showed, on the one hand, that electrode reduction supported growth of the bacteria and, on the other hand, that Geobacter sulfurreducens is capable of producing electric current when attached to electrodes.

Previously, Geobacter sp. have been classified as strict anaerobes. However, in the genome of Geobacter sulfurreducens homologs of catalase, superoxide dismutase, rubrerythrin, peroxidases and cytochrome $c$ oxidase were identified (Methé et al., 2003). These enzymes provide the possibility of scavenging oxygen radicals and therefore allow for exposure to oxygen or even to utilize oxygen as terminal electron acceptor. Growth experiments revealed that G. sulfurreducens can grow at least for $24 \mathrm{~h}$ with oxygen as single electron source (Lin et al., 2004). This suggests that the organism may be able to survive at the anoxic-oxic interface.

\subsection{Electron Transfer in DMRB}

The electron transfer chain to insoluble Fe(III) oxides in Geobacter species is of special interest, as insoluble $\mathrm{Fe}(\mathrm{III})$ oxides are the primary source of $\mathrm{Fe}(\mathrm{III})$ for the dissimilatory iron reduction. In contrast to classical respiratory metabolism, this pathway of iron reduction ends in an electron transfer system localized in the outer 
membrane, where it is in direct contact to insoluble iron minerals. Hence, two membranes need to be crossed.

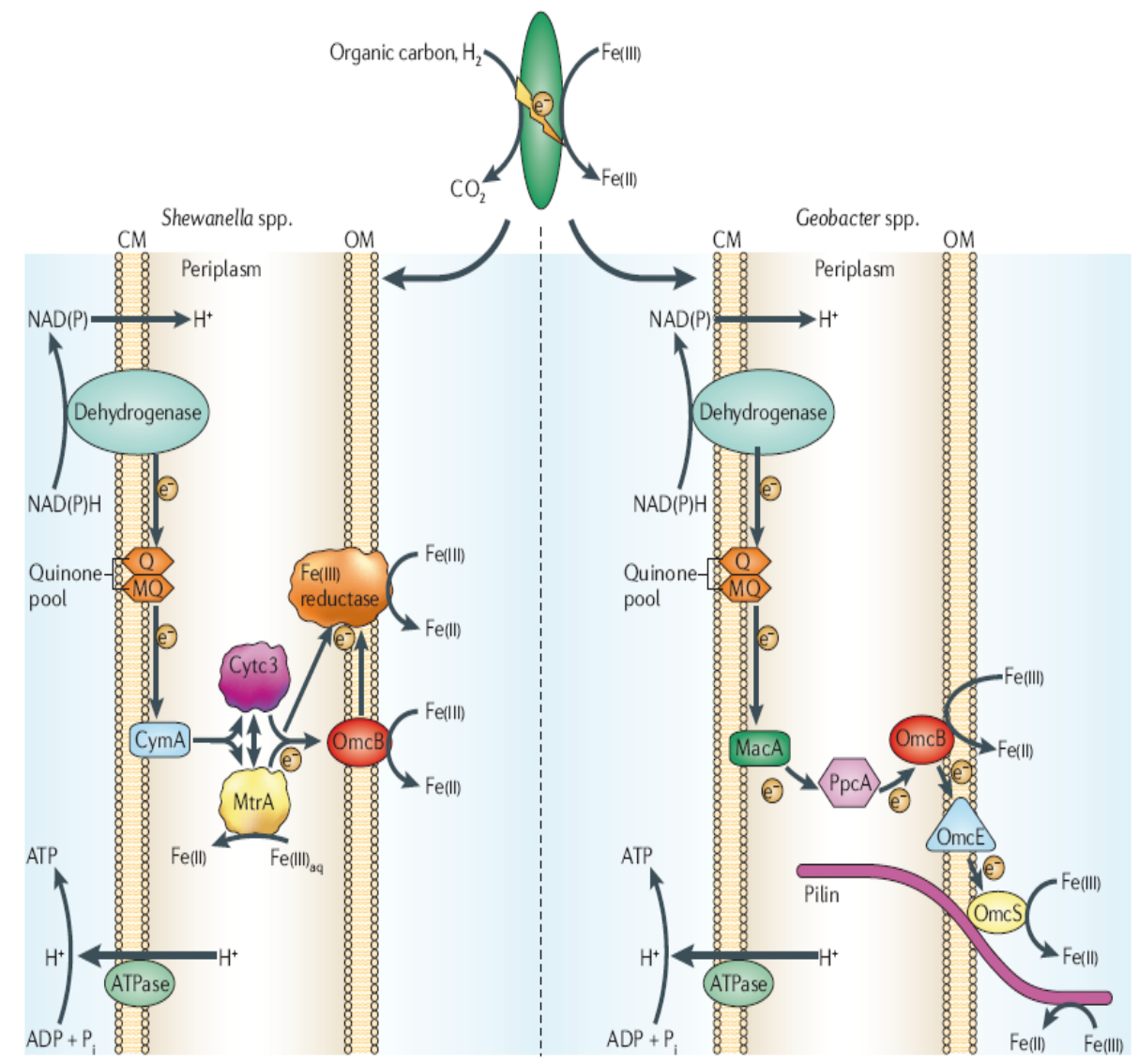

Figure 3: Model of the electron transport chain involved in dissimilatory Fe(III) reduction by Shewanella and Geobacter species (Weber et al., 2006). The description of the electron transfer proteins is found in the text. CM, cytoplasmic membrane; OM, outer membrane; $\mathrm{Q}$, quinone; $\mathrm{MQ}$, menaquinone.

Electron transfer has been most investigated in Geobacter and Shewanella species. In both cases, electron transport proteins and quinones in the inner membrane are considered to transfer electrons to electron transport proteins in the periplasm. Subsequently, $c$-type cytochromes act as carriers transferring electrons to a reductase localized in the outer membrane. Due to the identification of $c$-type cytochromes proposed to be involved in electron transport to insoluble iron (Leang et al., 2003; Lloyd et al., 2003; Butler et al., 2004), different models for the dissimilatory iron reduction have been developed (see figure 3) (Weber et al., 2006) and need to be verified.

In Shewanella species, electrons are transferred from menaquinone to the membranebound tetraheme $c$-type cytochrome CymA and subsequently to further electron carriers in the periplasm. The tetraheme $c$-type cytochrome Cyt $c_{3}$ and the decaheme 
cytochrome MtrA are considered to be the electron carriers to an outer membrane protein (Gordon et al., 2000; Pitts et al., 2003). OmcB is an outer membrane $c$-type cytochrome that can reduce extracellular Fe(III) directly (Myers and Myers, 2002). However, some Fe(III) reduction still occurs in the $o m c B$ mutant indicating that $\mathrm{Fe}$ (III) reduction is not exclusively dependent on OmcB (Myers and Myers, 2002; Weber et al., 2006).

The large number of c-type cytochromes in Geobacter sulfurreducens reflects the complex electron transport systems that lead to a huge variability in utilizing different electron acceptors, giving rise to the assumption that various alternative electron transfer chains to the outer membrane may exist (Leang et al., 2005).

In the currently proposed model for Geobacter sulfurreducens, the diheme cytochrome MacA is considered to be the primary acceptor for the electrons derived from menaquinone in the inner membrane (Weber et al., 2006). Subsequently, electrons are transferred to periplasmic $c$-type cytochromes such as $\mathrm{PpcA}$, a $9.6 \mathrm{kDa}$ periplasmic triheme cytochrome $c$ (Lloyd et al., 2003).

Obviously, multiheme $c$-type cytochromes in the outer membrane are key players in the reduction of metal ions. Gene expression and functional studies revealed that the $85.5 \mathrm{kDa}$ dodecaheme cytochrome $\mathrm{OmcB}$ is required for optimal $\mathrm{Fe}(\mathrm{III})$ reduction (Leang et al., 2003). The rate of Fe(III) reduction in an $o m c B$ deletion mutant was significantly impaired and was only $3-6 \%$ of that of the wild type. However, the mutant adapted to growth on soluble Fe(III) but not on insoluble Fe(III) (Leang et al., 2005). At least two further outer membrane $c$-type cytochromes, OmcE and OmcS (Mehta et al., 2005), have been reported to be required for the electron transfer to solid Fe(III) oxides. Not only cytochromes are involved in this electron transfer chain. When respiring Fe(III) oxides, Geobacter sulfurreducens produces pili. It was shown that these cell appendages not only serve for the attachment of the cells to the ferric iron but they are also conductive and active in transfer of electrons to the iron oxides (Reguera et al., 2005).

In spite of all recent progress, the mechanism DMRB apply to reduce metals like ferric iron or manganese oxides remains unclear and further investigations are warranted. 


\subsection{Cytochromes}

\subsubsection{The Porphyrin Cofactor}

Members of the $\alpha$-proteobacteria condense the heme precursor molecule $\delta$-aminolevulinic acid from glycine and succinyl-coenzymeA, whereas most of the bacteria including Escherichia coli use the $\mathrm{C}_{5}$ pathway (Jahn et al., 1991; Thöny-Meyer, 1997). Several subsequent reactions are necessary to make protoporphyrin IX (Daily, 1997). The final incorporation of the ferrous iron is catalyzed by the enzyme ferrochelatase.

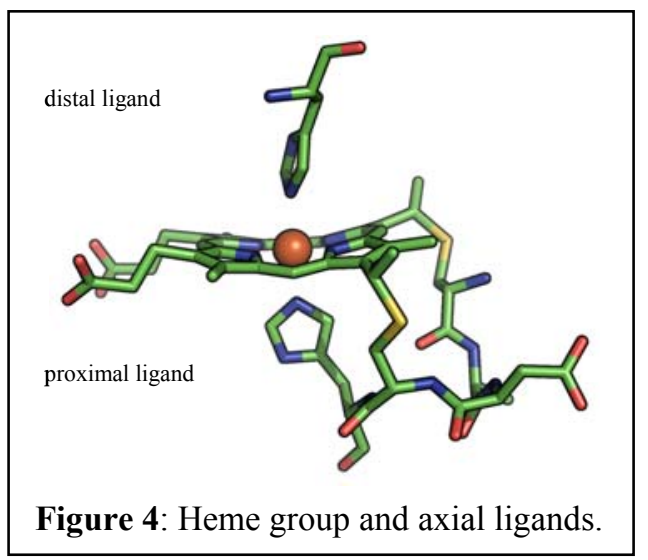

The four pyrrole nitrogen atoms of the heme group are strong chelators for metal ions such as ferric or ferrous iron. In addition, iron is ligated by one or two axial, protein-derived ligands. Heme iron occurs in 5- or 6-coordinated state with ligands in the form of histidine $\mathrm{N}^{\varepsilon}$ or - more rarely - $\mathrm{N}^{\delta}$, cysteine $\mathrm{S}^{\gamma}$, methionine $\mathrm{S}^{\delta}$, tyrosine $\mathrm{O}^{\eta}$ and lysine $\mathrm{N}^{\zeta}$ side chains or terminal amino groups provided by the peptide chain (Fita and Rossmann, 1985; Sundaramoorthy et al., 1995; Einsle et al., 2000). The distal ligand is positioned distantly in the primary sequence from the $\mathrm{CXXCH}$ motif. Furthermore, non-protein ligands may be bound that in most cases are related to the function of the protein, such as oxygen in hemoglobin or substrates and reaction intermediates in many enzymes.

The heme cofactor is redox-active and can be in the reduced $\left(\mathrm{Fe}^{2+}\right)$ or oxidized $\left(\mathrm{Fe}^{3+}\right)$ state. Therefore, these proteins are part of one-electron transfer reactions. Their redox potential determines the direction of electron transfer and usually falls into the range of $-400-+400 \mathrm{mV}$ (Moore and Pettigrew, 1990). The redox potential is strongly dependent on the axial ligands. Methionine sulfur is a good electron acceptor and favors the relatively electron-rich reduced state resulting in a more positive redox potential compared to bis-histidinyl coordinated heme groups (Moore and Pettigrew, 1990).

The heme group is a conjugated system leading to prominent spectroscopic features. The most important transitions are the alpha, beta and Soret bands. This characteristic absorption pattern which is due to charge transfer and $\pi$ to $\pi^{*}$ transitions within the 
pyrrole ring and the different oxidation states of the iron can be used to gain informations about the protein by electron excitation spectroscopy, an efficient analytical tool in the research of $c$-type cytochromes.

\subsubsection{C-Type Cytochromes}

$C$-type cytochromes are a widespread group of proteins that are found in animals, plants and bacteria. Besides the specific heme binding site, they have a second specific property in common. A characteristic N-terminal signal sequence serves for the export from the place of protein synthesis to the appropriate compartment. Bacterial $c$-type cytochromes are soluble or membrane-bound proteins outside the cytoplasm, located in the periplasm or in the inner or outer membrane.

Iron protoporphyrin IX is the cofactor of cytochromes, and it is found in various modifications in nature. Heme proteins serve a wide range of biological functions including the binding of oxygen (hemoglobins), electron transfer reactions and the catalysis of enzymatic reactions, especially of the oxygen metabolism (oxidases, peroxidases, catalases and hydroxylases). The catalytic variability of cytochromes originates from the nature of the protoporphyrin IX substituents as well as from the environment and the axial ligand provided by the surrounding protein (Moore and Pettigrew, 1990).
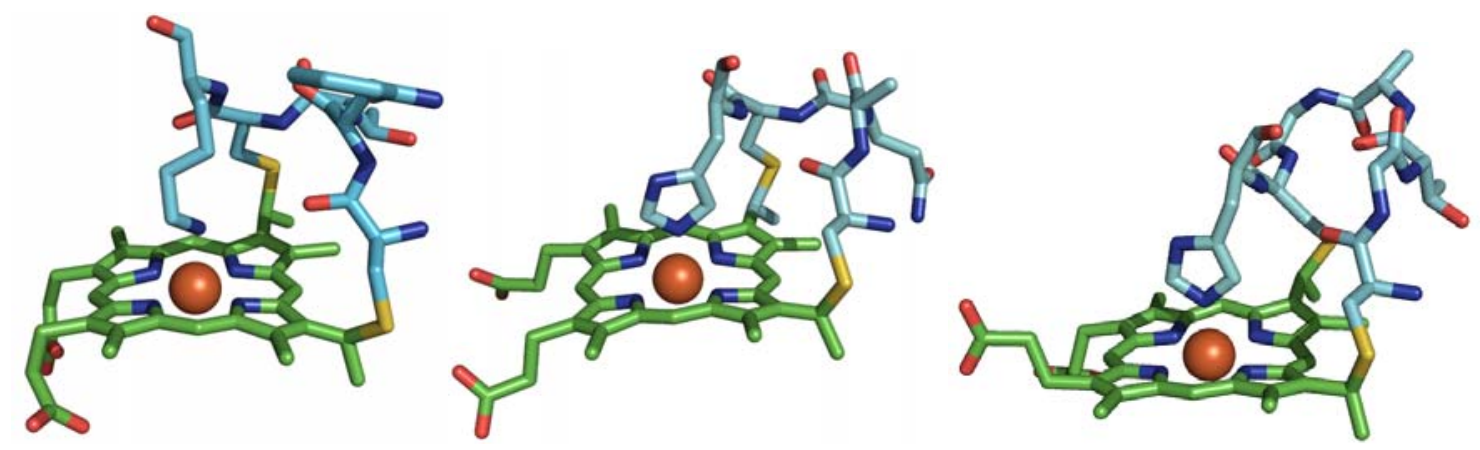

Figure 5: left: CXXCK-motif (cytochrome $c$ nitrite reductase, pdb accession code 1FS7), mid: CXXCHmotif (cytochrome $c$, pdb accession code 1HRC), right: CXXXXCH-motif (cytochrome $c_{3}$, pdb accession code $2 \mathrm{CTH})$

This work is focussed on heme $c$ as it occurs in $c$-type cytochromes. Their characteristic feature is the covalent attachment of the heme group via thioether bonds from the vinyl groups to the cysteine side chains of a conserved binding motif in the protein matrix. The cysteines are most commonly arranged within a $\mathrm{CXXCH}$-motif, but rare exceptions like $\mathrm{CXXXCH-}, \mathrm{CXXXXCH-}$ or $\mathrm{CXXCK}$-motives for the cofactor binding to the 
protein are also possible (Bushnell et al., 1990; Einsle et al., 2000). Histidine and lysine, provided by the common heme binding motif, are found as proximal axial ligands. Often, also a sixth ligand exists which is mostly a methionine or a histidine. The number of heme groups per protein chain is variable, from one up to 27 , as predicted for a protein in Geobacter sulfurreducens (Methé et al., 2003).

\subsubsection{C-Type Cytochrome Maturation}

$C$-type cytochrome maturation is a posttranslational process involving the transport of heme, secretion of the polypeptide chain through the membrane and covalent attachment of the heme to the apoprotein. This process converts a linear apoprotein to a three-dimensional holoprotein with one or more covalently bound and structure-giving heme groups (Thöny-Meyer, 1997; Kranz et al., 1998; Barker and Ferguson, 1999). However, the detailed mechanism during which the two thioether bonds between the cysteines of the $\mathrm{CXXCH}$-motif and the vinyl groups of the heme group are formed is still unclear.

The $c$-type cytochrome maturation system comprises several components and differs remarkably within several bacteria and eukaryotic cells. Three systems for the biogenesis of $c$-type cytochromes have been evolved.

\subsubsection{System I}

System I is the most common maturation system for $c$-type cytochromes found e.g. in $\alpha$ and $\gamma$-proteobacteria, in plant or protozoal mitochondria and in archaea (Kranz et al., 1998).

E. coli does not synthesize $c$-type cytochromes under aerobic conditions. However, under anaerobic respiratory conditions, E. coli was found to involve system $\mathrm{I}$ in the synthesis of $c$-type cytochromes (see figure 6). Five different $c$-type cytochromes can be detected in $E$. coli when nitrate, nitrite or trimethylamine N-oxide (TMAO) are present as terminal electron acceptors (Iobbi-Nivol et al., 1994). This is due to the fact that the expression of genes of the aeg-46.5 region is induced under anaerobic conditions and in the presence of nitrate, nitrite or TMAO. Further investigations revealed that genes of the cluster $c c m A B C D E F G H$ present in the aeg-46.5 region are required for $c$-type cytochrome maturation (Thöny-Meyer et al., 1995). Ccm proteins presumably form a 
maturase complex that coordinates the different steps of cytochrome $c$ maturation. The key steps occur on the periplasmic side of the cytoplasmic membrane.

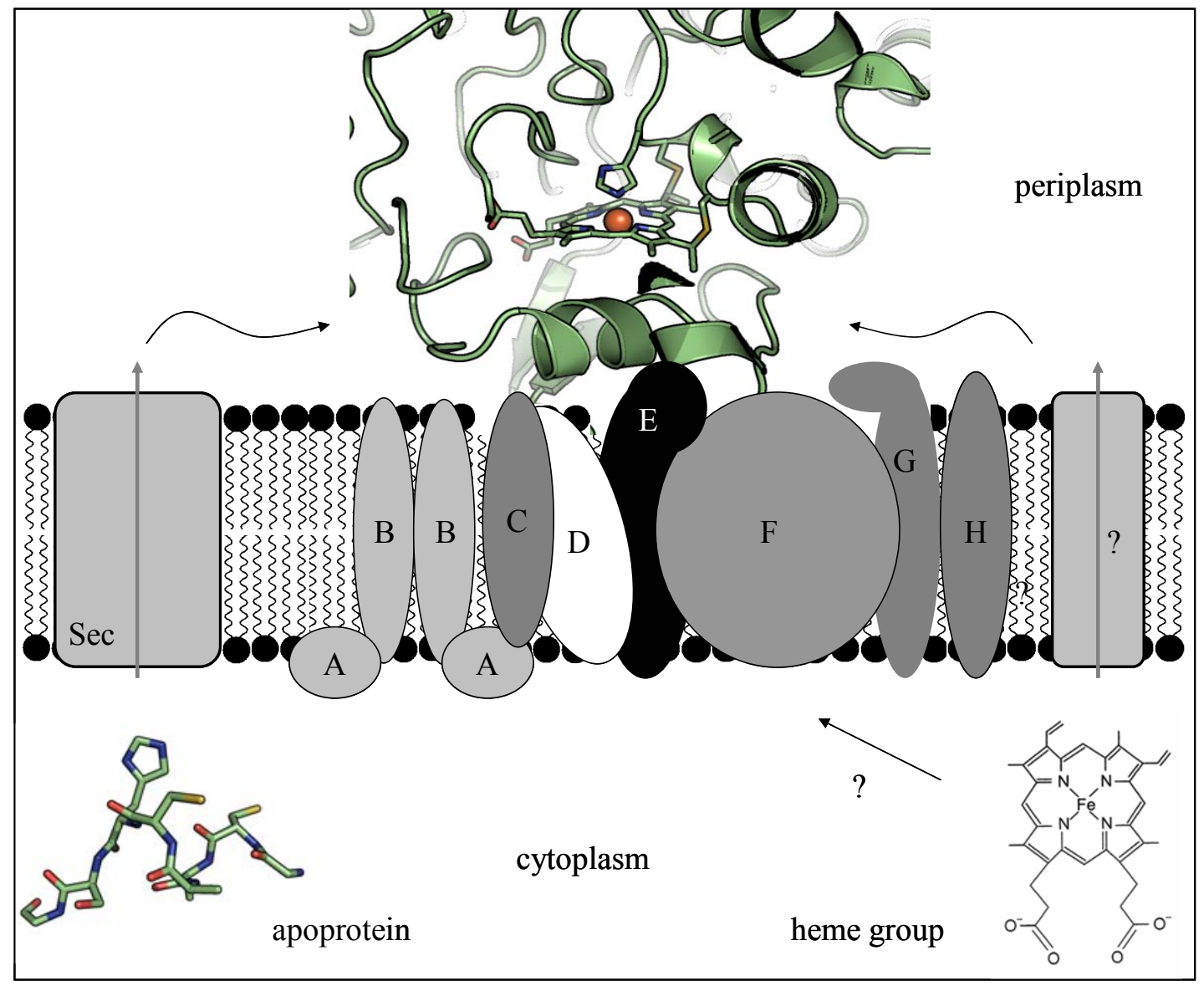

Figure 6: System I. $C$-type cytochrome maturation occurs in the periplasm. The apoprotein is transported via the Sec-dependent pathway into the periplasm; the transport mechanism of the heme group into the periplasm is still unknown. CcmAB: ABC transporter, CcmE: heme chaperone.

The heme group and the apoprotein are synthesized separately in the bacterial cytoplasm. The apoprotein is then translocated via the Sec-dependent pathway (ThönyMeyer, 2002) across the cytoplasmic membrane. How many and which heme carriers are involved in the transport of the heme group into the periplasm is not known so far. After the translocation, heme is covalently but transiently bound to the heme chaperone CcmE (Schulz and Thöny-Meyer, 2000). The small protein CcmD is implicated in heme delivery to the heme chaperone CcmE (Ahuja and Thöny-Meyer, 2005), forming a ternary complex that consists of CcmCDE. CcmF is involved in the release of heme from the heme chaperone (Thöny-Meyer, 2002). From there on, heme is transferred to the apoprotein. The reduction of the cysteines of the $\mathrm{CXXCH}$-motif prepares the 
binding reaction. For this, electrons are transported from a cytoplasmic thioredoxin to the transmembrane protein DsbD and finally on to the reductases $\mathrm{CcmG}$ and $\mathrm{CcmH}$. Biotechnologically, the ccm machinery can also be coerced into producing $c$-type cytochromes in the presence of oxygen. When the $c c m A B C D E F G H$ genes are expressed from a plasmid, the formation of holocytochrome $c$ can be achieved (Arslan et al., 1998; Huston et al., 2007). This method is employed in the present work to express the $c$-type cytochromes of interest.

\subsubsection{System II}

System II is found in gram-positive bacteria, chloroplasts as well as in some $\beta$-, $\delta$ - and $\varepsilon$-proteobacteria. It bears some resemblances to system I with respect to components ensuring the reduction of the cysteines; otherwise both systems are quite different. At least the four proteins CcsA, Ccs1, ResA and CcdA are involved in the assembly of c-type cytochromes (Kranz et al., 1998).

Geobacter sulfurreducens uses system II (Stevens et al., 2004). Nevertheless, it is possible to heterologously overproduce c-type cytochromes from Geobacter sulfurreducens in E. coli by means of coexpressing system I (see 3.5.3.1) (Lloyd et al., 2003; Heitmann and Einsle, 2005).

\subsubsection{System III}

This is the simplest known kind of $c$-type cytchrome maturation machinery and is found e.g. in mitochondria of fungi, vertebrates and invertebrates (Kranz et al., 1998). Two different types of cytochrome $c$ lyases representing central components of the $c$-type cytochrome biogenesis system III have been identified. Cytochrome $c$ lyase (CCHL) is required for the formation of the two thioether bonds between the heme group and the apocytochrome, and the cytochrome $c_{1}$ heme lyase $\left(\mathrm{CC}_{1} \mathrm{HL}\right)$ is required for the maturation of cytochrome $c_{1}$, an integral part of the $b c_{1}$-complex.

\subsection{Peroxidases}

Oxidative stress can manifest itself in the generation of toxic oxygen intermediates, including the superoxide anion $\left(\mathrm{O}_{2}^{-}\right)$, hydrogen peroxide $\left(\mathrm{H}_{2} \mathrm{O}_{2}\right)$ and the hydroxyl 
radical $\left(\mathrm{HO}^{\circ}\right)$, that evolve from the incomplete reduction of oxygen (see figure 7$)$. The reactive oxygen species can cause damage to proteins, DNA and membranes.

$$
2 \mathrm{H}_{2} \mathrm{O} \longleftrightarrow 2 \mathrm{OH}^{-} \longleftrightarrow 2 \mathrm{O}^{2-} \longleftrightarrow\left[\mathrm{O}^{2-}+\mathrm{O}^{\bullet}\right] \longleftrightarrow \mathrm{O}_{2}{ }^{2-} \longleftrightarrow \mathrm{O}_{2}{ }^{--} \longleftrightarrow \mathrm{O}_{2}
$$

Figure 7: Toxic oxygen intermediates of the incomplete reduction of oxygen (Kaim and Schwederski, 2004). Hydrogen peroxide is formed by the protonation of peroxide $\left(\mathrm{O}_{2}{ }^{2-}\right)$.

In bacteria, three main classes of enzymes are involved in the removal of hydrogen peroxide from the cell (Atack and Kelly, 2007). Cytoplasmic catalases cleave hydrogen peroxide into water and oxygen whereas glutathione peroxidases catalyze the reduction of $\mathrm{H}_{2} \mathrm{O}_{2}$ in the presence of glutathione. Finally, there are the cytochrome $c$ peroxidases catalyzing the reduction of hydrogen peroxide to water which draw electrons from the electron transfer chain. They are a widespread family of extracytoplasmic enzymes catalyzing the conversion of $\mathrm{H}_{2} \mathrm{O}_{2}$ by means of the heme cofactor. Eukaryotes as well as prokaryotes contain cytochrome $c$ peroxidases but they differ in mechanism and structure.

\subsubsection{Eukaryotic Peroxidases}

Eukaryotic peroxidases are located in the inter-membrane space of mitochondria. They contain one single $b$-type heme group as active site. The overall reaction is similar to bacterial peroxidases, but the catalytic mechanism is significantly different ( $\mathrm{Lu}, 2006$; Atack and Kelly, 2007).

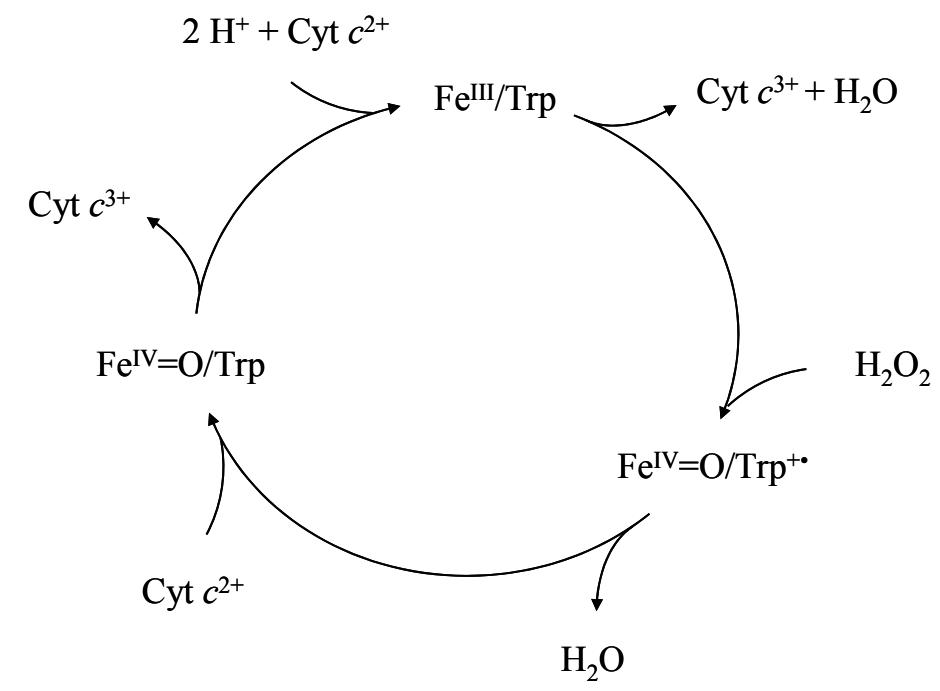

Figure 8: Catalytic reaction mechanism of eukaryotic peroxidases. 
The reaction generates an oxo-ferryl intermediate of the heme and a cation radical on a nearby tryptophan as the reduction of hydrogen peroxide requires two electrons (Sivaraja et al., 1989). In contrast to eukaryotic peroxidases, the bacterial cytochrome $c$ peroxidases (Ccps) incorporate a second heme group avoiding the generation of this radical.

Interestingly, cytochrome $c$ peroxidase and manganese peroxidase catalyzing the biodegradation of lignin show a similar heme binding site. The main differences are found in the $\mathrm{Mn}^{\mathrm{II}}$ binding site and a conserved aromatic residue near the heme group. In the eukaryotic Ccps there is a tryptophan instead of a phenylalanine. Additionally, many ligands for $\mathrm{Mn}^{\mathrm{II}}$ in $\mathrm{MnP}$ are missing in $\mathrm{CcP}(\mathrm{Lu}, 2006)$. These two enzymes are an example for proteins with similar scaffolds but different substrates and thus different catalyzed reactions.

\subsubsection{Bacterial Peroxidases}

Cytochrome $c$ peroxidases receive electrons from the central metabolism via cytochrome $c$ or in some cases from copper proteins (Pauleta et al., 2004b). They are located in the periplasm where they catalyze the two-electron reduction of hydrogen peroxide to water.

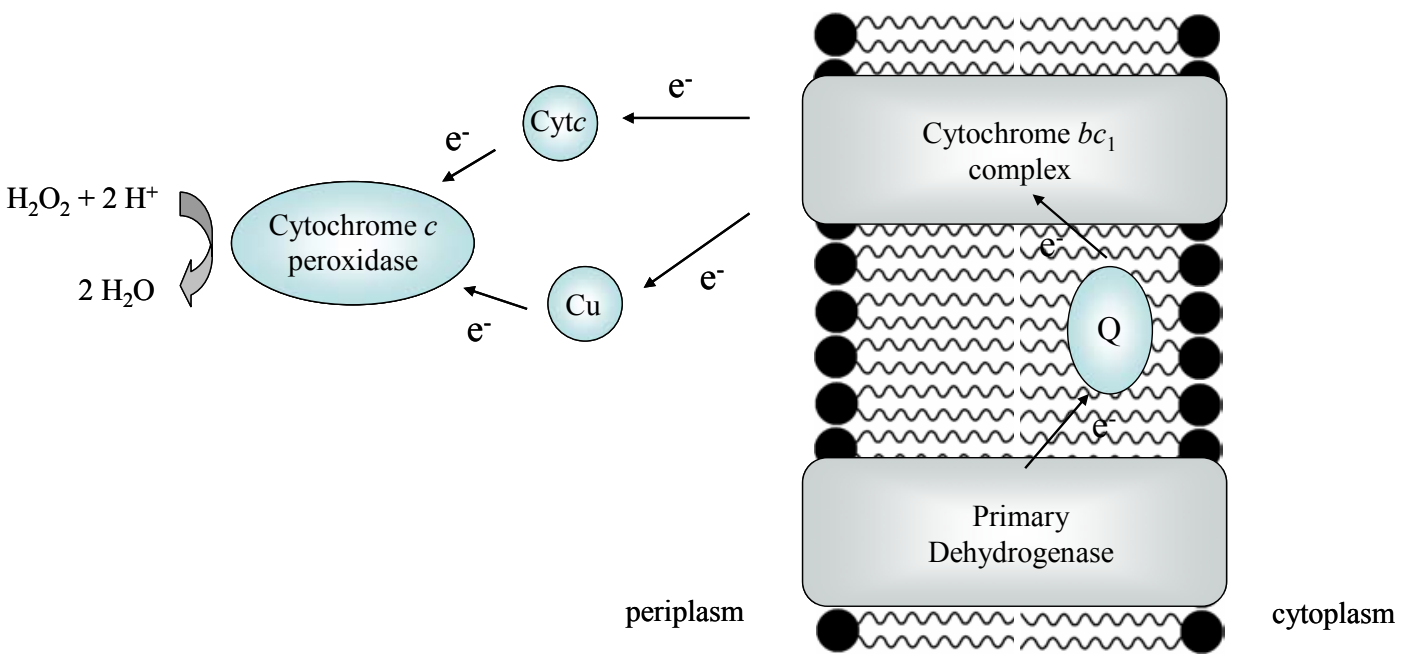

Figure 9: Scheme of a typical bacterial electron transport system. In gram-negative bacteria the cytochrome $c$ peroxidase is located in the periplasm. Most of the bacteria possess only one peroxidase (Atack and Kelly, 2007). Cytochromes $c$ (Cytc) and cupredoxins $(\mathrm{Cu})$ are currently considered to be electron $\left(\mathrm{e}^{-}\right)$donors to the peroxidase. Q: quinone pool 
Bacterial cytochrome $c$ peroxidases have been isolated from Methylococcus capsulatus (Zahn et al., 1997), Nitrosomonas europaea (Arciero and Hooper, 1994), Paracoccus pantotrophus (Goodhew et al., 1990), Pseudomonas aeruginosa (Ellfolk and Soininen, 1970), Pseudomonas stutzeri (Villalain et al., 1984) and Rhodobacter capsulatus (Hanlon et al., 1992). Depending on the species, molecular weights range from $35-40 \mathrm{kDa}$ (Atack and Kelly, 2007) and they are commonly purified as homodimers (Gilmour et al., 1994; Alves et al., 1999; De Smet et al., 2001). Crystal structures are available from Pseudomonas aeruginosa (Fülöp et al., 1995), Nitrosomonas europaea (Shimizu et al., 2001), Paracoccus denitrificans (Echalier et al., 2004) and Paracoccus pantotrophus (Echalier et al., 2006).

In contrast to eukaryotic peroxidases, bacterial CCPs consist of two domains, each with one covalently bound heme group. The high potential (HP) heme acting as the electron transfer center is situated in the C-terminal domain and its heme iron is methioninehistidine coordinated. The midpoint redox potential varies between the bacterial species from $+320 \mathrm{mV}$ in P. aeruginosa (Ellfolk et al., 1983) to $+130 \mathrm{mV}$ in N. europaea (Shimizu et al., 2001). The low potential (LP) heme is located in the N-terminal domain and is the site of peroxidase activity. In the oxidized form, the low potential heme is coordinated by two histidine residues and therefore is inactive. Here, the LP site has a midpoint redox potential of $-330 \mathrm{mV}$ in $P$. aeruginosa and $+70 \mathrm{mV}$ in $N$. europaea (Shimizu et al., 2001).

\subsubsection{Structure of Cytochrome $c$ Peroxidases}

The two heme groups are roughly perpendicular to each other and are separated by an iron-iron distance of about $21 \AA$ (see figure 10). The shortest distance between the heme groups is approximately $10 \AA$ between their propionate groups.

Both domains are connected by three strands of protein chain. The interface in between is hydrophobic, providing a typical $\mathrm{Ca}^{2+}$ binding site (Fülöp et al., 1995), where the amide oxygen of an asparagine, the main chain carbonyls of a threonine and a proline and four water molecules are ligating the $\mathrm{Ca}^{2+}$ ion. 

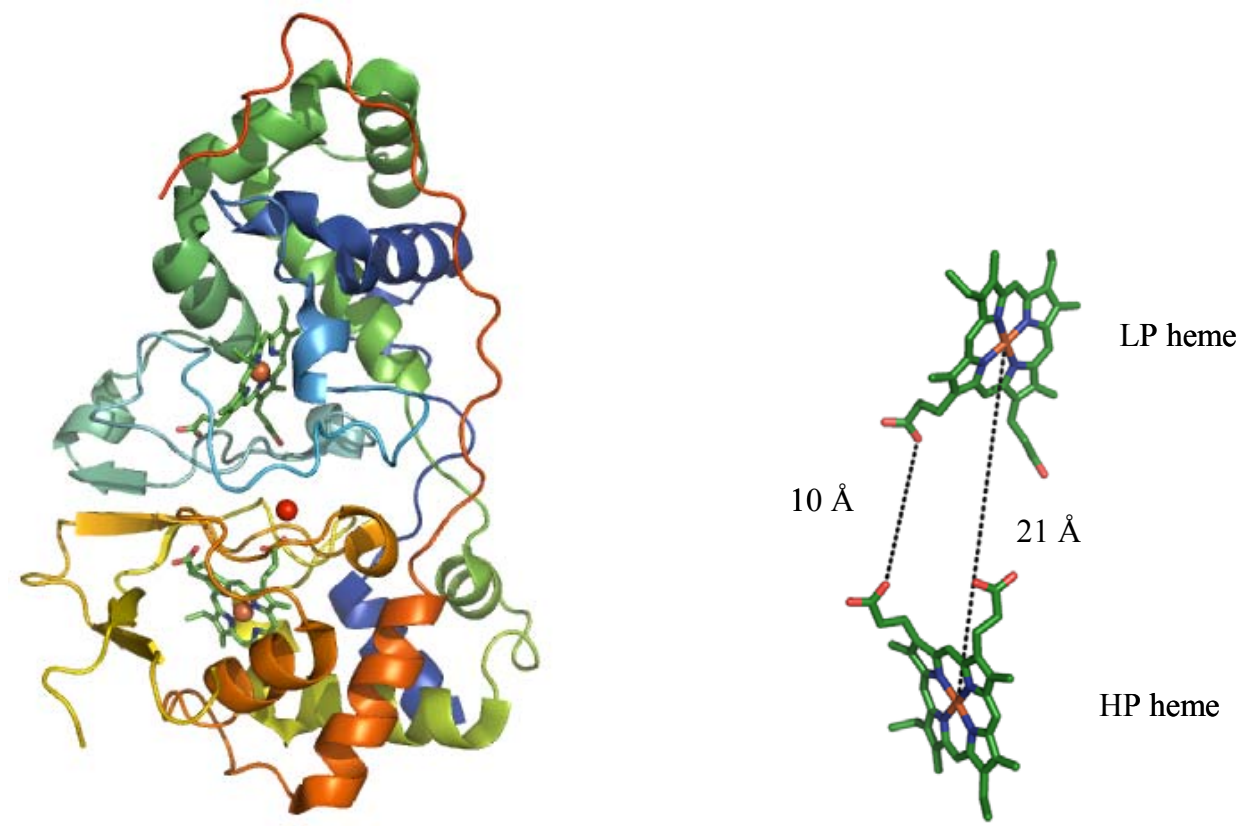

Figure 10: The structure of the cytochrome $c$ peroxidase of Pseudomonas aeruginosa (Fülöp et al., 1995) is the first structure solved of a bacterial cytochrome $c$ peroxidase ( $\mathrm{pdb}$ accession code 1EB7).

\subsubsection{Reaction Mechanism}

In its oxidized form, the peroxidase of Pseudomonas aeruginosa exhibits the high potential heme $\mathrm{Fe}^{\mathrm{III}}$ in a high spin/ low spin equilibrium (Foote et al., 1984) whereas the iron is ligated by methionine and histidine. The low potential heme is coordinated by two histidines in the oxidized state. Consequently, the N-terminal domain has to undergo a conformational rearrangement to allow access for and binding of hydrogen peroxide. The current model suggests that the reduction of the high potential heme results in the switch of the low potential heme to high spin state. In this mixed valence form, the second histidine ligand of the low potential heme is released from the iron so that $\mathrm{H}_{2} \mathrm{O}_{2}$ has access to the active site. One electron is abstracted from the high potential iron and one from the low potential iron with the formation of an oxo-ferryl intermediate. However, the mechanism of hydrogen peroxide reduction in bacterial cytochrome $c$ peroxidases is not yet fully understood.

\subsubsection{IN and OUT Conformation}

Bacterial Ccps are active in the mixed valence state, where the high potential electron transferring heme is in its reduced state and the low potential peroxidatic heme is in its oxidized state. The only exception known so far represents the peroxidase of 
$N$. europaea which is also active in its oxidized state. The flexible loop that is rearranged in the peroxidase of e.g. P. aeruginosa or $P$. nautica is here always in the OUT-confirmation, hence the heme is always 5-coordinated and therefore the enzyme is always accessible to substrate (Arciero and Hooper, 1994).
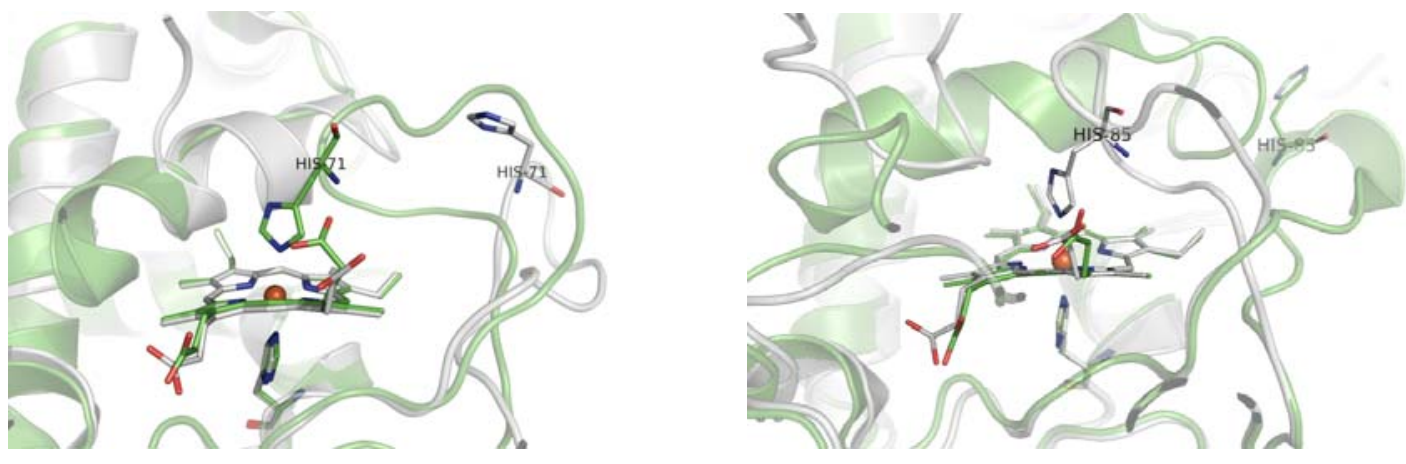

Figure 11: left: IN-form (green, pdb accession code 1RZ6) and OUT-form (grey, pdb accession code 1RZ5) of Pseudomonas nautica, right: oxidized-form (grey, pdb accession code $2 \mathrm{C} 1 \mathrm{U}$ ) and mixedvalence form (green, pdb accession code $2 \mathrm{C} 1 \mathrm{~V}$ ) of Paracoccus pantotrophus.

The other peroxidases need to be reduced before they can function as catalysts; only a change in the coordination of the heme iron at the active site allows substrate binding.

Two structures of the peroxidase of $P$. nautica are available due to photoreduction in the $\mathrm{X}$-ray beam (Dias et al., 2004). The IN-form is inactive and contains no calcium. The OUT-form has calcium bound and the loop comprising His71 is flipped out in the photoreduced state (Dias et al., 2004).

\subsubsection{Electron Transfer within the Cytochrome $c$ Peroxidases}

For the electron transfer to the substrate hydrogen peroxide, it is necessary that electrons derived from an electron donor such as cytochrome $c$ or pseudoazurin are first transferred to the HP heme and furtheron via an electron transport pathway to the active site.

Ccps can accept two electrons from ferrous cytochrome $c$ during catalysis according to:

$$
\mathrm{H}_{2} \mathrm{O}_{2}+2 \mathrm{H}^{+}+2 \mathrm{Cyt} c\left(\mathrm{Fe}^{2+}\right) \rightarrow 2 \mathrm{H}_{2} \mathrm{O}+2 \mathrm{Cyt} c\left(\mathrm{Fe}^{3+}\right) .
$$

The high potential heme receives electrons from external donors and mediates the transfer to the active site located about $21 \AA$ away from the transferring heme. Currently, the way of the electrons from the electron transfer center to the active site is subject for speculations. It is proposed that the heme propionates and the conserved 
Trp94 located in the hydrophobic patch are conduits for the electrons (Dias et al., 2004; De Smet et al., 2006).
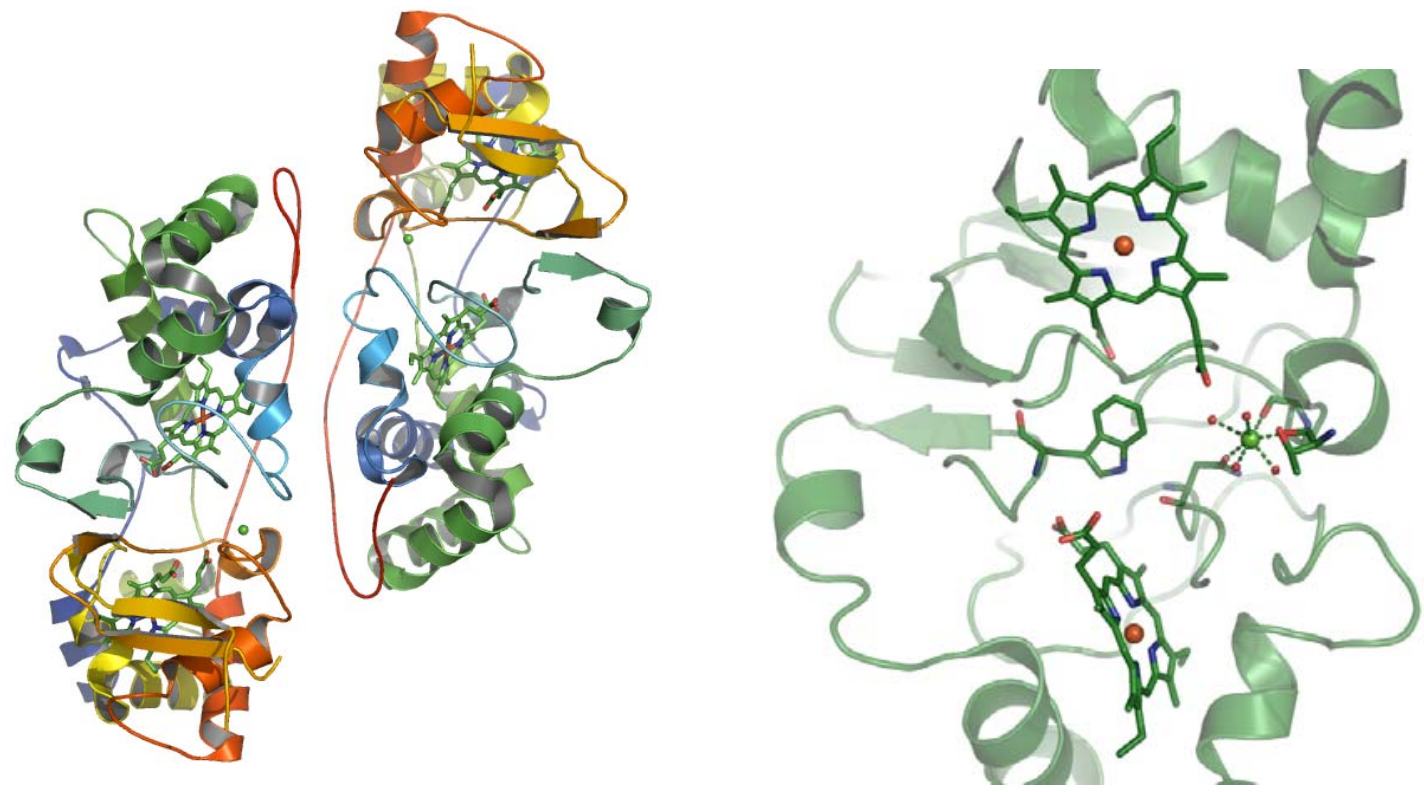

Figure 12: One heme group is located in each domain; tryptophan and calcium are located in the hydrophobic interface.

\subsubsection{Other Diheme Cytochrome $c$ Enzymes}

Bacterial peroxidases are an example for proteins with similar scaffold performing different functions. MauG proteins are very similar to the bacterial peroxidases considering their sequences, but they show differences with respect to their function. MauG is one of the four proteins responsible for the biosynthesis of the methylamine dehydrogenase (MADH) (Wang et al., 2003), involved in the generation of the tryptophan tryptophylquinone cofactor. The enzyme shows just a low peroxidase activity.

The rubber oxygenase A (RoxA) is a further example. Sequence comparison with cytochrome $c$ peroxidases displays a few conserved residues, but for this enzyme no peroxidase activity was detected (Jendrossek and Reinhardt, 2003; Braaz et al., 2004).

\subsection{The Rubber Oxygenase RoxA}

Natural rubber is synthesized by many plants and several fungi. Its main source is the rubber tree (Hevea brasiliensis). One of the main components, the biopolymer poly (cis1,4-isoprene) contains many linear isoprene-subunits $\left(\mathrm{C}_{5} \mathrm{H}_{8}\right)$ and two trans-isoprene units at each end (see figure 13) (Eng et al., 1994; Tanaka et al., 1996). Natural rubber 
does not accumulate in the environment, consequently there has to be continuous biological degradation. From a variety of bacteria, especially belonging to the actinomycetes, it is known that they exist on natural rubber medium and use rubber as carbon source. Xanthomonas sp. strain $35 \mathrm{Y}$ is so far the only known gram-negative bacterium degrading natural rubber. It was shown that Xanthomonas sp. strain $35 \mathrm{Y}$ secrets a rubber-degrading component into the polyisoprene containing medium that leads mainly to the formation of one degradation product, 12-oxo-4,8-dimethyl-trideca4,8-dien-1-al (ODTD) (Braaz et al., 2004). First indications of an extracellular enzyme that is responsible for the degradation of natural rubber were found by Tsuchii and Takeda (Tsuchii and Takeda, 1990).

A

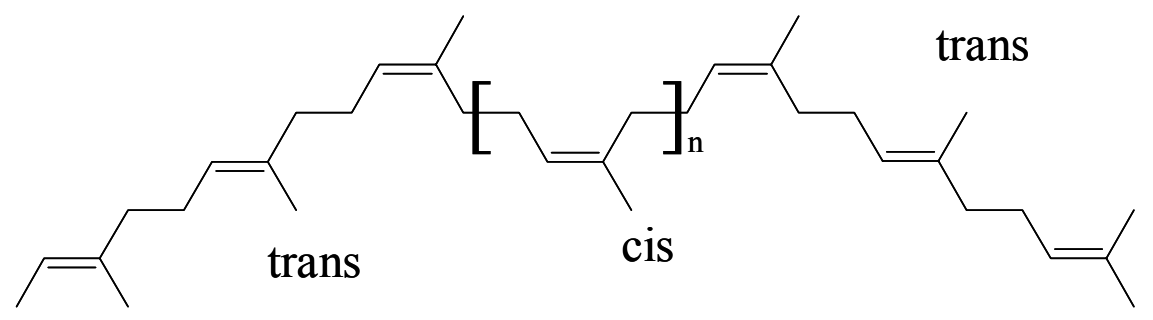

$\mathrm{B}$<smiles>CC(=O)CC/C=C(\C)CC/C=C(\C)CCC=O</smiles>

12-oxo-4,8-dimethyl-trideca-4,8-dien-1-al

Figure 13: Structure of (A) polyisoprene, $n=100-10000$, and (B) ODTD.

The rubber oxygenase A (RoxA) was first purified from medium of rubber-grown Xanthomonas sp. strain $35 \mathrm{Y}$ and it showed a strong absorbance maximum at $406 \mathrm{~nm}$ (Braaz et al., 2004). The amino acid sequence then turned out to comprise two heme binding motifs agreeing with this specific absorbance (Jendrossek and Reinhardt, 2003). RoxA degrades natural rubber in vitro as well as synthetically produced poly (cis-1,4isoprene), but it seems to be specific for oligomers and polymers of 1,4-isoprene. Natural rubber as well as synthetically produced poly (cis-1,4-isoprene) were cleaved by purified RoxA whereas oligomers from trans-1,4-isoprene and aromatic compounds 
were not degraded by RoxA. By the means of labeling experiments it could be shown that the dioxygen dependent reaction at least incorporates one oxygen atom from $\mathrm{O}_{2}$ into ODTD (Braaz et al., 2005). 


\subsection{Goals of this Study}

One goal of this study was to elucidate the protein structures of components of the dissimilatory metal reduction pathway in DRMB. The cytochrome $c$ peroxidase homologs MacA and CcpA from Geobacter sulfurreducens were shown to be related to the electron transfer chain to insoluble electron acceptors outside the bacterial cells (Butler et al., 2004; Leang et al., 2005). Additionally, it was found out that MacA is not required for the oxidative stress response and that there is no homolog of cytochrome $c$ that usually functions as electron donor to Ccps in the genome of Geobacter sulfurreducens. Thus, the question arose whether the structures of MacA and CcpA are similar to classical Ccps and if both enzymes show peroxidase activity.

First, an expression and purification system for the two $c$-type cytochromes needed to be established, as both proteins should be overexpressed heterologously in E. coli and purified by affinity chromatography without the use of a possibly heme interacting Histag. Then, CcpA and MacA should be characterized biochemically and structurally. Furthermore, the structure of the diheme cytochrome $c$ enzyme RoxA from Xanthomonas sp. strain $35 \mathrm{Y}$ ought to be evaluated and compared to the structures of cytochrome $c$ peroxidases. RoxA exhibits conserved residues of the core region of Ccps (Jendrossek and Reinhardt, 2003) leading to the assumption that general properties of electron transfer between the two heme groups within the proteins or parallels between the reaction mechanisms can be pointed out. 


\section{$4 \quad$ Material and Methods}

\subsection{Material}

\subsubsection{Chemicals}

All standard chemicals were of analytical purity grade (p.a.) and were obtained from the following companies: Applichem (Darmstadt, Germany), Merck (Darmstadt, Germany), Roth (Karlsruhe, Germany) and Sigma-Aldrich (Deisenhofen, Germany).

\subsubsection{DNA and Protein Molecular Weight Marker}

The GeneRuler (MBI Fermentas, St. Leon-Rot, Germany) served as DNA marker. For sizing of proteins by SDS-PAGE, the unstained protein molecular weight marker from MBI Fermentas was used.

\subsubsection{Enzymes and Proteins}

Restriction endonucleases, $P f u$ DNA polymerase and T4 DNA ligase were obtained from MBI Fermentas (St. Leon-Rot, Germany).

\subsubsection{Bacterial Strains}

\subsubsection{Escherichia coli}

XL10-Gold (Stratagene, USA):

$\operatorname{Tet}^{\mathrm{r}} \Delta(m c r A) 183 \Delta(m c r C B-h s d S M R-m r r) 173$ endA1 supE44 thi-1 recAl gyrA96 relA1 lac Hte [F' proAB lacl $\left.{ }^{\mathrm{q}} Z \Delta M 15 \operatorname{Tn} 10\left(\mathrm{Tet}^{\mathrm{r}}\right) \operatorname{Tn} 5\left(\mathrm{Kan}^{\mathrm{r}}\right) \mathrm{Amy}\right]$.

BL21(DE3) (Novagen, Darmstadt, Germany):

[F $\mathrm{F}^{-}$omp $T h s d S_{\boldsymbol{B}}\left(r_{B}^{-} m_{B}^{-}\right)$gal dcm (DE3)] 


\subsubsection{Geobacter sulfurreducens}

The strain Geobacter sulfurreducens PCA (DSM 12127) (Caccavo et al., 1994) was obtained from the German Collection of Microorganisms and Cell Cultures (DSMZ, Braunschweig, Germany).

\subsubsection{DNA-Oligonucleotides}

DNA-oligonucleotides were obtained from MWG (Ebersberg, Germany) in HPSF (high purity salt free) quality.

Primers were constructed for the pETSN-22 vector (4.1.6.2). For this, the signal sequences of MacA and CcpA were determined by the SignalP v 3.0 server (Bendtsen et al., 2004) in order to omit the Geobacter leader sequences as the pETSN-22 vector provides the OmpA signal sequence from E. coli.

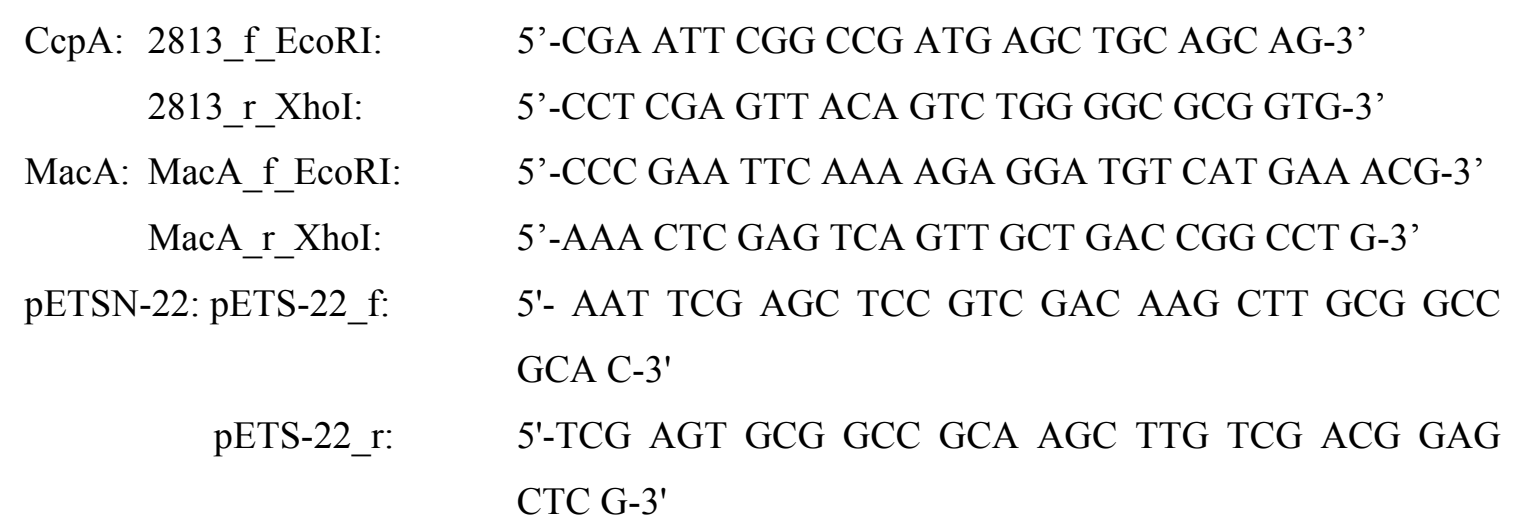

\subsubsection{Plasmids}

\subsubsection{1 pEC86}

By means of the pEC86 plasmid (figure 14), the ccm (cytochrome $c$ maturation) genes are constitutively expressed under the control of a tet promoter. This vector is based on the pACYC184 plasmid and contains besides the genes ccmABCDEFGH, providing the cytochrome $c$ maturation machinery, a chloramphenicol resistance marker (Arslan et al., 1998) and was generously provided by Prof. Linda Thöny-Meyer. 


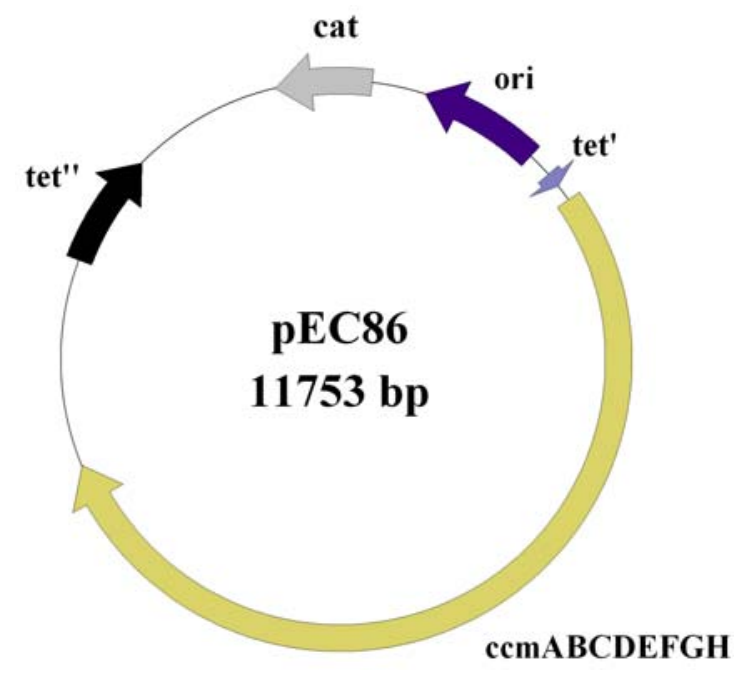

Figure 14: Schematic representation of the vector pEC86. Cat: chloramphenicol resistance marker, ori: origin, ccmABCDEFGH: cytochrome $c$ maturation genes, tet': tet promoter, tet" ${ }^{\prime \prime}$ tetracycline resistance marker

\subsubsection{2 pETSN-22}

The plasmids used for heterologous expression of the two $c$-type cytochromes from Geobacter sulfurreducens are based on the vector pET22b(+) (Novagen, Darmstadt, Germany). However, the pET22b(+) vector was modified by replacing the ribosome binding site and the pelB signal sequence with the analogous sequence from the pASKIBA44 vector (IBA, Göttingen, Germany) using the XbaI and XhoI restriction sites. Afterwards, the multiple cloning site (mcs) derived from pASK-IBA44 was exchanged for the sequence between EcoRI and XhoI restriction sites in pET22b(+) using the primers $\mathrm{pETS}-22 \_\mathrm{f} / \mathrm{r}$.

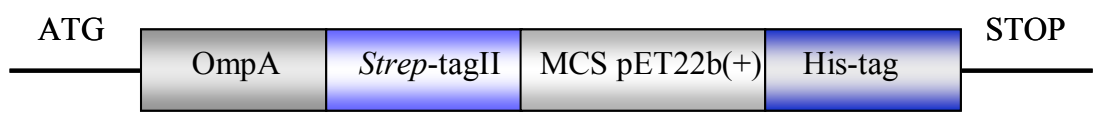

Figure 15: Organization of the pETSN-22 cloning site. The genes $c c p A$ and $\operatorname{mac} A$ were cloned into the pETSN-22 vector via EcoRI and XhoI restriction sites resulting in constructs that consist of the sequence of $c c p A$ and $m a c A$, respectively, with preceding OmpA signal sequence and N-terminal Strep-tagII.

During secretion of the recombinant proteins into the periplasm, the OmpA leader sequence is cleaved off so that the processed protein starts with an alanine-serine linker. 


\subsection{Methods}

\subsubsection{Microbiological Methods}

\subsubsection{Cultivation of Escherichia coli}

\begin{tabular}{l}
\hline Luria-Bertani (LB) medium \\
\hline $1 \%(\mathrm{w} / \mathrm{v})$ tryptone \\
$0.5 \%(\mathrm{w} / \mathrm{v})$ yeast extract \\
$1 \%(\mathrm{w} / \mathrm{v})$ sodium chloride \\
\hline
\end{tabular}

Escherichia coli strains were grown in Luria-Bertani medium. Precultures for DNA isolation or the expression of protein were incubated overnight at $37^{\circ} \mathrm{C}$.

The proteins MacA and CcpA were expressed heterologously in E.coli BL21(DE3)::pEC86 overnight at $30^{\circ} \mathrm{C}$. Therefore, LB medium supplemented with $100 \mu \mathrm{g} / \mathrm{ml}$ ampicillin and $20 \mu \mathrm{g} / \mathrm{ml}$ chloramphenicol for antibiotic resistance selection was inoculated with $1(\mathrm{v} / \mathrm{v}) \%$ of inoculum.

\subsubsection{Cultivation of Geobacter sulfurreducens}

\begin{tabular}{lc}
\hline Modified NBAF medium & \\
\hline acetate & $15 \mathrm{mM}$ \\
fumarate & $40 \mathrm{mM}$ \\
$\mathrm{NH}_{4} \mathrm{Cl}$ & $0.20 \mathrm{~g}$ \\
$\mathrm{KH}_{2} \mathrm{PO}_{4}$ & $0.42 \mathrm{~g}$ \\
$\mathrm{~K}_{2} \mathrm{HPO}_{4}$ & $0.22 \mathrm{~g}$ \\
$\mathrm{KCl}$ & $0.38 \mathrm{~g}$ \\
$\mathrm{NaHCO}_{3}$ & $1.80 \mathrm{~g}$ \\
$\mathrm{Na}_{2} \mathrm{CO}_{3}$ & $0.50 \mathrm{~g}$ \\
\hline & \\
\hline Vitamin solution $\mathbf{m 1 4 1}$ & \\
\hline biotin & $2.0 \mathrm{mg}$ \\
folic acid & $2.0 \mathrm{mg}$ \\
pyridoxine-HCl & $10.0 \mathrm{mg}$ \\
thiamine-HCl $\cdot 2 \mathrm{H} \mathrm{H}_{2} \mathrm{O}$ & $5.0 \mathrm{mg}$ \\
riboflavin & $5.0 \mathrm{mg}$ \\
nicotinic acid & $5.0 \mathrm{mg}$ \\
$D$-Ca-pantothenate & $5.0 \mathrm{mg}$ \\
vitamin $\mathrm{B}_{12}$ & $0.1 \mathrm{mg}$ \\
$p$-aminobenzoic acid & $5.0 \mathrm{mg}$ \\
lipoic acid & $5.0 \mathrm{mg}$ \\
dH & $\mathrm{O}$
\end{tabular}




\begin{tabular}{ll}
\hline \multicolumn{2}{l}{ Trace element solution m141+ } \\
\hline nitrilotriacetic acid & $1.50 \mathrm{~g}$ \\
$\mathrm{MgSO}_{4} \cdot 7 \mathrm{H}_{2} \mathrm{O}$ & $3.00 \mathrm{~g}$ \\
$\mathrm{MnSO}_{4} \cdot 2 \mathrm{H}_{2} \mathrm{O}$ & $0.50 \mathrm{~g}$ \\
$\mathrm{NaCl}$ & $1.00 \mathrm{~g}$ \\
$\mathrm{FeSO}_{4} \cdot 7 \mathrm{H}_{2} \mathrm{O}$ & $0.10 \mathrm{~g}$ \\
$\mathrm{CoSO}_{4} \cdot 7 \mathrm{H}_{2} \mathrm{O}$ & $0.18 \mathrm{~g}$ \\
$\mathrm{CaCl}_{2} \cdot 2 \mathrm{H}_{2} \mathrm{O}$ & $0.10 \mathrm{~g}$ \\
$\mathrm{ZnSO}_{4} \cdot 7 \mathrm{H}_{2} \mathrm{O}$ & $0.18 \mathrm{~g}$ \\
$\mathrm{CuSO}_{4} \cdot 5 \mathrm{H}_{2} \mathrm{O}$ & $0.01 \mathrm{~g}$ \\
$\mathrm{KAl}_{\left(\mathrm{SO}_{4}\right)_{2} \cdot 12 \mathrm{H}_{2} \mathrm{O}}$ & $0.02 \mathrm{~g}$ \\
$\mathrm{H}_{3} \mathrm{BO}_{4}$ & $0.01 \mathrm{~g}$ \\
$\mathrm{Na}_{2} \mathrm{MoO}_{4} \cdot 2 \mathrm{H}_{2} \mathrm{O}$ & $0.01 \mathrm{~g}$ \\
$\mathrm{NiCl}_{2} \cdot 6 \mathrm{H}_{2} \mathrm{O}$ & $0.025 \mathrm{~g}$ \\
$\mathrm{Na}_{2} \mathrm{SeO}_{3} \cdot 5 \mathrm{H}_{2} \mathrm{O}$ & $0.50 \mathrm{mg}$ \\
$\mathrm{Na}_{2} \mathrm{WO}_{4} \cdot 2 \mathrm{H}_{2} \mathrm{O}$ & $0.40 \mathrm{mg}$ \\
$\mathrm{dH}_{2} \mathrm{O}$ & $1000 \mathrm{ml}$ \\
\hline
\end{tabular}

Cells of Geobacter sulfurreducens were cultivated in modified NBAFYE medium (Coppi et al., 2001).

The modified NBAF medium was supplemented with $1 \%(\mathrm{v} / \mathrm{v})$ vitamin solution $\mathrm{m} 141$ (DSMZ, Braunschweig, Germany), 1\% (v/v) trace element solution m141+ (DSMZ) and $0.1 \%(\mathrm{w} / \mathrm{v})$ yeast extract and autoclaved at $121^{\circ} \mathrm{C}$ for 20 minutes in a Widdel flask. Afterwards, the medium was cooled down while gassing with inertal gas $\left(80 \% \mathrm{~N}_{2}\right.$, $20 \% \mathrm{CO}_{2}$ ) (Airliquide, Germany). Sterile filtered cysteine serving as reductant and sulfur source was added and the $\mathrm{pH}$ was adjusted with $6 \mathrm{M} \mathrm{HCl}$ to 7.2. The medium was inoculated with $5-10 \%$ of its volume or with a DMSO stock (see 4.2.1.5) of G. sulfurreducens cells and incubated at $30^{\circ} \mathrm{C}$ on a roller.

\subsubsection{Production and Transformation of Competent $E$. coli Cells}

\begin{tabular}{l|l}
\hline TFB-1 buffer: $\mathrm{pH} 5.8$ with acetic acid & TFB-2 buffer: $\mathrm{pH} 6.5$ with $1 \mathrm{M} \mathrm{NaOH}$ \\
\hline $30 \mathrm{mM}$ potassium acetate $\mathrm{pH} 7.0$ & $10 \mathrm{mM} \mathrm{NaMOPS} \mathrm{pH} 7.2$ \\
$50 \mathrm{mM} \mathrm{MnCl}$ & $75 \mathrm{mM} \mathrm{CaCl}_{2}$ \\
$10 \mathrm{mM} \mathrm{CaCl}$ & $10 \mathrm{mM} \mathrm{RbCl}$ \\
$100 \mathrm{mM} \mathrm{RbCl}$ & $15 \%$ glycerol \\
$15 \%$ glycerol & \\
\hline
\end{tabular}

$500 \mathrm{ml} \mathrm{LB}$ medium, supplemented with appropiate antibiotics, were inoculated with a $5 \mathrm{ml}$ preculture to produce chemically competent $E$. coli cells. The cells were grown at $37^{\circ} \mathrm{C}$ to an optical density of $\mathrm{OD}_{600}=0.6$ before they were pelleted by centrifugation ( 10 minutes at $4,000 \times g$ and $4^{\circ} \mathrm{C}$ ). Subsequently, the cell pellet was carefully resuspended in $150 \mathrm{ml}$ ice-cold TFB-1 buffer and chilled for 5 minutes on ice. After one further centrifugation, the pellet was dissolved in $5 \mathrm{ml}$ ice-cold TFB-2 buffer and divided into $50 \mu 1$ aliquots that were frozen in liquid nitrogen and stored at $-80^{\circ} \mathrm{C}$. 
Prior to transformation, the cells were thawed on ice and 20-100 ng of DNA or the ligation mixture were added. After 30 minutes of incubation on ice, cells were subjected to a $37^{\circ} \mathrm{C}$ heat shock for 10 minutes. Afterwards, cells were chilled on ice for further 10 minutes before addition of $200 \mu \mathrm{LB}$ medium without antibiotics. In order to develop the antibiotic resistance, cells were incubated for $30-60$ minutes at $37^{\circ} \mathrm{C}$ and then plated on selective agar or inoculated in a selective medium.

\subsubsection{Cultivation of Geobacter sulfurreducens in Soft Agar Tubes}

$7.5 \%(\mathrm{w} / \mathrm{v})$ brain heart infusion agar was boiled in water. Yeast extract and cysteine were added to final concentrations of $0.1 \%(\mathrm{w} / \mathrm{v})$ and $8 \mathrm{mM}$, respectively, before $3 \mathrm{ml}$ of this mixture were filled into a hungate tube. Subsequently, the tubes were sealed with aluminium foil and autoclaved. Immediately afterwards, the tubes containing liquid agar were placed in a $60^{\circ} \mathrm{C}$ water bath. $6 \mathrm{ml}$ of NBAFYE medium were added and after a short cooling time the agar was inoculated with $200 \mu 1$ pre-culture. Every following tube was inoculated with $1 \mathrm{ml}$ of the preceding tube. Finally, inertal gas $\left(80 \% \mathrm{~N}_{2}\right.$, $20 \% \mathrm{CO}_{2}$ ) (Airliquide, Germany) was directed by means of a sterile filter over the agar and the tube was closed air-tight. The bacteria were incubated at $30^{\circ} \mathrm{C}$.

\subsubsection{Production of Geobacter sulfurreducens DMSO Stocks}

\begin{tabular}{l}
\hline Buffer \\
\hline $1 \mathrm{mM} \mathrm{HEPES} / \mathrm{NaOH} \mathrm{pH} 7$ \\
$1 \mathrm{mM} \mathrm{MgCl}$ \\
$175 \mathrm{mM}$ sucrose \\
\hline
\end{tabular}

A single colony of Geobacter sulfurreducens was taken out of the agar using a Pasteur pipette and then amplified in $5 \mathrm{ml}$ NBAFYE medium. $500 \mathrm{ml}$ NBAFYE medium were inoculated with this preculture and incubated at $30^{\circ} \mathrm{C}$ to an $\mathrm{OD}_{600}=0.5$. From that point on, the cells were treated with a glas pipette and handled under anaerobic conditions. After one centrifugation step ( 8 minutes at $3,500 \times g, 4^{\circ} \mathrm{C}$ ), the cells were carefully resuspended in $400 \mathrm{ml}$ ice-cold buffer and then spinned down again. This washing step was repeated once. Finally, the pellet was taken in $2 \mathrm{ml}$ buffer $+400 \mu 1(60 \%$ DMSO + $40 \%$ buffer) and aliquoted. The $100 \mu 1$ aliquots were frozen in liquid nitrogen and stored at $-80^{\circ} \mathrm{C}$. 


\subsubsection{Molecular Biological Techniques}

\subsubsection{Polymerase Chain Reaction}

\begin{tabular}{ll}
\hline PCR reaction mixture \\
\hline $1 \mathrm{X}$ & Pfu buffer \\
$250 \mu \mathrm{M}$ & $\mathrm{dNTPs}$ \\
$10 \%(\mathrm{v} / \mathrm{v})$ & $\mathrm{DMSO}$ \\
$8 \mathrm{mM}$ & $\mathrm{MgSO}_{4}$ \\
$0.2 \mu \mathrm{l}$ & genomic DNA of G. sulfurreducens \\
$0.2 \mu \mathrm{l}$ & Pfu DNA polymerase \\
$1 \mu \mathrm{l}$ & 5'-Primer \\
$1 \mu \mathrm{l}$ & 3'-Primer \\
& $\mathrm{dH} \mathrm{H}_{2} \mathrm{O}, 50 \mu \mathrm{l}$ \\
\hline
\end{tabular}

The Polymerase chain reaction (PCR) (Mullis and Faloona, 1987; Saiki et al., 1988) is an in vitro method for the exponential amplification of any DNA fragment. This technique enables the selective amplification of a short, exactly defined part of a DNA strain out of a complex DNA mixture.

A PCR cycler from Biometra (Göttingen, Germany) was used for DNA amplification.

For the amplification of genes from genomic DNA from Geobacter sulfurreducens, the highly thermostable $P f u$ DNA polymerase (MBI Fermentas, St. Leon-Rot, Germany) derived from the hyperthermophilic archaeum Pyrococcus furiosus was used. The enzyme catalyzes the synthesis of duplex DNA in $5^{\prime} \rightarrow 3^{\prime}$ direction and possesses an additional $3^{\prime} \rightarrow 5$ ' exonuclease activity correcting nucleotide incorporation errors. In order to reduce non-specific PCR products, an established touch-down PCR protocol was used starting at a high annealing temperature that was subsequently stepwise decreased. The size of the generated PCR product was subsequently verified by means of agarose gel electrophoresis.

\subsubsection{DNA Isolation from Agarose Gels \& Purification of PCR Products}

For the isolation of DNA fragments from agarose gels, the QIAquick Gel Extraction kit (Qiagen, Hilden, Germany) and the Nucleotrap kit (Macherey\& Nagel, Düren, Germany) were used. Purification of the PCR products was carried out with the QIAquick PCR purification kit (Qiagen).

\subsubsection{Isolation of Plasmid DNA from Bacteria}

The preparation of plasmid DNA in analytical scale was performed with the QIAprep Spin Miniprep kit (Qiagen, Hilden, Germany) or the Nucleo Spin kit (Macherey\& Nagel, Düren, Germany). Isolation of plasmid DNA in preparative scale 
was carried out according to manufacturer's instructions for the Plasmid Midi kit (Qiagen).

\subsubsection{Isolation of Genomic DNA from Geobacter sulfurreducens}

\begin{tabular}{l}
\hline $\mathbf{C T A B} / \mathbf{N a C l}$ \\
\hline $10 \%(\mathrm{w} / \mathrm{v}) \mathrm{CTAB}$ (hexadecyl-trimethyl-ammoniumbromide) \\
$0.7 \mathrm{M} \mathrm{NaCl}$ \\
\hline \\
\hline TE-buffer \\
$10 \mathrm{mM}$ Tris $\mathrm{pH} 8$ \\
$1 \mathrm{mM}$ EDTA \\
\hline
\end{tabular}

$2 \mathrm{ml}$ of an overnight culture of Geobacter sulfurreducens were sedimented by centrifugation. The pellet was resuspended in $567 \mu 1$ TE-buffer, $30 \mu 1$ 10\% (w/v) SDS and $3 \mu \mathrm{l}$ Proteinase $\mathrm{K}(20 \mathrm{mg} / \mathrm{ml})$ and the mixture was incubated at $37^{\circ} \mathrm{C}$ for one hour. Then, $100 \mu 15 \mathrm{M} \mathrm{NaCl}$ and $80 \mu \mathrm{CTAB} / \mathrm{NaCl}$ were added, vortexed and incubated at $65^{\circ} \mathrm{C}$ for 10 minutes. $700 \mu 1$ of a $24: 1$ mixture of chloroform/ isoamyl alcohol (Applichem, Darmstadt, Germany) were added. Again, the mixture was vortexed before it was centrifuged 5 minutes at $16,000 \times \mathrm{g}$. The aqueous phase was transferred into a new cup. The chloroform/ isoamyl (24:1) alcohol extraction step ( $500 \mu 1$, vortex, $\circlearrowright 5$ minutes at $16,000 \times g$, fresh cup) was repeated three times. $0.5 \mu 1$ RNase were added prior to the incubation at $37^{\circ} \mathrm{C}$ for 30 minutes. $500 \mu 1$ ice-cold isopropanol were added and the mixture was incubated one hour at $-20^{\circ} \mathrm{C}$. The precipitated DNA was pelleted for 20 minutes at $16,000 \mathrm{x} g$ and $4{ }^{\circ} \mathrm{C}$. Subsequently, the pellet was washed with $70 \%$ ethanol, dried and then dissolved in 50-100 $\mu 110 \mathrm{mM}$ Tris $\mathrm{pH} 8$.

\subsubsection{DNA Restriction Digestion}

The restriction digestion was performed according to manufacturer's instructions (MBI Fermentas, St. Leon-Rot, Germany). Usually, the DNA was incubated one hour at $37^{\circ} \mathrm{C}$ before the enzymes were inactivated by a heat shock at $65^{\circ} \mathrm{C}$ for 20 minutes.

\subsubsection{DNA Ligation}

The DNA ligation was carried out with the T4 DNA ligase according to manufacturer's instructions (MBI Fermentas, St. Leon-Rot, Germany). Generally, a fivefold molar excess of insert fragment compared to the vector fragment was applied and the mixture was incubated at $4^{\circ} \mathrm{C}$ overnight. 


\subsubsection{DNA Sequencing}

\begin{tabular}{ll}
\hline PCR reaction mixture \\
\hline $200 \mathrm{ng}$ & DNA \\
$8 \mathrm{pmol}$ & primer \\
$1 \mu 1$ & Seq-mix BigDye ${ }^{\circledR}$ Terminator v1.1 (Applied Biosystems) \\
$1 \mu 1$ & $10 \mathrm{X}$ sequencing buffer (Applied Biosystems) \\
& $\mathrm{dH}_{2} \mathrm{O} @ 10 \mu \mathrm{l}$ \\
\hline
\end{tabular}

Amplification of the DNA was carried out using a single primer and the following protocol according to the chain termination method (Sanger et al., 1977):

\section{Cycle}

Denaturation $\quad 94^{\circ} \quad 2^{\prime}$

Denaturation $\quad 94^{\circ} \quad 30^{\circ}$,

$\begin{array}{lll}\text { Primer-hybridisation } & 50^{\circ} & 30, \\ \text { Elongation } & 60^{\circ} & 2,\end{array}$ Elongation

$1 \mu \mathrm{l} 125 \mathrm{mM}$ EDTA, $1 \mu 13 \mathrm{M}$ sodium acetate and $50 \mu 1100 \%$ ethanol were added before the reaction mixture was chilled on ice for 5 minutes. DNA was spinned down by centrifugation $\left(16,000 \times g, 4^{\circ} \mathrm{C}, 15\right.$ minutes $)$ and then washed with $70 \mu 1$ $70 \%$ ethanol. The supernatant after one further centrifugation $\left(16,000 \times g, 4^{\circ} \mathrm{C}\right.$, 5 minutes) was discarded and the DNA was dried prior to solving in $30 \mu \mathrm{ld} \mathrm{d}_{2} \mathrm{O}$. Analysis and documentation of the samples was kindly performed with an ABIPrism 3100 DNA Sequencer in the Department of Developmental Biochemistry (University of Göttingen).

\subsubsection{Agarose Gel Electrophoresis}

\begin{tabular}{l|l}
\hline TAE-buffer & Agarose gel loading buffer \\
\hline $40 \mathrm{mM}$ Tris base & $0.25 \%$ bromphenol blue \\
$20 \mathrm{mM}$ acetic acid & $0.25 \%$ xylene cyanol FF \\
$2 \mathrm{mM}$ EDTA & $30 \%$ glycerol \\
\hline
\end{tabular}

Agarose forms a matrix meshwork in which larger DNA fragments are more strongly retained than smaller ones, leading to a separation of the sample by size. For this, $1 \%$ agarose gels $(1 \%(\mathrm{w} / \mathrm{v})$ agarose in TAE-buffer) were used. The solid gel was placed in the electrophoresis chamber filled with TAE-buffer such that the gel was completely submerged in buffer. Samples were mixed with sample buffer and SYBR Green I (Molecular Probes, Karlsruhe, Germany) was added as fluorescence dye. For the size determination of the resulting DNA bands, a DNA molecular weight marker (MBI Fermentas, St. Leon-Rot, Germany) was used. 
Electrophoresis was performed with a field intensitiy between 5 to $10 \mathrm{~V} / \mathrm{cm}$. Afterwards, the documentation was carried out with the GelDoc 2000 (BioRad, München, Germany).

\subsubsection{Protein Biochemical Methods}

\subsubsection{Cell Disruption}

\begin{tabular}{l}
\hline Lysis buffer \\
\hline $20 \mathrm{mM}$ Tris $\mathrm{pH} 8$ \\
$250 \mathrm{mM} \mathrm{NaCl}$ \\
ALP (protease-inhibitor cocktail) \\
\hline
\end{tabular}

The cells were resuspended in $3 \mathrm{ml}$ lysis buffer per gramm cells. The cell suspension was disrupted by five passages through a microfluidizer S100 (Microfluidics, Newton, USA) and cooled on ice in between the cycles. After centrifugation for 20 minutes at $20,000 \times g$ and then for one hour at $100,000 \times g$, the supernatant was ready for purification by affinity chromatography.

\subsubsection{Affinity Chromatography}

\begin{tabular}{l|l|l}
\hline Loading Buffer & Elution Buffer & Storage Buffer \\
\hline $20 \mathrm{mM} \mathrm{Tris} \mathrm{pH} 8$ & $20 \mathrm{mM} \mathrm{Tris} \mathrm{pH} 8$ & $20 \mathrm{mM}$ Tris $\mathrm{pH} 8$ \\
$250 \mathrm{mM} \mathrm{NaCl}$ & $\begin{array}{l}250 \mathrm{mM} \mathrm{NaCl} \\
2.5 \mathrm{mM} \text { desthiobiotin }\end{array}$ & $\begin{array}{l}1 \mathrm{mM} \mathrm{HABA} \\
\text { (hydroxy-azophenyl-benzoic acid) }\end{array}$ \\
\hline
\end{tabular}

All purification steps were performed at $20^{\circ} \mathrm{C}$ with an Äkta Prime chromatography system (GE Healthcare, München, Germany).

The Strep-tag purification system is based on the selective binding of Strep-tagII fusion proteins to modified streptavidin (Strep-tactin) (Skerra and Schmidt, 2000). The soluble fraction was loaded with a rate of $1 \mathrm{ml} / \mathrm{min}$ to the Strep-tactin column equilibrated with loading buffer. Proteins that did not bind to the sepharose were washed from the column with loading buffer. Absorbance at $280 \mathrm{~nm}$ was monitored and the bound protein was eluted with elution buffer as soon as the absorbance stayed constant. The eluate was collected in $2 \mathrm{ml}$ fractions. Subsequently, the column was washed with 2 column volumes of elution buffer, 5 column of loading buffer and then with 5 column volumes of storage buffer.

The fractions were analyzed by SDS-PAGE (see 4.2.3.4). Cytochrome-containing fractions were pooled and concentrated by ultrafiltration (30.000 Da cut-off) (Vivaspin, Sartorius, Germany) to a volume of 1-2 $\mathrm{ml}$. 


\subsubsection{Size Exclusion Chromatography}

\begin{tabular}{l}
\hline Buffer \\
\hline $20 \mathrm{mM}$ Tris pH 8 \\
$150 \mathrm{mM} \mathrm{NaCl}$ \\
\hline
\end{tabular}

The separation of the proteins by size was achieved by size exclusion chromatography, whereby the protein was simultaneously rebuffered and separated from impurities and misfolded protein.

The concentrated protein was filtrated with a $0.22 \mu \mathrm{m}$ centrifugal filter device (Millipore, Schwalbach, Germany) and then loaded at a rate of $1 \mathrm{ml} / \mathrm{min}$ to a preequilibrated Superdex 200 26/60 column (GE Healthcare, München, Germany). Fractions containing the pure protein were analyzed by SDS-PAGE and afterwards pooled and concentrated by ultrafiltration.

\subsubsection{SDS-PAGE}

\begin{tabular}{l|l}
\hline Resolving gel $\mathbf{1 2 . 5 \%}$ & Volume \\
\hline $30 \%$ bis-acrylamid & $3.8 \mathrm{ml}$ \\
$1.88 \mathrm{mM}$ Tris $\mathrm{pH} 8.8$ & $1.8 \mathrm{ml}$ \\
$0.5 \%$ SDS & $1.8 \mathrm{ml}$ \\
TEMED & $16 \mu \mathrm{l}$ \\
$10 \%$ APS & $45 \mu \mathrm{l}$ \\
$\mathrm{ddH}_{2} \mathrm{O}$ & $1.6 \mathrm{ml}$ \\
\hline
\end{tabular}

\begin{tabular}{l|l}
\hline Stacking gel 5\% & Volume \\
\hline $30 \%$ bis-acrylamid & $0.5 \mathrm{ml}$ \\
$0.625 \mathrm{mM}$ Tris pH 8.8 & $0.6 \mathrm{ml}$ \\
$0.5 \%$ SDS & $0.6 \mathrm{ml}$ \\
TEMED & $6 \mu \mathrm{l}$ \\
$10 \%$ APS & $15 \mu \mathrm{l}$ \\
$\mathrm{ddH}_{2} \mathrm{O}$ & $1.3 \mathrm{ml}$ \\
\hline
\end{tabular}

\begin{tabular}{l|l}
\hline \multicolumn{1}{c|}{$\begin{array}{c}\text { Coomassie Staining } \\
\text { solution }\end{array}$} & Destaining solution \\
\hline $10 \%$ ethanol & $10 \%$ ethanol \\
$5 \%$ acetic acid & \\
$0.002 \%$ Coomassie & \\
$(\mathrm{G} 250: \mathrm{R} 250=4: 1)$ & \\
\hline
\end{tabular}

\begin{tabular}{l|l}
\hline $\mathbf{5 X}$ loading buffer & $\mathbf{1}$ X running buffer \\
\hline $0.5 \mathrm{M}$ Tris/ $\mathrm{HCl} \mathrm{pH} 6.8$ & $25 \mathrm{mM}$ Tris base \\
$40 \%$ glycerol & $192 \mathrm{mM}$ glycine \\
$8 \%(\mathrm{w} / \mathrm{v}) \mathrm{SDS}$ & $0.1 \%(\mathrm{w} / \mathrm{v}) \mathrm{SDS}$ \\
$0.004 \%$ bromphenol blue & \\
\hline
\end{tabular}

Proteins were separated according to their electrophoretic properties by SDS-PAGE (Laemmli, 1970). This occurs in dependence on the length of the peptide chain or of the molecular weight as well as on protein folding state. The samples were mixed with 
sample buffer and boiled for 5 minutes. By using the anionic detergent SDS in the sample buffer, proteins are denatured and obtained a net negative charge proportional to the length of the polypeptide chain, corresponding to their molecular weight. After 5 minutes of centrifugation, the samples were applied to the stacking gel pockets.

SDS gels were prepared with the Hoefer miniVE SDS gel system (GE Healthcare, Müchen, Germany). The separation was carried out at $25 \mathrm{~mA}$ for one and at $50 \mathrm{~mA}$ for two gels, respectively. By application of an electric field, molecules are separated according to their charge and size, so that the negatively charged proteins migrate across the electric field to the anode.

Subsequently, the gels were incubated in $20 \mathrm{ml}$ Coomassie staining solution for about 30 minutes. After destaining with $10 \%$ ethanol, gels were analyzed and documented with a GelDoc 2000 (Biorad, München, Germany).

\subsubsection{Heme Staining}

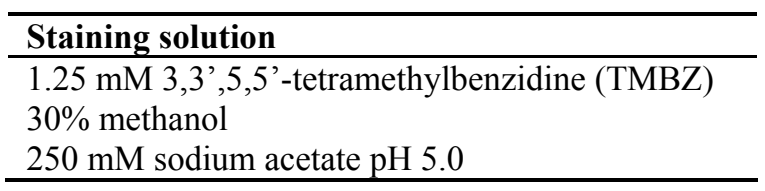

TMBZ was solved in methanol and then acetate was added. The gel was incubated in this staining solution for 30 minutes before $\mathrm{H}_{2} \mathrm{O}_{2}$ from a fresh $30 \%$ stock solution was added to a final concentration of $52 \mathrm{mM}$ (Goodhew et al., 1986). The developing color reaction was observed and stopped by washing with 30\% 1-propanol and $250 \mathrm{mM}$ sodium acetate $\mathrm{pH}$ 5. Documentation of the gel was carried out immediately.

\subsubsection{Protein Concentration Determination}

Protein concentration was determined by the bicinchoninic acid method (BCA) (Smith et al., 1985).

\subsubsection{Spectroscopic Methods}

\subsubsection{Electron Excitation Spectroscopy}

Electron excitation spectroscopy uses electromagnetic waves of the ultraviolet (UV) and the visible light. The resulting electron excitation spectra are due to electronic transitions, including charge transfer (ligand-to-metal charge transfer, metal-to-ligand charge transfer and metal-to-metal charge transfer), $\mathrm{d}$ to $\mathrm{d}$ and $\pi$ to $\pi^{*}$ transitions. 
Lambert-Beer's law quantifies the absorbance of radiation from the spectrum according to

$$
\mathrm{E}=\varepsilon \cdot \mathrm{c} \cdot \mathrm{d},
$$

where $\mathrm{E}$ is the absorbance, $\mathrm{d}$ is the pathlength through the cuvette $[\mathrm{cm}], \mathrm{c}$ is the concentration of the absorbing compound $\left[\mathrm{mol} \cdot \mathrm{l}^{-1}\right]$ and $\varepsilon$ is the molar extinction coefficient $\left[1 \cdot \mathrm{mol}^{-1} \cdot \mathrm{cm}^{-1}\right]$.

Spectra were recorded using an Ultrospec ${ }^{\mathrm{TM}} 2100$ pro spectrophotometer (GE Healthcare, München, Germany).

\subsubsection{Activity Assay}

The peroxidase activity was determined by the $\mathrm{ABTS}^{\circ} / \mathrm{ABTS}^{2-}$ (2,2'-azino-bis(3ethylbenzthiazoline-6-sulfonic acid)) system (Childs and Bardsley, 1975). ABTS was obtained from Sigma (Deisenhofen, Germany).

$$
\mathrm{H}_{2} \mathrm{O}_{2}+\text { reduced ABTS } \rightarrow 2 \mathrm{H}_{2} \mathrm{O}+\text { oxidized ABTS. }
$$

The colorless $\mathrm{ABTS}^{2-}$ anion reduces the peroxidase and becomes the oxidized radical ABTS $^{--}$ion due to the release of one electron. This ABTS $^{--}$radical is relatively stable and has an extinction coefficient of $36 \mathrm{mM}^{-1} \mathrm{~cm}^{-1}$ at $420 \mathrm{~nm}$ (Chen et al., 2002). Reduction of hydrogen peroxide requires two electrons such that two ABTS ions transfer electrons to one $\mathrm{H}_{2} \mathrm{O}_{2}$.<smiles>CCn1/c(=N/N=c2/sc3cc([Se])ccc3n2C)sc2cc([Se])ccc21</smiles>

$$
+\mathrm{e}^{-} \uparrow \downarrow-\mathrm{e}^{-}
$$<smiles></smiles>

Figure 16: ABTS is oxidized by one electron, forming a metastable radical cation; the radical cation then slowly disproportionates into ABTS (initial state) and an azodication

The activity was assayed under anaerobic conditions. Therefore all solutions were degassed prior to the measurement in an anarobic cuvette. The enzymes were reduced by the addition of $10 \mu \mathrm{M}$ sodium dithionite $\left(\mathrm{Na}_{2} \mathrm{~S}_{2} \mathrm{O}_{4}\right)$ to the protein solution. 


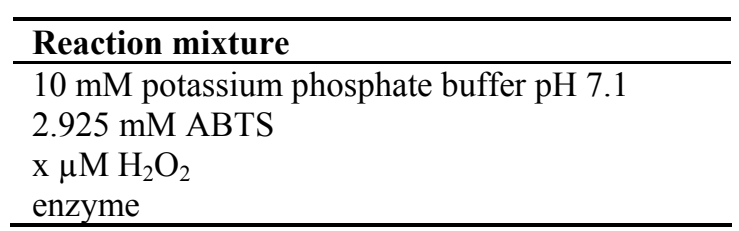

The increase of absorbance was followed photometrically at $420 \mathrm{~nm}$ upon addition of enzyme or hydrogen peroxide.

The $\mathrm{H}_{2} \mathrm{O}_{2}$ concentration was verified photometrically by its extinction coefficient at $240 \mathrm{~nm}\left(\varepsilon_{240}=39.4 \mathrm{M}^{-1} \mathrm{~cm}^{-1}\right)$ (Nelson and Kiesow, 1972).

\subsubsection{Crystallographic Methods}

\subsubsection{Crystallization}

The aim of a crystallization experiment is the reproducible growth of ordered crystals that are used for X-ray diffraction experiments in order to determine the electron density and consequently the 3-dimensional structure of the molecule.

Proteins were crystallized by vapour diffusion using sitting drop Cryschem crystallization plates (Hampton Research, USA) sealed with Crystal Clear Tape. This method allows the equilibration of a drop containing a defined mixture of protein and precipitant via gas phase against the reservoir solution.
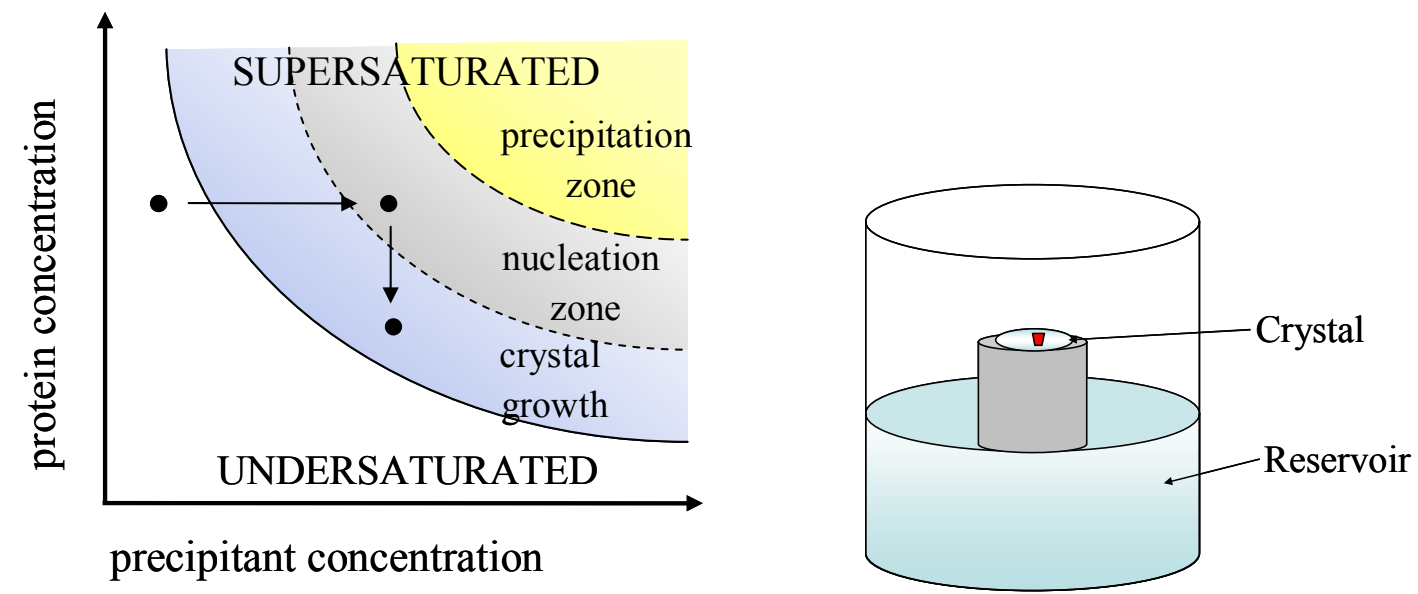

Figure 17: left: Phase diagram showing the solubility of a protein in solution in dependence of the precipitant concentration; right: crystallization by the sitting drop method

Initially the protein in the drop is in a metastable or undersaturated state concerning crystal nucleation. Drop and reservoir are connected via gas phase and the vapor pressure for the reservoir is lower which results in a net transfer of water from the protein drop to the reservoir. Through this controlled evaporation, equilibrium between reservoir and drop slowly develops. The concentrations of both protein and precipitant 
are increased, and the sample increasingly supersaturates resulting in precipitation or ideally crystal nucleation and finally crystal growth.

Footprint Screens (Stura et al., 1994), the Nextal Screens Classics, PACT Suite, the PEGS and MPD Suite (Qiagen, Hilden, Germany), the Hampton Sreens 1-2, the Peg/Ion Screen (Hampton Research, USA) and JB Screens 1-10 (Jena Bioscience, Jena, Germany) served as initial screens. $1 \mu \mathrm{l}$ of a $5-7.5 \mathrm{mg} / \mathrm{ml}$ protein solution was mixed with $1 \mu 1$ of the reservoir solution for initial screening. These setups were stored at $20^{\circ} \mathrm{C}$.

\subsubsection{Cryo-Cooling}

Data collection of crystals at room temperature leads to radiation damage, whereas crystals at $100 \mathrm{~K}$ can be exposed much longer to X-rays without loss of diffraction quality.

However, freezing of the crystals facilitates the formation of ice crystals. This should be avoided as the internal order of the crystal is affected and the ice rings disturb the diffraction pattern of the protein. Therefore it is crucial to find a cryopotectant that prevents this phenomenon and also guarantees optimal data quality. On the other hand, it is important that the protectant does not manipulate or even destroy the crystal to conserve its physical state (Garman and Owen, 2006).

\subsubsection{Data Collection}

First data were collected in-house using a Rigaku copper rotating anode at a wavelength of $1.54 \AA$ A. Diffraction images were recorded on a mar345 imageplate detector (Mar Research, Norderstedt, Germany). In order to get higher resolution data, well-diffracting crystals were flash-frozen in liquid nitrogen and further data were collected at EMBL Hamburg, at the synchrotron beamlines BW7B and X13.

\subsubsection{Structure Determination}

The smallest repeating unit within a crystal is called unit cell characterized by the lattice constants $\mathrm{a}, \mathrm{b}, \mathrm{c}$ and the three base vectors with angles $\alpha, \beta, \gamma$ spanned in between. The repetition of this unit cell by translation forms the regularly ordered, 3-dimensional crystal.

X-ray beams can be described as electromagnetic waves that interact with the electrons in the crystal, producing scattering. In the case of elastic scattering, there is no energy 
change with the molecule. Hence, the scattered waves have the same energy and frequency as the incident waves.

In case of destructive interference, the diffracted X-ray beams are not in phase, thus deleting one another. All diffracted waves are in phase when the diffracted X-ray beams fulfill Bragg's law and constructive interference occurs:

$$
\left.2 \mathrm{~d}_{\mathrm{hkl}} \sin \theta=\mathrm{n} \lambda \quad \text { (Eq. } 4.2 .6 .4 \mathrm{a}\right)
$$

In this process, the set of parallel lattice planes with index hkl and distance $\mathrm{d}_{\mathrm{hkl}}$ produces a diffracted beam when the X-ray beams of the wavelength $\lambda$ hit a plane in an angle of $\theta$ and are reflected at the same angle.

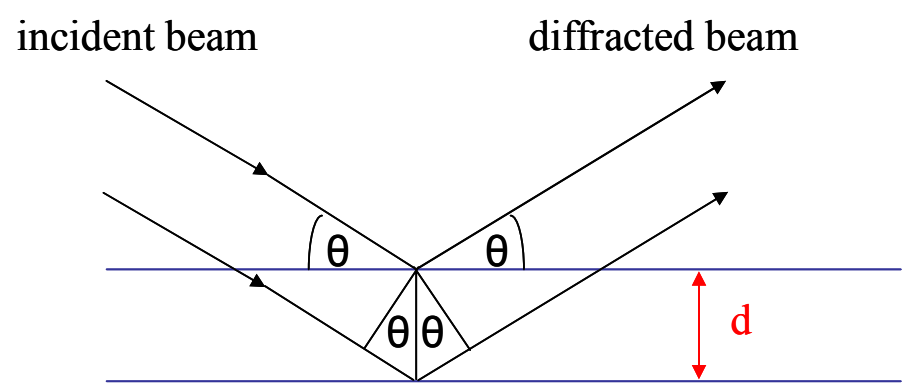

Figure 18: Two beams reflected by two parallel lattice planes; the difference in path length is $2 \mathrm{~d} \sin \theta$ whereas constitutive interference occurs if $2 \mathrm{~d} \sin \theta$ is equal a multiple interger of the wavelength $\lambda \rightarrow$ $2 \mathrm{~d}_{\mathrm{hkl}} \sin \theta=\mathrm{n} \lambda$ (Bragg's law).

Diffracted X-rays can be characterized by the structure factors $\mathrm{F}_{\mathrm{hkl}}$ :

$$
\mathrm{F}_{\mathrm{hkl}}=\sum_{\mathrm{j}} \mathrm{f}_{\mathrm{j}} \mathrm{e}^{2 \pi i(\mathrm{hx}+k y+l z)}
$$

The summation considers all scattering factors $f_{j}$ within the cell and therefore $F_{h k l}$ is a

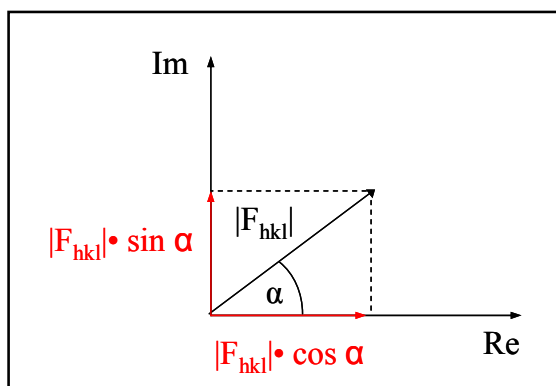

Figure 19: Argand diagram in the Gaussian plane. The wave function can be described as a vector with phase angle $\alpha$ and length $\left|F_{\text {hkl }}\right|$ (amplitude). function of all atom positions in the unit cell.

As $F_{h k l}$ is a vector with an orientation given by the phase angle $\alpha_{\mathrm{hkl}}$ and a length given by the amplitude $\left|F_{h k l}\right|$, the structure factor can be represented as product (see figure 19):

$$
\mathrm{F}_{\mathrm{hkl}}=\left|\mathrm{F}_{\mathrm{hkl}}\right| e^{i \alpha_{h k l}}
$$

The structure factor describes a diffracted beam producing a diffraction spot on the detector. As the phenomenon of X-ray diffraction occurs at the electron shell, the atomic scattering factor depends on the electron density distribution and the structure factor can be presented in the following way: 


$$
\mathrm{F}_{\mathrm{hkl}}=\int_{V} \rho(x, y, z) e^{2 \pi i(h x+k y+l z)} \mathrm{dV} \quad(\text { Eq. } 4 \cdot 2 \cdot 6.4 \mathrm{~d})
$$

where $\mathrm{V}$ is the volume of the unit cell.

By means of an X-ray diffraction experiment, the 3-dimensional electron density function $\rho(x, y, z)$ of the crystal ought to be determined. However, only the intensities of the spots proportional to the square of the amplitudes of the structure factors can be measured:

$$
\mathrm{I}_{\mathrm{hkl}} \sim\left|\mathrm{F}_{\mathrm{hkl}}\right|^{2}
$$

The phase information is lost during the diffraction experiment and can only be determined indirectly. This dilemma is referred to as the "phase problem" in crystallography, as the electron density can only be calculated by fourier transform with informations about both amplitude and phase:

$$
\rho(\mathrm{x}, \mathrm{y}, \mathrm{z})=\frac{1}{V} \sum_{h k l} F_{h k l} e^{-2 \pi i(h x+k y+l z)} \quad \text { (Eq. 4.2.6.4f). }
$$

\subsubsection{Phase Determination}

For macromolecules, phase information can be obtained by following methods:

- Molecular replacement (MR)

- Isomorphous replacement (MIR/SIR)

- Anomalous dispersion (MAD: multiple wavelength anomalous dispersion /SAD)

- Combination of isomorphous replacement and anomalous dispersion (MIRAS: multiple isomorphous replacement /SIRAS)

\subsection{Molecular Replacement}

The method of molecular replacement is one of the principal techniques to determine the structure of macromolecules (Rossmann and Blow, 1962). A homologous model structure is used to obtain an atomic model from which estimates of the phases can be computed. Those serve as initial phases for the unknown structure.

The method is based on the fact that proteins sharing homologies in their sequence have a similar structure. Consequently, the level of sequence identity between phasing model and target structure and also the completeness of the model play an important role for the success of this method. As a rule of thumb, the amino acid sequences should be at least by $40 \%$ identical.

Several programs for molecular replacement exist, including MOLREP (Vagin and Teplyakov, 1997), PHASER (Storni et al., 2004), CNS (Brünger et al., 1998), AMoRe (Navaza, 1994) and EPMR (Kissinger et al., 1999). 
Usually, the process of locating the phasing model in the unit cell is divided into two independent steps. First, the right orientation of the model is determined by a rotation search using a rotation function. Afterwards, the right position of the model is found by a translational search using a translation function. Within the molecular replacement six variables need to be determined, three parameters to specify orientation and three parameters to specify position. The resulting structure factors of the positioned phasing model are then used as an initial estimate of the searched phases.

The rotation function determines the best orientation of the search model. This exploits the fact that intramolecular vectors (Patterson vectors) depend only on the orientation of the molecule and not on the position in the unit cell. If the search model and the target protein are oriented in the same way within the unit cell, Patterson-maps should look similar. This concurrence of Patterson peaks is examined by the determination of the rotation function maxima calculated by the computer programs.

Subsequently, comparisons of the structure factors are employed to locate the best position of the model protein via translational search. For each trial position the observed structure factor amplitudes $\left|\mathrm{F}_{\mathrm{obs}}\right|$ of the native data set are calculated and compared to the structure factor amplitudes $\left|\mathrm{F}_{\text {calc }}\right|$. The R-factor compares both sets of structure factor amplitudes for every reflection:

$$
\mathrm{R}=\frac{\sum\left\|F_{o b s}|-| F_{c a l c}\right\|}{\sum\left|F_{o b s}\right|}
$$

In the case of consistent structure factor amplitudes a small difference and thus a low Rfactor are expected.

\subsection{MAD}

Absorption edges for heavy atoms are in the range of X-ray wavelengths used in an X-ray diffraction experiment. If the wavelength of the incident photons is in the range of the specific absorption edge and hence the photons have high enough energy, X-ray photons are absorbed by the heavy atoms and re-emitted with an altered phase producing anomalous scattering (Hendrickson et al., 1988). 

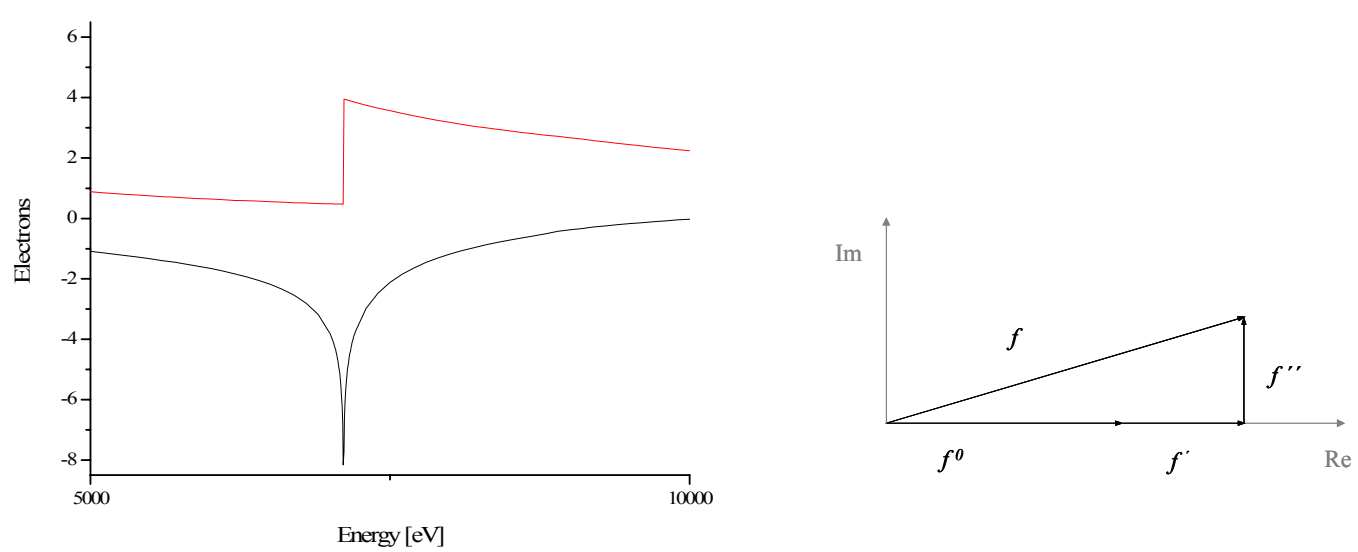

Figure 20: left: Theoretical absorption edge of iron $(7112 \mathrm{eV})$ and values for $\mathrm{f}^{\prime}$ (black line) and $\mathrm{f}^{\text {" }}$ (red line) (http:www.bmsc.washington.edu/scatterer). Right: The anomalous contribution to the atomic scattering factor consists of the real part $f$ ' and the imaginary part $f^{\prime}$.'

The scattering of an atom for which anomalous scattering occurs is wavelengthdependent and can be written as

$$
f(\lambda)=f^{0}+f^{\prime}(\lambda)+i f^{\prime \prime}(\lambda) \quad(\text { Eq. 4.2.6.5.2a). }
$$

In this case, $f^{0}$ is the normal scattering contribution, $f^{\prime}$ is the real scattering component and $f^{\prime \prime}$ is the anomalous signal. $f^{\prime \prime}$ can be obtained from a fluorescence scan, while $f^{\prime}$ can be calculated from $f^{\prime \prime}$ as the scattering components $f^{\prime}$ and $f^{\prime \prime}$ are related via the Kramers-Kronig relationship:

$$
\mathrm{f}^{\prime}(\omega)=\frac{2}{\pi} \int_{0}^{\infty} \frac{\omega^{\prime} f^{\prime \prime}\left(\omega^{\prime}\right) \partial \omega^{\prime}}{\omega^{2}-\omega^{2}}
$$

Friedel's law states that the reflection (hkl) and the - by inversion through the origin related reflection $(-\mathrm{h},-\mathrm{k},-1)$ have equal amplitude and opposite phase. Whenever there is anomalous dispersion, Friedel's law is broken

$$
\left(\left|F_{h k l}\right| \neq\left|F_{\overline{h k l}}\right|\right)
$$

From this discrepancy, phase information can be obtained. By Patterson methods, the location of heavy atoms can be determined at first.

The Patterson function in its general form is a variation of the Fourier sum for which only the amplitude is required:

$$
\mathrm{P}(\mathrm{u}, \mathrm{v}, \mathrm{w})=\frac{1}{V} \sum_{h k l}|F(h k l)|^{2} \cos [2 \pi(h u+k v+l w)] \quad(\text { Eq. 4.2.6.5.2d). }
$$

The difference Patterson map is calculated with coefficients $(\Delta \mathrm{F})^{2}=\left(\left|\mathrm{F}_{\mathrm{P}}\right|-\left|\mathrm{F}_{\mathrm{PH}}\right|\right)^{2}$ showing interatomic vectors with amplitudes contributed by the heavy atoms solely.

$$
\Delta \mathrm{P}(\mathrm{u}, \mathrm{v}, \mathrm{w})=\frac{1}{V} \sum_{h k l}|\Delta F(h k l)|^{2} \cos [2 \pi(h u+k v+l w)](\text { Eq. 2.2.6.5.2e). }
$$


A MAD experiment comprises several datasets around the absorption edge of the heavy atom. In case of metalloproteins, datasets are recorded at the edge of the incorporated metal. A peak dataset at the maximum of $f^{\prime \prime}(\lambda)$ is collected as well as the inflection dataset (minimum of $f^{\prime}(\lambda)$ ) and the high remote dataset (medium values for $f^{\prime \prime}(\lambda)$ and $\left.f^{\prime}(\lambda)\right)$.

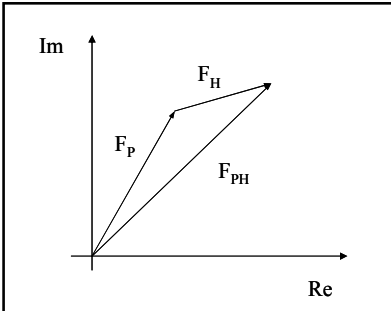

Figure 21: Determination of the structure factors $\mathrm{F}_{\mathrm{P}}$ of the protein.
Once the positions of the heavy atoms are found, structure factors of the protein can be determined. For this, the structure factor can be written as $F_{P}=F_{P H}-F_{H}$ where $F_{P}$ is the structure factor of the remote dataset, $\mathrm{F}_{\mathrm{PH}}$ is the structure factor of the peak dataset and $\mathrm{F}_{\mathrm{H}}$ is the structure factor of the heavy atom.

\subsection{Isomorphous Replacement}

Isomorphous replacement is a method for the determination of initial phases for a new structure (Green et al., 1954). Phases are derived from several data sets collected from native crystals and isomorphous crystals into which heavy atoms have been soaked that must not disturb crystal packing or the conformation of the protein. These heavy atoms cause perturbations in the diffraction pattern resulting in differences between native and derivative structure factors.

\subsubsection{Graphical Representation}

Molecular graphics were made with PyMOL (DeLano Scientific LLC, San Francisco, USA) (DeLano, 2002). The final model was validated with the program PROCHECK (Laskowski et al., 1993). Surface was calculated with the program AREAIMOL (Lee and Richards, 1971) included in the CCP4 suite. Electrostatic surface potentials were calculated with DELPHI (Honig and Nicholls, 1995) based on the numerical solution of the Poisson-Boltzmann equation, assuming standard charges for amino acids. 


\section{$5 \quad$ Results}

\subsection{Purification of the Recombinant Peroxidases from G. sulfur- reducens}

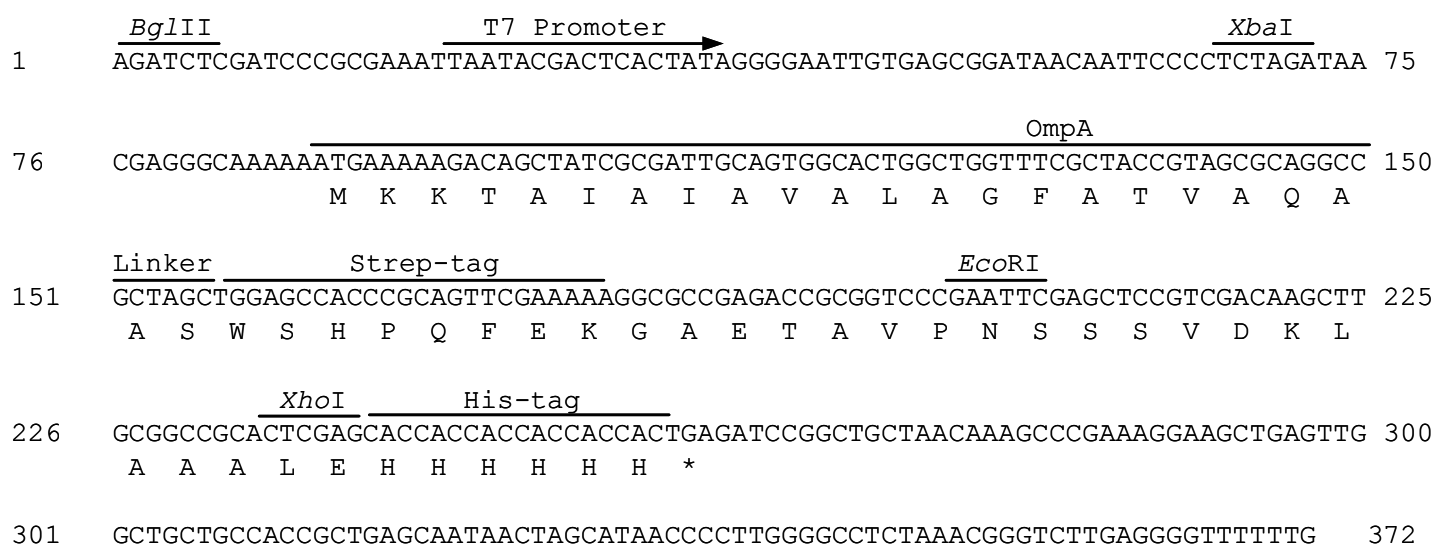

Figure 22: Organization of the pETSN-22 expression vector insert region. The OmpA signal sequence is cleaved off after secretion of the apoprotein into the periplasm.

The Geobacter sulfurreducens cytochrome $c$ peroxidases MacA and CcpA were overproduced in E. coli strain BL21(DE3) by coexpressing the pEC86 plasmid encoding the $c$-type cytochrome maturation genes $c c m A B C D E F G H$ (see figure 14) (Thöny-Meyer, 1997). The expression vector pETSN-22 was created for this purpose and provides an N-terminal signal sequence for the secretion of the protein into the periplasm, an N-terminal Strep-tagII and a C-terminal His-tag. The macA gene (978 bp) and the cсpA gene $(975 \mathrm{bp})$ were cloned via the EcoRI and XhoI restriction sites into pETSN-22. In order to obtain a construct without His-tag, the stop codon of the genes was retained.

Protein expression could be optimized by reducing the expression rate of the apoprotein. The leakiness of the promoter was exploited, thus without addition of IPTG the basal transcription level was sufficient for the production of holoprotein.

The original expression vector pASK-IBA44 with its tet promoter was unsuitable because this construct just produced apoprotein. This might be due to the fact that a relatively high rate of protein expression can be harmful for correct posttranslational processing (Londer et al., 2005). 


\subsubsection{Purification of CcpA}

The cells were cultivated and broken as described previously (see 4.2.1.1 and 4.2.3.1). After centrifugation, the soluble fraction was loaded onto a Strep-tactin column (4.2.3.2). The fractions containing CcpA were pooled and concentrated by ultrafiltration (30,000 Da molecular weight cut-off; Vivaspin) (Sartorius, Göttingen, Germany). Furthermore, the protein was purified and rebuffered by size exclusion chromatography (Superdex 200) (GE Healthcare, München, Germany). Protein of the right size could be separated from misfolded protein which elutes in the exclusion volume making the size exclusion chromatography an essential step in spite of the observed electrophoretic homogeneity after the affinity step.
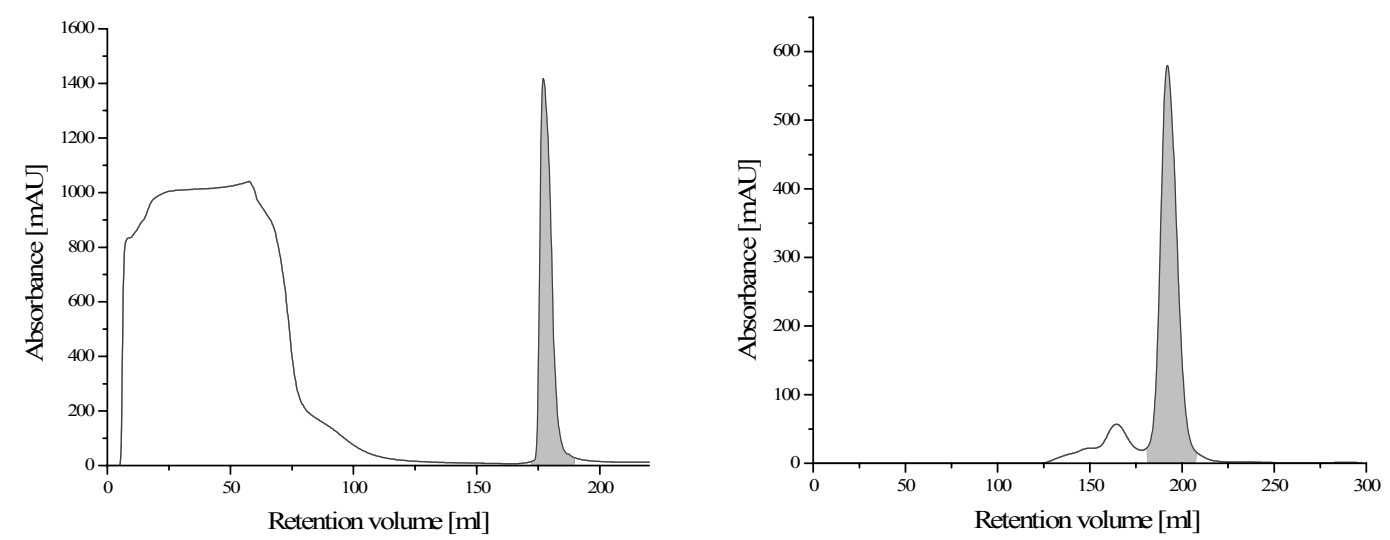

Figure 23: left: Chromatogram of the Strep-tactin column; right: Chromatogram of the S200 gelfiltration column; the pooled fractions are indicated in grey.

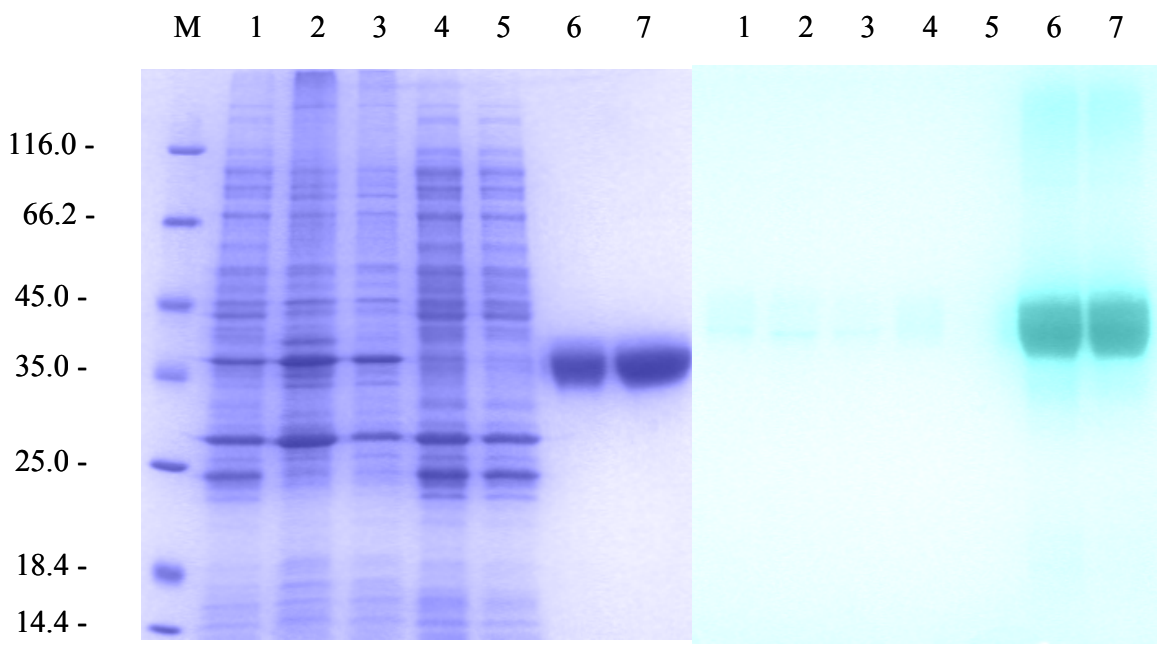

Figure 24: left: Coomassie-stained gel, right: Heme-stained gel; M: marker with corresponding molecular weight in $\mathrm{kDa}$, 1: cell extract, 2: 20,000 x $g$ pellet, 3: 100,000 x $g$ pellet, 4: 100,000 x $g$ supernatant, 5: flowthrough Strep-tactin column, 6: pool after Strep-tactin column, 7: pool after gelfiltration; $15 \mu \mathrm{g}$ protein per lane were applied.

Molecular weight prediction with the ExPaSy webservice (http://www.expasy.org) (Bjellqvist et al., 1993) results in $36.78 \mathrm{kDa}$ per monomer if linker and Strep-tag are 
taken into account. The addition of $616 \mathrm{Da}$ per heme group leads to a calculated molecular weight of $38.02 \mathrm{kDa}$ and subsequently of $76.04 \mathrm{kDa}$ per dimer. CcpA elutes at $191.97 \mathrm{ml}$ from the $\mathrm{S} 200$ column which corresponds to a molecular weight of $73.94 \mathrm{kDa}$ according to the calibration curve $\mathrm{y}=-0.0155 \mathrm{x}+7.8445$. Furthermore, a $\mathrm{pI}$ of 8.7 was calculated by Compute $p I$ from the ExPaSy webservice.

\subsubsection{Purification of MacA}

The purification of MacA was performed in analogy to the procedure for CcpA.
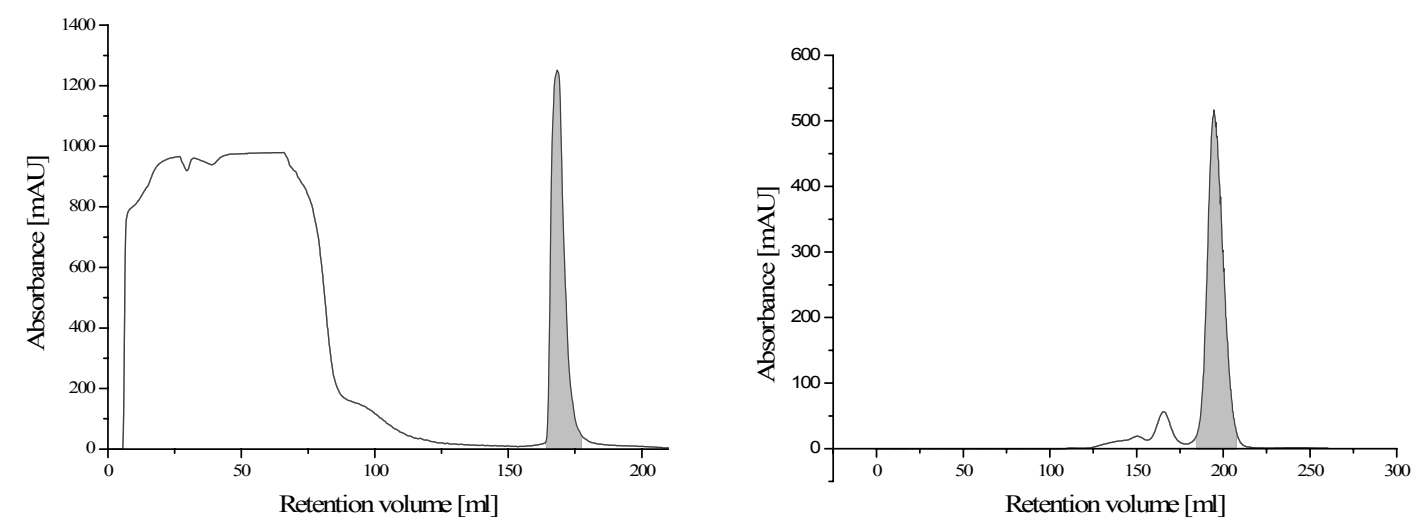

Figure 25: left: Chromatogram of the Strep-tactin column; right: Chromatogram of the gelfiltration column S200; the pooled fractions are indicated in grey.

According to the ExPaSy-webservice, MacA has a molecular weight of $37.06 \mathrm{kDa}$ and of $38.29 \mathrm{kDa}$ including the two heme groups. Thus, the theoretical molecular weight of the dimer is $76.58 \mathrm{kDa}$ while MacA elutes at $194.55 \mathrm{ml}$ corresponding to a molecular weight of $67.45 \mathrm{kDa}$. A theoretical pI of 8.9 was calculated.

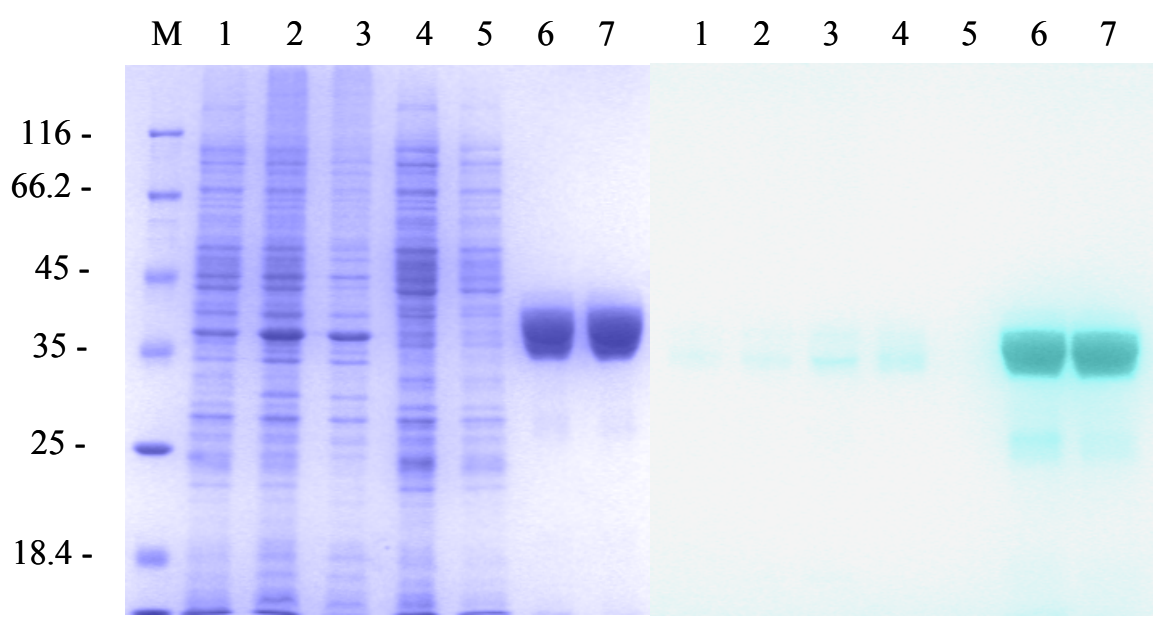

Figure 26: left: Coomassie-stained gel, right: Heme-stained gel; M: marker with corresponding molecular weight in $\mathrm{kDa}$, 1: cell extract, 2: 20,000 $\mathrm{x} g$ pellet, 3: 100,000 $\mathrm{x} g$ pellet, 4: 100,000 $\mathrm{x} g$ supernatant, 5: flowthrough Strep-tactin column, 6: pool after Strep-tactin column, 7: pool after gelfiltration; $12 \mu \mathrm{g}$ protein per lane were applied. 


\subsubsection{Representative Purification of CcpA and MacA}

MacA and CcpA were purified from 51 expression cultures that had been harvested at $\mathrm{OD}_{600}$ of 5-6.

\begin{tabular}{l|ccc|ccc}
\hline $\begin{array}{c}\text { Purification } \\
\text { step }\end{array}$ & \multicolumn{3}{|c|}{ MacA } & \multicolumn{3}{c}{ CcpA } \\
\hline & $\begin{array}{c}\text { Protein } \\
{[\mathrm{mg}]}\end{array}$ & $\begin{array}{c}\mathrm{A}_{405} / \\
\mathrm{A}_{280}\end{array}$ & $\begin{array}{c}\text { specific } \\
\text { activity }[\mu \mathrm{mol} \\
\left.\mathrm{min}^{-1} \mathrm{mg}^{-1}\right]\end{array}$ & $\begin{array}{c}\text { Protein } \\
{[\mathrm{mg}]}\end{array}$ & $\begin{array}{c}\mathrm{A}_{405} / \\
\mathrm{A}_{280}\end{array}$ & $\begin{array}{c}\text { specific } \\
\text { activity }[\mu \mathrm{mol} \\
\left.\mathrm{min}^{-1} \mathrm{mg}^{-1}\right]\end{array}$ \\
\hline Soluble fraction & 1008 & 0.05 & 0.027 & 935 & 0.06 & 0.013 \\
Strep-tactin & 30 & 4.10 & 0.954 & 48 & 2.16 & 0.836 \\
Superdex 200 & 17.5 & 4.21 & 2.066 & 26.6 & 3.86 & 2.005 \\
\hline
\end{tabular}

CcpA was purified from $20 \mathrm{~g}$ cells yielding $1.33 \mathrm{mg} \mathrm{g}^{-1}$ cells. The yield of MacA was lower with $0.92 \mathrm{mg} \mathrm{g}^{-1}$ cells.

\subsection{Electron Excitation Spectra}

The oxidized form of CcpA shows a typical $c$-type cytochrome spectrum with absorption maxima at $406.5 \mathrm{~nm}$ and at $530 \mathrm{~nm}$. The extinction coefficient at $406.5 \mathrm{~nm}$ was determined to $\varepsilon_{406.5 \mathrm{~nm}}=231,000 \mathrm{M}^{-1} \mathrm{~cm}^{-1}$. Upon reduction with $1 \mathrm{mM}$ ascorbate, one heme is reduced and the Soret band shifts to $411 \mathrm{~nm}$ while $\alpha$ - and $\beta$-bands become apparent. Additional incubation with $\mathrm{CaCl}_{2}$ shifts the $\gamma$-band to $417 \mathrm{~nm}$, a shoulder at lower wavelength remains correponding to the second non-reduced heme group. An additional band at $630 \mathrm{~nm}$ is slightly more pronounced upon addition of calcium and indicates a Fe(III) high spin signal.

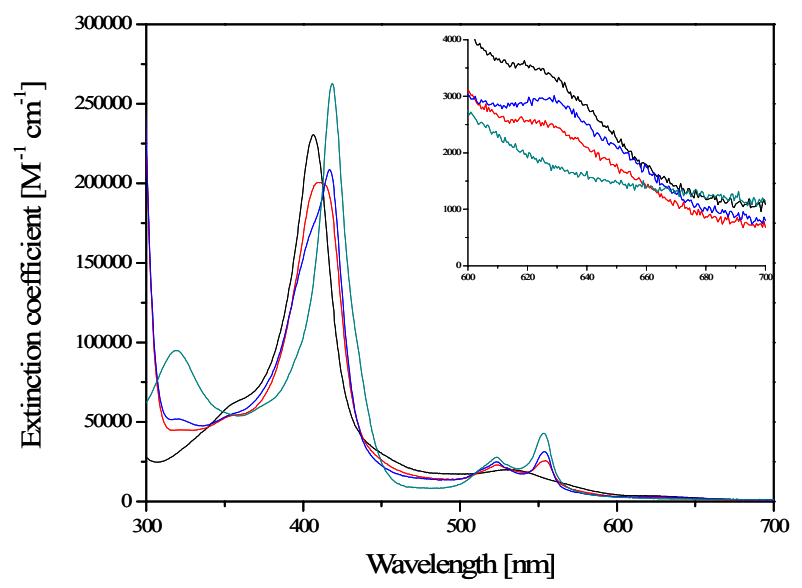

Figure 27: Electron excitation spectra of CcpA in $20 \mathrm{mM}$ Tris $\mathrm{pH} 8,150 \mathrm{mM} \mathrm{NaCl}$ buffer; native enzyme (oxidized, black line), ascorbate-reduced enzyme (1 mM ascorbate, $\mathrm{pH} 7.2 ; 15$ minutes incubation, red line), addition of $1 \mathrm{mM} \mathrm{CaCl}$ to the ascorbate-reduced enzyme (blue line), dithionite-reduced enzyme (green line). 
In the dithionite-reduced form of CcpA, the Soret band has its absorption maximum at $418.5 \mathrm{~nm}$; the $\beta$-band is visible at $523 \mathrm{~nm}$ and the $\alpha$-band at $553.5 \mathrm{~nm}$.

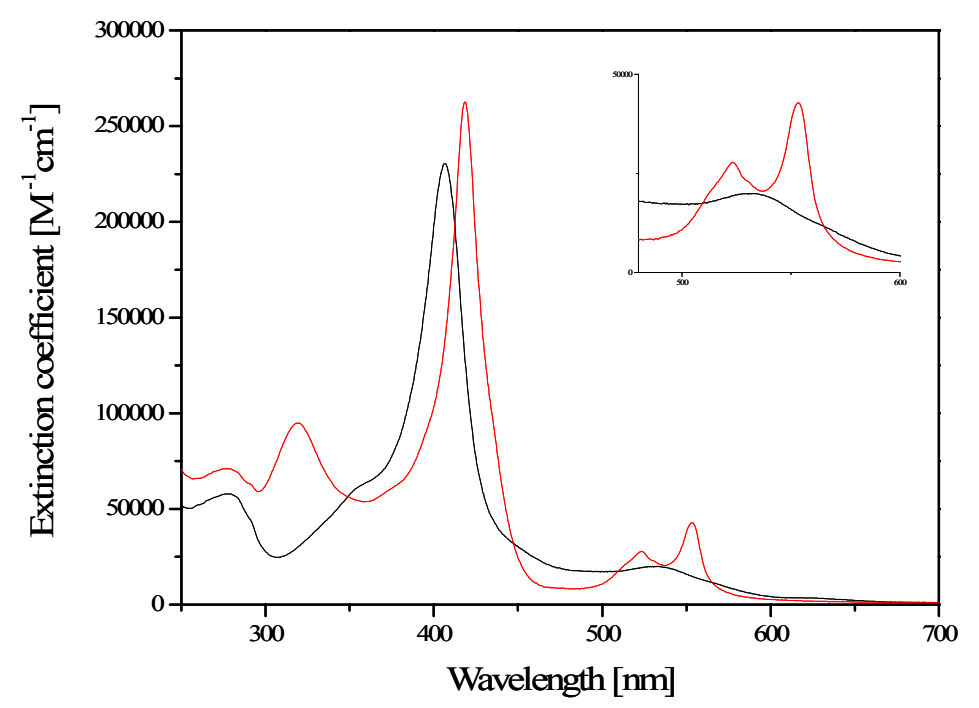

Figure 28: Electron excitation spectra showing the oxidized (black) and reduced (red) form of CcpA in $20 \mathrm{mM}$ Tris $\mathrm{pH} 8,150 \mathrm{mM} \mathrm{NaCl}$ buffer.

The oxidized form of MacA also reveals a typical spectrum of a $c$-type cytochrome with absorption maxima at $406.5 \mathrm{~nm}$ and at $525 \mathrm{~nm}$.

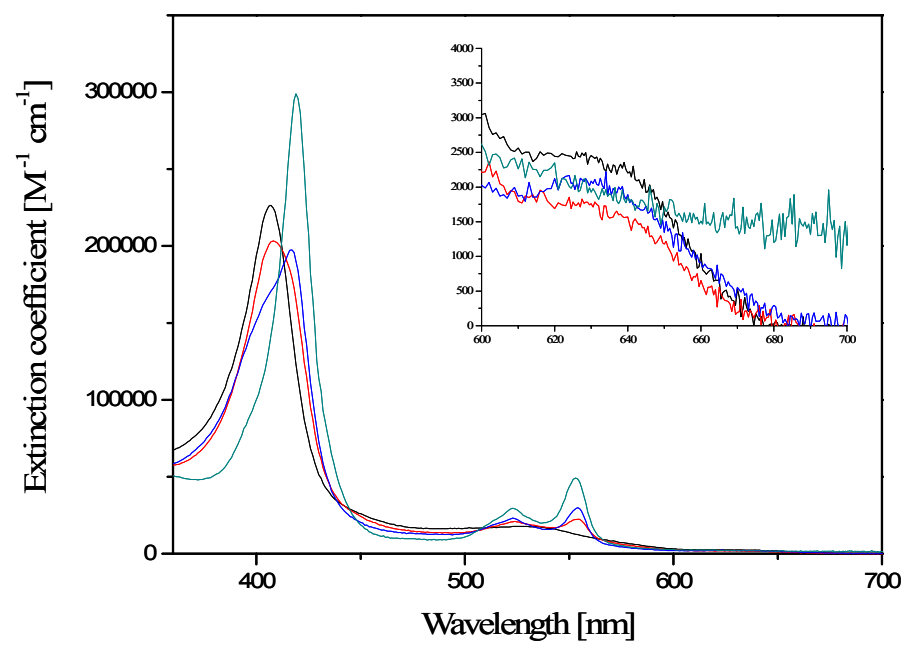

Figure 29: Electron excitation spectra of MacA in $20 \mathrm{mM}$ Tris $\mathrm{pH} 8,150 \mathrm{mM} \mathrm{NaCl}$ buffer; native enzyme (oxidized, black line), ascorbate-reduced enzyme (1 mM ascorbate, $\mathrm{pH} 7.2 ; 15$ minutes incubation, red line), addition of $1 \mathrm{mM} \mathrm{CaCl}_{2}$ to the ascorbate-reduced enzyme (blue line) and dithionitereduced enzyme (green line).

The extinction coefficient at $406.5 \mathrm{~nm}$ was determined to $226,000 \mathrm{M}^{-1} \mathrm{~cm}^{-1}$. Upon reduction with ascorbate and additional incubation with $\mathrm{CaCl}_{2}$ spectroscopic features 
are generated resembling those of CcpA. The fully-reduced spectrum of MacA exhibits absorption maxima at $419 \mathrm{~nm}, 523 \mathrm{~nm}$ and $553 \mathrm{~nm}$.

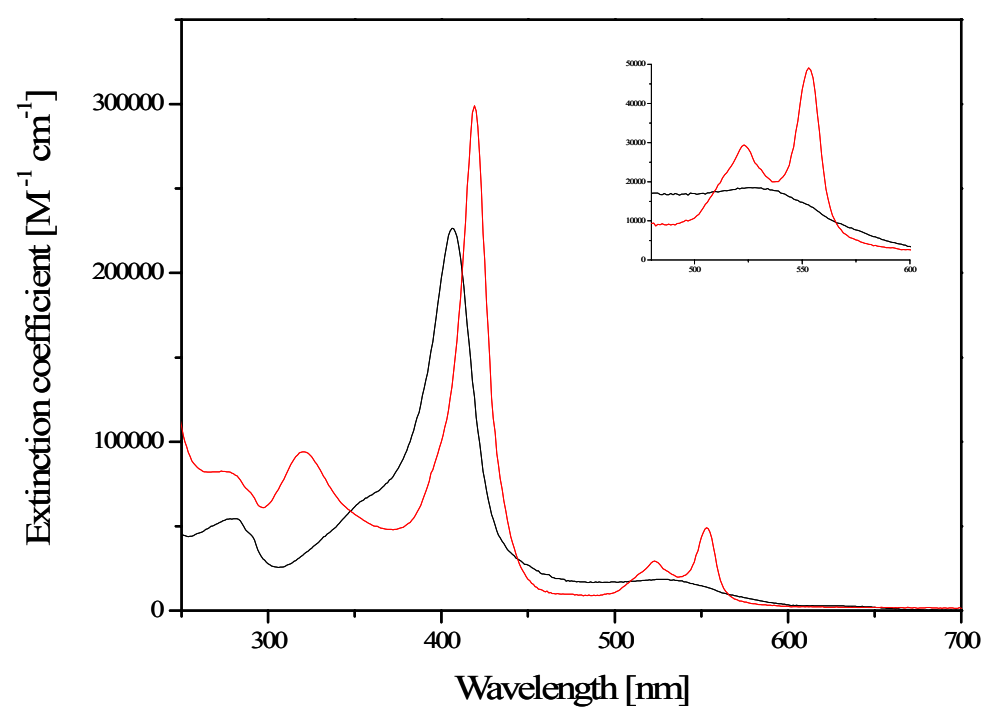

Figure 30: Electron excitation spectra of MacA in $20 \mathrm{mM}$ Tris pH 8, $150 \mathrm{mM} \mathrm{NaCl}$ buffer; oxidized (black) and reduced (red) form.

\subsection{Peroxidase Activity Assay}

Both diheme $c$-type cytochromes from Geobacter sulfurreducens revealed peroxidase activity as determined by the ABTS method (see 4.2.5.2). Usually, the physiological electron donor of cytochrome $c$ peroxidases, ferrocytochrome $c_{550}$, serves as electron donor in the activity assay (Gilmour et al., 1994). Initially, an analogous assay containing bovine heart cytochrome $c$ as electron donor was performed as Geobacter sulfurreducens lacks any homologs of cytochrome $c$ (Butler et al., 2004). Just like the cytochrome $c$ peroxidase of Pseudomonas nautica (Alves et al., 1999), MacA did not show any significant activity using bovine heart ferrocytochrome $c$ as electron donor. Hence, ABTS was used to detect peroxidase activity.

Oxidized MacA revealed a specific activity of $0.064 \mu \mathrm{mol} \mathrm{min}^{-1} \mu \mathrm{g}^{-1}$ at a concentration of $18 \mu \mathrm{M} \mathrm{H}_{2} \mathrm{O}_{2}$. As cytochrome $c$ peroxidases are active in the mixed valence state, the enzyme was incubated with ascorbate, ascorbate and calcium or dithionite prior to the assay (see 5.2 and 4.2.5.2). Only the reduction of the enzyme with dithionite had an effect on the activity so that following activities were determined for the reduced enzyme. 


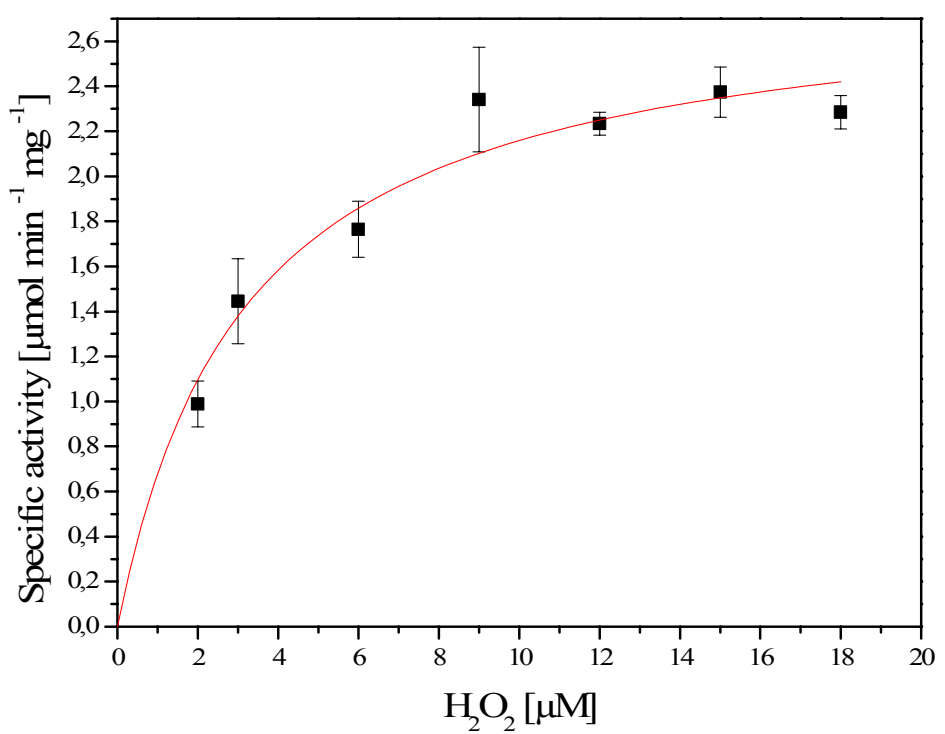

Figure 31: Effect of the hydrogen peroxide concentration on the specific activity of MacA. The reaction was started upon addition of MacA $(c=391 \mathrm{nM})$. Each value represents an average of three measurements. The curve was fitted by the Hill-function $y=\frac{v_{\max } \bullet x^{n}}{k^{n}+x^{n}}$ with $\mathrm{n}=1$.

The curve obtained for the specific activity in dependence on $\mathrm{H}_{2} \mathrm{O}_{2}$ obeys MichaelisMenten kinetics. Based on the fitting by the Hill-function and Hill coefficient $n=1$, $\mathrm{V}_{\max }=2.85 \pm 0.18 \mu \mathrm{mol} \min ^{-1} \mathrm{mg}^{-1}$ and $\mathrm{K}_{\mathrm{M}}=3.20 \pm 0.70 \mu \mathrm{M} \mathrm{H}_{2} \mathrm{O}_{2}$ were obtained for MacA.

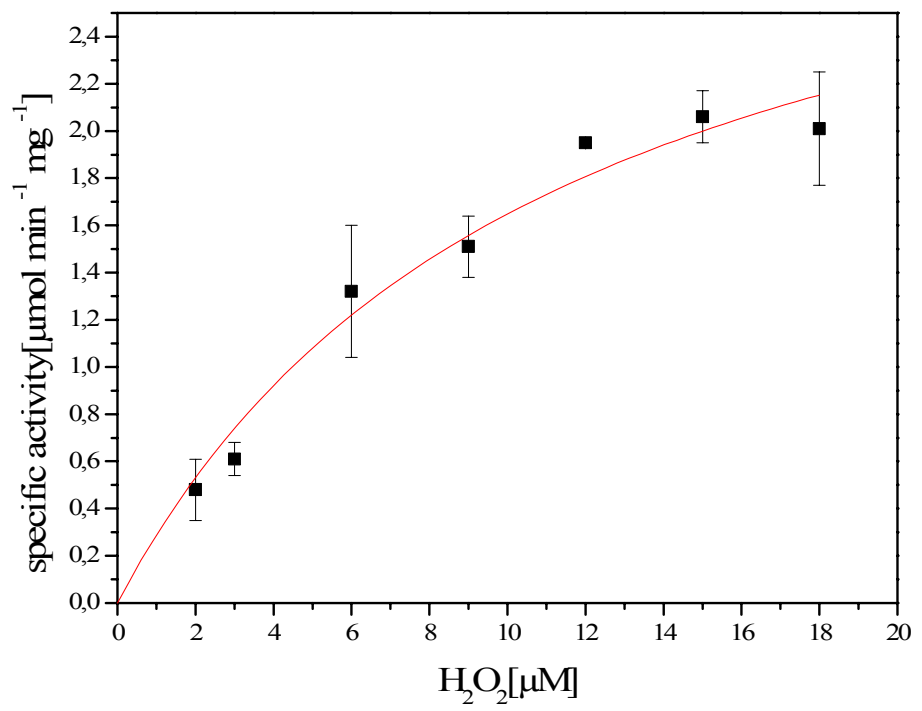

Figure 32: Effect of the hydrogen peroxide concentration on the specific activity of CcpA. The reaction was started upon addition of $\mathrm{H}_{2} \mathrm{O}_{2} \quad(\mathrm{c}=900 \mathrm{nM})$. Each value represents an average of three measurements. The curve was fitted by the Hill-function. 
The peroxidase activity of CcpA is in a similar range as the activity of MacA. The

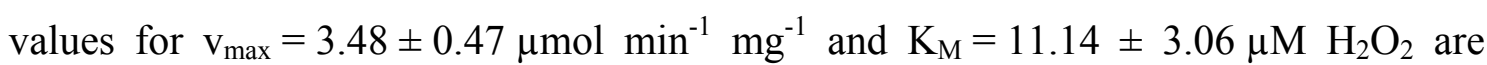
obtained from the fitted curve. In the range of low $\mathrm{H}_{2} \mathrm{O}_{2}$ concentration, the activity is lower than the activity of MacA resulting in $\mathrm{v}_{\max }$ and $\mathrm{K}_{\mathrm{M}}$ values that were presumably overestimated. Especially, the $K_{M}$ value is espected to be much lower. Therefore, these values have to be regarded as approximate because hydrogen peroxide concentrations above $18 \mu \mathrm{M}$ do not increase the specific activity.

\subsection{Sequence Analysis}
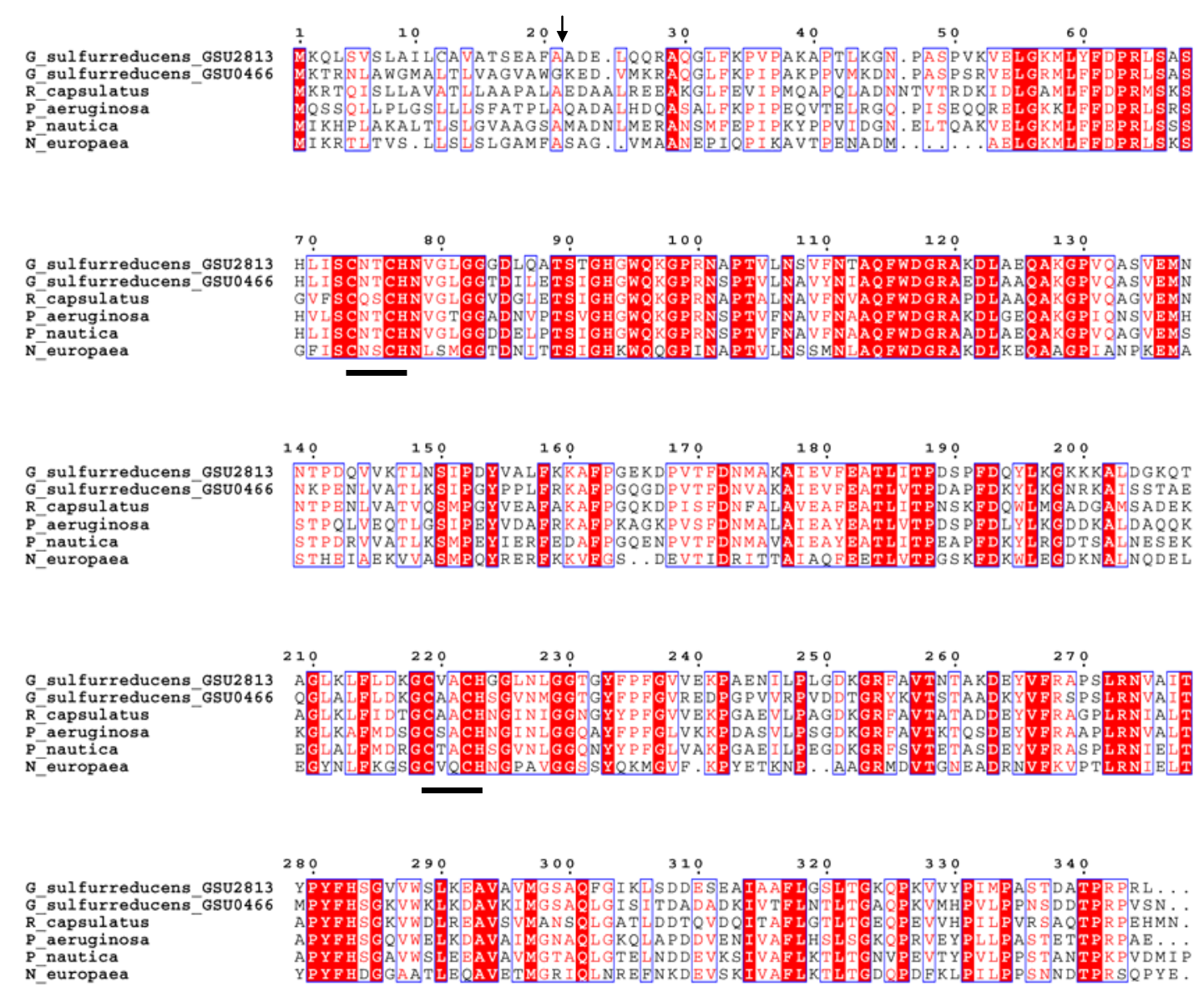

Figure 33: Multiple sequence alignment of CcpA (GSU2813), MacA (GSU0466) and related cytochrome $c$ peroxidases from Rhodobacter capsulatus, Pseudomonas aeruginosa, Pseudomonas nautica and Nitrosomonas europaea. Identical sequences are colored in red and areas of homology are indicated by red letters. The predicted signal sequence cleavage sites of CcpA and MacA were obtained from the SignalP server and are indicated with an arrow. Heme-binding motives are highlighted with bars. The sequence alignment was generated by ClustalW (Thompson et al., 1994).

BLAST searches (BLASTP 2.2.15) (Altschul et al., 1997) were performed in order to identify other bacterial diheme cytochrome $c$ peroxidases in sequence databases. Both Geobacter sulfurreducens enzymes are $68 \%$ identical with respect to the mature protein. The sequence identity between the peroxidase from $P$. aeruginosa and CcpA and MacA 
are $66 \%$ and $58 \%$, respectively. Apart from the homologs listed below, cytochrome $c$ peroxidases from many other organisms were found in the BLAST (e.g. from Geobacter metallireducens, Geobacter uraniumreducens and Rhodospirillum rubrum).

\subsection{Crystallization and Structure Determination}

\subsubsection{Crystallization of CcpA and Data Collection}

In many PEG (polyethylene glycol) containing conditions, crystals were visible already after one day. But in most of these conditions extremely thin needles grew from one single center of nucleation (figure 34A).

Only in some conditions 2- or even 3-dimensional crystals appeared. In the condition containing 15\% PEG 3350, 0.1 M sodium citrate $\mathrm{pH} 5.4$ and 20\% 2-propanol, the third dimension was developed better compared to all the other crystallization conditions. However, a diffraction test showed that crystals were disordered in one direction and therefore were not suitable for diffraction data collection.
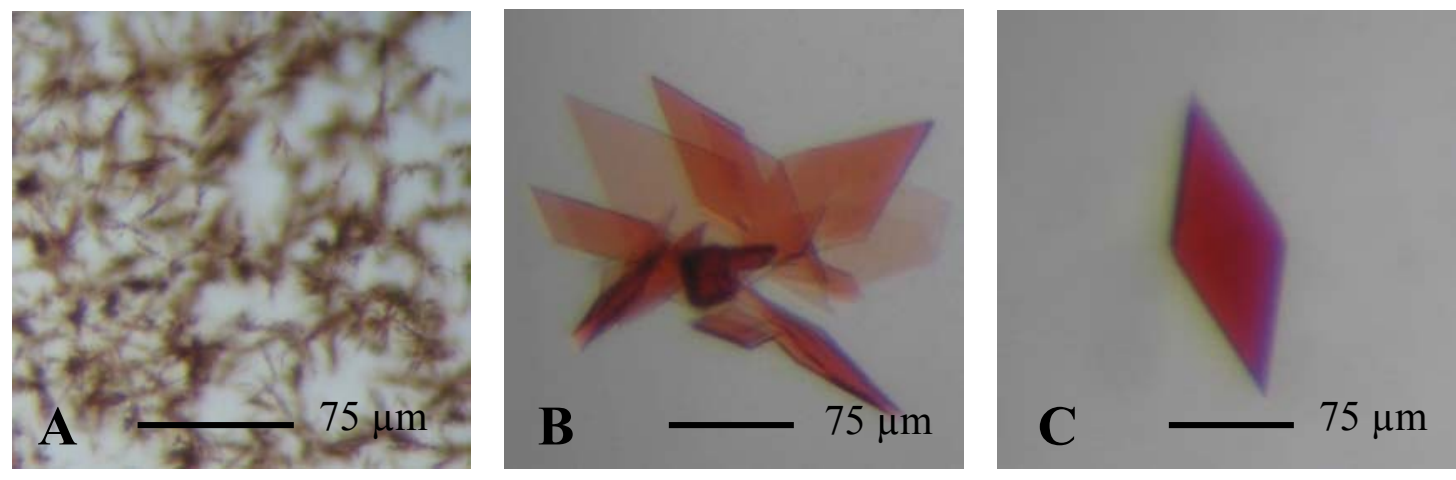

Figure 34: (A) Needle clusters of CcpA appearing in many different PEG containing conditions. (B + C) CcpA crystals obtained from the condition containing 15\% PEG 3350, 0.1 M sodium citrate pH 5.4 and 20\% 2-propanol.

Starting from the condition 41 of the Nextal Screen The PEGS (0.1 M Hepes pH 7.5 and $20 \%$ PEG 10,000), crystals were reproduced and improved.

Several techniques were employed to reduce the number of nucleation centers, the speed of crystal growth and to improve the thin $3^{\text {rd }}$ dimension of the crystals. The application of the Additive Screen (Hampton Research, USA) as well as the reduction of the temperature to $4^{\circ} \mathrm{C}$ and seeding techniques were involved herein. But for all conditions the huge number of nucleation centers is common even if the sample was filtered directly before pipetting into crystallization plates.

Variation of PEGs, $\mathrm{pH}$ and buffer finally lead to the crystallization condition $16 \%$ PEG 10,000 and 0.1 M Hepes pH 7.4. Crystals were thin plates that were grown together and tended to break easily. 

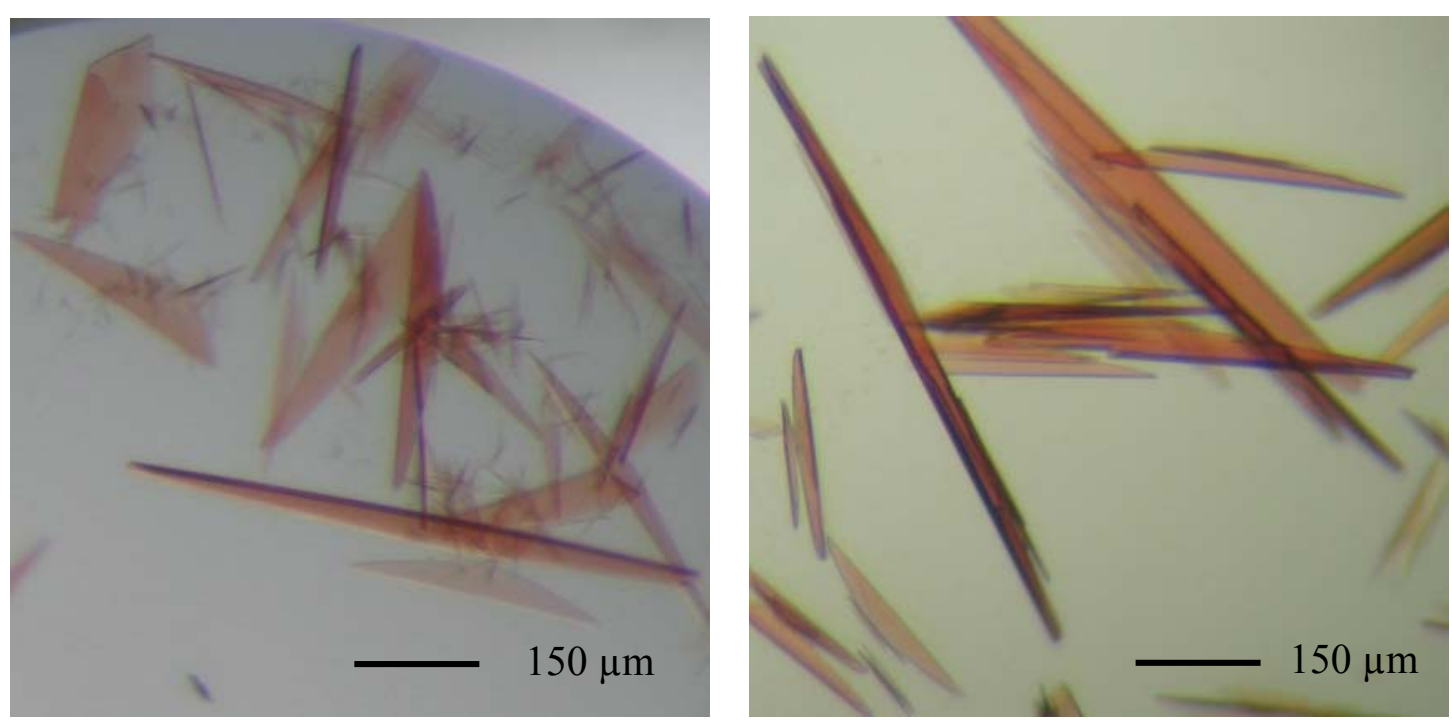

Figure 35: Final crystals used for structure determination of CcpA.

The crystals were soaked in a protective cryo solution containing $10 \% 2 \mathrm{R}, 3 \mathrm{R}$ butanediol in the reservoir solution, mounted in nylon loops and flash-frozen in liquid nitrogen.

At the in-house X-ray source, the crystals diffracted to $2.6 \AA$. In order to reach higher resolution, 300 diffraction images were collected at the EMBL beamline BW7B (DESY, Hamburg) where the crystals diffracted to $1.89 \AA$.

Data were indexed and integrated with the program DENZO (Otwinowski and Minor, 1997), scaling was performed with the program SCALEPACK.

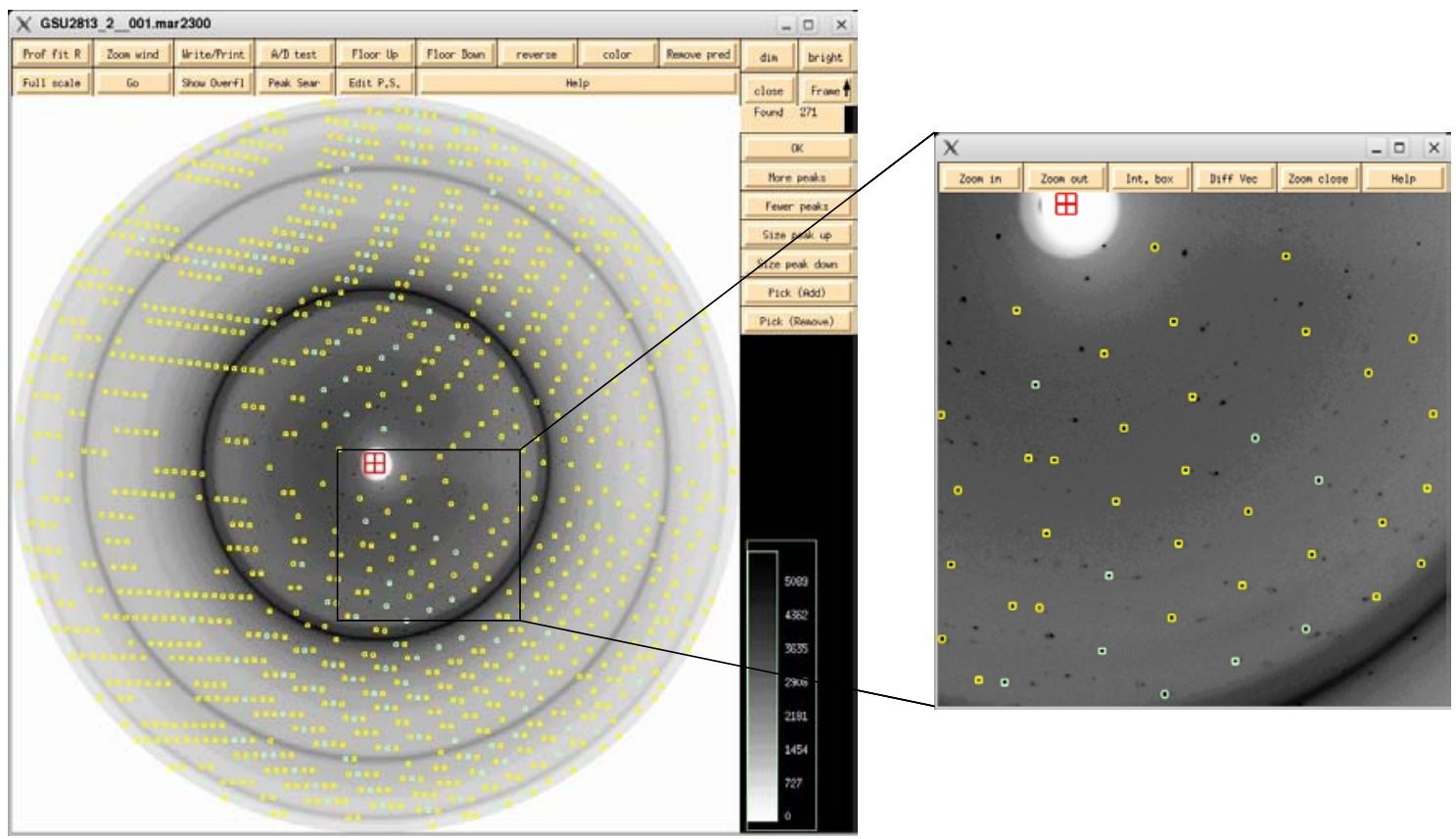

Figure 36: Diffraction image used for indexing. The image was recorded at the EMBL beamline BW7B while the crystal was rotated $1^{\circ}$ per image during exposure. Data were collected at a wavelength of $0.8423 \AA$. 
The crystals of CcpA belonged to the triclinic space group P1 with unit cell parameters $\mathrm{a}=54.2 \AA, \mathrm{b}=55.8 \AA, \mathrm{c}=78.6 \AA, \alpha=68.7^{\circ}, \beta=71.8^{\circ}, \gamma=57.8^{\circ}$ and an estimated mosaicity of 0.6. As crystals were grown together in most cases, it was always a problem of indexing the datasets properly. Several lattices were present (see figure 36) and visible on the diffraction image so that in many cases indexing failed. Even although there were icerings, this dataset was most suitable for structure determination of CcpA as the dataset could be indexed.

\begin{tabular}{ll}
\hline Resolution $(\AA)$ & $50.00-2.00(2.03-2.00)$ \\
\hline Redundancy & $3.0(2.9)$ \\
Number of observations & 361320 \\
Number of unique reflections & 48703 \\
Completeness (\%) & $95.2(97.1)$ \\
I/ sigma & $9.6(2.2)$ \\
$\mathrm{R}_{\text {sym }}$ & $0.099(0.421)$ \\
\hline
\end{tabular}

Table 1: Data collection statistics for CcpA. Numbers in parentheses refer to the values within the highest resolution shell. $\mathrm{R}_{\text {sym }}=\left(\sum|\mathrm{I}-<\mathrm{I}>| / \sum \mathrm{I}\right)$

There are two monomers in the asymmetric unit and the solvent content of the crystal is $48.70 \%$ with a Matthews coefficient (Matthews, 1968) of $V_{M}=2.42 \AA^{3} /$ Da. Due to deteriorating data quality, only data up to a resolution of $2 \AA$ were used for refinement.

\subsubsection{Structure Determination of CcpA and Refinement}

The structure was solved by molecular replacement using the program MOLREP (Vagin and Teplyakov, 1997) from the CCP4 suite (Collaborative Computional Project Number $4,1994)$ with data to a resolution of $3.5 \AA$. Cytochrome $c$ peroxidase of Pseudomonas aeruginosa (pdb accession code 1EB7) (Fülöp et al., 1995) sharing 66\% sequence identity with CcpA served as search model. A preliminary model was obtained with data collected in-house. Different residues were mutated using the mutation function in COOT (Emsley and Cowtan, 2004). This model was subsequently used as search model for molecular replacement using synchrotron data. 


\begin{tabular}{ll}
\hline Resolution $(\AA)$ & $72.357-2.0$ \\
\hline r.m.s.d. in bond length $(\AA)$ & 1.690 \\
r.m.s.d. in bond angles $\left(^{\circ}\right)$ & 0.014 \\
$\mathrm{R}_{\text {work }}(\%) / \mathrm{R}_{\text {free }}(\%)$ & $21.4 / 27.0$ \\
Figure of merit & 0.718 \\
Average B-factor for the protein $\left(\AA^{2}\right)$ & chain A: 24.45, \\
& chain B: 21.99 \\
Average B-factor for waters $\left(\AA^{2}\right)$ & 25.13 \\
\hline
\end{tabular}

Table 2: Data statistics from the refinement using the synchrotron data set. $\mathrm{R}_{\text {work }}=\sum|| \mathrm{F}_{\text {obs }}|-| \mathrm{F}_{\text {calc }}|| \sum\left|\mathrm{F}_{\text {obs }}\right|$, where $\left|\mathrm{F}_{\text {obs }}\right|$ and $\left|\mathrm{F}_{\text {calc }}\right|$ are structure factor amplitudes from the data and the model, respectively. In order to monitor $\mathrm{R}_{\text {free }}$ (Brünger, 1992), 5.1\% of the reflections were excluded from the refinement. The figure of merit for a reflection (hkl) is $\mathrm{m}=\left|\mathrm{F}(\mathrm{hkl})_{\text {best }}\right| / \mathrm{F}(\mathrm{hkl}) \mid$ where $\mathrm{F}(\mathrm{hkl})_{\text {best }}=$ $\sum \mathrm{P}(\alpha) \mathrm{F}_{\mathrm{hkl}}(\alpha) / \sum \mathrm{P}(\alpha)$.

Further model building was performed with the graphics program COOT. In order to get a consistent model of the protein structure, the model was refined against experimental amplitudes and phases after every round of model rebuilding. After rebuilding and 10 refinement cycles in Refmac5 (Murshudov et al., 1997) water molecules were added automatically by COOT and subsequently manually by checking the electron density peaks and taking the possibility of hydrogen bond formation into account.

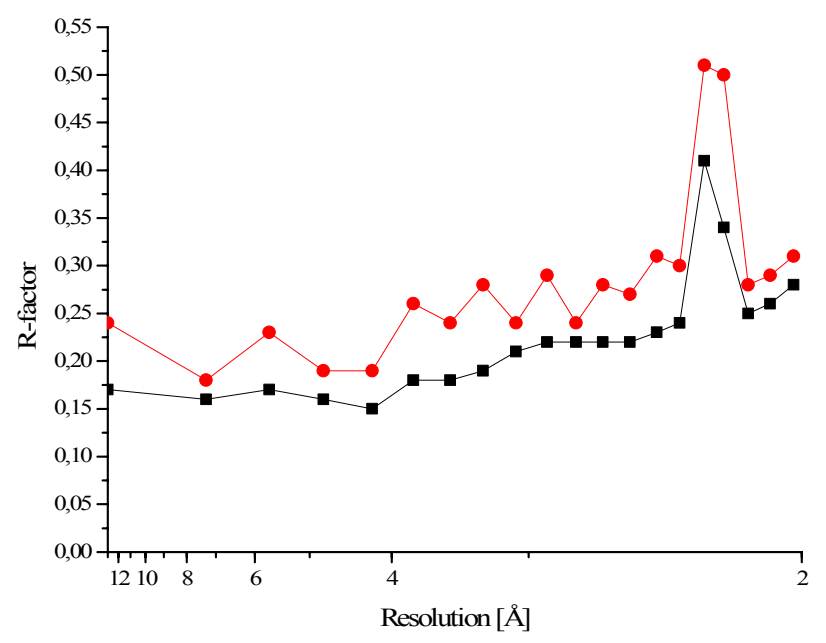

Figure 37: R-factor versus resolution. The ice ring around $2.24 \AA$ influences $\mathrm{R}_{\text {work }}$ (black) and $\mathrm{R}_{\text {free }}$ (red).

Despite the ice ring and the resulting bad statistics in the resolution shell between 2.25-2.31 $\AA$, data could be used to $2 \AA$. The final model of CcpA after the last refinement with Refmac5 had $\mathrm{R}$-factors of $\mathrm{R}_{\mathrm{work}}=21.4 \%$ and $\mathrm{R}_{\text {free }}=27.0 \%$, containing 
637 residues and 4 heme groups in two monomers, as well as 481 waters. At the aminoterminal end, an alanine belonging to the linker between protein and Strep-tag was defined in the electron density. In molecule A, all residues were modeled, but in molecule B residues 220-230 are missing. This flexible loop is absent in most of the cytochrome $c$ peroxidase structures determined up to now (Fülöp et al., 1995; Dias et al., 2004; De Smet et al., 2006).

\subsubsection{Structure Analysis of CepA}

The Ramachandran plot (Ramachandran et al., 1963) was calculated with PROCHECK (Laskowski et al., 1993) in order to analyze the model quality. $85.9 \%$ of the residues are located in the most favorite regions, $13 \%$ in the allowed regions, $0.8 \%$ in generously allowed regions and $0.4 \%$ in the disallowed region.

Of these, the side chains of residues A144, A241 and A279 are not well defined in the electron density, with $\mathrm{B}$ values of $31.0 \AA^{2}, 38.5 \AA^{2}$ and $35.2 \AA^{2}$, respectively. Rebuilding of these residues in allowed conformations and subsequent refinement resulted again in disallowed conformations.

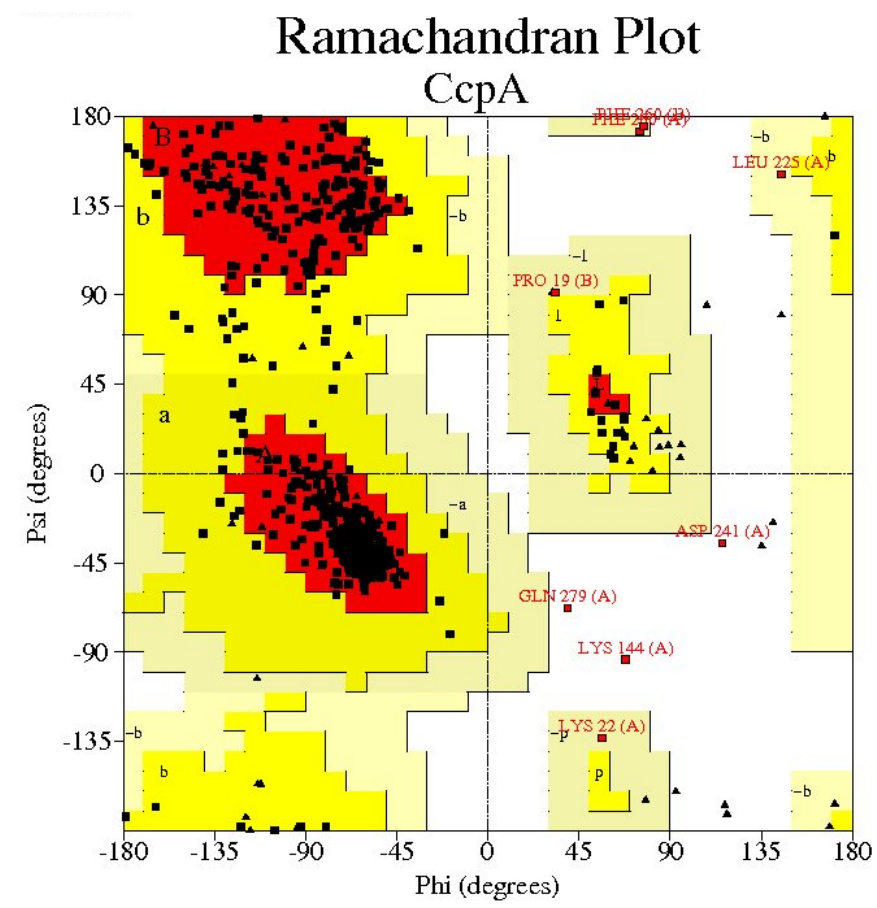

Figure 38: Ramachandran plot. The red area displays the most favourable region, the yellow area is the additional allowed region and the beige area is the generously allowed region. Glycines are presented as triangles.

\subsubsection{Crystallization and Data Collection of MacA}

Crystals used for the structure determination were obtained from the condition $1 \mathrm{~A}$ of the home-made Footprint Screen 2 (Stura et al., 1994). Initially, many little crystals appeared within one drop. Variation of the protein to reservoir ratio improved the 
crystal size and finally, by using $2 \mu 1$ protein and $1 \mu 1$ reservoir, fewer but bigger crystals grew in the conditions around the initial Footprint Screen 2 condition.

Several hexagonal crystal forms appeared, but only the trapezoid prism shaped crystals were tested as the others macroscopically seemed to be accreted to each other. MacA crystals for structure determination were finally taken from the condition $0.1 \mathrm{M}$ ammonium acetate $\mathrm{pH} 5.5,1.3 \mathrm{M}$ sodium/ potassium phosphate and $6 \%$ ethanol.

Lithium sulfate served as cryoprotectant. The cryoprotectant solution was mixed freshly out of $40 \mu \mathrm{l}$ of $0.1 \mathrm{M}$ ammonium acetate $\mathrm{pH}$ 5.5, 1.3 M sodium/ potassium phosphate and $210 \mu \mathrm{l}$ of $3 \mathrm{M}$ lithium sulfate to avoid precipitation of cryosolution ingredients.
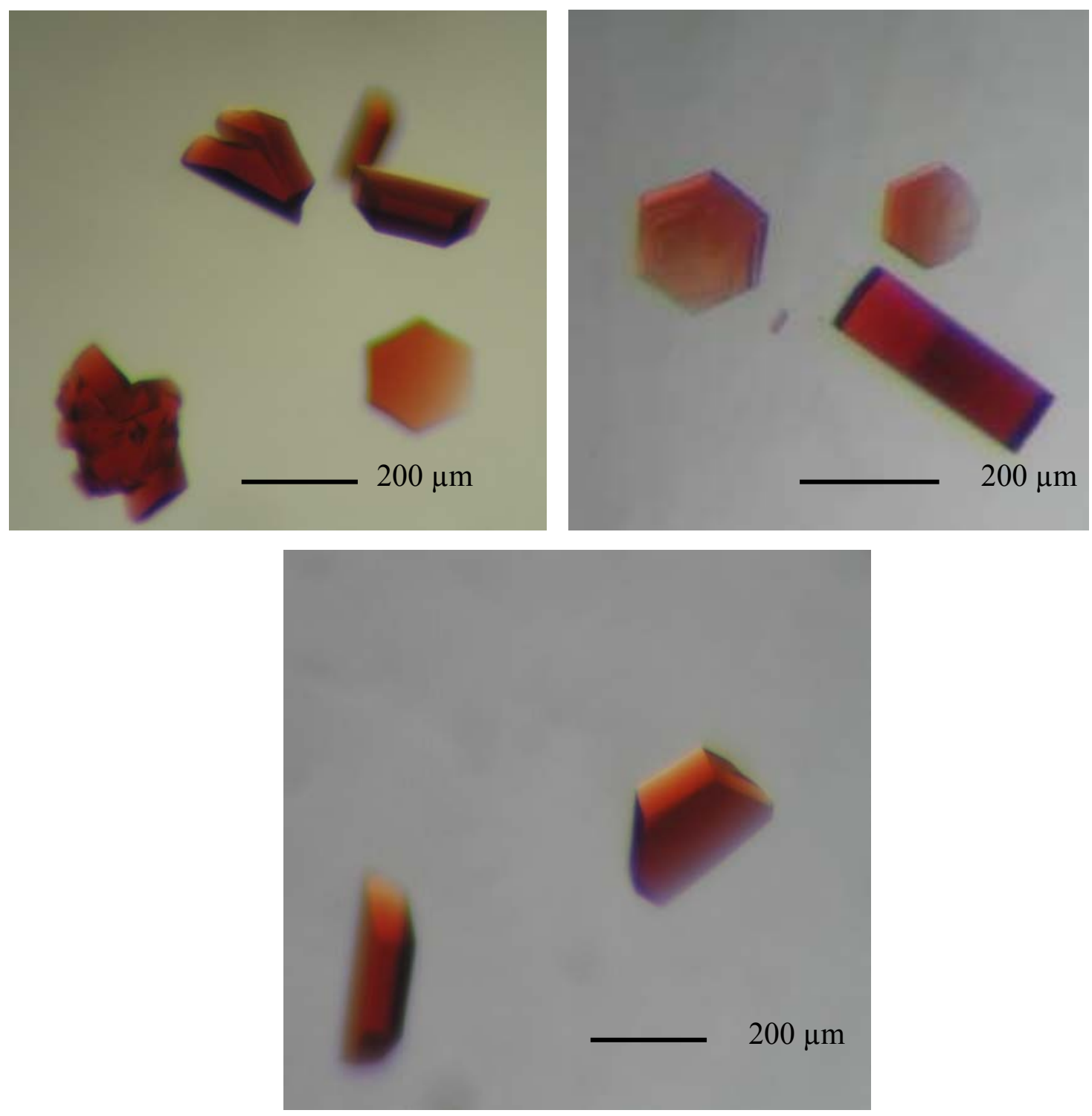

Figure 39: MacA crystals. Crystals grew overnight at $20^{\circ} \mathrm{C}$ in $0.1 \mathrm{M}$ ammonium acetate $\mathrm{pH} 5.5,1.3 \mathrm{M}$ sodium, potassium phosphate and $6 \%$ ethanol.

At the X-ray home-source, MacA crystals diffracted to $2.05 \AA$. Higher resolution data were collected at the EMBL beam line X13 (DESY, Hamburg) at an X-ray wavelength of $0.801 \AA$. Diffraction images were recorded with a CCD-detector while rotating the 
crystal around $0.5^{\circ}$ per image during exposure. The crystal measured at the synchrotron diffracted to $1.84 \AA$ and belonged to the spacegroup $\mathrm{P}_{5} 22$ with unit cell parameters $\mathrm{a}=\mathrm{b}=118.0 \AA, \mathrm{c}=242.0 \AA, \alpha=\beta=90^{\circ}, \gamma=120^{\circ}$ and an estimated mosaicity of 0.4.

The data were indexed and integrated with the program DENZO (Otwinowski and Minor, 1997). Scaling was performed with the Bruker program $S A D A B S$ and statistics were gained from the Bruker program XPREP.

A Matthews coefficient of $2.99 \AA^{3} /$ Da was calculated, corresponding to a solvent content of $58.5 \%$.

\begin{tabular}{ll}
\hline Resolution $(\AA)$ & $50.01-1.95(2.05-1.95)$ \\
\hline Redundancy & $13.49(8.35)$ \\
Number of observations & 988380 \\
Number of unique reflections & 73166 \\
Completeness (\%) & $99.9(99.5)$ \\
I/sigma & $16.10(2.84)$ \\
$\mathrm{R}_{\text {pim }}$ & $0.0246(0.1836)$ \\
\hline
\end{tabular}

Table 3: Data collection statistics for MacA. Numbers in parentheses refer to the values within the highest resolution shell. The $\mathrm{R}$-factor $\mathrm{R}_{\text {pim }}$ represents the precision indicating merging $\mathrm{R}$-factor (Weiss and Hilgenfeld, 1997): $\mathrm{R}_{\mathrm{pim}}=\sum_{h k l} \sqrt{\frac{1}{N-1}} \sum_{i} \mid I_{i}(h k l)-\overline{I(h k l)} / \sum_{h k l} \sum_{i} I_{i}(h k l)$.

\subsubsection{Structure Determination of MacA and Refinement}

The structure of MacA was determined by molecular replacement using the known structure model for the cytochrome $c$ peroxidase of $P$. aeruginosa (pdb accession code 1EB7) (Fülöp et al., 1995) as search model. Both proteins share a sequence identity of $58 \%$. For molecular replacement, the program MOLREP was used with experimental data to $3.5 \AA$. Two molecules per asymmetric unit were found.

The initial model was acquired with in-house data. First model building implicated the mutation of residues different from the model with the mutation function of the program COOT. Subsequently, synchrotron data were used to refine to a resolution of $1.95 \AA$. 


\begin{tabular}{ll}
\hline Resolution $(\AA)$ & $102.06-1.95$ \\
\hline r.m.s.d. in bond length $(\AA)$ & 1.570 \\
r.m.s.d. in bond angles $\left(^{\circ}\right)$ & 0.014 \\
$\mathrm{R}_{\text {work }}(\%) / \mathrm{R}_{\text {free }}(\%)$ & $20.6 / 25.6$ \\
Figure of merit & 0.803 \\
Average B value for the protein $\left(\AA^{2}\right)$ & Chain A: 32.02, \\
& Chain B: 32.92 \\
Average B value for waters $\left(\AA^{2}\right)$ & 39.94 \\
\hline
\end{tabular}

Table 4: Data statistics from the refinement of the synchrotron data. $\mathrm{R}_{\text {work }}=\sum|| \mathrm{F}_{\text {obs }}|-| \mathrm{F}_{\text {calc }}|| / \sum\left|\mathrm{F}_{\text {obs }}\right|$, where $\left|\mathrm{F}_{\mathrm{obs}}\right|$ and $\left|\mathrm{F}_{\text {calc }}\right|$ are structure factor amplitudes from the data and the model, respectively. In order to monitor $\mathrm{R}_{\text {free }}$ (Brünger, 1992), 5.1\% of the reflections were excluded from the refinement.

After the last refinement with Refmac5, the final model of MacA had R-factors of $\mathrm{R}_{\text {work }}=20.6 \%$ and $\mathrm{R}_{\text {free }}=25.6 \%$ and contains two monomers, 608 water molecules, one ethanol molecule, six acetate molecules and 23 phosphate molecules. The modeled protein chain begins with Glul and ends with Asn324 while residues A223-225 and B222-226 are missing in the model. This flexible loop is also absent in molecule B of the Geobacter sulfurreducens peroxidase CcpA as in most of the bacterial cytochrome $c$ peroxidase structures.

\subsubsection{Structure Analysis of MacA}

The stereochemistry of the two MacA molecules in the asymmetric unit is evaluated by the Ramachandran plot that has been generated with PROCHECK (Laskowski et al., 1993). According to this, $89.1 \%$ of the residues are located in the most favorite regions, $10.3 \%$ within the allowed regions, $0.2 \%$ in the generously allowed regions and $0.4 \%$ in the disallowed region. 


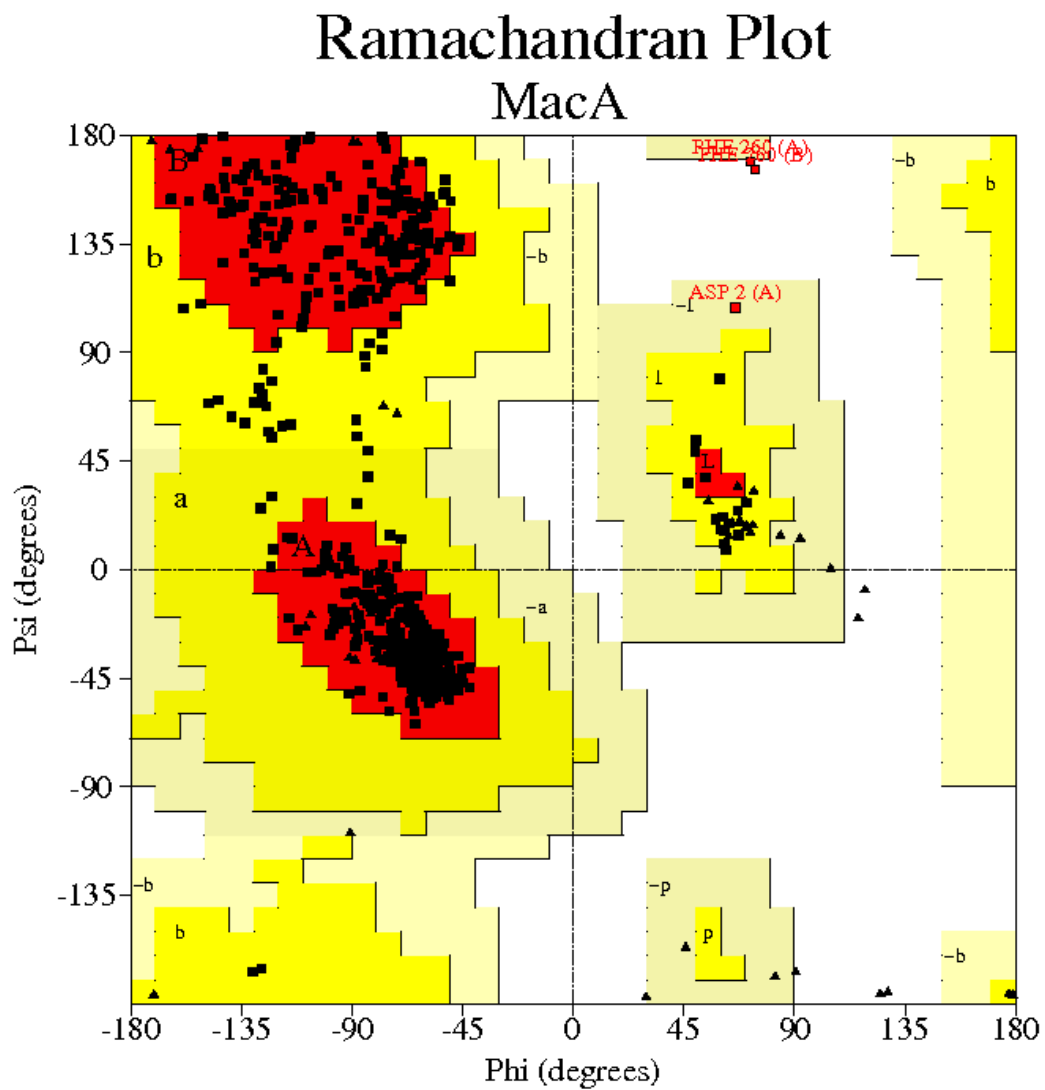

Figure 40: Ramachandran plot. The red area displays the most favourable region, the yellow area is the additional allowed region and the beige area is the generously allowed region. Glycines are presented as triangles.

Strikingly, the two residues found in the disallowed region (Phe260) are also located in the disallowed region of the CcpA model (see 5.5.3). 


\subsection{Overall Structures: CcpA and MacA}

\subsubsection{CсрA}

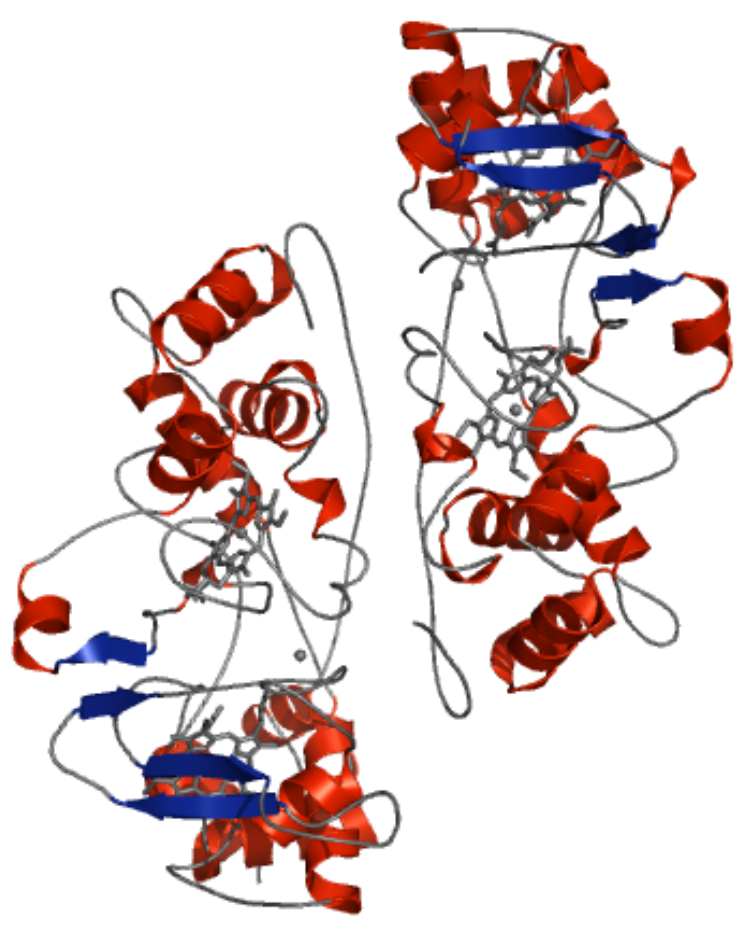

Figure 41: Overall structure of CcpA from Geobacter sulfurreducens. $\alpha$-helices are indicated in red and $\beta$-strands are indicated in blue. The calicum ion and the heme groups are colored in grey.

The structure of CcpA reveals the typical topology of cytochrome $c$ peroxidases (Fülöp et al., 1995; Shimizu et al., 2001; Dias et al., 2004; De Smet et al., 2006) with $\alpha$-helices and $\beta$-strands as secondary structural motives. Each of the two domains reveals a typical c-type cytochrome fold (Moore and Pettigrew, 1990). As in the other determined stuctures, the two domains are connected by three stretches with the calcium binding site located in the domain interface.

\subsubsection{Heme Groups}

Both domains accommodate one heme group. In the following, distances are referred to molecule A unless stated otherwise. The N-terminal domain is built by residues 17-164 and 303-324 with the heme group attached to the polypeptide chain by the cysteines Cys51 and Cys54. The heme iron is bis-histidinyl coordinated and the dihedral angle between the imidazole planes is $54.15^{\circ}$.

The nitrogen $\mathrm{N}^{\delta}$ of one axial histidine (His55) interacts with the carbonyl group of proline $81(3.07 \AA)$, as well as the nitrogen $\mathrm{N}^{\delta}$ of the second axial ligand (His71), is oriented by the interaction with the $\mathrm{C}=\mathrm{O}$ group of proline $108(2.82 \AA)$. 
The position of the heme group is further stabilized by interactions of the propionates with the water molecules 153 and 154 and the main chain nitrogen atom of Trp94. The other propionate interacts with Asn89 and the water molecules 137 and 138.

The C-terminal domain comprises residues 1-16 and 165-302. The second heme group is located within this domain and is attached to the polypeptide chain via the cysteines of the Cys197-X-Y-Cys200-His201-...-Met275 motif while the iron is histidinemethionine coordinated. The imidazole ring of histidine 201 is oriented by the carbonyl group of proline $248(3.12 \AA)$.

The heme group imposes stereogeometrical restraints on the protein fold by the interaction of the propionate with the main chain nitrogen and the side chain nitrogen $\mathrm{N}^{\delta}$ of histidine 261 as well as with the main chain nitrogen of valine 216 . The other propionate interacts with the main chain nitrogen of phenylalanine 260 and the water molecules 128, 400 and 402.

The two heme groups are arranged roughly perpendicular to each other with an ironiron distance of $21.05 \AA$. The shortest distance between the heme groups is via the propionates $(9.99 \AA)$ that point inside the protein.

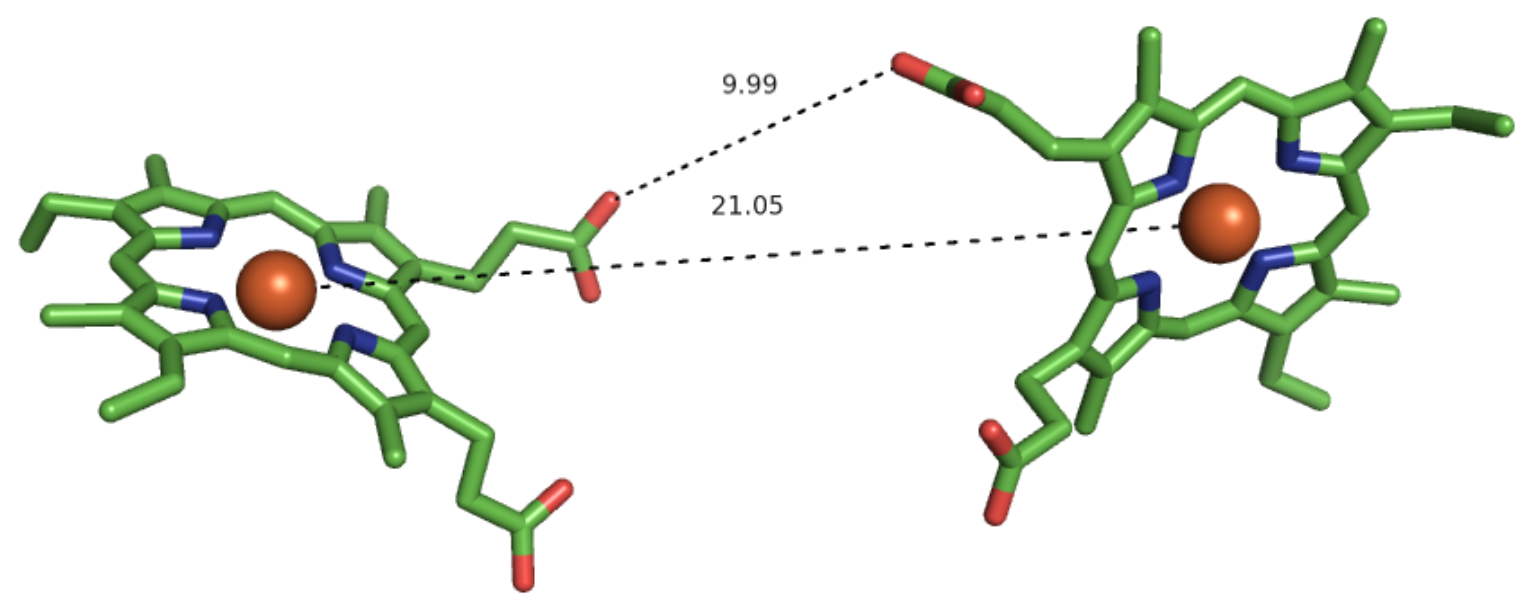

Figure 42: Heme group arrangement in CcpA. 


\subsubsection{MacA}

The structure of MacA shows the overall scaffold seen in the other bacterial cytochrome c peroxidases (see 5.6.1).
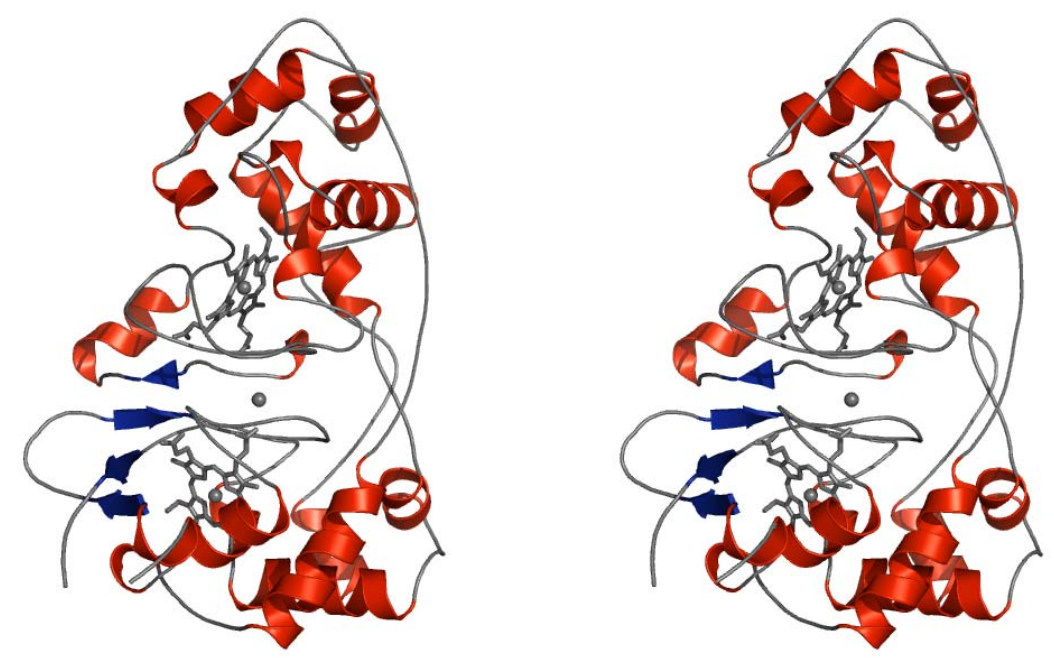

Figure 43: Stereo view of the MacA monomer. $\alpha$-helices are indicated in red and $\beta$-strands are indicated in blue. The calicum ion and the heme groups are colored in grey.

\subsubsection{Heme Groups}

The two heme groups are arranged roughly perpendicular to each other with an ironiron distance of $21.19 \AA$. The closest distance between the cofactors is $9.59 \AA$ via the propionates.

The N-terminal domain is made up by the residues 15-166 and 302-324 with one heme group attached to the polypeptide chain by cysteines Cys51 and Cys54. As in CcpA, the iron is ligated by the two histidines 55 and 71. Carbonyl groups of other residues form hydrogen bonds with the $\mathrm{N}^{\delta}$ of the iron coordinating histidines, thus orienting the histidine imidazole ring. Nitrogen $\mathrm{N}^{\delta}$ of histidine 55 is bonded to the carbonyl group of proline $81(2.79 \AA)$. In a similar way, histidine 71 is interacting with the carbonyl group of alanine $111(2.82 \AA)$ while in CcpA the carbonyl group interacting with the $\mathrm{N}^{\delta}$ of His71 belongs to proline 108. The dihedral angle between the imidazole planes is $45.51^{\circ}$.

The electron transferring heme group is stabilized by asparagine 89, arginine 246 and by the water molecule 188 forming hydrogen bonds to one of the propionates. The other propionate interacts with tryptophan 73 and the water molecules 275 and 416. 
Histidine 71 is located in a flexible loop that has to be released from the iron in the active form as hydrogen peroxide has to get access to the active center. In order to determine the structure of the active enzyme, crystals of the P. pantotrophus cytochrome $c$ peroxidase in its mixed valence state have been produced by Echalier and coworkers (2006).

Photoreduction of MacA crystals and reduction with dithionite or ascorbate were attempted. Subsequently, datasets of those crystals were recorded and evaluated, but no difference electron density around this putatively flexible loop was detected (data not shown). Growth of reduced crystals under anaerobic conditions in order to determine the structure of active MacA did not succeed so far.

The C-terminal domain comprises residues 1-14 and 167-301. The heme group located in this domain is coordinated by the residues Cys197-X-Y-Cys200-His201-...-Met275 and the iron is ligated by a histidine and a methionine. The orientation of the histidine 201 is maintained by interaction with the carbonyl group of proline 248 $(2.92 \AA)$.

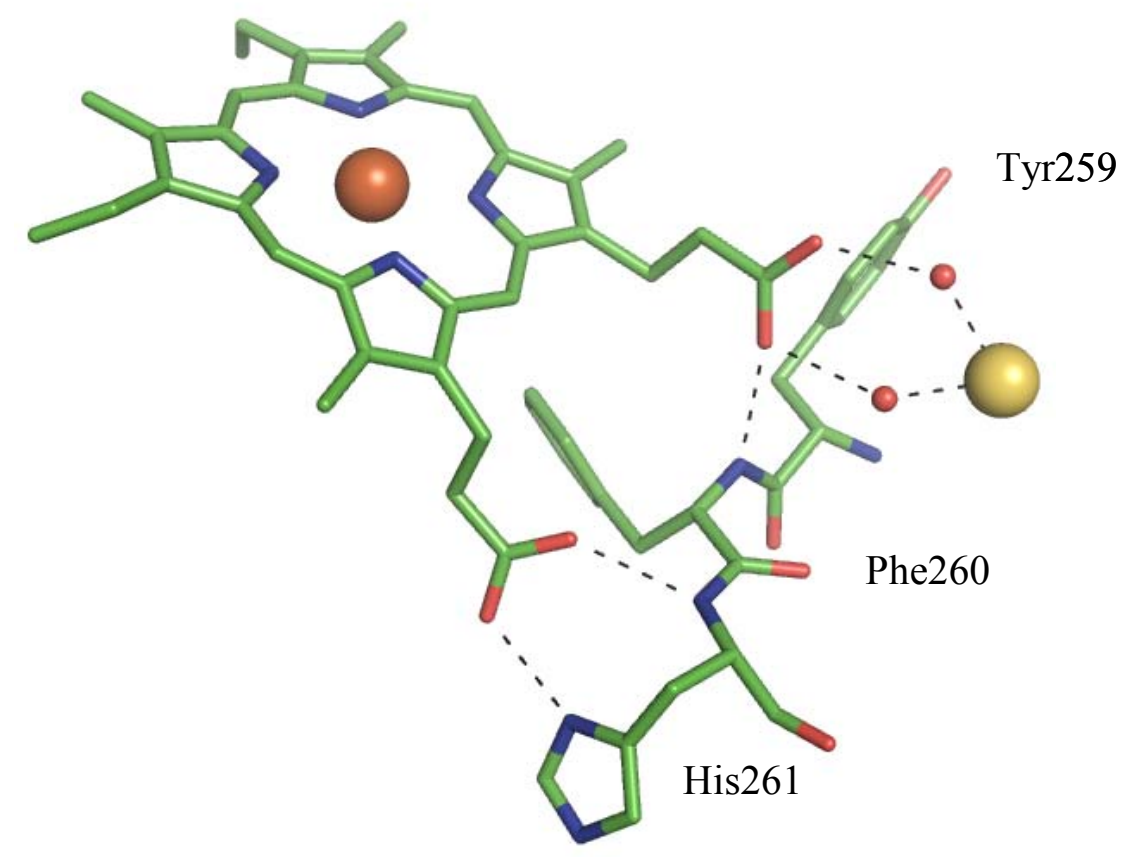

Figure 44: Stereochemical restraints imposed by the heme group in MacA. The iron is colored in brown, the water molecules are colored in red and the calcium ion is colored in yellow.

One propionate is stabilized by the main chain nitrogen from His 261 as well as by the nitrogen $\mathrm{N}^{\delta}$ of the imidazole ring and the main chain nitrogen of valine 216 . The water molecules 110 and 118 as well as the main chain nitrogen of phenylalanine 260 stabilize the other propionate. These hydrogen bonds formed by the propionates and the main 
chain nitrogen atoms of Phe 260 and His261 impose stereochemical restraints that are the reason for the disallowed confirmation of Phe260 in both peroxidases from Geobacter sulfurreducens. This stereochemical feature has also been reported for the cytochrome $c$ peroxidase from Pseudomonas nautica (Dias et al., 2004).

\subsubsection{Comparison of the Overall Structure to Other Peroxidases}

On the basis of their pdb (protein data bank) coordinates, families of structurally similar proteins to MacA and CcpA were searched with the DALI server (Holm and Sander, 1993). The cytochrome $c$ peroxidase of $P$. aeruginosa already served as search model in molecular replacement for both, CcpA and MacA. Likewise, the peroxidase of $P$. aeruginosa is the first hit upon DALI database search with Z-values of 42.7 in case of MacA and 44.5 in case of CcpA. The similarity to the other database hits only arises due to the classical $c$-type cytchrome fold of the two domains which is reflected by rather low Z-values (maximum 4.4).

MacA and CcpA have $69 \%$ identical amino acid residues. Their similarity is maintained on the structural level and is reflected by the root-mean-square deviation (rmds) of 0.924 Å for 302 aligned residues.
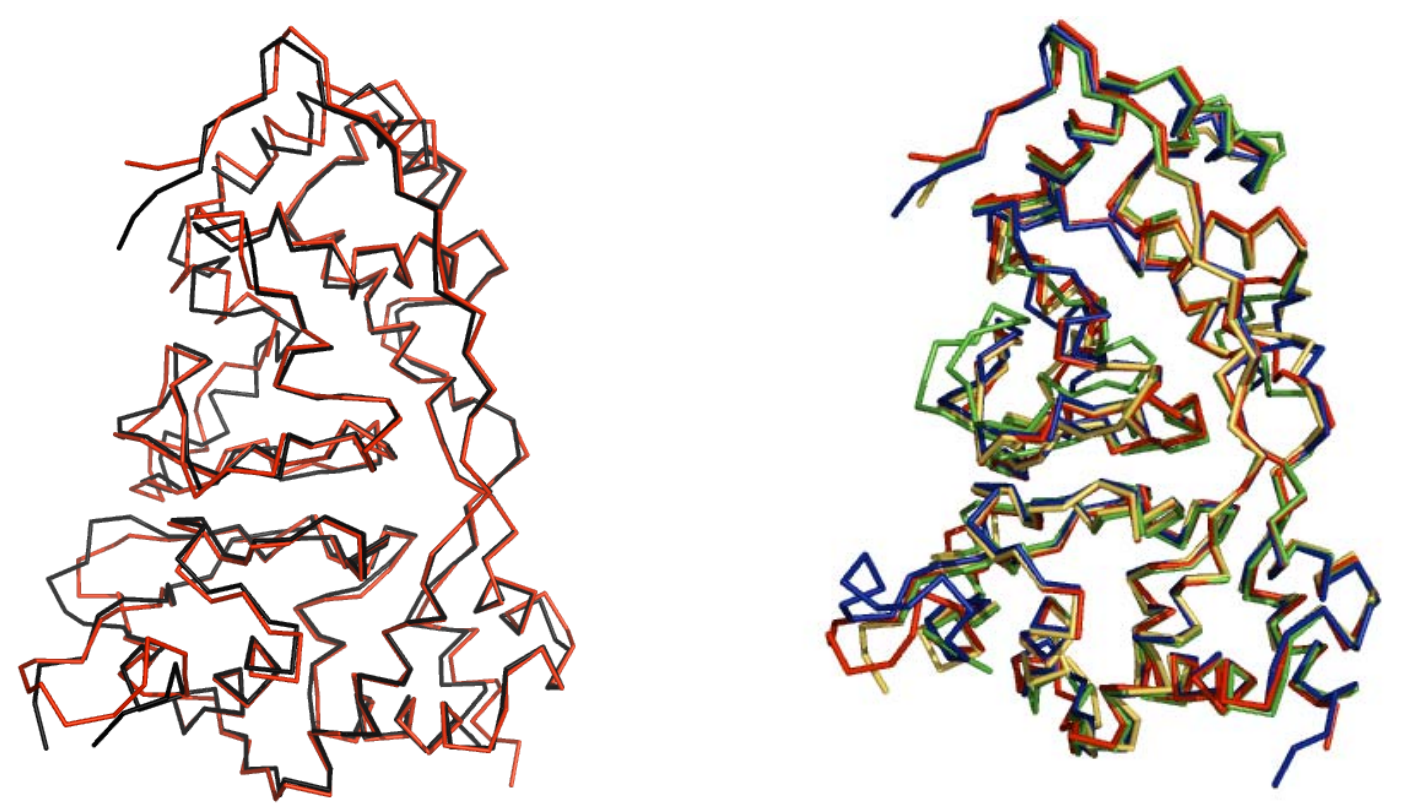

Figure 45: left: MacA (black) and CcpA (red) from Geobacter sulfurreducens. Right: Comparison of the oxidized form of cytochrome $c$ peroxidases from different organisms, CcpA from G. sulfurreducens (red), P. pantotrophus (blue), P. aeruginosa (yellow) and P. nautica (green).

As expected from sequence alignment, $\mathrm{CcpA}$, MacA and peroxidases from other organisms are very similar. Especially, the residues coordinating the heme groups and in the domain interface where electron transfer between the heme groups takes place are conserved (see figure 33). The most prominent differences are found in the loop 
comprising the axial iron ligand histidine 71 and in the loop formed by the residues 219232 which is not complete in most Ccp structures. In CcpA this loop is very flexible with B-factors higher than $50 \AA^{2}$.

\begin{tabular}{lccc}
\hline & CcpA-1EB7 & CcpA-1RZ6 & CcpA-2C1U \\
\hline Aligned residues & 308 & 301 & 306 \\
RMSD $(\AA)$ & 0.973 & 1.264 & 1.122 \\
\hline
\end{tabular}

Table 5: Pairwise superposition of CcpA from Geobacter sulfurreducens with 1RZ6 (Pseudomonas nautica), 2C1U (Paracoccus pantotrophus) and 1EB7 (Pseudomonas aeruginosa). Superposition of the molecules was performed with lsqman (Kleywegt, 1996). The comparison of MacA to the Ccp of $P$. aeruginosa which served as model for the molecular replacement gave a rmsd of $1.081 \AA$ for 300 residues.

\subsubsection{Crystal Packing and Accessible Surface}

The accessible surface of CcpA has a size of $15,047 \AA^{2}$ (molecule B: $14,515 \AA^{2}$ ). As mentioned above, bacterial Ccps are believed to form functional dimers. In the dimer an area of $26,871 \AA^{2}$ is accessible, therefore the dimer interface has a size of 2,691 $\AA^{2} / 2$ reminiscent of the dimer interface of the inactive $P$. nautica $\mathrm{IN}$ form $\left(2412 \AA^{2}\right)$ (Dias et al., 2004).

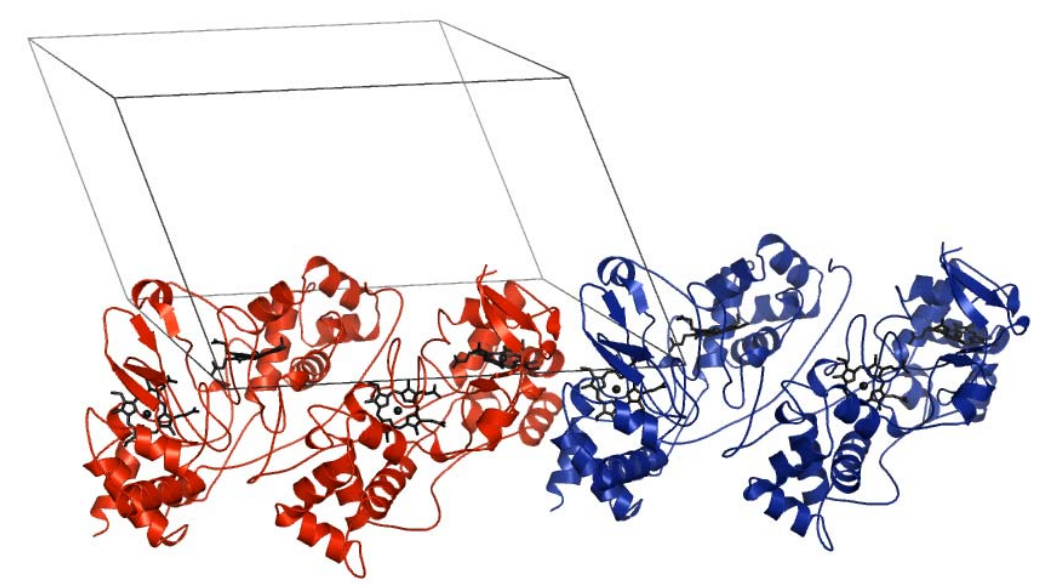

Figure 46: The crystal of CcpA is formed by the translation of the dimer in the three directions in space (space group P1).

The monomer of MacA provides a total accessible surface area of $14,677 \AA^{2}$ (molecule B: $14,456 \AA^{2}$ ). In the crystal two large interface areas between the monomers are present. The typical dimer formed by the other cytochrome $c$ peroxidases has an accessible surface area of $26,007 \AA^{2}$ and a dimer interface of $3126 \AA^{2} / 2$ resembling the dimer interface of the active $P$. nautica OUT form $\left(3031 \AA^{2}\right.$ ) (Dias et al., 2004). On the 
other hand, the alternative dimer has an accessible surface of $26,056 \AA^{2}$ with a dimer interface of $3,077 \AA^{2} / 2$.

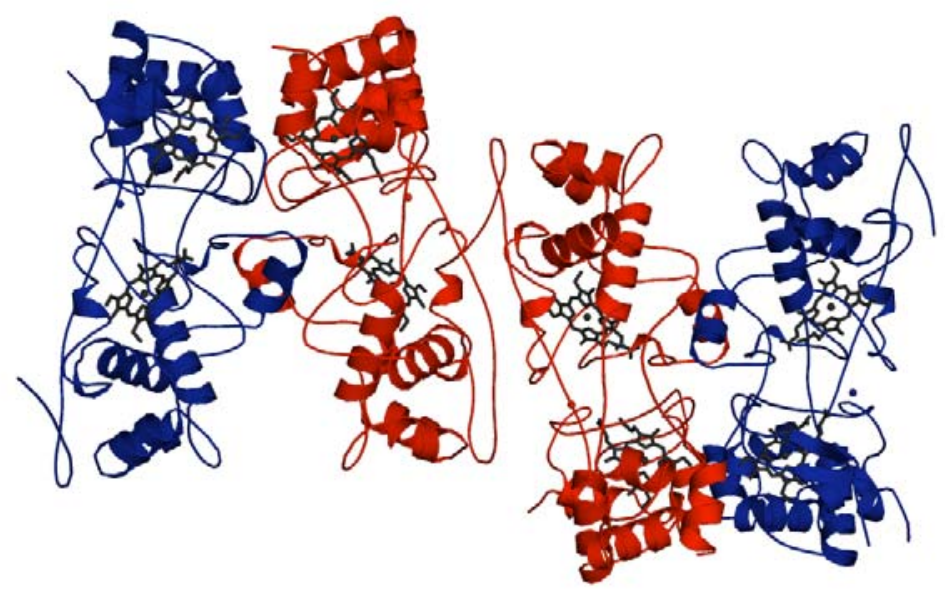

Figure 47: The crystal packing of MacA in space group $\mathrm{P}_{5} 22$ creates two possible dimer interfaces. According to cytochrome $c$ peroxidases from other organisms, the red monomers belong to the functional dimer. For CcpA, this crystal packing is impossible due to side chains constraining each other.

\subsubsection{Electrostatic Potential}

The most apparent difference of MacA and CcpA compared to the other bacterial cytochrome $c$ peroxidases resides in their different electrostatic potentials. Much of the divergence is due to the substitution of charged residues located on the surface, with more positively charged residues and the loss of many negatively charged residues. Therefore MacA and CcpA are more basic than e.g. the $P$. aeruginosa cytochrome $c$ peroxidase. 
A
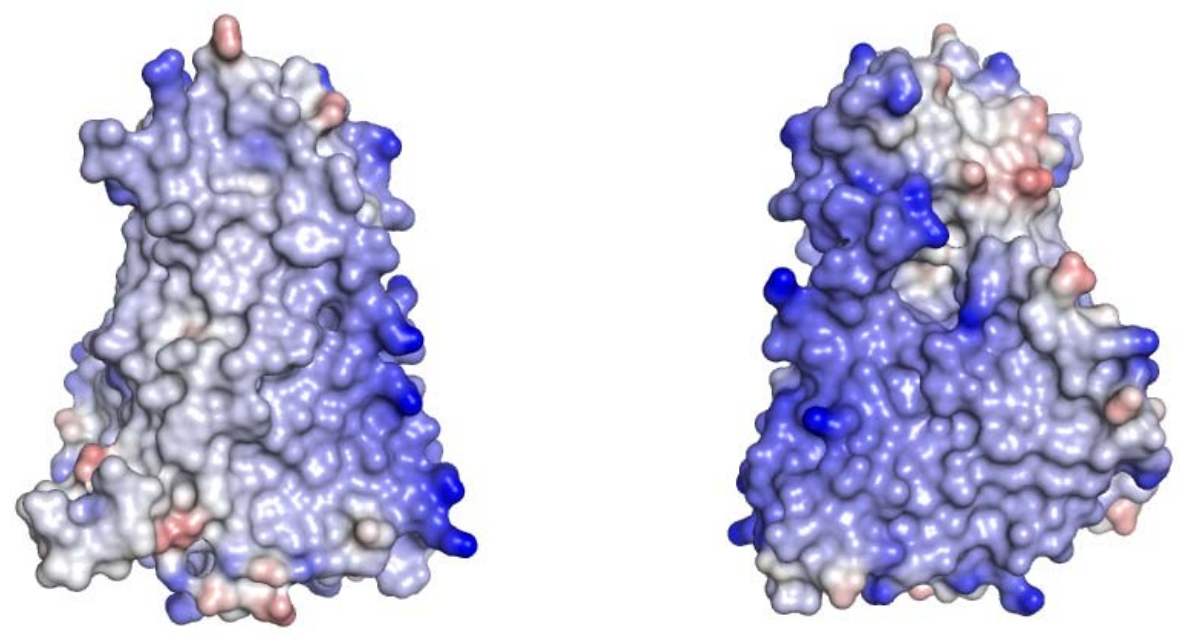

B
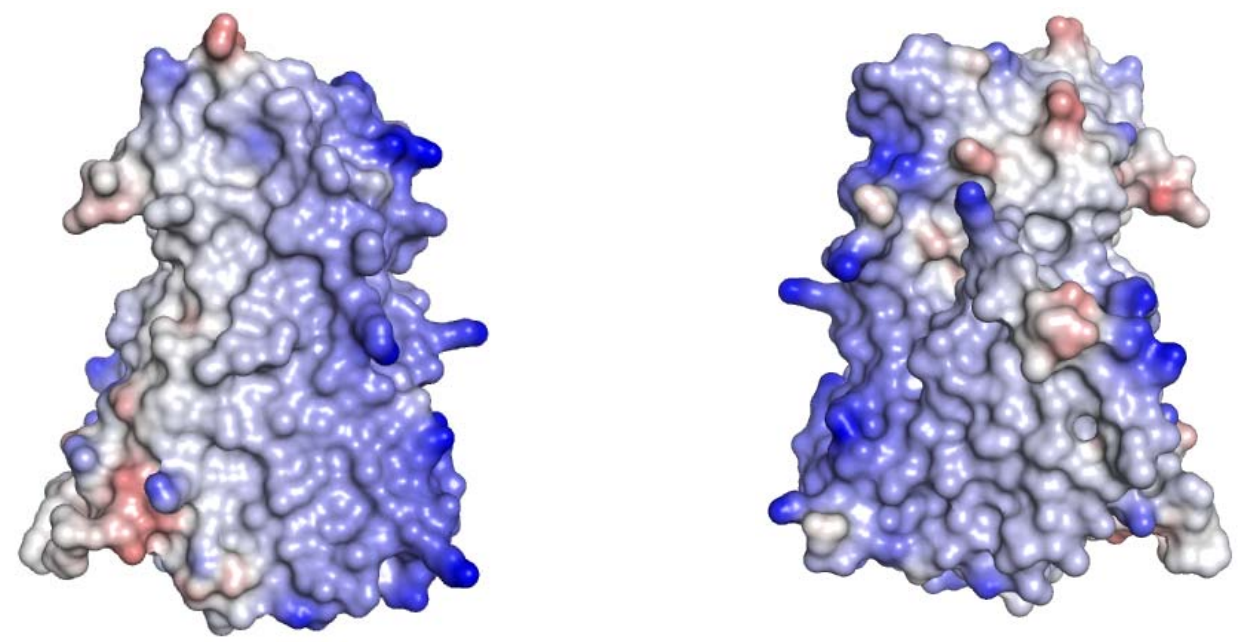

C
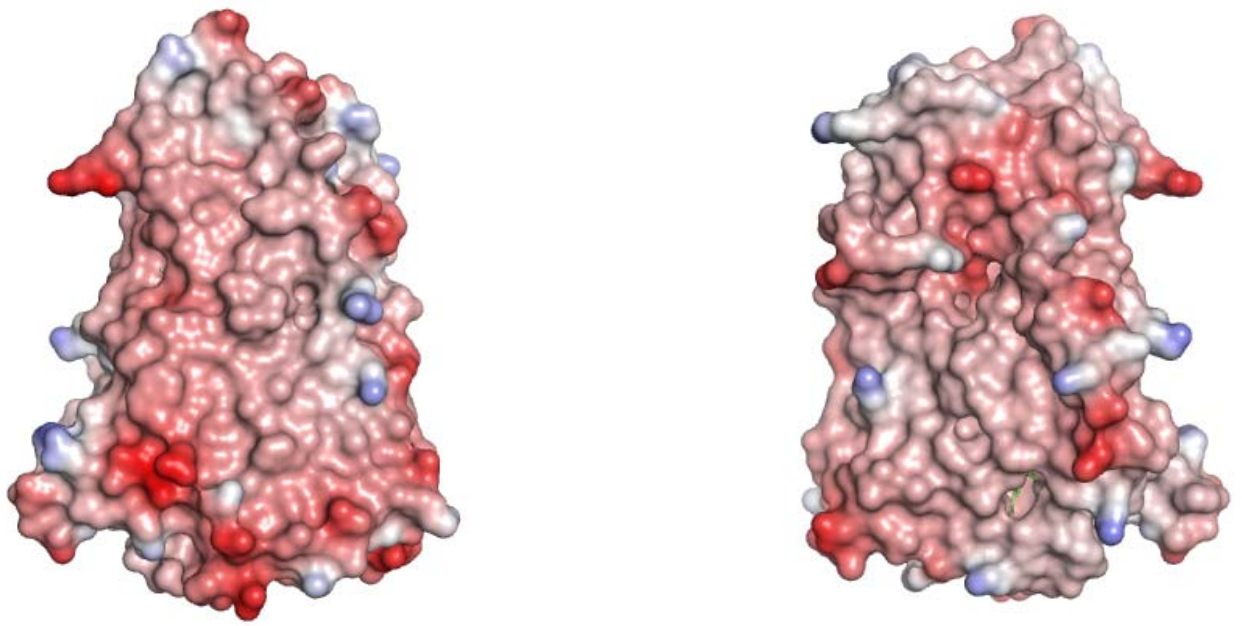

Figure 48: Comparison of the electrostatic surface potentials of the (A) CcpA monomer, (B) MacA monomer and (C) the P. aeruginosa Ccp monomer (pdb accession code 1EB7). The molecules on the right hand side have been rotated $180^{\circ}$ (y-axis). The blue patches represent the basic, positively charged parts on the surface; the red patches represent the acidic, negatively charged parts on the protein surface. The electrostatic surface potentials were calculated with DELPHI (Honig and Nicholls, 1995) and presented with PYMOL (DeLano, 2002) in a range of -402 to $402 \mathrm{kT}$. 


\subsubsection{Calcium Binding Site}

The calcium binding site is located in the hydrophobic interface between the two domains. In both peroxidases of Geobacter sulfurreducens, the ion is equidistant from each iron $(\sim 12.6 \AA$ to the His-Met coordinated iron and $\sim 12.1 \AA$ to the bis-histidinyl coordinated iron). The B-factors for $\mathrm{Ca}^{2+}$ in MacA are $23.66 \AA^{2}$ and $23.77 \AA^{2}$, respectively, and in CcpA, they are $16.70 \AA^{2}$ and $18.61 \AA^{2}$, respectively.

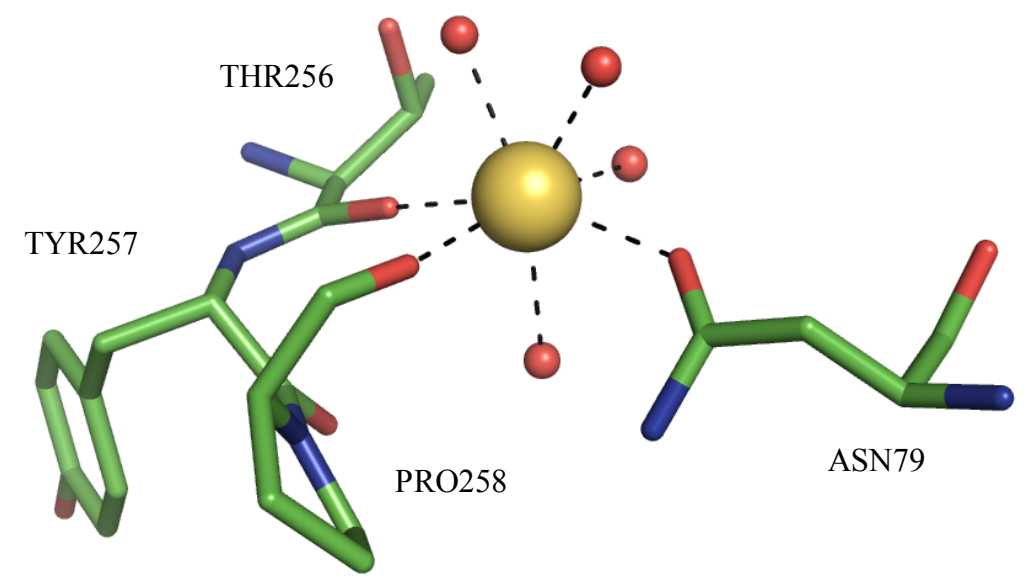

Figure 49: Calcium binding site of CcpA. The calcium ion is colored in yellow, the water molecules are colored in red.

In MacA as well as in CcpA, the amino acids complexing the calcium ion are asparagine 79, the carbonyl group of threonine 256 and the carbonyl group of proline 258. The cis conformation of Pro258 and Met257 in MacA and of Pro258 and Tyr257 in CcpA, respectively, might be due to the restraints imposed by the calcium ion coordination geometry. Furthermore, the calcium ion is coordinated by four water molecules so that the seven ligands are bound in distorted pentagonal bipyramidal geometry to the calcium ion.

These protein ligands are located in highly conserved regions within bacterial cytochrome $c$ peroxidases. Likewise, one of the propionates is coordinated to two of the coordinating water molecules as found in other peroxidases (see figure 44).

Not only the calcium binding site contributes to the interaction of the two domains, also the residues 244-246 and 94-96 are interacting with each other via the main chain as well as residues 90-91 and 208 do in case of MacA. The side chains of Asn205 and Trp94 also make contact between both domains. In CcpA, the contact is mainly established by the interaction of the two $\beta$-strands comprising the residues 95-97 and 243-245. 


\subsubsection{B-Factor Analysis}
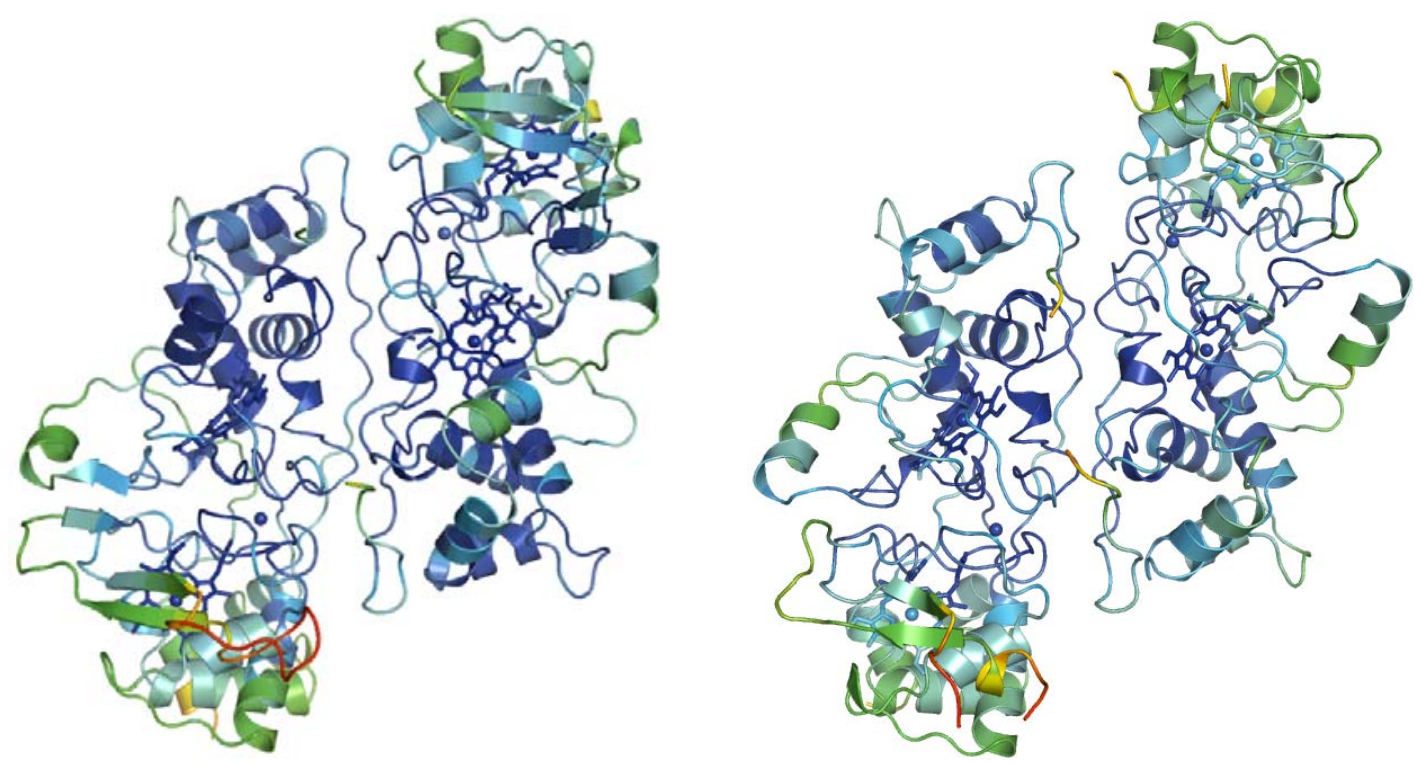

Figure 50: Cartoon representation of CcpA (left) and MacA (right). The structures are colored according to the B-factors (Debye-Waller factors) where blue symbolizes low and red symbolizes high B-factors.

In regions around the heme groups of both MacA and CcpA, the B-factors are lower which is reflected by the dark blue color. Residues located in the interface between both monomers as well as residues around the calcium binding site are the most rigid. Flexible loops are found in domain of the electron transferring heme. 


\subsection{Structure Determination of RoxA}

\subsubsection{Crystallization, Data Collection and Structure Determination of RoxA}

Due to the similarity of the rubber oxygenase A (RoxA) from Xanthomonas sp. strain $35 \mathrm{Y}$ to bacterial cytochrome $c$ peroxidases (Jendrossek and Reinhardt, 2003), this project was taken over in order to evalute and compare the structure of RoxA to those of CcpA and MacA. Crystallization, structure determination and initial model building was performed by Prof. Oliver Einsle.

RoxA was crystallized in 8\% PEG 8000 and 0.1 M Hepes pH 7.5. 10\% (v/v) of 2R,3Rbutanediol served as cryoprotectant.

The crystal belonged to the monoclinic space group $\mathrm{P} 2{ }_{1}$ with unit cell parameters of $\mathrm{a}=72.4 \AA, \mathrm{b}=97.1 \AA, \mathrm{c}=101.1 \AA, \alpha=90^{\circ}, \beta=98.39^{\circ}$ and $\gamma=90^{\circ}$ and diffracted to $1.68 \AA$. The data were integrated with DENZO (Otwinowski and Minor, 1997) and scaled with the Bruker program SADABS.

RoxA has a calculated, sequence-derived molecular weight of $74.1 \mathrm{kDa}$. There are two monomers in the asymmetric unit and the solvent content is $48.14 \%$ with a Matthews coefficient of $\mathrm{V}_{\mathrm{M}}=2.37 \AA^{3} / \mathrm{Da}$ (Matthews, 1968).

Different attempts of phase determination had to be performed as initial trials to solve the structure of RoxA by Fe-SAD failed due to the low phasing power. Two high redundant datasets for Fe-SAD were recorded and the iron sites were immediately found by this method. However, the structure could only be solved by Fe-MAD with data recorded at four different wavelengths. The MAD experiment was performed at the EMBL in Hamburg at the synchrotron beamline X 12.

\begin{tabular}{lllll}
\hline & \multicolumn{1}{c}{$\begin{array}{c}\text { High } \\
\text { redundancy }\end{array}$} & \multicolumn{1}{c}{ Peak } & \multicolumn{1}{c}{ Inflection } & \multicolumn{1}{c}{$\begin{array}{c}\text { High } \\
\text { resolution }\end{array}$} \\
\hline Wavelength $(\AA)$ & 1.7316 & 1.7384 & 1.7398 & 0.9184 \\
Resolution $(\AA)$ & 2.4 & 2.7 & 2.7 & 1.68 \\
Redundancy & 56.5 & 5.7 & 7.2 & 4.9 \\
No. of observations & 3159992 & 698564 & 782909 & 764808 \\
No. of unique reflections & 54970 & 36932 & 37559 & 156762 \\
Completeness (\%) & $98.3(92.3)$ & $94.9(80.6)$ & $96.5(80.6)$ & $96.6(86.6)$ \\
$\mathrm{I} /$ sigma & $30.2(6.5)$ & $16.7(5.7)$ & $19.9(6.5)$ & $8.9(1.5)$ \\
$\mathrm{R}_{\text {sym }}(\%)$ & 0.164 & 0.091 & 0.089 & 0.116 \\
& $(0.632)$ & $(0.251)$ & $(0.251)$ & $(0.711)$ \\
\hline
\end{tabular}

Table 6: Data collection statistics for RoxA. Numbers in parentheses refer to the values within the highest resolution shell. $\mathrm{R}_{\mathrm{sym}}=\left(\sum|\mathrm{I}-<\mathrm{I}>| / \sum \mathrm{I}\right)$ 
The iron sites were acquired with ShelxD (Schneider and Sheldrick, 2002) and phasing was performed in Sharp (La Fortelle et al., 1997). The density of both monomers was averaged with Ave (Kleywegt and Read, 1997) to improve the quality of the electron density. Initial model building was performed in COOT.

\subsubsection{Structure Determination of RoxA and Refinement}

Initial refinement was performed in CNS (Brünger et al., 1998) providing higher geometry-restraints. Subsequently, alternating cycles of model building in COOT and refinement in Refmac5 were performed. Water molecules were added automatically and later on manually in COOT.

After the final refinement in Refmac5, the $\mathrm{R}$-factors reached $\mathrm{R}_{\mathrm{work}}=17.7 \%$ and $\mathrm{R}_{\text {free }}=22.6 \%$.

\begin{tabular}{ll}
\hline Resolution $(\AA)$ & $100.00-1.80$ \\
\hline Rms deviation in bond length $(\AA)$ & 1.612 \\
Rms deviation in bond angles $\left(^{\circ}\right)$ & 0.015 \\
$\mathrm{R}_{\text {work }}(\%) / \mathrm{R}_{\text {free }}(\%)$ & $17.7 / 22.6$ \\
Figure of merit & 0.829 \\
Average B value for the protein & Chain A: 20.51, \\
$\left(\AA^{2}\right)$ & Chain B: 22.59 \\
Average B value for waters $\left(\AA^{2}\right)$ & 29.93 \\
\hline
\end{tabular}

Table 8: Data statistics from the refinement of the RoxA structure. $R_{\text {work }}=\sum|| F_{\text {obs }}|-| F_{\text {calc }}||\left|\sum\right| F_{\text {obs }} \mid$, where $\left|\mathrm{F}_{\mathrm{obs}}\right|$ and $\left|\mathrm{F}_{\text {calc }}\right|$ are structure factor amplitudes from the data and the model, respectively. In order to monitor $\mathrm{R}_{\text {free }}$ (Brünger, 1992), $5 \%$ of the reflections were excluded from the refinement.

Altogether 647 amino acids and two heme groups per monomer, two Hepes molecules and 1457 water molecules could be modeled. From Ala15 to Leu662, the amino acids could be continuously built into the electron density.

\subsubsection{Structure Analysis of RoxA}

The quality of the final RoxA model was verified with the Ramachandran plot and is fully satisfactory for this resolution. $89.2 \%$ of the residues are in the most preferred region, $10.3 \%$ are found in the additional allowed regions and $0.1 \%$ in the generously 
allowed region. Strinkingly, as well as in the models of CcpA and MacA, phenylalanines (Phe301 and Phe516) are located within the disallowed region.

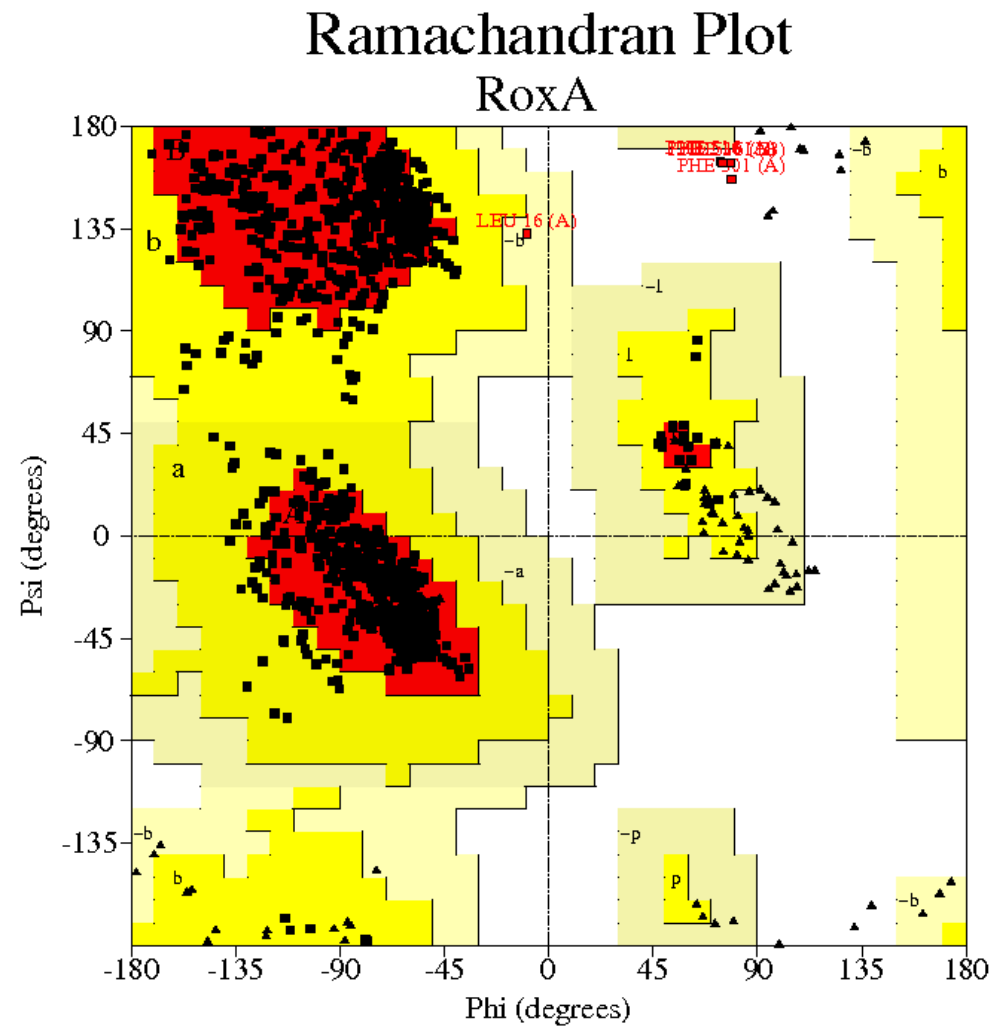

Figure 51: Ramachandran plot. The red area displays the most favorable region, the yellow area is the additional allowed region and the beige area is the generously allowed region. Glycines are presented as triangles. 


\subsection{Overall Structure of $\operatorname{Rox} A$}

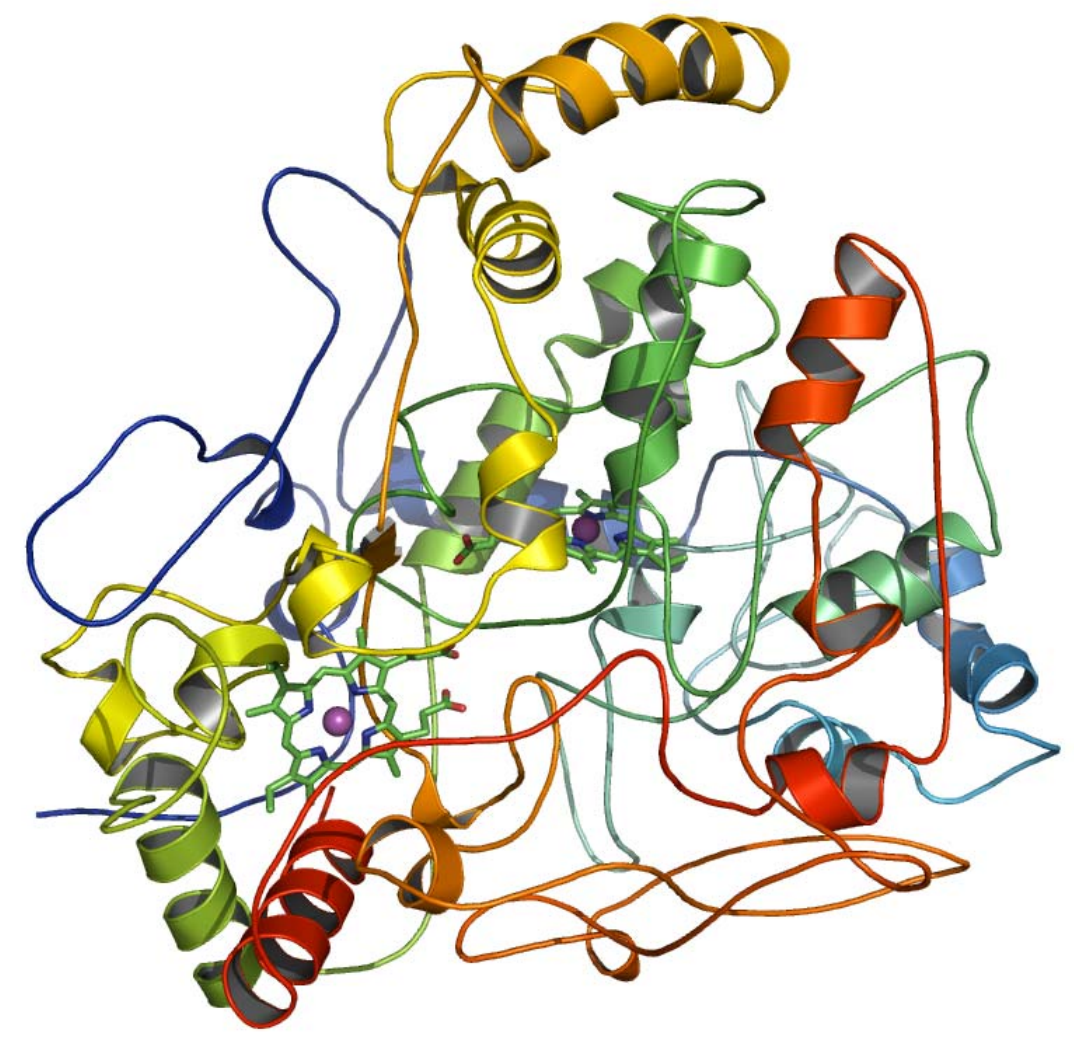

Figure 52: Cartoon representation of RoxA. The peptide chain is colored blue from the N-terminal end to red at the $\mathrm{C}$-terminal end. The heme groups are displayed as sticks.

RoxA is a monomeric enzyme that consists of one compact domain of $\sim 60 \AA$ x $60 \AA$ x $65 \AA$ with $\alpha$-helices representing the main secondary structural motif and an unusually large portion of loops. Two short antiparallel $\beta$-strands comprising residues 420-422 and residues 500-502 face each other and shield the bis-histidinyl coordinated heme group from the solvent. The accessible surface of molecule A is 22,660 $\AA^{2}$ (molecule B: 22,657 $\AA^{2}$ ).

Both molecules in the asymmetric unit are very similar, reflected by a root-mean square deviation of $0.18 \AA$.

\subsubsection{Heme Groups}

Both heme groups are fully buried within the protein. They are oriented approximately perpendicular to each other with an iron-iron distance of $21.46 \AA$. The shortest distance between the heme groups is via the propionates $(9.17 \AA)$.

One heme group is attached to the peptide chain by the cysteines Cys390 and Cys393 while the iron is coordinated by two histidines 394 and 641 . Nitrogen $\mathrm{N}^{\delta}$ of His394 interacts with the carbonyl group of proline $504(2.76 \AA)$ while nitrogen $\mathrm{N}^{\delta}$ of His 641 
forms a hydrogen bond to its own carbonyl group $(2.77 \AA)$, thus orienting the imidazole ring. The dihedral angle between the imidazole planes is $59.74^{\circ}$.

One propionate is stabilized by interactions with the water molecules 87 (2.82 $\AA$ ), 86 $(3.01 \AA)$ and $80(2.62 \AA)$ as well as with the main chain nitrogen of Phe516 (2.78 $)$. The other propionate interacts with the main chain nitrogen of His517 (2.60 $\AA$ ), the nitrogen $\mathrm{N}^{\delta}$ of His517 (2.51 $\AA$ ) and with the hydroxyl group of threonine $428(2.80 \AA)$. As seen above, the coordination of Phe516 and His517 imposes stereogeometrical restraints which explain the localization of Phe516 in the disallowed region of the Ramachandran plot.

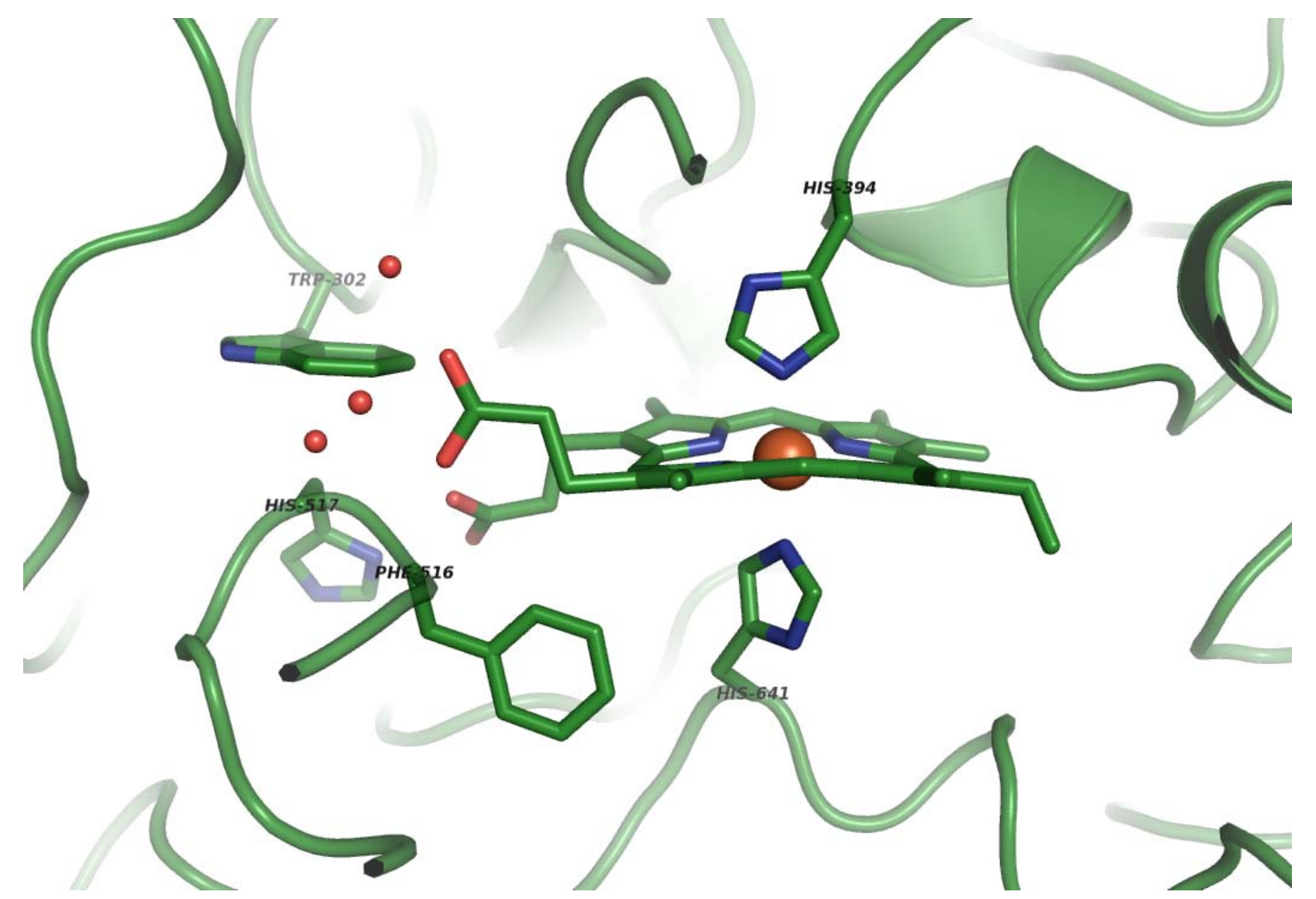

Figure 53: Stick representation of the bis-histidinyl coordinated heme group. The water molecules 80,86 and 87 are included in the picture.

The second heme group is attached to the peptide chain via the cysteines Cys191 and Cys194. In the crystallized form of RoxA, the heme group has only one protein-derived axial ligand, His195. In a distance of $2.10 \AA$, a water molecule is positioned. The nitrogen atom $\mathrm{N}^{\delta}$ of His195 is not oriented by the peptide chain but forms a hydrogen bond with water molecule 1272 (2.93 $\AA$ ).

One propionate is oriented through interactions with the hydroxyl group of threonine $286(2.68 \AA)$, the nitrogen $\mathrm{N}^{\varepsilon}$ of arginine $432(2.68 \AA)$, the main chain nitrogen of tryptophan $302(2.86 \AA)$ and the nitrogen $\mathrm{N}^{\eta}$ of arginine 432 (2.93 $\AA$ ). The other propionate interacts with the main chain nitrogen of Phe301 (2.73 $\AA$ ) which explains the restrained stereogeometry of Phe301 located in the disallowed region of the 


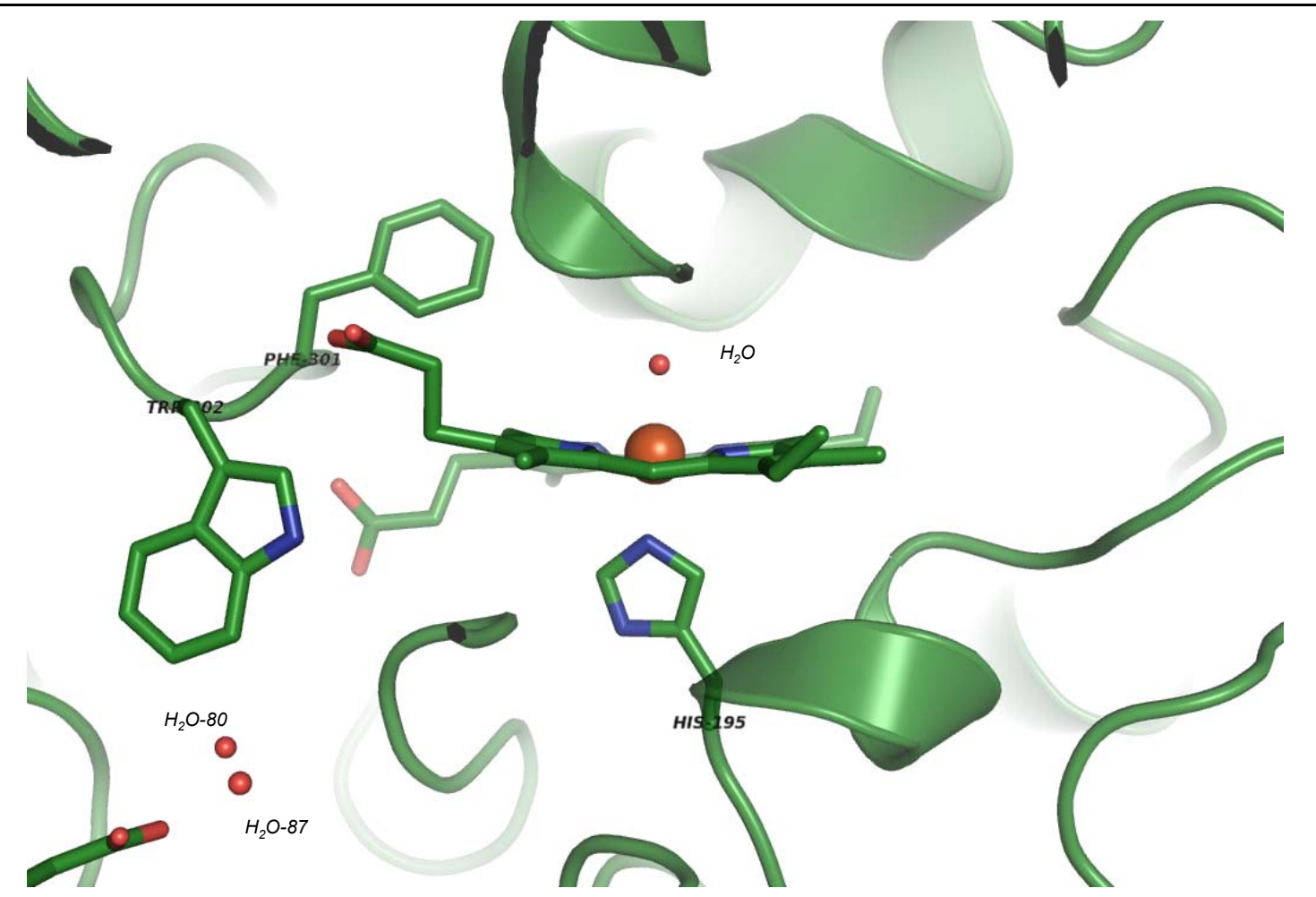

Figure 54: Stick representation of the histidine coordinated heme group.

Ramachandran plot. The water molecules $89(2.59 \AA)$ and $1273(2.68 \AA)$ as well as the nitrogen $\mathrm{N}^{\eta}$ of arginine 294 represent further ligands of this propionate.

\subsubsection{Disulfide Bridges}

There are two disulfide bridges in the structure of RoxA, Cys574-Cys586 and Cys32Cys88. They are located at the surface of the protein, distant from the heme groups, and are presumed to stabilize the protein.

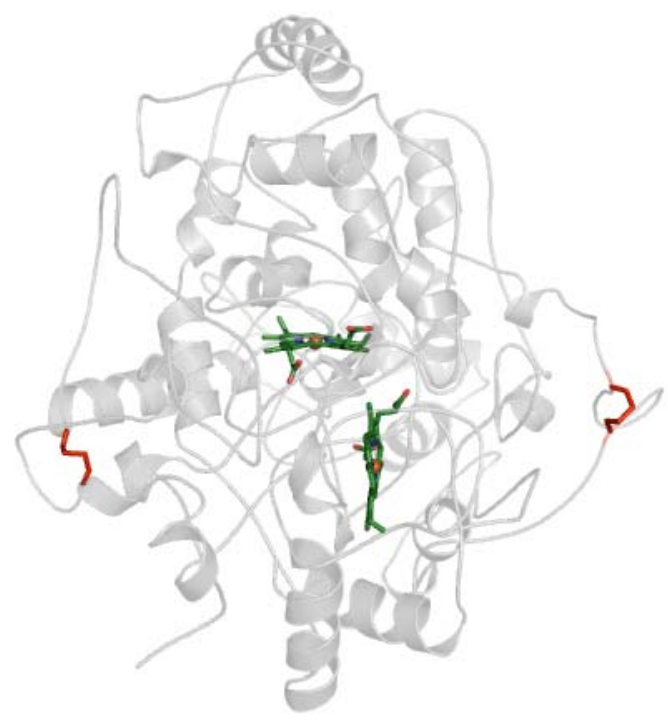

Figure 55: Cartoon representation of RoxA. The two heme groups are colored in green, the disulfide bridges are colored in red. The molecule is rotated around $90^{\circ}$ (y-axis) in comparison to figure 52 . 


\subsubsection{Surface Properties}

RoxA exhibits a differential distribution of negatively and positively charged residues on the surface. The lower part is quite basic compared to other proteins. As depicted in figure 56, both heme groups are accommodated in this lower part of the enzyme.

The heme group in the center of RoxA representing the active site has only one axial ligand (His195). The substrate probably gains access to the reaction center from the upper, more hydrophobic part of the enzyme.
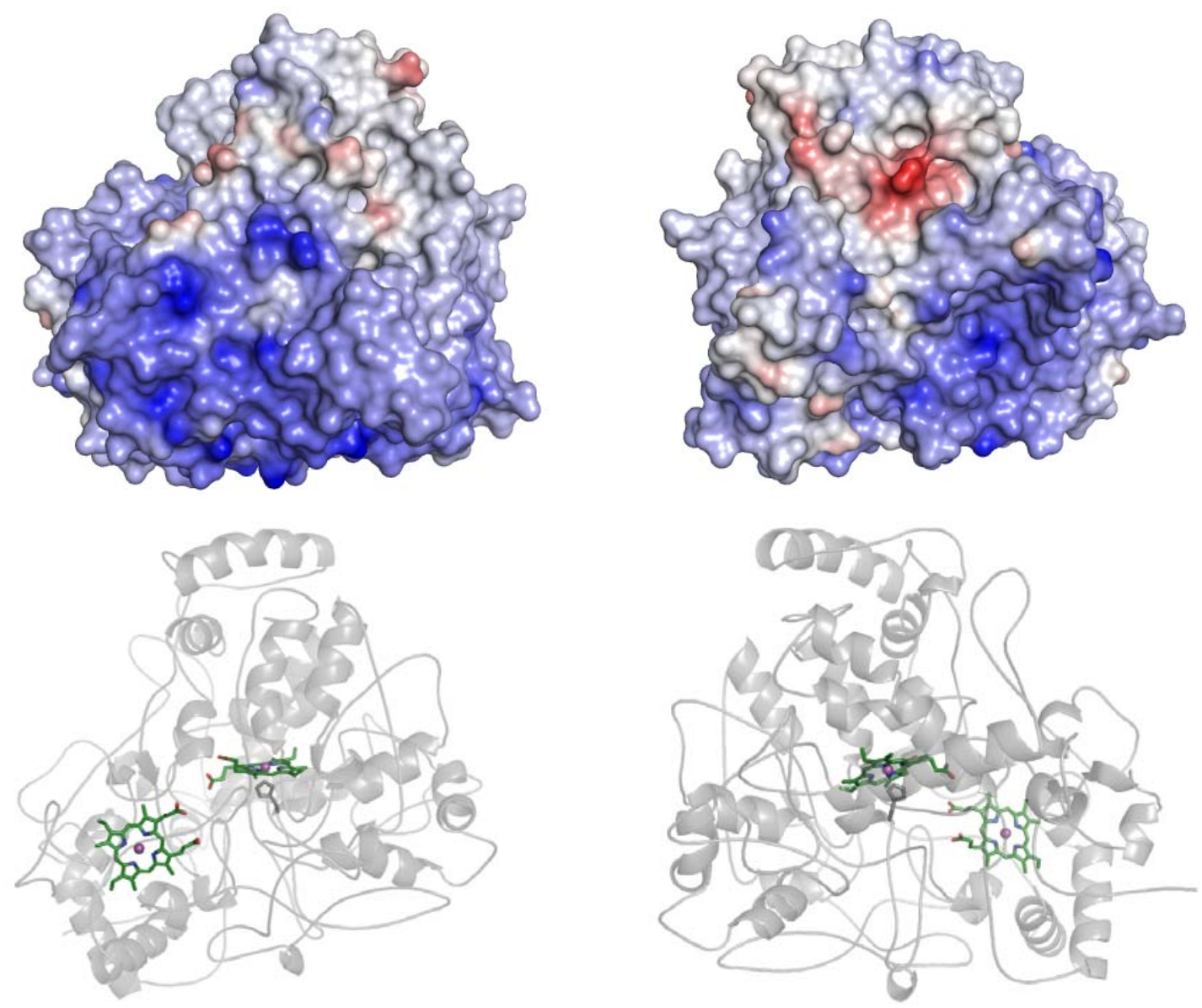

Figure 56: Surface representation of RoxA colored according to the electrostatic surface potential. On the left hand side, the molecule is oriented comparable to figure 3.8 and on the right hand side, it is rotated around $180^{\circ}$ (y-axis). Blue patches indicate basic residues while red patches indicate acidic residues. The electrostatic surface potential is calculated with DELPHI (Honig and Nicholls, 1995) and presented with PYMOL (DeLano, 2002) in the range of -403 to $403 \mathrm{kT}$. The heme group orientation is indicated below. 


\section{Discussion}

\subsection{The Physiological Role of CcpA and MacA in Geobacter sulfurreducens}

In contrast to the reduction of soluble electron acceptors that can diffuse into bacterial cells, the reduction of insoluble iron oxides by Geobacter species requires electron transfer from the cytoplasm to the outside of the outer membrane where the reduction of insoluble ferric iron occurs (see figure 3). The genus Geobacter sulfurreducens has adapted to these demands by the large number of $c$-type cytochromes (Methé et al., 2003). Some of these $c$-type cytochromes have been shown to be required for optimal electron transfer to iron (Leang et al., 2003; Lloyd et al., 2003; Butler et al., 2004; Mehta et al., 2005). The identification of key players involved in the electron transport to and finally the reduction of insoluble iron is based on genetic studies and growth experiments with knock-out mutants of Geobacter sulfurreducens performed by Lovley and coworkers.

First indications that MacA and CcpA could be involved in electron transport to iron were found by the comparison of G. sulfurreducens cells grown on $\mathrm{Fe}(\mathrm{III})$ citrate and fumarate (Butler et al., 2004). Both proteins were detected in the membrane fraction and could be extracted from it by treatment with low salt $(150 \mathrm{mM} \mathrm{NaCl})$. MacA as well as CcpA can be heterologously expressed in E. coli and subsequently purified as soluble proteins in a buffer containing at least $150 \mathrm{mM} \mathrm{NaCl}$ (see results 5.1). The positively charged surface (see figure 48) is consistent with the idea that both proteins are peripherally associated to the membrane. Depending on $\mathrm{pH}$ and ionic strength, any positively charged protein can make contact to the negatively charged membrane by non-specific electrostatic interactions.

The suggestion that MacA and probably also CcpA might be central intermediates in the reduction of $\mathrm{Fe}(\mathrm{III})$ in Geobacter sulfurreducens arose from the finding that cells grown on $\mathrm{Fe}(\mathrm{III})$ citrate revealed higher levels of macA mRNA and that the macA deletion mutant showed a decreased ability to reduce Fe(III) citrate compared to the wild type (Butler et al., 2004). The Geobacter sulfurreducens knock-out mutant of OmcB, a proposed key player in the dissimilatory iron reduction pathway (see figure 3) (Leang et al., 2003), revealed a significant up-regulation of the $c c p A$ expression level compared to the wild type grown in acetate-limiting Fe(III) citrate continuous culture (Leang et al., 
2005). This indicates that CcpA may play a role in an alternative electron transport chain to the terminal ferric iron reductase under these conditions.

Otherwise, CcpA and MacA reveal typical spectroscopic features (see results 5.2) and a typical threedimensional structure (see results 5.6) of bacterial diheme cytochrome $c$ peroxidases as well as peroxidases activity in vitro (see results 5.3).

\subsubsection{Gene Expression of $\operatorname{ccp} A$ and $\operatorname{mac} A$ in the $\operatorname{rel}_{G s u}$ Mutant}

Evidence that CcpA and MacA are not necessarily involved in Fe(III) reduction but rather in stress response was provided by the analysis of the rel $_{G s u}$ mutant of Geobacter sulfurreducens (DiDonato et al., 2006). The gene rel $_{G s u}$ encodes a RelA/ SpoT homolog predicted to be involved in stress response. In bacteria and plants, the stringent response occurs in reaction to limiting growth conditions with the signal molecule guanosine 3',5'-bispyrophosphate (ppGpp) acting as a broad regulator during the adaptation of the organism to a variety of environmental conditions (Chatterji and Ojha, 2001; Braeken et al., 2006). In E. coli, two paralogous enzymes, RelA and SpoT, were detected that catalyze the synthesis and degradation of ppGpp (Magnusson et al., 2005). However, in G. sulfurreducens (DiDonato et al., 2006), as in several other organisms (Wendrich and Marahiel, 1997; Wendrich et al., 2000), one homolog of RelA/ SpoT is assumed to be responsible for both, synthesis and degradation of ppGpp. For G. sulfurreducens, it was shown that genes involved in protein synthesis are up-regulated and genes involved in stress responses and electron transport are down-regulated in the rel $_{G s u}$ mutant (DiDonato et al., 2006). Genes that are down-regulated include pilA, omcS, omcB, $m a c A, c c p A$, desulfoferrodoxin and the rubrerythrin encoding gene GSU2814. In addition to the finding that the oxidative stress response was impaired in the rel $_{G s u}$ mutant, the capacity of Fe(III) reduction was also lower compared to the wild type. Thus, the study illustrates the complexity of the regulation of both, the stringent response and the $\mathrm{Fe}(\mathrm{III})$ reduction in G. sulfurreducens. But probably, the stringent response plays an important role in adjusting growth in a substrate-limiting environment and hence, the decreased ability of the rel $_{G s u}$ mutant to reduce $\mathrm{Fe}$ (III) is only a concequence of the oxidative stress.

\subsubsection{Gene Expression of $\operatorname{ccp} A$ and $\operatorname{mac} A$ in the $\operatorname{rpoS}$ Deletion Mutant}

On the transcriptional level, sigma factors represent further prokaryotic regulators of the stress response. It is well known that they confer specific binding of the RNA polymerase to promoter sites, thus initiating transcription (Wosten, 1998). 
G. sulfurreducens has at least six genes encoding homologs of sigma factors (Nunez et al., 2004).

Expression analysis showed that the sigma factor $\sigma^{\mathrm{S}}$ (RpoS) of G. sulfurreducens activates genes involved in oxidative stress resistance and adaption to nutrient limitation. Activation of these genes by RpoS corresponds to a decreased gene expression in the $\operatorname{rpoS}$ mutant.

The macA gene is RpoS dependent (Nunez et al., 2006) and is significantly downregulated in the $r p o S$ mutant during growth on fumarate, as well as the genes encoding CcpA and the proteins ferredoxin (GSU3187), rubredoxin (GSU3188) and desulfoferrodoxin (GSU0720) which are implicated in the oxidative stress response. The transcriptional regulation of these genes is consistent with the role of RpoS in oxidative stress response which is additionally confirmed by the decreased tolerance of oxygen during growth of the rpoS mutant. (Nunez et al., 2004)

During growth on Fe(III) citrate a similar change in gene expression is observed in case of macA suggesting that the expression is not regulated by the electron acceptor. Likewise, the expression of $c с p A$ is positively regulated by $\mathrm{RpoS}$ in the presence of Fe(III) (Nunez et al., 2006).

As the expression levels of cсpA and macA are diminished in the rpoS mutant (Nunez et $a l ., 2006)$, a decrease in the reduction of Fe(III) citrate is expected for the $r p o S$ mutant if $\mathrm{CcpA}$ or MacA were directly involved in electron transfer to Fe(III). But the mutation in the rpoS gene only effected the reduction of insoluble Fe(III) and not the reduction of fumarate or soluble iron in form of Fe(III) citrate (Nunez et al., 2004).

\subsubsection{Genome Regions of $\operatorname{ccp} A$ and $\operatorname{mac} A$}

The genetic arrangement of the $c c p A$ region differs from that of macA. The region around the $с с p A$ gene contains a rubrerythrin-encoding gene (GSU2814) which has been implicated in oxidative stress response in anaerobic microorganisms (Fournier et $a l ., 2003)$ and a glutaredoxin gene (GSU2812). 


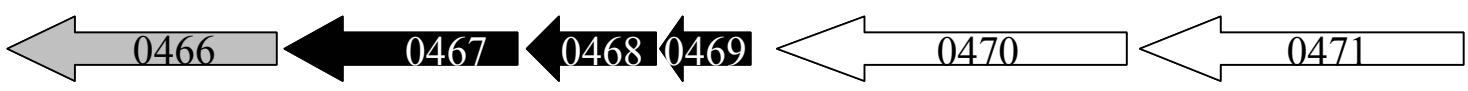

Operon 1251

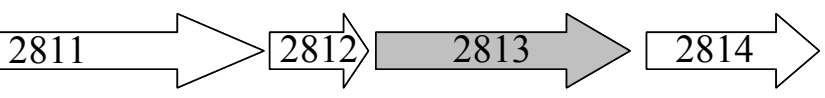

Figure 57: Genome region of MacA (GSU0466) and CcpA (GSU2813). GSU0467 and GSU0468 are hypothetical proteins with most similar proteins found in G. uraniumreducens Rf4 and G. lovleyi SZ (BLASTP). According to The Institute of Genomic Research (TIGR) GSU0469 is annotated as a hypothetical protein, GSU0470 as sigma-54 dependent response regulator and GSU0471 as sensor histidine kinase. GSU2811 is annotated as cytochrome $c$ Hsc, GSU2812 as glutaredoxin family protein and GSU2814 as rubrerythrin. The operons are designated according to www.geobacter.org/research/genomescan/Gsul_annotation.txt.

Upstream of the macA gene, a sigma-54 dependent response regulator and a sensor histidine kinase are located. The presence of genes encoding proteins involved in the oxidative stress response in the immediate surrounding of the cсpA and macA genes strongly indicates that both proteins are involved in stress regulation.

\subsubsection{Description of the macA Deletion Mutant}

Growth experiments with the macA deletion mutant lead to the conclusion that MacA is not required for the toleration of oxidative stress (Butler et al., 2004). However, Geobacter sulfurreducens tolerates $\mathrm{O}_{2}$ (Lin et al., 2004) and possesses several enzymes that putatively participate in the elimination of reactive oxygen species (Methé et al., 2003).

The superoxide dismutase (SOD) catalase oxidative stress defense system generates oxygen and hydrogen peroxide from superoxide (SOD) and subsequently catalyzes the conversion from hydrogen peroxide to oxygen and water (catalase). An alternative system consists of rubrerythrin (Rbr) and rubredoxin oxidoreductase (Rbo, also called desulfoferrodoxin) and is suggested to play a role in cytoplasmic oxidative stress response in anaerobic microorganisms (Lumppio et al., 2001):

$$
\begin{gathered}
\mathrm{e}^{-}+\mathrm{O}_{2}^{-}+2 \mathrm{H}^{+} \rightarrow \mathrm{H}_{2} \mathrm{O}_{2} \\
\mathrm{NADH}+\mathrm{H}^{+}+\mathrm{H}_{2} \mathrm{O}_{2} \rightarrow \mathrm{NADH}+2 \mathrm{H}_{2} \mathrm{O}
\end{gathered}
$$


By this system, superoxide and hydrogen peroxide are reduced to water without the generation of oxygen which is especially important for the detoxification of reactive oxygen species in anaerobes. In addition to the possible presence of proteins involved in oxidative stress response, CcpA was detected in the same membrane fraction of Geobacter sulfurreducens as MacA (Butler et al., 2004). Expression of CcpA is still possible in the macA mutant so that CcpA could have taken over the function of MacA. Geobacter sulfurreducens cells grown on ferric citrate instead of fumarate revealed a higher expression of Rbo and lower expression of SOD (Khare et al., 2006). In addition, a cytosolic protein was identified as a catalase/ peroxidase in ferric iron grown but not in fumarate grown cultures, thus illustrating that the mechanism of protection against oxidative stress is differentially regulated under various growth conditions. The presence of several proteins involved in the "decomposition" of hydrogen peroxide explains that wild type cells as well as macA deficient mutant cells exposed to low concentrations of hydrogen peroxide survive.

The fact that growth of the macA mutant was significantly inhibited during growth on iron (Butler et al., 2004) does not necessarily lead to the conclusion that MacA is an intermediate in the electron transfer chain to iron. On one hand, the experiments with the macA deletion mutant were performed with the soluble iron source Fe(III) citrate which may result in unexpected and unrecognized consequences. Furthermore, MacA might influence the expression levels of proteins directly involved in electron transfer (Kim et al., 2005) leading to the observed, inhibited Fe(III) reduction in the macA deletion mutant.

MacA was more highly expressed during growth on Fe(III) than on fumarate (Butler et al., 2004), but in another study no correlation between the expression pattern of MacA and iron (III) reduction was exhibited (Ding et al., 2006). Instead, new c-type cytochrome candidates (GSU0105, GSU0701, GSU2515) have been discovered, that might also be involved in the electron transfer pathway to Fe(III) (Ding et al., 2006).

\subsubsection{Inspection of the omcB Deletion Mutant}

The $o m c B$ deletion mutant can adapt to growth on soluble Fe(III) but not on insoluble $\mathrm{Fe}(\mathrm{III})$, pointing out that there are differences in electron transfer to soluble Fe(III) citrate and to the environmentally relevant iron oxides (Leang et al., 2005). Furthermore, this study demonstrates that there are different mechanisms of electron transport to $\mathrm{Fe}(\mathrm{III})$ citrate as $\mathrm{OmcB}$ is not required for the growth on soluble $\mathrm{Fe}(\mathrm{III})$. The adaption of the $\operatorname{smcB}$ deletion mutant to growth on Fe(III) citrate was accompanied 
by increased transcription levels of electron transfer protein encoding genes GSU0594, GSU2494, GSU2495, GSU2503 (OmcT), GSU2504, GSU2811 and GSU2813 (CcpA). Up-regulation of the relA homolog as well as other stress response protein encoding genes indicates that the $o m c B$ deletion mutant is exposed to oxidative stress, thus explaining the increased transcription levels of CcpA.

\subsubsection{Implications for the Function of CepA and MacA}

The identification of many proteins that are putatively involved in Fe(III) reduction indicates a network of $c$-type cytochromes acting in electron transfer to insoluble iron. The finding that the disruption of one single gene impairs the Fe(III) reduction can have many reasons and does not necessarily prove the identification of an intermediate in the $\mathrm{Fe}$ (III) reduction pathway. The high number of $c$-type cytochromes in the genome of Geobacter sulfurreducens provides the possibility of several alternative electron transfer chains, depending on the physiological and metabolic state of the cells. This hypothesis is supported by the study of Ding and coworkers (2006) that illustrates the difference in expression pattern depending on the metabolic state (differences in late-log and mid-log phase cultures). Furthermore, solid iron oxides represent the most abundant electron acceptors in subsurface environments, but in most laboratory experiments soluble iron citrate is used for comparative analysis of the physiological or metabolic adaptation to the presence or absence of metals. This means that many of the observed effects may not be connected to the dissimilatory metal reduction.

It was proposed above that Geobacter sulfurreducens can employ different mechanisms in the reduction of $\mathrm{Fe}(\mathrm{III})$ that may involve any electron transferring protein including CcpA and MacA. But CcpA and MacA reveal in vitro peroxidase activity, and in addition, the transcription and expression patterns of CcpA and MacA discussed precedingly suggest that both enzymes are involved in stress response rather than in electron transfer to insoluble Fe(III) oxides.

\subsection{Bacterial Cytochrome $c$ Peroxidases}

\subsubsection{Dimer Formation}

The heterologous expression of $\mathrm{CcpA}$ and $\mathrm{MacA}$ (see results 5.1) allowed an easier handling of the cells and the purification by affinity chromatography facilitated the specific purification. Size exclusion chromatography of both enzymes revealed a molecular weight of $73.94 \mathrm{kDa}$ for CcpA and of $67.45 \mathrm{kDa}$ for MacA resulting from 
dimer formation as observed in other bacterial cytochrome $c$ peroxidases (Arciero and Hooper, 1994; Gilmour et al., 1994; Alves et al., 1999; De Smet et al., 2001). The lower value of $67.45 \mathrm{kDa}$ provided by size exclusion chromatography in comparison to the calculated molecular weight of $76.58 \mathrm{kDa}$ for the MacA dimer might be explained by a monomer-dimer equilibrium (Alves et al., 1999) rather than by proteolysis (see results 5.5.5).

The dimeric appearance of CcpA and MacA becomes visible in the crystal packing (see figures 46 and 47). However, MacA exhibits a further, large interface in the crystal packing that has nearly the same area as the expected dimer interface. The mutation of one residue in both possible dimer interfaces did not have any effect on the retention time in size exclusion chromatography (data not shown), such that the formation of an alternative dimer cannot be excluded at this point.
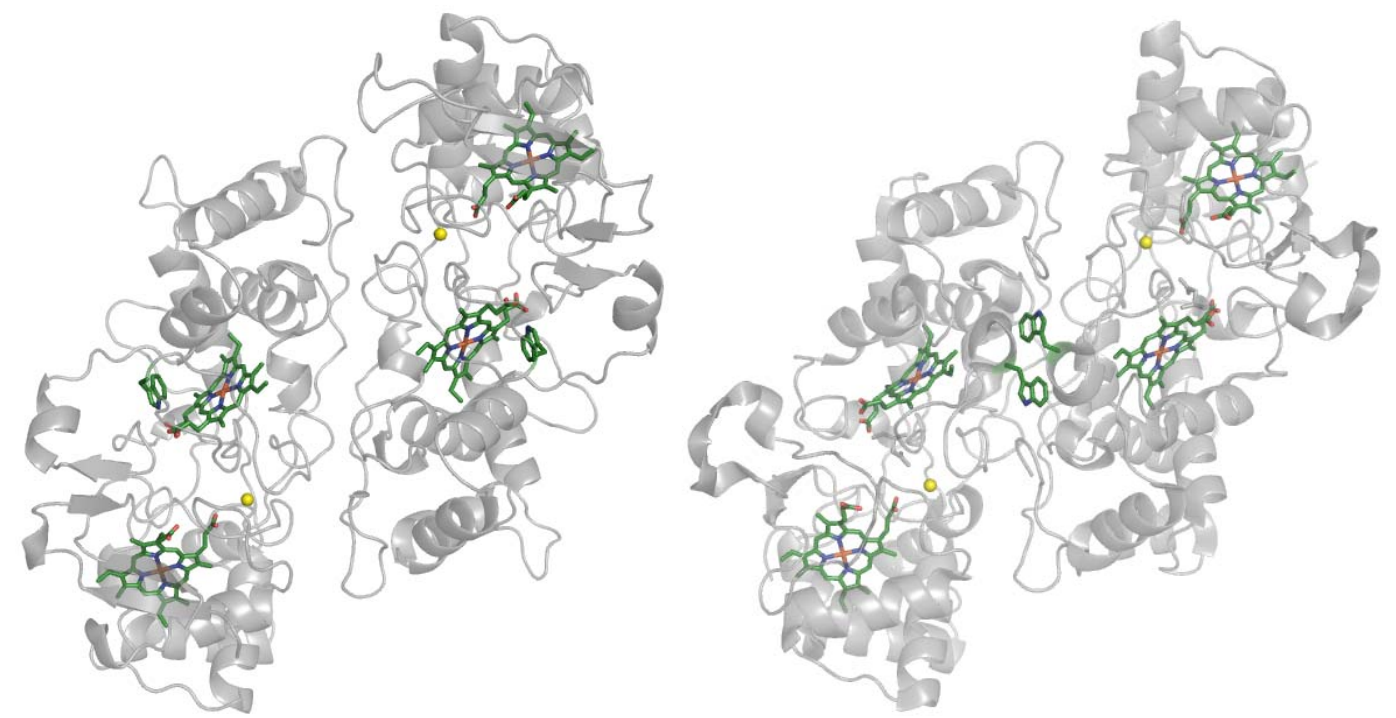

Figure 58: Dimer of CcpA from Geobacter sulfurreducens (left) and of the Nitrosomonas europaea (Nie) cytochrome $c$ peroxidase. The calcium ion is colored in yellow and the heme groups are colored in green. Tryptophan 73 from CcpA and the homologous tryptophan 61 of the Nie cytochrome $c$ peroxidase are depicted in stick mode.

Like the dimer interface in other cytochrome $c$ peroxidases (Fülöp et al., 1995), the dimer interface in the CcpA as well as in the MacA dimer is hydrophobic by nature. In the active form of the enzyme, the contact between the two monomers is additionally stabilized by a $\pi$-stacking interaction. The flexible loop of the Nitrosomonas europaea peroxidase carrying His59 (Shimizu et al., 2001) as well as the flexible loop of the Paracoccus pantotrophus enzyme containing His85 (Echalier et al., 2006) are oriented towards the dimer interface where the side chain of two related tryptophan residues form contact. In the structures of the oxidized forms of CcpA and MacA, the conformation of the corresponding loop places Trp73 close to the heme group. 


\subsubsection{Electron Excitation Spectra}

The electron excitation spectra of MacA and CcpA show a weak absorption maximum at $640 \mathrm{~nm}$ in the oxidized as well as in the ascorbate-reduced and calcium-treated protein (see 5.2). This signal suggests a high spin/ low spin equilibrium of one heme group. Cytochrome $c$ peroxidases of Paracoccus denitrificans (Gilmour et al., 1993) and Pseudomonas stutzeri (Timoteo et al., 2003) also show a weak absorption band at $630 \mathrm{~nm}$ that has been shown to be due to high spin/ low spin equilibrium in the high potential heme. However, the formation of the high spin state at the low potential heme is correlated to the enzyme activation in Paracoccus denitrificans (Gilmour et al., 1994).

The cytochrome $c$ peroxidase of Pseudomonas stutzeri exhibits no difference between the spectrum of the ascorbate-reduced and the ascorbate-reduced and calcium-treated enzyme (Timoteo et al., 2003), in accordance with the calcium-independent activity of the enzyme. Obviously, the cytochrome $c$ peroxidase of Pseudomonas stutzeri does not need additional calcium for high spin formation when the enzyme is reduced with ascorbate only. The spectra of CcpA and MacA suggest that there is a difference in the activity of untreated and calcium-treated enzyme. However, no calcium-dependent increase could be detected for the cytochrome $c$ peroxidases of Geobacter sulfurreducens so far (see results 5.3).

\subsubsection{The Calcium Binding Site}

The calcium binding site localized in the domain interface is occupied in most of the cytochrome $c$ peroxidase structures (Fülöp et al., 1995; Shimizu et al., 2001; Echalier et al., 2006) including the CcpA and MacA structures (see results 5.6.6), but is missing in the low pH structure of the Pseudomonas nautica IN-form (Dias et al., 2004). The protein of Pseudomonas nautica was crystallized at a $\mathrm{pH}$ value of 4 which might have caused non-physiological conformations. Hence, the oxidized and mixed valence structures of Paracoccus pantotrophus cytochrome $c$ peroxidase (Echalier et al., 2006) are consulted in the following to compare the inactive and active state of the enzyme.

The cytochrome $c$ peroxidase from Paracoccus denitrificans was proposed to have two different calcium binding sites (Gilmour et al., 1995). One is usually occupied (site I), corresponding to the calcium binding site identified in most of the structures of cytochrome $c$ peroxidases, and the other is empty or only partially occupied in the oxidized enzyme (site II). Binding of $\mathrm{Ca}^{2+}$ to site II of the Paracoccus denitrificans 
enzyme corresponds to the dimerization state and is essential for the formation of the high spin state at the low potential heme (Gilmour et al., 1995).

Members of the bacterial diheme cytochrome $c$ peroxidases vary in the affinity of site II for $\mathrm{Ca}^{2+}$. The enzymes of Pseudomonas nautica and Paracoccus denitrificans behave similarly (Alves et al., 1999), but the enzymes of Rhodobacter capsulatus and Pseudomonas stutzeri do not require added $\mathrm{Ca}^{2+}$ for activation (De Smet et al., 2001; Timoteo et al., 2003).

Both enzymes from Geobacter sulfurreducens, MacA and CcpA, show high affinity for calcium at site $\mathrm{I}$ as the $\mathrm{Ca}^{2+}$ ion was found in the structures even without addition of calcium througout the whole purification procedure (see 4.2.3.2, 4.2.3.3 and 5.1). The second calcium binding site proposed to be involed in dimerization (Gilmour et al., 1995; Atack and Kelly, 2007) has neither been found in the structures of CcpA and MacA nor in any cytochrome $c$ peroxidases structure, although CcpA and MacA form dimers (see 5.1.1 and 5.1.2).

Until now, the exact role of the second calcium binding site remains unclear because it could not be identified so far and is inconsistent through the cytochrome $c$ peroxidases of different species. Furthermore, physiological concentrations of free $\mathrm{Ca}^{2+}$ are between 100 to $300 \mathrm{~nm}$ (Dominguez, 2004) and thus are much lower than the calcium concentration of $1 \mathrm{mM}$ employed in the calcium treatment of the enzymes.

\subsubsection{Enzyme Activity}

Bacterial cytochrome $c$ peroxidases are located in the periplasm where their likely function is the protection of the cell against reactive oxygen species. The enzyme catalyzes the conversion of hydrogen peroxide to water by transferring electrons from electron donors such as cytochrome $c$ and pseudoazurin to $\mathrm{H}_{2} \mathrm{O}_{2}$ (Timoteo et al., 2003; Pauleta et al., 2004a; Pauleta et al., 2004b). However, in Geobacter sulfurreducens, no homologs of putative electron donors could be identified (Butler et al., 2004).

As are CcpA and MacA, the cytochrome $c$ peroxidase from Neisseria gonorrhoeae is associated with the membrane (Turner et al., 2003; Butler et al., 2004), but in contrast to the Geobacter sulfurreducens enzymes, the Neisseria gonorrhoeae protein was also found membrane-associated when it was expressed heterologously in E. coli. It is unclear why the protein is membrane-associated (Atack and Kelly, 2007), but one possibility is that the cell keeps the enzyme in closer proximity to its electron donor in the membrane. 
Due to the positively charged surface of CcpA and MacA, a peripheral association of the proteins to the membrane is possible so that electrons might be received directly from electron transport proteins located in the inner membrane, such as the cytochrome $b c_{1}$ complex. A BLAST search pointed out that Geobacter sulfurreducens has neither a homolog of cytochrome $c_{1}$ nor of cytochrome $f$. Instead, Geobacter sulfurreducens possesses unusual $b c_{1}$-complexes consisting of typical cytochrome $b$ and iron-sulfur protein subunits, but having replaced the cytochrome $c_{1}$ and cytochrome $f$, respectively, by a different $c$-type cytochrome (Yanyushin et al., 2005).

Cytochrome $c$ and the cytochrome $c$ peroxidase are thought to interact electrostatically in Paracoccus dentrificans, Pseudomonas aeruginosa and in Pseudomonas nautica (Atack and Kelly, 2007). In vitro, horse heart cytochrome $c$ can also act as electron donor, thus replacing the physiological electron donor in the assay (De Smet et al., 2001). However, docking simulations revealed that the physiological electron donor cytochrome $c_{550}$ of Paracoccus denitrificans and horse heart cytochrome $c$ bind at different positions of the cytochrome $c$ peroxidase, with horse heart cytochrome $c$ between the two heme groups (Pettigrew et al., 1999).

The fact that enzyme activity of CcpA and MacA could not be detected with bovine heart cytochrome $c$ might be due to the significantly different surface potential of the two enzymes compared to other cytochrome $c$ peroxidases (see 5.3 and 5.6.5).

The low activity of oxidized MacA (see 5.3) can be explained by the fact that the oxidized enzyme can neither provide enough reducing equivalents, nor an accessible active site. The enzyme of Paracoccus denitrificans is most active when the high potential heme is reduced and the low potential heme is oxidized in high spin state (Gilmour et al., 1994). Reduction of the enzyme with ascorbate or diaminodurol enhances the activity 15-fold compared to the oxidized enzyme. Additional incubation with $\mathrm{Ca}^{2+}$ doubles the activity in Paracoccus denitrificans supporting the hypothesis that the mixed valence high spin form of the enzyme is the active form and $\mathrm{Ca}^{2+}$ promotes this state. The calcium effect can be replaced by $\mathrm{Mg}^{2+}$ (Gilmour et al., 1994). The specific activity of reduced CcpA and MacA is within the range of $2 \mu \mathrm{mol} \mathrm{min}{ }^{-1}$ $\mathrm{mg}^{-1}$ (see results 5.3) while the cytochrome $c$ peroxidase of e.g. Pseudomonas nautica reveals a specific activity of $\sim 100 \mu \mathrm{mol} \mathrm{min} \mathrm{mg}^{-1}$ (Alves et al., 1999), approximately 50 -fold higher. However, comparison of enzyme activities of the cytochrome $c$ peroxidase of Pseudomonas aeruginosa and Rhodobacter capsulatus revealed a large difference as well, with a turnover number of $90 \mathrm{~s}^{-1}$ and $1060 \mathrm{~s}^{-1}$, respectively (De Smet et al., 2006). Furthermore, different enzyme activities were determined with different 
electron donors (Timoteo et al., 2003). The physiological electron donor of the cytochrome $c$ peroxidase of Nitrosomonas europaea is not identified yet (Arciero and Hooper, 1994) so that the activity was determined with horse heart cytochrome $c$ as electron donor. The turnover number of $3 \mathrm{~s}^{-1}$ shows clearly that the absolute value of the activity depends on the method. In comparison, MacA has a turnover number of $35 \mathrm{~s}^{-1}$. In case of Paracoccus denitrificans, calcium activation was required in order to obtain optimal enzyme activity (Gilmour et al., 1994). Pre-incubation had no effect on the activity of the Pseudomonas stutzeri enzyme with cytochrome $c_{551}$ as electron donor. The presence of calcium even inhibited the oxidation of horse heart cytochrome $c$ (Timoteo et al., 2003).

All these results indicate that absolute values for the enzyme activity strongly depend on the electron donor as well as on the treatment of the enzyme.

\subsubsection{Catalytic Reaction Mechanism of Cytochrome $c$ Peroxidases}

The mechanism of hydrogen peroxide reduction differs within eukaryotic monoheme cytochrome $c$ peroxidases and diheme bacterial cytochrome $c$ peroxidases how they store oxidizing equivalents and the type of heme they use. In contrast to the eukaryotic cytochrome $c$ peroxidases, the bacterial enzymes do not generate a free radical intermediate.

Several studies indicate that upon reduction of the C-terminal, high potential heme and in the presence of calcium, the active site gets accessible to the substrate (De Smet et al., 2006), thus representing the active state of the enzyme. Two models of the activation mechanism have been proposed (Prazeres et al., 1995; De Smet et al., 2006). In the first model, the N-terminal heme represents the peroxidatic center and would switch from low spin to high spin state while the active site is accessible from the solvent upon release of the sixth heme ligand. In the second model, in addition to a spin change a ligand switch is proposed. In the low potential heme, the distal histidine would be replaced by a methionine packing in the mixed valence form of Paracoccus pantotrophus against one edge of the distal surface of the active site heme group (De Smet et al., 2006), while the high potential heme would lose the distal methionine. In contrast to the prevailing opinion, this activation mechanism would place the active site at the high potential heme.

Structural data of the Nitrosomonas europaea and Paracoccus pantotrophus peroxidases showing that the N-terminal heme group is penta-coordinated and that the distal histidine is released in the active form of the enzyme favor the first model. In 
addition, mutagenesis of the proposed switch ligand methionine to leucine in the Rhodobacter capsulatus enzyme results in an enzyme that is less active than the wild type. But the fact that the leucine mutant is still active supports the first model more than the second one (De Smet et al., 2006).

Independent of the difference in the reaction mechanism between the Nitrosomonas europaea enzyme type and the other peroxidases, there is still a difference in the regulation of the accessibility for the hydrogen peroxide to the active site. The enzyme of Nitrosomonas europaea is unable to protect the active site in reaction to a decrease of electron supply (Pettigrew et al., 2006), in contrast to the other peroxidases that can regulate the resting and the mixed valence state so that the binding of hydrogen peroxide can be avoided under conditions of insufficient electron availability.

In the structure of the active Nitrosomonas europaea enzyme as well as in the structure of the active Paracoccus pantotrophus cytochrome $c$ peroxidase (Shimizu et al., 2001; Echalier et al., 2006), a glutamic acid is in close proximity to the active site and is proposed to act as the initial proton acceptor from hydrogen peroxide in a way similar to chloroperoxidase (Sundaramoorthy et al., 1995; Sundaramoorthy et al., 1998). In chloroperoxidase, the catalytic base essential to promote the cleavage of the $\mathrm{O}-\mathrm{O}$ bond and thus to form compound $\mathrm{I}$ is glutamic acid rather than histidine as in other peroxidases (Poulos and Kraut, 1980).

This glutamic acid residue is conserved among the bacterial cytochrome $c$ peroxidases. Probably due to the flexibility of the loop, the residue is missing in the oxidized structure of the Paracoccus pantotrophus enzyme. In the oxidized structures of MacA and CcpA, the glutamic acid is distant to the active site and need to be rearranged if the residue is considered as heterolytic catalyst. But even if the residue is missing in the oxidized Paracoccus pantotrophus structure, it is expected to be located in a similar way. Upon enzyme activation, the loop is rearranged and brings the glutamic acid residue in close proximity to the active center (figure 59). 


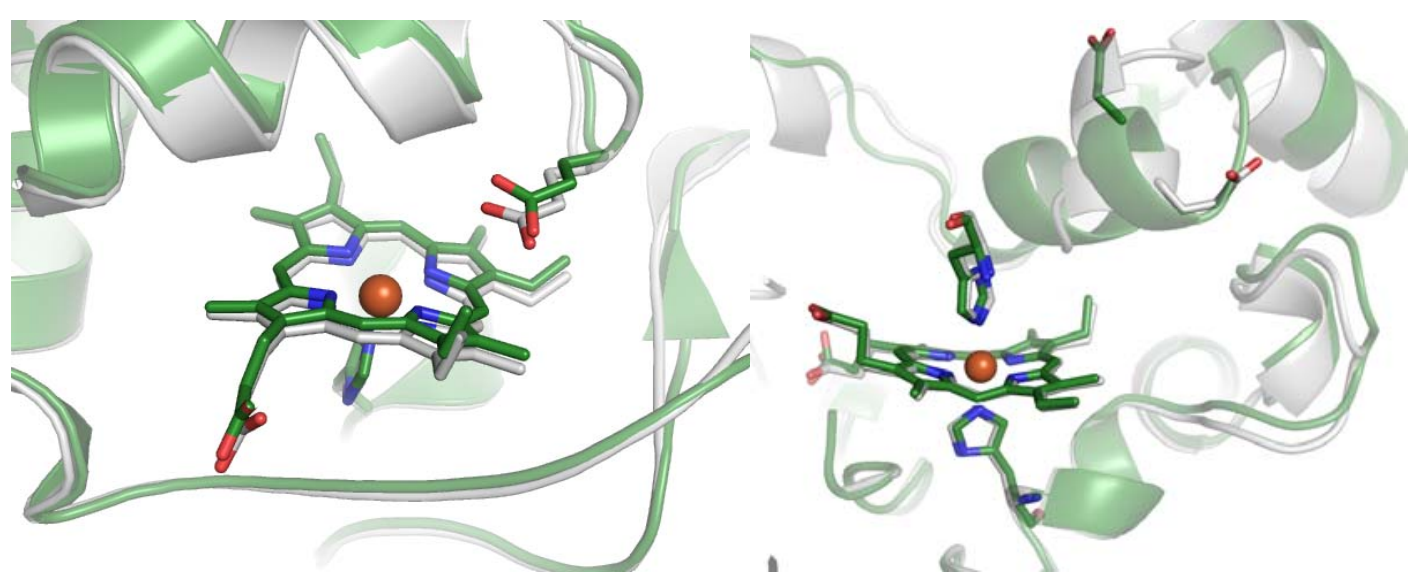

Figure 59: left: Glutamic acid as putative catalytic base. The heme groups, the proximal histidine and the glutamic acid are shown in stick mode. The distal histidine in the oxidized form of the cytochrome $c$ peroxidase of Nitrosomonas europaea (green, pdb accession code 1IQC) and in the mixed valence form of the cytochrome $c$ peroxidase of Paracoccus paracoccus (grey, pdb accession code $2 \mathrm{C} 1 \mathrm{~V}$ ) is released from the heme. Right: The glutamic acid in the oxidized, inactive form of MacA (grey) and CcpA (green) points away from the active center.

Site-directed mutagenesis of the glutamic acid residue to a leucine leads to the loss of activity in Rhodobacter capsulatus indicating that glutamic acid is essential for the activity (De Smet et al., 2006). However, the expected pH-dependent change in activity upon mutation of Glu117 to a histidine or a lysine was not observed as all the three glutamic acid mutants of Rhodobacter capsulatus were inactive.

Upon reduction of hydrogen peroxide, one electron is drawn from the reduced high potential heme getting re-oxidized. The second electron is extracted from the low potential heme forming an oxo-ferryl center (Ellfolk et al., 1983). While one of the two substrate oxygens leaves as water, the other is bound to the iron forming the $\mathrm{Fe}^{\mathrm{IV}}=\mathrm{O}$ species of compound I. Subsequently, compound I is reduced yielding compound II. According to DeSmet et al. (2006), the low potential heme group then is pentacoordinated and a water molecule is released. Atack and Kelly (2007) however suggest a $\mathrm{Fe}^{3+}-\mathrm{OH}$ group at the low potential heme and the release of a water molecule in a subsequent step. The final reduction of the high potential heme closes the reaction cycle.

The cytochrome $c$ peroxidase of Nitrosomonas europaea represents the only exception known so far. In comparison to other bacterial cytochrome $c$ peroxidases, the active site of the Nitrosomonas europaea enzyme is able to bind substrate in the oxidized state (Shimizu et al., 2001; Bradley et al., 2004). The suggested mechanism is more similar to that of eukaryotic cytochrome $c$ peroxidases (see figure 8), as the formation of a stable radical $\mathrm{Fe}^{\mathrm{IV}}=\mathrm{O} \mathrm{R}^{+\bullet}$ is involved in the generation of compound I while the nature 
of the residue $\mathrm{R}$ is not clear so far. However, the possibility that the $\mathrm{Fe}^{\mathrm{IV}}=\mathrm{O} \mathrm{R}^{+\bullet}$ state is an intermediate as well in the other cytochrome $c$ peroxidases cannot be excluded, because the reduction by an electron from the electron-transferring heme is very rapid (Pettigrew et al., 2006).

\subsubsection{Electron Transfer in Cytochrome $c$ Peroxidases}

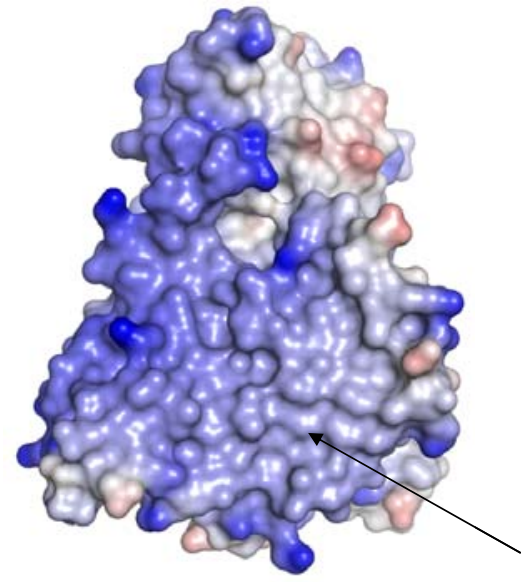

CcpA

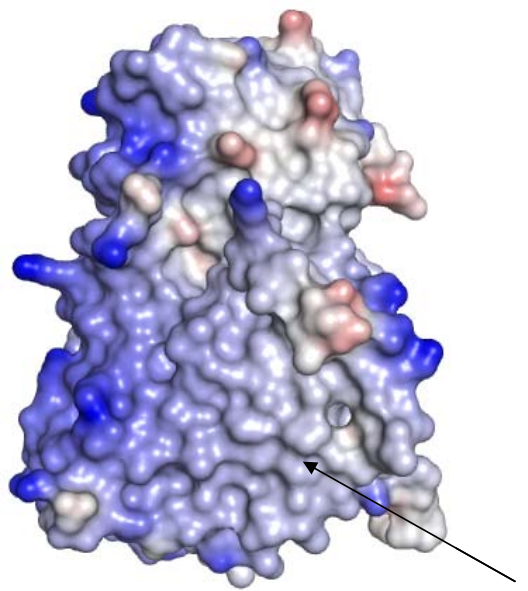

MacA
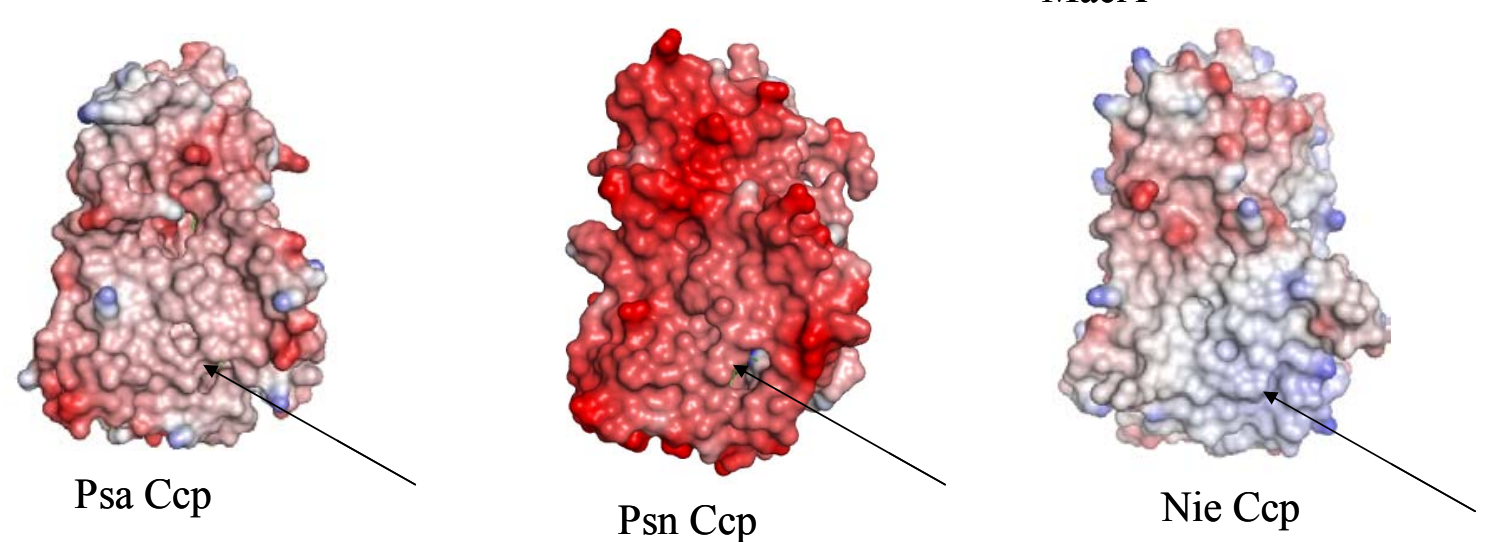

Figure 60: Electrostatic surface potential of several cytochrome $c$ peroxidases. The cytochrome $c$ peroxidases of Geobacter sulfurreducens are compared to the enzymes of Pseudomonas aeruginosa (Psa), Pseudomonas nautica (Psn) and Nitrosomonas europaea (Nie). The site of the electron transferring heme is indicated with arrows.

The high potential heme is directly accessible from the surface. The proposed interaction surfaces for the small redox proteins surround the exposed edge of the electron transferring heme. It was shown for Paracoccus pantotrophus that cytochrome $c$ and pseudoazurin bind competively at the same site close to the electron-transferring heme and the pair of electrons is delivered one at a time to the electron-transferring heme (Pauleta et al., 2004a). 
Besides the activation of the enzyme and the reaction cycle, the cytochrome $c$ peroxidase enzymatic reaction involves also electron transfer between the two heme groups. Neither the heme distance nor the orientation of the cofactors is altered in the different redox states (Echalier et al., 2006), so that the electrons have to overcome a distance of at least $10 \AA$ from one propionate to the other.

Electron transfer between redox centers often occurs over distances of 10-20 $\AA$ through the mechanism of electron-tunneling (Canters, 1992; Page et al., 2003). Several routes for electron transfer from the high potential heme to the low potential heme have been proposed (Fülöp et al., 1995). One pathway includes the proximal histidine of the high potential heme, the protein backbone and the propionate of the low potential heme. Alternatively, the electrons could leave the heme via the propionates and reach the proximal histidine of the low potential heme via the calcium and the protein backbone. However, the most likely pathway exhibits the shortest distance and the most direct way for electron transfer via the propionates and involves the conserved tryptophan lying in the same plane as the high potential heme, perpendicular to the low potential heme. This region in between the two heme groups is conserved within the cytochrome $c$ peroxidases (see figure 12 and 33) and probably reflects the precisely and optimally evolved electron-conducting pathway between the two hemes.
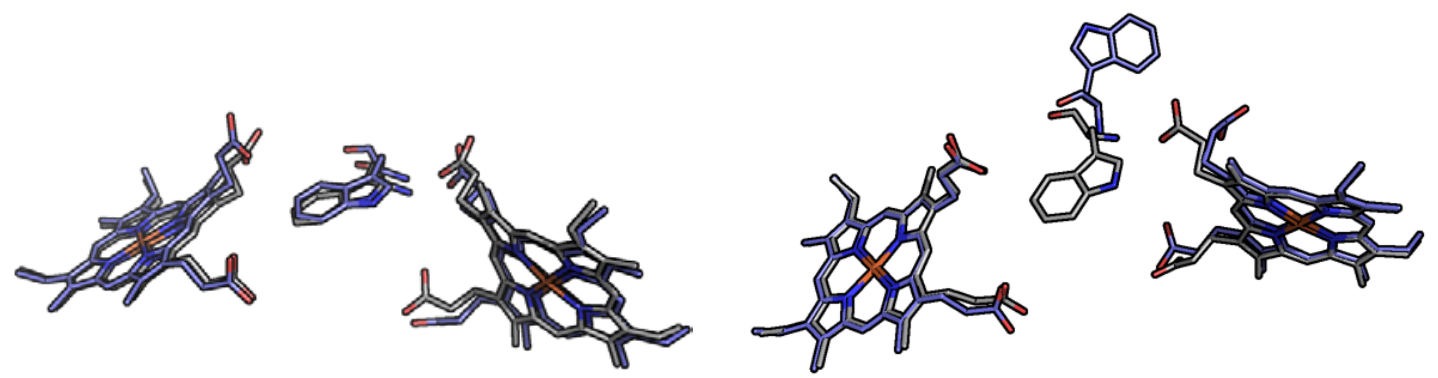

Figure 61: Arrangement of the heme groups and the tryptophan. Left: Oxidized (blue) and mixed valence state (grey) form of Paracoccus pantotrophus cytochrome c peroxidases. Right: IN (blue) and OUT (grey) form of Pseudomonas nautica cytochrome $c$ peroxidases.

Comparing both crystal forms, the IN and the OUT form of Pseudomonas nautica, a rearrangement in the tryptophan residue thought to be involved in electron transfer occurs (Dias et al., 2004). Phe93 is moving out of the pathway in the OUT form allowing Trp94 to occupy the position between both propionates. However, this conformation of Trp94 in the IN form is so far only observed in the Pseudomonas nautica structure and might be due to the crystallization conditions (see 6.2.3). The disruption of the calcium binding site probably causes this conformational change of the tryptophan, thus the localization of the tryptophan in between the heme groups as 
observed in the structures of CcpA and MacA represents the physiological conformation.

\subsection{RoxA}

In many cases, comparing 3D structures may reveal biologically interesting similarities that are not detected by sequence comparison alone. The sequences of RoxA (74.1 kDa) and MacA (38.3 $\mathrm{kDa})$ are not very similar concerning the whole amino acid sequence. However, several sequence regions are conserved.

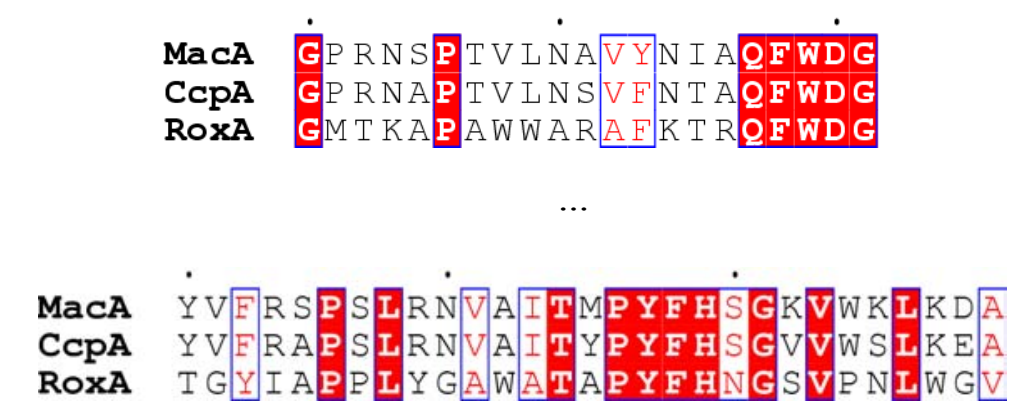

Figure 62: Alignment of the RoxA sequence to the sequences of the G. sulfurreducens peroxidases CcpA and MacA. In the upper part, the sequences of MacA and CcpA comprise residues 76-96, and the sequence of RoxA comprises residues 284-304. In the lower part, the sequences of MacA and CcpA comprise residues 243-271, and the sequence of RoxA comprises residues 499-527.

Structurally similar proteins should be detected with DALI by a multiple alignment of structural neighbours. The database search resulted in the identification of three $c$-type cytochromes with maximal Z-value of 4.7 indicating that the similarity is not very high. The sequence of RoxA has no significant similarity to any protein in the data base except for short sequence parts comprising amino acids that are located in between the two heme groups in bacterial diheme cytochrome $c$ peroxidases (see figure 62) (Jendrossek and Reinhardt, 2003). However, a DALI search did not uncover structural similarities among RoxA and the cytochrome $c$ peroxidases. 


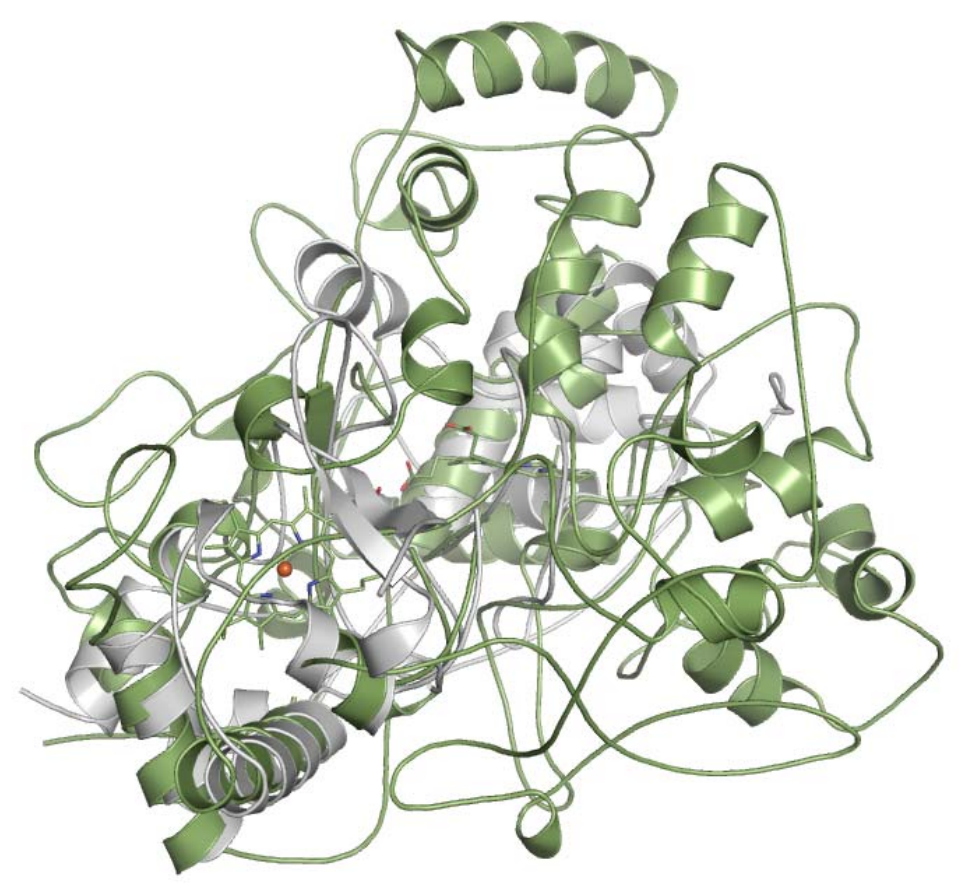

Figure 63: Superposition of RoxA and the cytochrome $c$ peroxidase MacA from Geobacter sulfurreducens by fitting of the heme groups in PYMOL. RoxA is colored in green and the MacA monomer is colored in grey.

RoxA is monomeric and the two domain structure of MacA can be placed inside the structure of RoxA by superimposing both heme groups (see figure 63). Concerning the overall structure of RoxA and the monomer of MacA, a representative of cytochrome $c$ peroxidases, the two structures are quite different. By closer examination of the amino acids around the heme groups, however, similarities among the two enzymes become apparent.

The calcium binding site is localized in the interface between the two peroxidase domains, thus serving the stability of the enzyme. In the structure of RoxA, two facing loops are arranged in a similar way, but instead of a calcium ion, a lysine interacts with the carbonyl groups of Thr512 and Pro514. The fact that this stabilization is important and promotes the right positioning of important residues in electron transfer between the hemes is shown by the IN-form of the Pseudomonas nautica cytochrome $c$ peroxidase which lacks the calcium ion due to non-physiological crystallization conditions (see figure 61). 


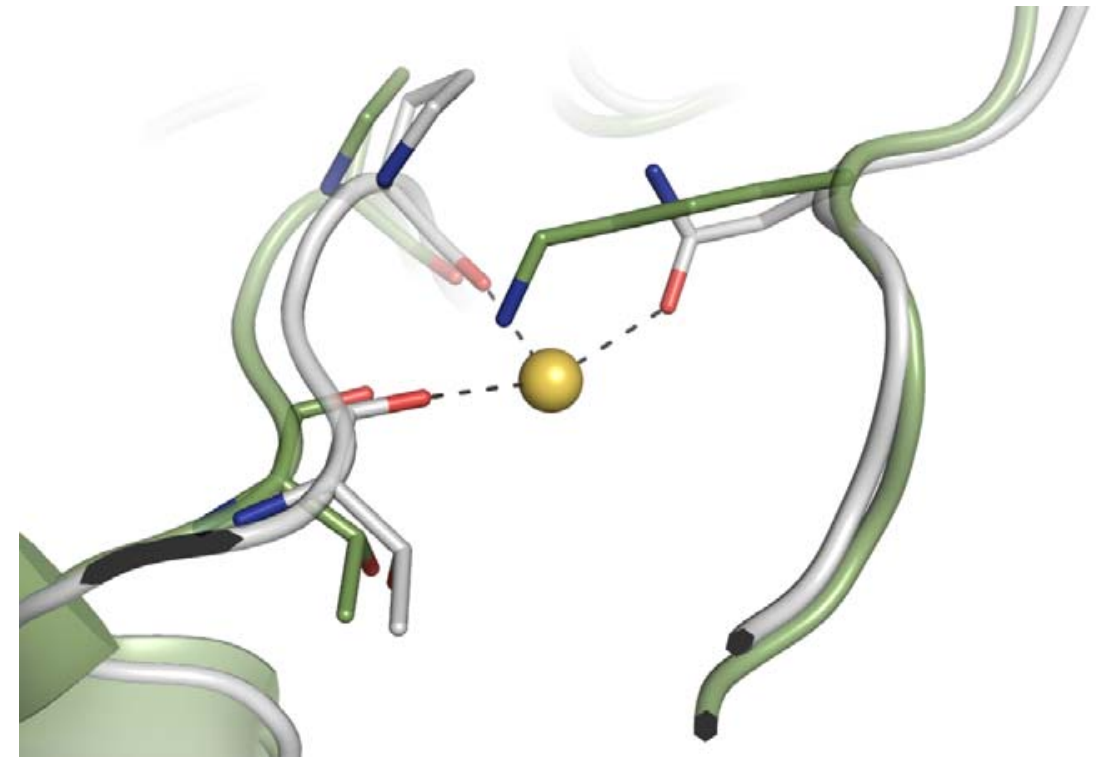

Figure 64: Superposition of RoxA and MacA by fitting the heme groups. MacA (grey) involves a calcium binding site in stabilizing the loops. The contact between the two loops in RoxA (green) is maintained by the interaction of lysine with two carbonyl groups $(2.72 \AA$ and $2.85 \AA$ distances $)$. This calcium ion is absent in the RoxA structure.

The electron-transferring heme in cytochrome $c$ peroxidase is histidine-methionine coordinated and is directly accessible from the surface. In the structure of RoxA, the corresponding bis-histidinyl coordinated heme group is near the surface but is shielded from the solvent by amino acids. The second heme group is proposed to be the active site and is penta-coordinated in the crystallized form of RoxA with a histidine as proximal iron ligand.

Electron transfer between both heme groups seems to be very similar to that in bacterial cytochrome $c$ peroxidases (see 6.2.6). Not only the distances between the heme groups and the orientation towards each other is homologous, but also important residues proposed to mediate electron transfer are present in the RoxA structure. Trp302 is situated between the propionates and is considered to be essential for the electron transport that runs from the bis-histidinyl coordinated heme group via the propionates and the tryptophan to the active center heme group. 


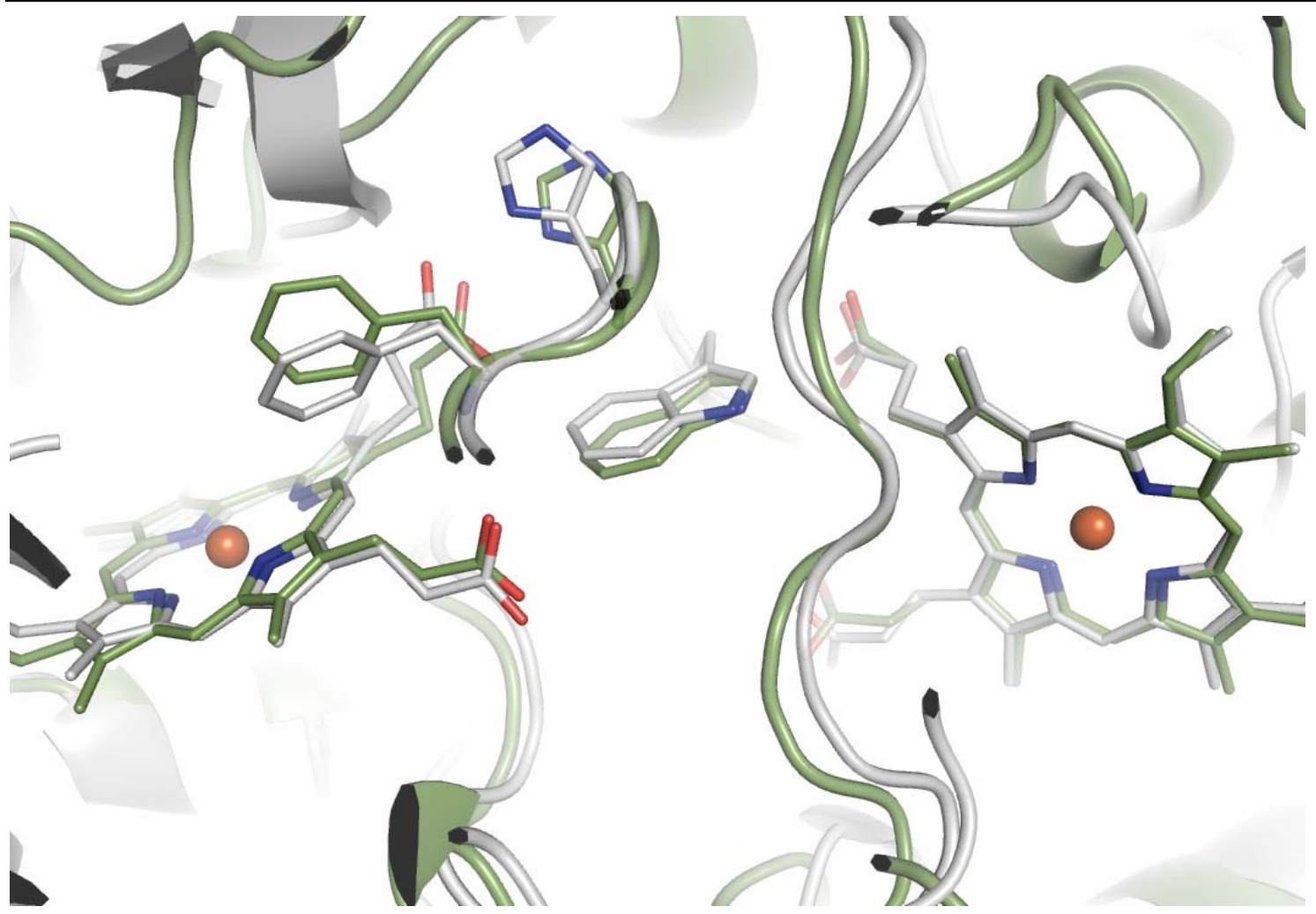

Figure 65: Superposition of RoxA and MacA by fitting the heme groups in PYMOL. View of the arrangement of the heme groups in MacA (grey) and RoxA (green). Residues with similar conformation include Trp302 (corresponding to Trp94 in MacA), His517 (corresponding to His261 in MacA) and the outlier in the Ramachandran plot Phe516 (corresponding to Phe260 in MacA, see 5.5.6).

The similarity of this region probably corresponds to a similar mode of electron transfer between the two heme groups. However, the mechanism of the reaction itself seems to be different. RoxA is suggested to catalyze a dioxygenase-mediated cleavage of natural rubber (Braaz et al., 2005). The distal heme binding pocket compared to the active form of the Paracoccus pantotrophus cytochrome $c$ peroxidase exhibits quite different residues and does not seem to be conserved.

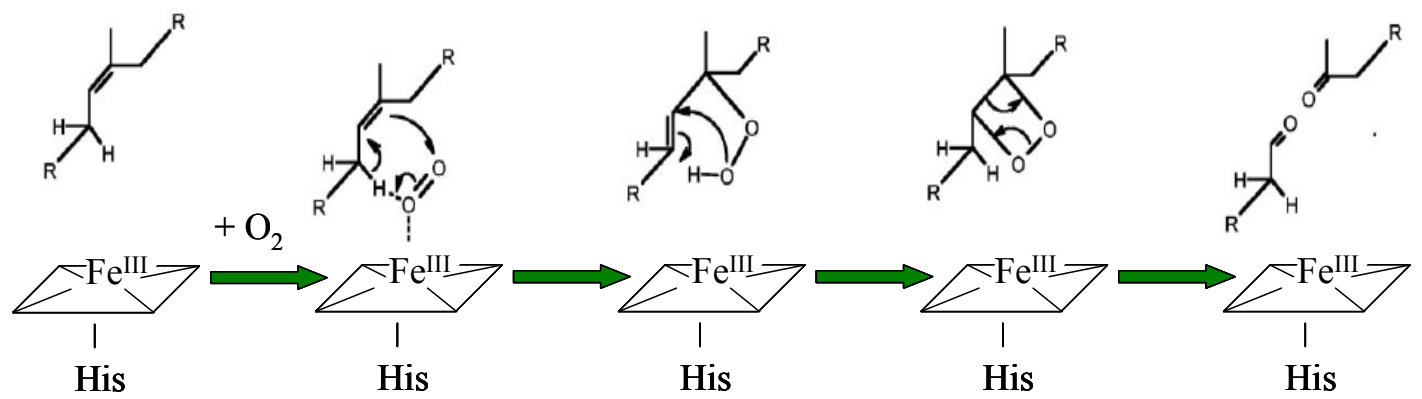

Figure 66: Proposed dioxygenase reaction mechanism for the cleavage of natural rubber by RoxA according to Braaz et al. (2005).

The access of the substrate to the active site is subject to speculations as the crystallized form of RoxA does not provide access to the active site. In order to create an accessible 
reaction center, rearrangements of the protein above the free coordination site of the heme group are necessary. The access of hydrogen peroxide to the active site of the cytochrome $c$ peroxidase is achieved by the movement of the loop containing the sixth heme ligand out of the protein. This enzyme activation cannot be transferred to RoxA as the structure above the heme group is totally different with compact $\alpha$-helices instead of a flexible loop. However, the $\alpha$-helices pointing up can be part of the substrate channel as many hydrophobic residues are located there. Probably, these large required rearrangements cause the low activity of $300 \mathrm{mU} / \mathrm{mg}$ (Braaz et al., 2005).

The assumption that electron transfer between the two heme groups occurs and is necessary for the reaction disagrees with the proposed dioxygenase reaction mechanism suggesting the transfer of the oxygen molecule to the substrate without electron transfer. Several possibilities explaining electron transfer during the enzymatic reaction are taken into account. The alternative that RoxA rather functions as a monooxygenase than as dioxygenase is consistent with experimental data that do not exclude a monooxygenase mechanism (Braaz et al., 2005). Alternatively, RoxA might catalyze further reactions which require electron transport. This shows that the model (see figure 66) of the dioxygenase mechanism is subject to speculations and needs to be confirmed or adapted.

Due to a similar core of the MauG protein to peroxidases, Pettigrew and coworkers (2006) suggest a different reaction mechanism as proposed by Wang et al. (2003) for the MauG protein. According to this, MauG binds methylamine dehydrogenase $(\mathrm{MADH})$ and a reactive species generated by MauG diffuses into the interior of MADH to react with the tryptophan. However, a peroxidase reaction mechanism cannot be considered for RoxA as the protein does not exhibit peroxidase activity (Braaz et al., 2005) but a similar scenario might be possible. 


\section{$7 \quad$ Danksagung}

Die vorliegende Arbeit wurde in der Zeit vom Oktober 2003 bis zum März 2007 in der Abteilung für Molekulare Strukturbiologie an der Georg-August-Universität Göttingen angefertigt.

Dass die Arbeit so zustande gekommen ist, verdanke ich einer Reihe von Menschen, deren Nennung an dieser Stelle meinen Dank ausdrücken soll.

Meinem Doktorvater Prof. Dr. Oliver Einsle danke ich für die interessante Aufgabenstellung, die stetige Unterstützung während dieser Zeit, seinen hilfreichen Anregungen und nicht zuletzt gilt mein besonderer Dank seinem Vertrauen in das Projekt und mich als seine erste Doktorandin.

Herrn Prof. Dr. Ralf Ficner danke ich für die Übernahme des Korreferats.

Herrn Prof. Dr. Jendrossek und seiner Gruppe danke ich für die Koorperation bei dem RoxA-Projekt.

Antje Dickmanns danke ich für die Einarbeitung und die Hilfestellungen zu Beginn meiner Promotionszeit.

Ich danke meinen Laborkollegen Anja, Peer und Haitham für die stets angenehme und lustige Arbeitsatmosphäre im Labor und Daniel speziell für die Hilfe mit Pymol.

Bedanken möchte ich mich weiterhin bei allen Kolleginnen und Kollegen der Abteilung Molekulare Strukturbiologie, die mir hilfreich zur Seite gestanden haben, bei Susana, Wei, Sarah, Andreas und insbesondere bei Julia, die immer auch spannende außeruniversitäre Unternehmungen organisiert und nicht nur mir damit die Promotionszeit äußerst angenehm und abwechslungsreich gestaltet hat.

Meinen anderen bereits promovierten ehemaligen Mitstreitern Jóhanna, Tine und José, die nun in alle Lande verstreut sind, danke ich für unvergessliche DoKo-Abende.

And last but not least danke ich meinen Freunden und meiner Familie für Anregungen und den stetigen Zuspruch, der zum Gelingen dieser Arbeit beigetragen hat. Insbesondere gilt Malte der Dank, der mich in jeder Phase der Doktorarbeit unterstützt und insbesondere die letzten Wochen mit stoischer Ruhe ertragen hat. Vielen Dank! 


\section{Abbreviations}

$\AA$

ABTS

APS

BCA

bp

$\mathrm{ccm}$

Ccp

Da

DESY

DMRB

DMSO

DNA

dNTP

EDTA

EMBL

$\mathrm{Fe}$

HEPES

HP

IPTG

$\mathrm{K}_{\mathrm{M}}$

LB

LP

MAD

$\mathrm{Mn}$

MOPS

mRNA

NADH

$\mathrm{OD}_{600}$

PAGE

PCR

$\mathrm{pdb}$

PEG
Ångström

2,2'-azino-bis(3-ethylbenzthiazoline-6-sulfonic acid)

ammonium persulfate

bicinchoninic acid

base pairs

cytochrome $c$ maturation

cytochrome $c$ peroxidase

Dalton

Deutsches Elektronen-Synchrotron

dissimilatory metal-reducing bacteria

dimethyl sulfoxide

deoxyribonucleic acid

deoxy-nucleoside-triphosphate

(Ethylenedinitrilo)tetraacetic acid

European Molecular Biology Laboratory

iron

4-(2-Hydroxyethyl)piperazine-1-ethanesulfonic acid

high potential

Isopropyl $\beta$-D-thiogalactoside

Michaelis constant

Luria Bertani medium

low potential

multiwavelength anomalous dispersion

manganese

3-(N-Morpholino)propanesulfonic acid

messenger RNA

nicotinamide adenine dinucleotide, reduced form

optical density at $600 \mathrm{~nm}$

polyacrylamide gel electrophoresis

polymerase chain reaction

The RCSB Protein Data Bank

polyethylene glycol 
RNA ribonucleic acid

r.m.s.d. root-mean-square deviation

SDS sodium dodecyl sulfate

TAE Tris-acetate-EDTA

Tc Technetium

TE Tris-EDTA

TEMED 1,2-Bis(dimethylamino)ethane

TMAO trimetylamine $\mathrm{N}$-oxide

TMBZ 3,3',5,5' 'tetramethylbenzidine

Tris Tris(hydroxymethyl)aminomethane

U uranium

$\mathrm{v} / \mathrm{v} \quad$ volume per volume

$\mathrm{w} / \mathrm{v} \quad$ weight per volume

x g times gravity

\section{Amino acids}

$\begin{array}{llllll}\text { A } & \text { Ala } & \text { alanine } & \text { M } & \text { Met } & \text { methionine } \\ \text { C } & \text { Cys } & \text { cysteine } & \text { N } & \text { Asn } & \text { asparagine } \\ \text { D } & \text { Asp } & \text { aspartate } & \text { P } & \text { Pro } & \text { proline } \\ \text { E } & \text { Glu } & \text { glutamate } & \text { Q } & \text { Gln } & \text { glutamine } \\ \text { F } & \text { Phe } & \text { phenylalanine } & \text { R } & \text { Arg } & \text { arginine } \\ \text { G } & \text { Gly } & \text { glycine } & \text { S } & \text { Ser } & \text { serine } \\ \text { H } & \text { His } & \text { histidine } & \text { T } & \text { Thr } & \text { threonine } \\ \text { I } & \text { Ile } & \text { isoleucine } & \text { V } & \text { Val } & \text { valine } \\ \text { K } & \text { Lys } & \text { lysine } & \text { W } & \text { Trp } & \text { tryptophan } \\ \text { L } & \text { Leu } & \text { leucine } & \text { Y } & \text { Tyr } & \text { tyrosine }\end{array}$




\section{$9 \quad$ References}

Ahuja, U. and Thöny-Meyer, L. (2005). CcmD is involved in complex formation between $\mathrm{CcmC}$ and the heme chaperone $\mathrm{CcmE}$ during cytochrome c maturation. J Biol Chem. 280. 236-43.

Altschul, S. F., Madden, T. L., Schaffer, A. A., Zhang, J., Zhang, Z., Miller, W. and Lipman, D. J. (1997). Gapped BLAST and PSI-BLAST: a new generation of protein database search programs. Nucleic Acids Res. 25. 3389-402.

Alves, T., Besson, S., Duarte, L. C., Pettigrew, G. W., Girio, F. M., Devreese, B., Vandenberghe, I., Van Beeumen, J., Fauque, G. and Moura, I. (1999). A cytochrome c peroxidase from Pseudomonas nautica 617 active at high ionic strength: expression, purification and characterization. Biochim Biophys Acta. 1434. 248-59.

Arciero, D. M. and Hooper, A. B. (1994). A di-heme cytochrome c peroxidase from Nitrosomonas europaea catalytically active in both the oxidized and half-reduced states. J Biol Chem. 269. 11878-86.

Arslan, E., Schulz, H., Zufferey, R., Kunzler, P. and Thony-Meyer, L. (1998). Overproduction of the Bradyrhizobium japonicum c-type cytochrome subunits of the cbb3 oxidase in Escherichia coli. Biochem Biophys Res Commun. 251. 744-7.

Atack, J. M. and Kelly, D. J. (2007). Structure, mechanism and physiological roles of bacterial cytochrome c peroxidases. Adv Microb Physiol. 52. 73-106.

Barker, P. D. and Ferguson, S. J. (1999). Still a puzzle: why is haem covalently attached in c-type cytochromes? Structure. 7. R281-90.

Bendtsen, J. D., Nielsen, H., von Heijne, G. and Brunak, S. (2004). Improved prediction of signal peptides: SignalP 3.0. J Mol Biol. 340. 783-95.

Bjellqvist, B., Hughes, G. J., Pasquali, C., Paquet, N., Ravier, F., Sanchez, J. C., Frutiger, S. and Hochstrasser, D. (1993). The focusing positions of polypeptides in immobilized $\mathrm{pH}$ gradients can be predicted from their amino acid sequences.

Electrophoresis. 14. 1023-31.

Bond, D. R. and Lovley, D. R. (2003). Electricity production by Geobacter sulfurreducens attached to electrodes. Appl Environ Microbiol. 69. 1548-55.

Braaz, R., Armbruster, W. and Jendrossek, D. (2005). Heme-dependent rubber oxygenase RoxA of Xanthomonas sp. cleaves the carbon backbone of poly(cis-1,4Isoprene) by a dioxygenase mechanism. Appl Environ Microbiol. 71. 2473-8. 
Braaz, R., Fischer, P. and Jendrossek, D. (2004). Novel type of heme-dependent oxygenase catalyzes oxidative cleavage of rubber (poly-cis-1,4-isoprene). Appl Environ Microbiol. 70. 7388-95.

Bradley, A. L., Chobot, S. E., Arciero, D. M., Hooper, A. B. and Elliott, S. J. (2004). A distinctive electrocatalytic response from the cytochrome c peroxidase of nitrosomonas europaea. J Biol Chem. 279. 13297-300.

Braeken, K., Moris, M., Daniels, R., Vanderleyden, J. and Michiels, J. (2006). New horizons for (p)ppGpp in bacterial and plant physiology. Trends Microbiol. 14. 45-54.

Brünger, A. T. (1992). Free R value: a novel statistical quantity for assessing the accuracy of crystal structures. Nature. 355. 472-475.

Brünger, A. T., Adams, P. D., Clore, G. M., DeLano, W. L., Gros, P., GrosseKunstleve, R. W., Jiang, J. S., Kuszewski, J., Nilges, M., Pannu, N. S., Read, R. J., Rice, L. M., Simonson, T. and Warren, G. L. (1998). Crystallography \& NMR system: A new software suite for macromolecular structure determination. Acta Crystallogr D Biol Crystallogr. 54. 905-21.

Bushnell, G. W., Louie, G. V. and Brayer, G. D. (1990). High-resolution threedimensional structure of horse heart cytochrome c. J Mol Biol. 214. 585-95.

Butler, A. (1998). Acquisition and utilization of transition metal ions by marine organisms. Science. 281. 207-10.

Butler, J. E., Kaufmann, F., Coppi, M. V., Nunez, C. and Lovley, D. R. (2004). MacA, a diheme c-type cytochrome involved in Fe(III) reduction by Geobacter sulfurreducens. J Bacteriol. 186. 4042-5.

Caccavo, F., Jr., Lonergan, D. J., Lovley, D. R., Davis, M., Stolz, J. F. and McInerney, M. J. (1994). Geobacter sulfurreducens sp. nov., a hydrogen- and acetateoxidizing dissimilatory metal-reducing microorganism. Appl Environ Microbiol. 60. 3752-9.

Chatterji, D. and Ojha, A. K. (2001). Revisiting the stringent response, ppGpp and starvation signaling. Curr Opin Microbiol. 4. 160-5.

Chen, Y.-R., Deterding, L. J., Sturgeon, B. E., Tomer, K. B. and Mason, R. P. (2002). Protein oxidation of cytochrome $\mathrm{c}$ by reactive halogen species enhances its peroxidase activity. $J B C .277$.

Childers, S. E., Ciufo, S. and Lovley, D. R. (2002). Geobacter metallireducens accesses insoluble Fe(III) oxide by chemotaxis. Nature. 416. 767-9. 
Childs, R. E. and Bardsley, W. G. (1975). The steady-state kinetics of peroxidase with 2,2' -azino-di-(3-ethyl-benzthiazoline-6-sulphonic acid) as chromogen. Biochem. J. 145. 93-103.

Coates, J. D., Phillips, E. J., Lonergan, D. J., Jenter, H. and Lovley, D. R. (1996). Isolation of Geobacter species from diverse sedimentary environments. Appl Environ Microbiol. 62. 1531-6.

Collaborative Computional Project, Number 4 (1994). The CCP4 suite: programs for protein crystallography. Acta Crystallogr D Biol Crystallogr. 50. 760-3.

Coppi, M. V., Leang, C., Sandler, S. J. and Lovley, D. R. (2001). Development of a genetic system for Geobacter sulfurreducens. Appl Environ Microbiol. 67. 3180-7.

Coppi, M. V., O'Neil, R. A. and Lovley, D. R. (2004). Identification of an uptake hydrogenase required for hydrogen-dependent reduction of $\mathrm{Fe}(\mathrm{III})$ and other electron acceptors by Geobacter sulfurreducens. J Bacteriol. 186. 3022-8.

Daily, H. A. (1997). Enzymes of heme biosynthesis. JBIC. 2. 411-417.

De Smet, L., Pettigrew, G. W. and Van Beeumen, J. J. (2001). Cloning, overproduction and characterization of cytochrome $\mathrm{c}$ peroxidase from the purple phototrophic bacterium Rhodobacter capsulatus. Eur J Biochem. 268. 6559-68.

De Smet, L., Savvides, S. N., Van Horen, E., Pettigrew, G. and Van Beeumen, J. J. (2006). Structural and mutagenesis studies on the cytochrome c peroxidase from Rhodobacter capsulatus provide new insights into structure-function relationships of bacterial di-heme peroxidases. $J$ Biol Chem. 281. 4371-9.

DeLano, W. L. (2002). The PyMOL Molecular Graphics System. http://www.pymol.org.

Dias, J. M., Alves, T., Bonifacio, C., Pereira, A. S., Trincao, J., Bourgeois, D., Moura, I. and Romao, M. J. (2004). Structural basis for the mechanism of $\mathrm{Ca}(2+)$ activation of the di-heme cytochrome c peroxidase from Pseudomonas nautica 617. Structure. 12. 961-73.

DiChristina, T. J. (2005). Enzymology of electron transport: energy generation with geochemical consequences. Reviews in Mineralogy and Geochemistry. 59. $27-52$.

DiChristina, T. J., Arnold, R. G., Lidstrom, M. E. and Hoffmann, M. R. (1988). Dissimilative iron reduction by the marine eubacterium Alteromonas putrefaciens strain 200. Water science and technology. 20. 69-79.

DiDonato, L. N., Sullivan, S. A., Methe, B. A., Nevin, K. P., England, R. and Lovley, D. R. (2006). Role of RelGsu in stress response and Fe(III) reduction in Geobacter sulfurreducens. J Bacteriol. 188. 8469-78. 
Ding, Y. H., Hixson, K. K., Giometti, C. S., Stanley, A., Esteve-Nunez, A., Khare, T., Tollaksen, S. L., Zhu, W., Adkins, J. N., Lipton, M. S., Smith, R. D., Mester, T. and Lovley, D. R. (2006). The proteome of dissimilatory metal-reducing microorganism Geobacter sulfurreducens under various growth conditions. Biochim Biophys Acta. 1764. 1198-206.

Dominguez, D. C. (2004). Calcium signalling in bacteria. Molecular Microbiology. 54. 291-297.

Echalier, A., Goodhew, C. F., Pettigrew, G. W. and Fulop, V. (2004). Crystallization and preliminary X-ray diffraction analysis of a dihaem cytochrome c peroxidase from Paracoccus denitrificans. Acta Crystallogr D Biol Crystallogr. 60. 331-3.

Echalier, A., Goodhew, C. F., Pettigrew, G. W. and Fülöp, V. (2006). Activation and catalysis of the di-heme cytochrome c peroxidase from Paracoccus pantotrophus.

Structure. 14. 107-17.

Einsle, O., Stach, P., Messerschmidt, A., Simon, J., Kroger, A., Huber, R. and Kroneck, P. M. (2000). Cytochrome c nitrite reductase from Wolinella succinogenes. Structure at 1.6 A resolution, inhibitor binding, and heme-packing motifs. J Biol Chem. 275. 39608-16.

Ellfolk, N., Ronnberg, M., Aasa, R., Andreasson, L. E. and Vanngard, T. (1983). Properties and function of the two hemes in Pseudomonas cytochrome c peroxidase. Biochim Biophys Acta. 743. 23-30.

Ellfolk, N. and Soininen, R. (1970). Pseudomonas cytochrome c peroxidase. I. Purification procedure. Acta Chem Scand. 24. 2126-36.

Emsley, P. and Cowtan, K. (2004). Coot: model-building tool for molecular graphics. Acta Cryst. D60. 2126-2132.

Eng, A. H., Kawahara, S. and Tanaka, Y. (1994). Trans-isoprene units in natural rubber. Rubb.Chem.Technol. 67. 159-168.

Esteve-Núñez, A., Núñez, C. and Lovley, D. R. (2004). Preferential reduction of FeIII over fumarate by Geobacter sulfurreducens. J Bacteriol. 186. 2897-9.

Fita, I. and Rossmann, M. G. (1985). The NADPH binding site on beef liver catalase. Proc Natl Acad Sci U S A. 82. 1604-8.

Foote, N., Peterson, J., Gadsby, P. M., Greenwood, C. and Thomson, A. J. (1984). A study of the oxidized form of Pseudomonas aeruginosa cytochrome c-551 peroxidase with the use of magnetic circular dichroism. Biochem J. 223. 369-78.

Fournier, M., Zhang, Y., Wildschut, J. D., Dolla, A., Voordouw, J. K., Schriemer, D. C. and Voordouw, G. (2003). Function of oxygen resistance proteins in the 
anaerobic, sulfate-reducing bacterium Desulfovibrio vulgaris hildenborough. $J$ Bacteriol. 185. 71-9.

Fülöp, V., Ridout, C. J., Greenwood, C. and Hajdu, J. (1995). Crystal structure of the di-haem cytochrome c peroxidase from Pseudomonas aeruginosa. Structure. 3. 1225-33.

Garman, E. and Owen, R. L. (2006). Cryocrystallography of macromolecules: practice and optimization. Methods Mol Biol. 364. 1-18.

Gilmour, R., Goodhew, C. F., Pettigrew, G. W., Prazeres, S., Moura, I. and Moura, J. J. (1993). Spectroscopic characterization of cytochrome c peroxidase from Paracoccus denitrificans. Biochem J. 294 (Pt 3). 745-52.

Gilmour, R., Goodhew, C. F., Pettigrew, G. W., Prazeres, S., Moura, J. J. and Moura, I. (1994). The kinetics of the oxidation of cytochrome $\mathrm{c}$ by Paracoccus cytochrome c peroxidase. Biochem J. 300 (Pt 3). 907-14.

Gilmour, R., Prazeres, S., McGinnity, D. F., Goodhew, C. F., Moura, J. J., Moura, I. and Pettigrew, G. W. (1995). The affinity and specificity of $\mathrm{Ca}(2+)$-binding sites of cytochrome-c peroxidase from Paracoccus denitrificans. Eur J Biochem. 234. 878-86.

Goodhew, C. F., Brown, K. R. and Pettigrew, G. W. (1986). Heme staining in gels, a useful tool in the study of bacterial c-type cytochromes. BBA. 852. 288-294.

Goodhew, C. F., Wilson, I. B., Hunter, D. J. and Pettigrew, G. W. (1990). The cellular location and specificity of bacterial cytochrome c peroxidases. Biochem J. 271. 707-12.

Gordon, E. H., Pike, A. D., Hill, A. E., Cuthbertson, P. M., Chapman, S. K. and Reid, G. A. (2000). Identification and characterization of a novel cytochrome c(3) from Shewanella frigidimarina that is involved in Fe(III) respiration. Biochem J. 349. 153-8.

Green, D. W., Ingram, V. M. and Perutz, M. F. (1954). The structure of hemoglobin.IV.Sign determination by the isomorphous replacement method. Proc.Roy.Soc.A. 225. 287-307.

Hanlon, S. P., Holt, R. A. and McEwan, A. G. (1992). The 44 kDa c-type cytochrome induced in Rhodobacter capsulatus during growth with dimethylsulphoxide as an electron acceptor is cytochrome c peroxidase. FEMS Microbiol Lett. 97. 283-288.

Heitmann, D. and Einsle, O. (2005). Structural and biochemical characterization of DHC2, a novel diheme cytochrome c from Geobacter sulfurreducens. Biochemistry. 44. 12411-9. 
Hendrickson, W. A., Smith, J. L., Phizackerley, R. P. and Merritt, E. A. (1988). Crystallographic structure analysis of lamprey hemoglobin from anomalous dispersion of synchrotron radiation. Proteins. 4. 77-88.

Holm, L. and Sander, C. (1993). Protein structure comparison by alignment of distance matrices. J Mol Biol. 233. 123-38.

Honig, B. and Nicholls, A. (1995). Classical electrostatics in biology and chemistry. Science. 268. 1144-9.

Huston, W. M., Harhangi, H. R., Leech, A. P., Butler, C. S., Jetten, M. S., Op den Camp, H. J. and Moir, J. W. (2007). Expression and characterisation of a major c-type cytochrome encoded by gene kustc 0563 from Kuenenia stuttgartiensis as a recombinant protein in Escherichia coli. Protein Expr Purif. 51. 28-33.

Iobbi-Nivol, C., Crooke, H., Griffiths, L., Grove, J., Hussain, H., Pommier, J., Mejean, V. and Cole, J. A. (1994). A reassessment of the range of c-type cytochromes synthesized by Escherichia coli K-12. FEMS Microbiol Lett. 119. 89-94.

Jahn, D., Verkamp, E. and Söll, D. (1991). Glutamyl transfer RNA: a precursor of heme and chlorophyll biosynthesis. Trends Biochem. Sci. 17. 215-218.

Jendrossek, D. and Reinhardt, S. (2003). Sequence analysis of a gene product synthesized by Xanthomonas sp. during growth on natural rubber latex. FEMS Microbiol Lett. 224. 61-5.

Kaim, W. and Schwederski, B. (2004). Bioanorganische Chemie. Zur Funktion chemischer Elemente in Lebensprozessen. Stuttgart, Teubner.

Kane, S. R., Beller, H. R., Legler, T. C. and Anderson, R. T. (2002). Biochemical and genetic evidence of benzylsuccinate synthase in toluene-degrading, ferric ironreducing Geobacter metallireducens. Biodegradation. 13. 149-54.

Kappler, A. and Straub, K. L. (2005). Geomicrobiological cycling of iron. Reviews in Mineralogy and Geochemistry. 59. 85-108.

Khare, T., Esteve-Nunez, A., Nevin, K. P., Zhu, W., Yates, J. R., 3rd, Lovley, D. and Giometti, C. S. (2006). Differential protein expression in the metal-reducing bacterium Geobacter sulfurreducens strain PCA grown with fumarate or ferric citrate. Proteomics. 6. 632-40.

Kim, B. C., Leang, C., Ding, Y. H., Glaven, R. H., Coppi, M. V. and Lovley, D. R. (2005). OmcF, a putative c-Type monoheme outer membrane cytochrome required for the expression of other outer membrane cytochromes in Geobacter sulfurreducens. $J$ Bacteriol. 187. 4505-13. 
Kissinger, C. R., Gehlhaar, D. K. and Fogel, D. B. (1999). Rapid automated molecular replacement by evolutionary search. Acta Crystallogr D Biol Crystallogr. 55. 484-91.

Kleywegt, G. J. (1996). Use of non-crystallographic symmetry in protein structure refinement. Acta Cryst. D52. 842-857.

Kleywegt, G. J. and Read, R. J. (1997). Not your average density. Structure. 5. 1557 1569 .

Kraemer, S. M., Butler, A., Borer, P. and Cervini-Silva, J. (2005). Siderophores and the dissolution of iron-bearing minerals in marine systems. Reviews in Mineralogy and Geochemistry. 59. 53-84.

Kranz, R., Lill, R., Goldman, B., Bonnard, G. and Merchant, S. (1998). Molecular mechanisms of cytochrome c biogenesis: three distinct systems. Mol Microbiol. 29. 383-96.

La Fortelle, E. d., Irwin, J. J. and Bricogne, G. (1997). SHARP: A maximumlikelihood heavy-atom parameter refinement and phasing program for the MIR and MAD methods. Crystallograoh. Comp. 7. 1-9.

Laemmli, U. K. (1970). Cleavage of structural proteins during the assembly of the head of bacteriophage T4. Nature. 227. 680-5.

Laskowski, R. A., MacArthur, M. W., Moss, D. S. and Thornton, J. M. (1993). Procheck: a program to check the stereochemical quality of protein structures. J.Appl.Cryst. 26. 283-291.

Leang, C., Adams, L. A., Chin, K. J., Nevin, K. P., Methe, B. A., Webster, J., Sharma, M. L. and Lovley, D. R. (2005). Adaptation to disruption of the electron transfer pathway for Fe(III) reduction in Geobacter sulfurreducens. J Bacteriol. 187. 5918-26.

Leang, C., Coppi, M. V. and Lovley, D. R. (2003). OmcB, a c-type polyheme cytochrome, involved in Fe(III) reduction in Geobacter sulfurreducens. J Bacteriol. 185. 2096-103.

Lee, B. and Richards, F. M. (1971). The interpretation of protein structures: Estimation of static accessibility. J.Mol.Biol. 55. 379-400.

Lin, W. C., Coppi, M. V. and Lovley, D. R. (2004). Geobacter sulfurreducens can grow with oxygen as a terminal electron acceptor. Appl Environ Microbiol. 70. 2525-8.

Lloyd, J. R., Leang, C., Hodges Myerson, A. L., Coppi, M. V., Cuifo, S., Methe, B., Sandler, S. J. and Lovley, D. R. (2003). Biochemical and genetic characterization of 
PpcA, a periplasmic c-type cytochrome in Geobacter sulfurreducens. Biochem J. 369. 153-61.

Londer, Y. Y., Pokkuluri, P. R., Erickson, J., Orshonsky, V. and Schiffer, M. (2005). Heterologous expression of hexaheme fragments of a multidomain cytochrome from Geobacter sulfurreducens representing a novel class of cytochromes c. Protein Expr Purif. 39. 254-60.

Lovley, D. R. (1993). Dissimilatory metal reduction. Annu Rev Microbiol. 47. 263-90.

Lovley, D. R. (2001). Bioremediation. Anaerobes to the rescue. Science. 293. 1444-6.

Lovley, D. R. (2002). Analysis of the genetic potential and gene expression of microbial communities involved in the in situ bioremediation of uranium and harvesting electrical energy from organic matter. Omics. 6. 331-9.

Lovley, D. R., Giovannoni, S. J., White, D. C., Champine, J. E., Phillips, E. J., Gorby, Y. A. and Goodwin, S. (1993). Geobacter metallireducens gen. nov. sp. nov., a microorganism capable of coupling the complete oxidation of organic compounds to the reduction of iron and other metals. Arch Microbiol. 159. 336-44.

Lovley, D. R., Holmes, D. E. and Nevin, K. P. (2004). Dissimilatory Fe(III) and Mn(IV) reduction. Adv Microb Physiol. 49. 219-86.

Lu, Y. (2006). Biosynthetic Inorganic Chemistry. Angew.Chem:Int.Ed. 45. 5588-5601.

Lumppio, H. L., Shenvi, N. V., Summers, A. O., Voordouw, G. and Kurtz, D. M., Jr. (2001). Rubrerythrin and rubredoxin oxidoreductase in Desulfovibrio vulgaris: a novel oxidative stress protection system. J Bacteriol. 183. 101-8.

Madigan, M. T., Martinko, J. M. and Parker, J. (2002). Brock. Mikrobiologie. Heidelberg, Berlin, Spektrum Akademischer Verlag.

Magnusson, L. U., Farewell, A. and Nyström, T. (2005). ppGpp: a global regulator in Escherichia coli. TRENDS in Microbiology. 13. 236-242.

Matthews, B. W. (1968). Solvent content of protein crystals. J Mol Biol. 33. 491-7.

Mehta, T., Coppi, M. V., Childers, S. E. and Lovley, D. R. (2005). Outer membrane c-type cytochromes required for Fe(III) and Mn(IV) oxide reduction in Geobacter sulfurreducens. Appl Environ Microbiol. 71. 8634-41.

Methé, B. A., Nelson, K. E., Eisen, J. A., Paulsen, I. T., Nelson, W., Heidelberg, J. F., Wu, D., Wu, M., Ward, N., Beanan, M. J., Dodson, R. J., Madupu, R., Brinkac, L. M., Daugherty, S. C., DeBoy, R. T., Durkin, A. S., Gwinn, M., Kolonay, J. F., Sullivan, S. A., Haft, D. H., Selengut, J., Davidsen, T. M., Zafar, N., White, O., Tran, B., Romero, C., Forberger, H. A., Weidman, J., Khouri, H., Feldblyum, T. 
V., Utterback, T. R., Van Aken, S. E., Lovley, D. R. and Fraser, C. M. (2003). Genome of Geobacter sulfurreducens: metal reduction in subsurface environments. Science. 302. 1967-9.

Moore, G. R. and Pettigrew, G. W. (1990). Cytochromes c. Evolutionary, structural and physicochemical aspects. Berlin, Germany, Springer-Verlag.

Mullis, K. B. and Faloona, F. A. (1987). Specific synthesis of DNA in vitro via a polymerase-catalyzed chain reaction. Methods Enzymol. 155. 335-50.

Murshudov, G. N., Vagin, A. A. and Dodson, E. J. (1997). Refinement of macromolecular structures by the maximum-likelihood method. Acta Crystallogr D Biol Crystallogr. 53. 240-55.

Myers, J. M. and Myers, C. R. (2002). Genetic complementation of an outer membrane cytochrome omcB mutant of Shewanella putrefaciens MR-1 requires omcB plus downstream DNA. Appl Environ Microbiol. 68. 2781-93.

Navaza, J. (1994). AMoRe: an automated package for molecular replacement. Acta Cryst. A50. 157-163.

Nelson, D. P. and Kiesow, L. A. (1972). Enthalpy of decomposition of hydrogen peroxide by catalase at 25 degrees $\mathrm{C}$ (with molar extinction coefficients of $\mathrm{H} 2 \mathrm{O} 2$ solutions in the UV). Anal Biochem. 49. 474-8.

Newman, D. K. and Kolter, R. (2000). A role for excreted quinones in extracellular electron transfer. Nature. 405. 94-7.

Nunez, C., Adams, L., Childers, S. and Lovley, D. R. (2004). The RpoS sigma factor in the dissimilatory $\mathrm{Fe}(\mathrm{III})$-reducing bacterium Geobacter sulfurreducens. J Bacteriol. 186. 5543-6.

Nunez, C., Esteve-Nunez, A., Giometti, C., Tollaksen, S., Khare, T., Lin, W., Lovley, D. R. and Methe, B. A. (2006). DNA microarray and proteomic analyses of the RpoS regulon in Geobacter sulfurreducens. J Bacteriol. 188. 2792-800.

Otwinowski, Z. and Minor, W. (1997). Processing of X-ray Diffraction Data Collected in Oscillation Mode. Methods in Enzymology. 276. 307-326.

Pauleta, S. R., Cooper, A., Nutley, M., Errington, N., Harding, S., Guerlesquin, F., Goodhew, C. F., Moura, I., Moura, J. J. and Pettigrew, G. W. (2004a). A copper protein and a cytochrome bind at the same site on bacterial cytochrome c peroxidase. Biochemistry. 43. 14566-76.

Pauleta, S. R., Guerlesquin, F., Goodhew, C. F., Devreese, B., Van Beeumen, J., Pereira, A. S., Moura, I. and Pettigrew, G. W. (2004b). Paracoccus pantotrophus 
pseudoazurin is an electron donor to cytochrome c peroxidase. Biochemistry. 43. 1121425.

Pettigrew, G. W., Echalier, A. and Pauleta, S. R. (2006). Structure and mechanism in the bacterial dihaem cytochrome c peroxidases. J Inorg Biochem. 100. 551-67.

Pettigrew, G. W., Prazeres, S., Costa, C., Palma, N., Krippahl, L., Moura, I. and Moura, J. J. (1999). The structure of an electron transfer complex containing a cytochrome c and a peroxidase. J Biol Chem. 274. 11383-9.

Pitts, K. E., Dobbin, P. S., Reyes-Ramirez, F., Thomson, A. J., Richardson, D. J. and Seward, H. E. (2003). Characterization of the Shewanella oneidensis MR-1 decaheme cytochrome MtrA: expression in Escherichia coli confers the ability to reduce soluble Fe(III) chelates. J Biol Chem. 278. 27758-65.

Poulos, T. L. and Kraut, J. (1980). The stereochemistry of peroxidase catalysis. J Biol Chem. 255. 8199-205.

Prazeres, S., Moura, J. J., Moura, I., Gilmour, R., Goodhew, C. F., Pettigrew, G. W., Ravi, N. and Huynh, B. H. (1995). Mossbauer characterization of Paracoccus denitrificans cytochrome $\mathrm{c}$ peroxidase. Further evidence for redox and calcium bindinginduced heme-heme interaction. J Biol Chem. 270. 24264-9.

Ramachandran, G. N., Ramakrishnan, C. and Sasisekharan, V. (1963).

Stereochemistry of polypeptide chain configurations. J Mol Biol. 7. 95-9.

Reguera, G., McCarthy, K. D., Mehta, T., Nicoll, J. S., Tuominen, M. T. and Lovley, D. R. (2005). Extracellular electron transfer via microbial nanowires. Nature. 435. 1098-101.

Roden, E. E. and Lovley, D. R. (1993). Dissimilatory Fe(III) Reduction by the Marine Microorganism Desulfuromonas acetoxidans. Appl Environ Microbiol. 59. 734-742.

Rossmann, M. G. and Blow, D. M. (1962). The detection of sub-units within the crystallographic asymmetric unit. Acta Cryst. 15. 24-31.

Saiki, R. K., Gelfand, D. H., Stoffel, S., Scharf, S. J., Higuchi, R., Horn, G. T., Mullis, K. B. and Erlich, H. A. (1988). Primer-directed enzymatic amplification of DNA with a thermostable DNA polymerase. Science. 239. 487-91.

Sanger, F., Nicklen, S. and Coulson, A. R. (1977). DNA sequencing with chainterminating inhibitors. Proc Natl Acad Sci U S A. 74. 5463-7.

Schneider, T. R. and Sheldrick, G. M. (2002). Substructure solution with SHELXD. Acta Crystallogr D Biol Crystallogr. 58. 1772-9. 
Schulz, H. and Thöny-Meyer, L. (2000). Interspecies complementation of Escherichia coli ccm mutants: $\mathrm{CcmE}$ (CycJ) from Bradyrhizobium japonicum acts as a heme chaperone during cytochrome c maturation. J Bacteriol. 182. 6831-3.

Shimizu, H., Schuller, D. J., Lanzilotta, W. N., Sundaramoorthy, M., Arciero, D. M., Hooper, A. B. and Poulos, T. L. (2001). Crystal structure of Nitrosomonas europaea cytochrome $\mathrm{c}$ peroxidase and the structural basis for ligand switching in bacterial di-heme peroxidases. Biochemistry. 40. 13483-90.

Sivaraja, M., Goodin, D. B., Smith, M. and Hoffman, B. M. (1989). Identification by ENDOR of Trp191 as the free-radical site in cytochrome c peroxidase compound ES. Science. 245. 738-40.

Skerra, A. and Schmidt, T. G. (2000). Use of the Strep-Tag and streptavidin for detection and purification of recombinant proteins. Methods Enzymol. 326. 271-304.

Smith, P. K., Krohn, R. I., Hermanson, G. T., Mallia, A. K., Gartner, F. H., Provenzano, M. D., Fujimoto, E. K., Goeke, N. M., Olson, B. J. and Klenk, D. C. (1985). Measurement of protein using bicinchoninic acid. Anal Biochem. 150. 76-85.

Stevens, J. M., Daltrop, O., Allen, J. W. and Ferguson, S. J. (2004). C-type cytochrome formation: chemical and biological enigmas. Acc Chem Res. 37. 999-1007.

Storni, L. C., McCoy, A. J. and Read, R. J. (2004). Likelihood-enhanced fast rotation functions. Acta Cryst. D60. 432-438.

Stura, E. A., Satterthwait, A. C., Calvo, J. C., Kaslow, D. C. and Wilson, I. A. (1994). Reverse screening. Acta Crystallogr D Biol Crystallogr. 50. 448-55.

Sundaramoorthy, M., Terner, J. and Poulos, T. L. (1995). The crystal structure of chloroperoxidase: a heme peroxidase--cytochrome P450 functional hybrid. Structure. 3. 1367-77.

Sundaramoorthy, M., Terner, J. and Poulos, T. L. (1998). Stereochemistry of the chloroperoxidase active site: crystallographic and molecular-modeling studies. Chem Biol. 5. 461-73.

Tanaka, Y., Eng, A. H., Ohya, N., Tangpakdee, J., Kawahara, S. and Wititsuwannakul, R. (1996). Initiation of rubber biosynthesis in Hevea brasiliensis: characterization of initiation species by structural analysis. Phytochemistry. 41. 15011505 .

Thompson, J. D., Higgins, D. G. and Gibson, T. J. (1994). CLUSTAL W: improving the sensitivity of progressive multiple sequence alignment through sequence weighting, position-specific gap penalties and weight matrix choice. Nucleic Acids Res. 22. 467380 . 
Thöny-Meyer, L. (1997). Biogenesis of respiratory cytochromes in bacteria. Microbiol Mol Biol Rev. 61. 337-76.

Thöny-Meyer, L. (2002). Cytochrome c maturation: a complex pathway for a simple task? Biochem Soc Trans. 30. 633-8.

Thöny-Meyer, L., Fischer, F., Kunzler, P., Ritz, D. and Hennecke, H. (1995). Escherichia coli genes required for cytochrome c maturation. J Bacteriol. 177. 4321-6.

Timoteo, C. G., Tavares, P., Goodhew, C. F., Duarte, L. C., Jumel, K., Girio, F. M., Harding, S., Pettigrew, G. W. and Moura, I. (2003). Ca2+ and the bacterial peroxidases: the cytochrome c peroxidase from Pseudomonas stutzeri. J Biol Inorg Chem. 8. 29-37.

Tsuchii, A. and Takeda, K. (1990). Rubber-Degrading Enzyme from a Bacterial Culture. Appl Environ Microbiol. 56. 269-274.

Turner, S., Reid, E., Smith, H. and Cole, J. (2003). A novel cytochrome c peroxidase from Neisseria gonorrhoeae: a lipoprotein from a Gram-negative bacterium. Biochem $J$. 373. 865-73.

Vagin, A. and Teplyakov, A. (1997). MOLREP: an automated program for molecular replacement. J. Appl. Cryst. 30. 1022-1025.

Villalain, J., Moura, I., Liu, M. C., Payne, W. J., LeGall, J., Xavier, A. V. and Moura, J. J. (1984). NMR and electron-paramagnetic-resonance studies of a dihaem cytochrome from Pseudomonas stutzeri (ATCC 11607) (cytochrome c peroxidase). Eur J Biochem. 141. 305-12.

Wang, Y., Graichen, M. E., Liu, A., Pearson, A. R., Wilmot, C. M. and Davidson, V. L. (2003). MauG, a novel diheme protein required for tryptophan tryptophylquinone biogenesis. Biochemistry. 42. 7318-25.

Weber, K. A., Achenbach, L. A. and Coates, J. D. (2006). Microorganisms pumping iron: anaerobic microbial iron oxidation and reduction. Nat Rev Microbiol. 4. 752-64.

Weiss, M. and Hilgenfeld, R. (1997). On the use of the merging R factor as a quality indicator for X-ray data. J. Appl. Cryst. 30. 203-205.

Wendrich, T. M., Beckering, C. L. and Marahiel, M. A. (2000). Characterization of the relA/spoT gene from Bacillus stearothermophilus. FEMS Microbiol Lett. 190. 195201.

Wendrich, T. M. and Marahiel, M. A. (1997). Cloning and characterization of a relA/spoT homologue from Bacillus subtilis. Mol Microbiol. 26. 65-79.

Wosten, M. M. (1998). Eubacterial sigma-factors. FEMS Microbiol Rev. 22. 127-50. 
Yanyushin, M. F., del Rosario, M. C., Brune, D. C. and Blankenship, R. E. (2005). New class of bacterial membrane oxidoreductases. Biochemistry. 44. 10037-45.

Zahn, J. A., Arciero, D. M., Hooper, A. B., Coats, J. R. and DiSpirito, A. A. (1997). Cytochrome c peroxidase from Methylococcus capsulatus Bath. Arch Microbiol. 168. 362-72. 


\section{Curriculum vitae}

\section{Maren Hoffmann}

Date of birth: $\quad 21.03 .1978$

Place of birth: Göttingen

Birth name: $\quad$ Prieß

Marital status: $\quad$ married

Citizenship: German

\section{Education:}

1997

$1997-2003$

2002

2003-2007
Abitur, Gymnasium am Silberkamp, Peine

Studies of Biology and Mathematics (Lehramt an Gymnasien) at the Georg-August-Universität of Göttingen

Examination thesis in Molecular Plant Physiology; "Untersuchungen zur Stärkemobilisierung bei Arabidopsis (Wildtyp und NR-Mutante) in Abhängigkeit von verschiedenen Signalen”, (Prof. Dr. Rudolf Tischner)

Ph.D. studies at the Georg-August-University of Göttingen, Department of Molecular Structural Biology 